\title{
TGF-beta Signaling in Prostate Cancer
}

\author{
Glen Allan Bjerke \\ Boulder, Colorado
}

B.A. in Molecular, Cellular and Developmental Biology, University of Colorado, 2005

A Dissertation presented to the Graduate Faculty of the University of Virginia in Candidacy for the Degree of

Doctor of Philosophy

Biochemistry, Molecular Biology and Genetics

University of Virginia

December, 2013 


\begin{abstract}
In the first part of this dissertation I examine functions of the proteins Meis2 and Pbx1. Meis 2 and $\mathrm{Pbx} 1$ are homeodomain containing transcription factors that function cooperatively, both with each other and with other proteins to regulate gene transcription. Meis 2 and $\mathrm{Pbx} 1$ are both important regulators of development and cancer. Due to the presence of potential Meis/TGIF DNA binding sites in the promoter of the important cyclin dependent kinase $p 15$ $(C D K N 2 B)$, we hypothesized that Meis2 and $\mathrm{Pbx} 1$ regulated its transcription. $\mathrm{p} 15$ is an important inhibitor of the cell cycle and a well characterized tumor suppressor. I show that Meis2 and Pbx1 function to regulate transcription of p15 and E-cadherin. The regulation of $p 15$ was mapped to a region in its promoter containing GC boxes previously reported to bind Sp1. However, I found that Meis2 and Pbx1 were regulating p15 through a newly described interaction with Klf4. I show that Klf4 functions to recruit Meis2 and Pbx1 to DNA, where they help to activate gene transcription. Further, the DNA binding sequences for these components were used in a bioinformatics approach to find additional genes regulated in a cooperative manner by Meis2, Pbx1 and Klf4. Since we demonstrated that Meis2 and Pbx1 activated expression of the important tumor suppressors p15 and E-cadherin, we hypothesized that expression of Meis2 and Pbx1 would be decreased in cancer. Consequently, we found that expression of Meis2 and Pbx1 were decreased in prostate cancer. These experiments further the knowledge of Meis 2 and Pbx1's functions and help explain some of the many different roles played by these proteins.
\end{abstract}

In the second part of this dissertation I describe novel mouse models of prostate cancer. Prostate cancer is the second most common cancer in men in the US and causes the second most cancer deaths in men in the US. Mouse models that mimic human disease are a necessity in the field of prostate cancer research for studying tumor growth and for testing new drugs. Genetic deletion of genes that function in the TGF- $\beta$ signaling pathway are common in prostate cancer. Therefore, we hypothesized that deletion of the TGF- $\beta$ type II receptor (Tgfbr2), which 
effectively blocks activation of the TGF- $\beta$ signaling pathway, would lead to increased tumor formation in combination with other oncogenic stimuli. I describe how loss of TGF- $\beta$ signaling by knockout of $T g f b r 2$ cooperates with loss of the tumor suppressor Pten to cause a rapid progression to adenocarcinoma. This model also results in a significant number of metastases to the lymph nodes and lungs. The cancer cells are both highly proliferative, as shown by staining for Cyclin D \& Ki67, and resistant to androgen deprivation by castration. In this model, we also discovered activation of TGF- $\beta$ signaling downstream of loss of Pten. We think the induction of TGF- $\beta$ signaling functions as a tumor suppressive feedback mechanism in the event of loss of Pten. Furthermore, this activation of TGF- $\beta$ signaling is demonstrated to be downstream of the oncogenic kinase Akt. Accordingly, deletion of $T g f b r 2$ results in cancer when combined with a constitutively active Akt1. I also found that deletion of Tgfbr2 cooperates with loss of Apc (Adenomatous polyposis coli), a tumor suppressor and important inhibitor of Wnt signaling, resulting in adenosquamous carcinoma in the prostate. Subsequently, it was discovered that in all of these models loss of $T g f b r 2$ causes growth of the basal cell and stem-like cell populations, which we believe is driving tumor formation. Therefore, we hypothesize that the TGF- $\beta$ pathway is important for inhibiting growth of the basal lineage and for promoting differentiation of cells in the prostate. These models help further the knowledge of TGF- $\beta$ signaling in prostate cancer, which should lead to better ideas of critical components to target and thereby to better therapies in the future. 


\section{Dedication}

I dedicate this work to my wonderful family and especially to my amazing wife, Maureen Bjerke. I never would have been able to do this without her. 


\section{Abstract}

Table of Contents

List of Abbreviations

List of Figures

Chapter 1: Background

1.1 Meis and $\mathrm{Pbx}$ proteins

1.2 Meis family

1.3 Pbx family

1.4 Complexes formed by Meis

1.5 KLF family of proteins

1.6 Potential Transcriptional Target Genes of Meis, Pbx and Klf4

1.7 The TGF- $\beta$ signaling pathway

1.8 Pten (Phosphatase and tensin homolog)

$1.9 \mathrm{Wnt} / \mathrm{APC} / \beta$-catenin pathway

1.10 Prostate cancer

1.11 The TGF- $\beta$ pathway in prostate cancer

1.12 The Wnt/APC/ $\beta$-catenin pathway in prostate cancer

1.13 Mouse models of Prostate cancer

Chapter 2: Methods

2.1 Plasmids and oligonucleotides

2.2 Cell culture and siRNA knockdown 
2.4 Western blotting on prostate tissue

2.5 DNA affinity precipitation

2.6 Luciferase assays - HepG2

2.7 Luciferase assays - Pbx1 repression

2.8 ChIP assays

2.9 In silico site search

2.10 Mice

2.11 DNA and RNA analyses

2.12 Histology, IHC and IF

$2.13 \beta$-galactosidase staining

2.14 Primers used in this study

Chapter 3: Meis2 and Pbx1 Cooperate with Klf4 to Activate Gene Transcription

Meis2 and Pbx1, DNA binding and Meis2's transcription activation domain

3.2.3 Meis2 and $\mathrm{Pbx} 1$ regulate p15 through the proximal GC box

Klf4 in a DNA independent manner

3.2.5 Klf4 cooperates with Meis/Pbx to activate the $\mathrm{p} 15$ promoter 
3.2.7 Analysis of promoter sites necessary for activation by Meis2d, Pbx1 and Klf4 58

3.2.8 Additional genes activated by Meis2, Pbx1 and Klf4 identified by Site Search 61

3.2.9 Meis2 and Pbx1 are downregulated in human prostate cancer 64

3.2.10 Pbx1 is repressed by androgen $\quad 65$

$\begin{array}{ll}3.3 \text { Discussion } & 70\end{array}$

Chapter 4: Loss of Tgfbr2 in addition to Pten speeds progression to 72

invasive cancer in the murine prostate

$\begin{array}{ll}4.1 \text { Introduction } & 73\end{array}$

$\begin{array}{lll}4.2 \text { Results } & 74\end{array}$

4.2.1 Loss of Tgfbr2 in addition to Pten leads to an early onset of prostate cancer $\quad 74$

$\begin{array}{ll}\text { 4.2.2 Histology of tumors } & 75\end{array}$

4.2.3 Higher proliferation and loss of p27 in the progression from Pten null to $\quad 80$

Pten/Tgfbr2 double null

4.2.4 Pten/Tgfbr2 null prostate tumors are metastatic to lymph nodes and lung $\quad 83$

4.2.5 Pten/Tgfbr2 null prostate tumors are resistant to castration 84

4.2.6 The TGF- $\beta$ pathway is activated in the Pten null 87

4.2.7 The TGF- $\beta$ pathway is activated downstream of Akt 90

4.2.8 Loss of Tgfbr2 cooperates with activated Akt to cause cancer 93

4.2.9 Loss of Smad2 does not worsen the Pten ${ }^{\mathrm{r} / \mathrm{r}}$ phenotype 94

4.2.10 Proposed model of progression in the Pten $^{\mathrm{r} / \mathrm{r}} ;$ Tgfbr $^{\mathrm{r} / \mathrm{r}}$

$\begin{array}{ll}4.3 \text { Discussion } & 98\end{array}$ 
Chapter 5: Loss of Tgfbr2 also promotes rapid tumor progression in

combination with Apc knockout

5.1 Introduction

102

5.2 Results

103

5.2.1 Loss of Tgfbr2 cooperates with loss of Apc to cause invasive cancer

103

5.2.2 Comparative histology between Pten and Apc based models

5.2.3 Trichrome staining of Pten and Apc based models

106

5.2.4 Characterization of $\beta$-catenin and CollagenIV in Pten and Apc based models

5.2.5 Characterization of FoxA1 and Sma in Pten and Apc based models

5.2.6 Comparison of protein levels for key components of the Apc, Pten and TGF- $\beta$ pathways

5.2.7 Analysis of regulators of the cell cycle in Pten and Apc based models 
6.2.5 Loss of Tgfbr2 causes an increase in proliferation specific to the basal cells

6.2.7 CD44 and other stem cell genes are increased in the Pten ${ }^{\mathrm{r} / \mathrm{r}} ; \mathrm{Tgfbr}^{\mathrm{r} / \mathrm{r}}$

6.3 Discussion

7.1 Summary of work on Meis and $\mathrm{Pbx}$

7.2 How prevalent is the cooperation between Meis/Pbx and Klf4?

7.3 Does Pbx1 interact with other Klf family members?

7.4 Does the interaction between Meis/Pbx and Klf4 change the spectrum of genes activated by each factor alone?

7.5 Do Meis and Pbx have an antitumor effect in prostate cancer? metastases in this model? Could we stop bladder obstructions and increase the metastases?

7.8 Are the metastases colonizing somewhere else and can we capture them to characterize them?

7.9 Is the low level of pSmad2 staining significant?

7.10 Why did knockout of Smad2 in the background of Pten knockout have no effect? 160

7.11 How does Pten loss activate the TGF- $\beta$ pathway?

7.12 How might our model compare to the $\operatorname{Pten}^{\mathrm{r} / \mathrm{r}} ; \operatorname{Smad} 4^{\mathrm{r} / \mathrm{r}}$ ? 
7.14 Which cells in the $\mathrm{Apc}^{\mathrm{r} / \mathrm{r}}$ and $\mathrm{Apc}^{\mathrm{r} / \mathrm{r}} ; \mathrm{Tgfbr}^{\mathrm{r} / \mathrm{r}}$ are becoming squamous?

7.15 Why do the $\mathrm{Apc}^{\mathrm{r} / \mathrm{r}} ; \mathrm{Tgfbr}^{\mathrm{r} / \mathrm{r}}$ not metastasize?

7.16 What exactly is TGF- $\beta$ doing to restrain growth?

7.17 What stem cell genes are up in our model? Which cell population are they in, and do they indicate increased tumor initiating ability?

7.18 Conclusion 


\section{List of Abbreviations}

\begin{tabular}{|c|c|}
\hline Apc & Adenomatous Polyposis Coli \\
\hline CDK & Cyclin Dependent Kinase \\
\hline CKI & Cyclin dependent kinase inhibitor \\
\hline ChIP & Chromatin immunoprecipitation \\
\hline Co-IP & Co-immunoprecipitation \\
\hline CRPC & Castration resistant prostate cancer \\
\hline EdU & (5-ethynyl-2'-deoxyuridine) \\
\hline EMT & Epithelial to mesenchymal transition \\
\hline EtBr & Ethidium Bromide \\
\hline FACS & Fluorescence activated cell sorting \\
\hline GO & Gene Ontology \\
\hline $\mathrm{H} \& \mathrm{E}$ & Haematoxylin and eosin \\
\hline HGPIN & High Grade Prostatic Intraepithelial Neoplasia \\
\hline $\mathrm{IHC}$ & Immunohistochemistry \\
\hline IP & Immunoprecipitation \\
\hline p15 & CDKN2B, or p15 $5^{\text {INK4B }}$ \\
\hline PDA & Poorly differentiated adenocarcinoma \\
\hline PIN & Prostatic Intraepithelial Neoplasia \\
\hline Pten & Phosphatase and Tensin homolog \\
\hline qPCR & Quantitative polymerase chain reaction \\
\hline qRT-PCR & Quantitative reverse transcription polymerase chain reaction \\
\hline RNA-seq & RNA sequencing \\
\hline SBR2 & Smad Binding Region of p15 promoter \\
\hline TALE & Three-amino acid loop extension \\
\hline
\end{tabular}


TBS

Tris Buffered Saline

Tg-Akt1 Transgenic Akt1 (activated by myristoylation)

TGF- $\beta \quad$ Transforming growth factor beta

Tgfbr2 TGF- $\beta$ type II receptor

TGIF 5'-TG-3' Interacting Factor

Tx AD Transcriptional activation domain 


\section{List of Figures}

Figure 1: p15 and E-cadherin respond transcriptionally to Meis2d and Pbx1a

Figure 2: Requirements of Meis2d and Pbx1a domains on gene activation

Figure 3: Meis2 and $\mathrm{Pbx} 1$ regulation of the p15 promoter through the

proximal GC box

Figure 4: Meis2 and Pbx1 interact with $\mathrm{Sp} 1$ in a DNA dependent manner and

Klf4 in a DNA independent manner

Figure 5: Klf4 and Pbx1 also regulate p15 and E-cadherin in MCF7 cells

Figure 6: Analysis of promoter sites necessary for activation

by Meis2d, Pbx1 and Klf4

Figure 7: MEIS2 and PBX1 transcripts are down in prostate cancer

Figure 8: Repression of the Pbx1 promoter and expression of PLZF

Figure 9: Loss of Tgfbr2 in addition to Pten leads to an early onset of prostate cancer

Figure 10: Histology of prostate ducts from wild type, Tgfbr $2^{\mathrm{r} / \mathrm{r}}, \operatorname{Pten}^{\mathrm{r} / \mathrm{r}}$ and $\operatorname{Pten}^{\mathrm{r} / \mathrm{r}} ; \operatorname{Tgfbr}^{\mathrm{r} / \mathrm{r}}$

Figure 11: Higher proliferation and loss of CDK inhibitor p27 in the progression from Pten null to Pten/Tgfbr2 double null 
Figure 13: Expression of the TGF- $\beta$ pathway in Pten null mouse prostates

Figure 14: Induction of the TGF- $\beta$ pathway downstream of activated Akt

Figure 15: Phenotype comparison of $\operatorname{Pten}^{\mathrm{r} / \mathrm{r}}$ versus $\operatorname{Pten}^{\mathrm{r} / \mathrm{r}} ; \operatorname{Smad}^{\mathrm{r} / \mathrm{r}}$

Figure 16: Diagram of proposed progression in our model

Figure 17: Tgfbr2 knockout accelerates prostate cancer progression in an

Apc knockout model

Figure 18: Comparative histology of Pten and Apc models

Figure 19: Trichrome staining on the set of 6 genotypes

Figure 20: Immunofluorescence for $\beta$-catenin and CollagenIV in 6 genotypes

Figure 21: Immunofluorescence for FoxA1 and Sma in 6 genotypes

Figure 22: Comparison of protein levels for key components of the

Apc, Pten and TGF- $\beta$ pathways

Figure 23: Analysis of cell cycle and senescence in Pten and Apc models

Figure 24: Clustering of the RNA-seq data by principal component analysis

Figure 25: Table of the top $10 \mathrm{GO}$ terms upregulated or downregulated for the terminal Pten ${ }^{\mathrm{r} / \mathrm{r}} ;$ Tgfbr $^{\mathrm{r} / \mathrm{r}}$ versus the 22 week Pten $^{\mathrm{r} / \mathrm{r}}$ comparison

Figure 26: Overlap between RNA-seq data and published basal/luminal genes and changes in stem cell genes 
Figure 27: Immunofluorescence for Keratin 5 and Keratin 8

Figure 28: Proliferation comparison of luminal and basal cell types

Figure 29: Immunofluorescence of cell types in lung metastasis

Figure 30: Immunofluorescence for Keratin 5 and CD44 
Chapter 1

\section{Background}




\section{Section 1.1: Meis and Pbx Proteins}

Meis and Pbx are both homeodomain containing transcription factors. The homeodomain was first described in the important body segmentation genes of the Hox clusters. Hox is short for Homeobox, the DNA sequence encoding the homeodomain. The homeodomain was the defining feature of the Hox genes, but was subsequently found in other genes. Hox genes were discovered due to their importance in body segmentation in flies, but homeodomain proteins are also present in mammals, fungi and plants ${ }^{1}$. The homeodomain is a protein structure of approximately 60 amino acids that is used to bind DNA through three alpha helices. Helices 2 and 3 form a helix-turn-helix motif with helix 3 directly binding to the DNA ${ }^{2}$. Different families of homeodomain proteins are characterized by variations in the sequence of the homeodomain and by other domains present in the protein. Meis and Pbx both belong to the TALE family of homeodomain proteins. The TALE family of homeodomain factors is characterized by a Three Amino acid Loop Extension (TALE) between helices 1 and 2. This loop functions in proteinprotein interactions and binds to a hexapeptide motif in a subset of Hox proteins ${ }^{3}$. The TALE domain is evolutionarily old enough that a TALE family member can found in yeast, the MAT $\alpha 2$ gene. Also included in the TALE family are the KNOX, Iroquois and TGIF subfamilies of proteins ${ }^{4}$. Homeodomain proteins typically bind DNA as part of a complex to achieve greater affinity and specificity. Both Meis and Pbx are defined as Hox cofactors because they form complexes with Hox proteins to help each other bind DNA. However, Meis and Pbx clearly have functions that are separate from their interactions with Hox proteins ${ }^{3}$. Not all TALE members are Hox cofactors though, as TGIF has not been shown to bind Hox proteins.

\section{Section 1.2: Meis family}

Meis1 (Myeloid Ecotropic viral Integration Site 1) was originally characterized as a viral insertion site in the BXH-2 mouse model of myeloid leukemia. This model is used to find and 
characterize retroviral insertion sites that give rise to leukemia by activating an oncogene or disrupting a tumor suppressor ${ }^{5}$. MEIS1 was subsequently verified as a critical oncogene in human acute myeloid leukemia ${ }^{6,7}$ and the MEISI locus has also been associated with chronic myeloid leukemia ${ }^{8}$. Other Meis paralogs have also been characterized and there are three MEIS genes in humans (MEIS 1-3) and two other closely related genes in the MEIS family called PKNOX1 and PKNOX ${ }^{1}$. Meis paralogs 2 and 3 were identified by DNA cross-hybridization ${ }^{9}$. Interestingly, loss of the MEIS3 locus has also been associated with neuroblastoma and glioma ${ }^{8}$. The Meis family is characterized not only by its homeodomain sequence, but also by an aminoterminal MEIS domain ${ }^{1}$. This MEIS domain is also called the hth domain after the Drosophila homolog of Meis, homothorax (hth). This MEIS domain has two regions that are particularly well conserved, termed homology regions $1 \& 2(\mathrm{hr} 1 \text { and } \mathrm{hr} 2)^{4}$. Meis proteins can bind to $\mathrm{Pbx}$ proteins and this has been shown to localize to the $\mathrm{hr} 2$ portion of Meis ${ }^{10}$. Meis proteins are known to be extensively alternatively spliced; MEIS1 was shown to have a carboxyl-terminal activation domain in multiple splice variants ${ }^{11}$. MEIS2 also has at least 5 splice variants termed MEIS2a-MEIS2e. MEIS2d contains a carboxyl-terminal activation domain, while MEIS2e has a truncation within the homeodomain, making it unable to bind DNA or activate transcription ${ }^{12}$.

\section{Section 1.3: Pbx family}

The PBX (Pre-B-cell leukemia transcription factor) family was originally discovered via the E2A-PBX1 fusion protein in acute lymphoblastic leukemia. This oncogenic fusion protein contains the amino-terminal activation domain of E2A attached to the carboxyl-terminal DNA binding domain of PBX1. This results in the abnormal activation of Pbx target genes, in particular HOX genes, that are believed to cause leukemia ${ }^{13}$. In mice and humans there are four paralogs of Pbx numbered 1 to $4{ }^{14}$. Much of the work on the Pbx family of proteins is based on the Drosophila homolog extradenticle (exd). The Pbx proteins are thought to be very similar, enough so that they can be substituted for each other ${ }^{3}$. As stated above, Pbx proteins are also 
members of the TALE family of homeodomain proteins. They are then further categorized by their conserved PBC domain that is located amino-terminal to the homeodomain. The PBC domain is further broken down into two regions of conservation PBC-A and PBC-B. The interaction between $\mathrm{Pbx}$ and Meis has been shown to be via the PBC-A domain ${ }^{3}$. Pbx proteins themselves do not have an activation domain ${ }^{15}$, and require interaction with another protein, such as Meis, for activation. Pbx proteins were originally thought of mainly as Hox cofactors, but have since had many other interactions described. For example, Pbx1 was shown to mark genes for activation by $\mathrm{MyoD}^{16}$. Also, $\mathrm{Pbx} 1$ interacts with another homeodomain transcription factor Pdx1, and this interaction has been shown to be necessary for pancreas development ${ }^{17}$.

\section{Section 1.4: Complexes formed by Meis \& Pbx families}

Meis, $\mathrm{Pbx}$ and Hox proteins can form numerous different complexes. Meis and $\mathrm{Pbx}$ can dimerize to bind DNA at a composite Pbx/Meis site with the sequence TGATTGACAG ${ }^{18}$. It has also been shown that interactions between Meis and $\mathrm{Pbx}$ family members can regulate each other's stability and nuclear localization. Overexpression of the Meis homolog Prep1 was shown to increase the stability of $\mathrm{Pbx} 2$ protein ${ }^{19}$. Additionally, in murine fibroblasts it was shown that Prep1 is cytoplasmic and requires $\mathrm{Pbx} 1$ for nuclear import ${ }^{20}$. Pbx family members can bind DNA in cooperation with Hox proteins from paralog groups 1 through 10, forming a composite $\mathrm{Pbx} /$ Hox binding site ${ }^{14}$. Meis family members can form dimers with Hox proteins of paralogs 9, 10 and $13^{21,22}$. Additionally, trimers can be formed with Pbx-Hox directly binding DNA and Meis as a non-DNA binding partner or DNA bound Meis-Hox and Pbx as a non-DNA binding partner $^{21}$. With so many components in a complex, it is clear that the sign (activation or repression) of transcription by these complexes is going to be context dependent, in part determined by which members of Hox, Meis and Pbx are expressed. The multitude of complexes that can be formed with non-DNA bound components makes it plausible that homeodomain 
proteins could be recruited by non-homeodomain proteins to sites on DNA that do not fit their canonical binding site motifs.

\section{Section 1.5: KLF family of proteins}

The KLF (Krüppel-Like Factors) family of transcription factors is named for their similarity to the Drosophila protein Krüppel and includes the well known Sp (Specificity protein) family. There are at least 25 members of the KLF family in the mouse and human genomes ${ }^{23}$. The KLF family is defined by their carboxyl-terminal three tandem $\mathrm{Cys}_{2} \mathrm{His}_{2}$ zinc-finger structure that is used for binding DNA. All KLF family members bind to GC or GT boxes, with small variations in their sequence specificity ${ }^{23}$. To be defined as part of the KLF family requires at least $66 \%$ sequence identity within the zinc finger domain. However, outside of the zinc finger domain the sequences can be very divergent. Each sub family can be grouped according to what other domains the proteins contain. One such sub family is the Sp family which consists of Sp1-4 ${ }^{24}$. Sp1 was originally named as such due to the Sephacryl and Phosphocellulose columns used to purify it, but was then later named Specificity Protein $1^{25}$. Sp1 and Sp3 are widely expressed and both have similar glutamine rich activation sequences, however Sp3 has two alternative translation start sites resulting in two shorter isoforms. These shorter isoforms lack one of the activation domains. Both also have inhibitory domains, but at different locations within the protein, which may result in differences in regulation between the proteins. As expected for proteins with both activating and inhibitory domains, it has been shown that both Sp1 and Sp3 can result in gene transcription or repression in a cell context dependent manner ${ }^{25}$. It has been demonstrated that $\mathrm{Sp} 1$ and $\mathrm{Sp} 3$ can compete for the same site on DNA ${ }^{24}$. Additionally, it has been published that Sp1 can activate the $\mathrm{p} 15^{\mathrm{INK} 4 \mathrm{~B}}$ gene via GC boxes, while Sp3 cannot ${ }^{26}$. However, $\mathrm{Sp} 3$ was shown to be a stronger activator of the $\mathrm{p} 21^{\mathrm{CIP} 1 / \mathrm{WAF} 1}$ promoter than $\mathrm{Sp} 1{ }^{25}$. 
Amongst the remainder of the KLF proteins there exists even more variation. Klf4 has both transcriptional activation and repression domains, whereas Klf5 is thought to be only an activator ${ }^{24}$. Klf4 is famously one of the 4 factors used to make induced pluripotent stem cells ${ }^{27}$. However, it was shown that both Klf4 and Klf5 are necessary for the maintenance of pluripotency in mouse embryonic stem cells ${ }^{28}$. Seemingly contradictory to Klf4's use to make induced pluripotent stem cells, Klf4 has been shown to activate the p21 gene via a GC box in the p21 promoter $^{29}$. Accordingly, recurring deletions of the KLF4 locus and methylation of the gene have been reported in medulloblastoma ${ }^{30}$. Conversely, groups have reported that KLF4 mRNA and protein are upregulated during breast cancer progression ${ }^{31}$. Some of these seemingly contradictory results are likely due to the cellular context in which Klf4 is present, possibly due to differences in cell signaling or available interaction partners. As such, Klf4 has been shown to interact with other transcription factors such as Oct 4 and Sox $2^{32}$ and the transcription cofactor $\beta$ catenin ${ }^{33}$. Different interaction partners could be modulating where Klf4 binds to DNA and what effect is has on gene transcription.

\section{Section 1.6: Potential Transcriptional Target Genes of Meis, Pbx and Klf4}

p15 ${ }^{\mathrm{INK} 4 \mathrm{~B}}$ (Gene name: $\left.C D K N 2 B\right)$ is a well characterized cyclin dependent kinase inhibitor (CKI) that is part of the INK family of CKIs, which also includes INK4A (p16), INK4C (p18) and INK4D (p19). This family inhibits the cell cycle by directly contacting CDK4 and CDK6, thereby blocking their binding to D-type cyclins. This results in a blockage of the cell cycle at the $\mathrm{G} 1$ phase ${ }^{34}$. The $\mathrm{p} 15^{\mathrm{INK} 4 \mathrm{~B}}$ locus is lost in a wide range of cancers, but interpretation of this result is complicated because the locus harbors two other important tumor suppressors: $\mathrm{p} 16^{\mathrm{INK} 4 \mathrm{~A}}$ and $\mathrm{p} 19^{\mathrm{ARF}} \cdot \mathrm{p} 16^{\mathrm{INK} 4 \mathrm{a}}$ is very similar at the protein level to $\mathrm{p} 15^{\mathrm{INK} 4 \mathrm{~B}}$ and works in the same manner. $\mathrm{p} 19^{\mathrm{ARF}}$ binds to the $\mathrm{p} 53$ inhibitor MDM2, which releases $\mathrm{p} 53$, allowing it to activate cell cycle arrest and apoptosis ${ }^{35}$. Loss of the locus containing these tumor suppressors has been found to be especially important in ALL (Acute Lymphoblastic Leukemia) ${ }^{36}$ and glioma ${ }^{37}$. 
Many studies have been published on the transcription regulation of this locus and control of the three genes is probably interdependent. However, it has been well characterized that $\mathrm{p} 15^{\mathrm{INK} 4 \mathrm{~B}}$ is induced by TGF- $\beta^{38}$ and Ras signaling and repressed by Myc signaling ${ }^{39}$.

E-cadherin is a classical cadherin that is expressed from the $C D H 1$ gene. Cadherins are calcium dependent cell adhesion molecules that form homophilic bonds with cadherins on neighboring cells and are a major component of adherens junctions in epithelial cells. The cytoplasmic domain of E-cadherin physically interacts with p120 catenin, $\beta$-catenin and $\alpha$ catenin, each of which are important signaling molecules and mediate the interaction of Ecadherin with the actin cytoskeleton ${ }^{40}$. E-cadherin also functions in tissue sorting during development, as different tissues expressing different cadherins will self-adhere, thereby sorting themselves accordingly ${ }^{41}$. E-cadherin has also been shown to be an invaluable tumor suppressor. Very often for cancer cells to metastasize they must lose E-cadherin to be able to lose adhesion to the primary tumor. This frequently occurs via the process of Epithelial to Mesenchymal Transition (EMT) ${ }^{42}$. This is a process in which epithelial cells lose their epithelial characteristics and gain mesenchymal characteristics, including destabilization of cell-cell junctions, increased migration and loss of apical-basal polarity. In addition to physically keeping cells in place, E-cadherin interacts with a number of signaling pathways, including WNT/ $\beta$ catenin, cell migration via Rac/Rho and receptor tyrosine kinases EGFR, IGF-1R and c-met ${ }^{40}$. Transcription of the E-cadherin gene has been shown to be activated by $\mathrm{Rb}, \mathrm{c}-\mathrm{Myc}{ }^{40}$ and by AP2 and $\mathrm{Sp} 1^{41}$. In cancer, E-cadherin expression is often downregulated by the EMT regulators SNAIL, SNAI2, ZEB1 and ZEB2, or by hypermethylation ${ }^{40}$.

\section{Section 1.7: The TGF- $\beta$ signaling pathway}

The TGF- $\beta$ (Transforming growth factor $\beta$ ) pathway is the founding member of a large family of signaling pathways that are present in metazoans. It is vital for development and tissue 
homeostasis. There are two classes of TGF- $\beta$ receptors, type I and type II. Both type I and type II receptors are serine/threonine kinases and the type II receptors are constitutively active. Signaling begins when ligands (which are dimers) bind to a dimer of type II receptors. Ligand binding brings together the type I and type II receptors and the type II receptors subsequently phosphorylate the type I receptors, causing them to become activated. The activated type I receptors then phosphorylate receptor Smads (R-Smads), causing them to become activated. The phosphorylated R-Smads can then bind to Co-Smads, which together enter the nucleus. Smads form transcription factor complexes on the DNA inside the nucleus where they regulate target gene expression ${ }^{43}$. As many as 33 TGF- $\beta$ related ligands have been identified in mammals, with other families including the bone morphogenic protein (BMP) family, activin \& inhibins, nodal, growth and differentiation factors (GDFs) and anti-Müllerian hormone ${ }^{44}$. The TGF- $\beta$ ligand family itself contains 3 members: TGF $\beta 1-3$. These bind to the type II receptor Tgfbr2, which activates the type I receptor Tgfbr1. Tgfbr1 signals through the R-Smads for TGF- $\beta$ : Smad 2 and Smad3. Smads $2 \& 3$ bind to the common-mediator Smad (Co-Smad), Smad4. Signaling via Smads is considered the canonical TGF- $\beta$ pathway, however signaling can also occur through other pathways, usually via phosphorylation of proteins (other than Smads) by Tgfbr1. It has been shown that TGF- $\beta$ can also activate the Erk MAPK pathway, the JNK/p38 pathway, Rholike GTPases and the PI3-kinase pathway ${ }^{44}$.

The TGF- $\beta$ pathway is a very important regulator of cancer, but has a dual role in cancer progression: Early in tumor formation TGF- $\beta$ signaling is cytostatic, but after tumor formation it becomes pro-metastatic. One of the first examples of the dual role of TGF- $\beta$ in cancer was demonstrated by the Akhurst group in a mouse model of skin cancer. This group overexpressed TGF $\beta 1$ ligand in the skin of mice using several keratin promoters, then painted the mice with a carcinogen (DMBA) to induce tumor formation. They subsequently showed that overexpression of TGF $\beta 1$ resulted in fewer benign skin lesions per animal, but that these lesions were more likely 
to progress into carcinomas ${ }^{45}$. TGF- $\beta$ signaling also differs by cell type; it has a cytostatic effect on epithelial cells, but induces cell migration and inflammation in other cell types ${ }^{46}$. Since the majority of cancers are of epithelial origin (carcinomas), TGF- $\beta$ 's main function is thought to be keeping growth in check. Its most well studied anti-tumor effects are through activation of the CDK inhibitors $\mathrm{p} 15^{\mathrm{INK} 4 \mathrm{~B}}$ and $\mathrm{p} 21^{\mathrm{CIP} 1}$ and repression of the growth promoter c-Myc. It also promotes cell differentiation through repression of the ID (Inhibitor of differentiation/DNA binding) family of proteins ${ }^{46}$. Later in cancer TGF- $\beta$ can induce EMT, switching the response from epithelial-like to mesenchymal-like. Thus, after EMT, TGF- $\beta$ signaling causes dedifferentiation, cell migration and metastasis ${ }^{46}$. TGF- $\beta$ can also promote tumorigenesis through effects on the surrounding stroma by promoting inflammatory cell recruitment and angiogenesis, and by inhibiting immune surveillance ${ }^{47}$. This dual role can make it hard to interpret what effect TGF- $\beta$ is going to have. In the models used in this dissertation it is likely TGF- $\beta$ 's effect is mostly tumor suppressive.

\section{Section 1.8: Pten (Phosphatase and tensin homolog)}

Pten is a phosphatase that negatively regulates the phosphatidylinositide 3-kinases (PI3K) signaling pathway. The PI3K pathway is a vital cell growth and survival pathway that is present from yeast to humans. PI3K is activated by growth factor receptor tyrosine kinases and consists of a regulatory subunit and catalytic subunit. The catalytic subunit most commonly studied in cancer is known as p110 $\alpha$, which is encoded by the PIK3CA gene. p110 $\alpha$ phosphorylates phosphatidylinositol-4,5-bisphosphate (PIP2), thereby converting it into phosphatidylinositol3,4,5-trisphosphate (PIP3) ${ }^{48}$. PIP3 functions as a second messenger that recruits proteins to the cell membrane via their pleckstrin homology $(\mathrm{PH})$ domains, which bind PIP3. Proteins that are recruited to the membrane by PIP3 include PDK-1 and small GTPases of the Rho and Arf family (which are important in cellular movement), but the most well studied example is Akt (Protein Kinase B, PKB) ${ }^{49}$. There are 3 isoforms of Akt (Akt1-3). Amplification of Akt2 is the most 
common in human cancer, but Akt1 has been shown to have transformative activity also ${ }^{50}$. Akt is normally kept in an inactive state due to an interaction between its $\mathrm{PH}$ and kinase domains. Interaction of the PH domain with PIP3 causes a change in Akt conformation, allowing its phosphorylation at threonine 308 by 3-phosphoinositidedependent kinase (PDK1) and at serine 473 by mTORC2 or DNA-PK ${ }^{51}$. These phosphorylations activate Akt, which is vital to cell growth and survival. Important Akt targets include proteins that are activated by phosphorylation such as TSC2 (which promotes mTORC1 activity, increasing cell growth and survival), MDM2 (which inhibits and degrades the tumor suppressor p53) and NF- $\kappa \mathrm{B}$ signaling (important for cell survival and cytokine production). Some targets are also inhibited by phosphorylation including GSK-3 and the proapoptotic protein BAD ${ }^{48}$. Additionally, some groups have proposed that Pten's protein phosphatase activity is also important, and that not all of its tumor suppressive activity is through its lipid dephosphorylation activity ${ }^{52}$.

\section{Section 1.9: Wnt/APC/ $\beta$-catenin Pathway}

APC (Adenomatous Polyposis Coli) is a negative regulator of Wnt signaling and a vital tumor suppressor in many types of cancers. It was originally identified in colorectal cancer, but it is also important in other cancers such as in skin and liver ${ }^{53}$. Activation of Wnt signaling by methods other than loss of APC have also been shown to cause tumorigenesis in other tissues, such as in breast and bone marrow ${ }^{54}$. APC is part of the $\beta$-catenin destruction complex which also includes Axin, CKI, FBXW1A and GSK-3. This complex is a vital component of the Wnt pathway that keeps it from becoming overactive. In the normal state, glycogen synthase kinase (GSK-3) and CKI phosphorylate free $\beta$-catenin (that is not attached to adherens junctions), which targets it for ubiquitination and then destruction. However, in the presence of Wnt signaling, extracellular Wnt molecules bind to Frizzled receptors along with LRP-5/6, resulting in disruption of the APC complex, keeping it from phosphorylating $\beta$-catenin. $\beta$-catenin is then free to enter the nucleus where it binds to the transcription factors TCF/LEF-1, which activate target 
genes such as Myc, MMP7 and VEGF ${ }^{53}$. In the normal state, the majority of $\beta$-catenin is attached to cadherin complexes at adherens junctions and it is difficult to detect in the nucleus of cells. Only upon loss of APC or another insult, such as loss of E-cadherin, is it is free to enter the nucleus ${ }^{53}$. Loss of APC only affects the "canonical" Wnt pathway that functions through $\beta$ catenin and does not affect the non-canonical planar cell polarity or the Wnt calcium-mediated pathways ${ }^{55}$.

\section{Section 1.10: Prostate cancer}

The NCI estimates that 1 in 7 men born today will be diagnosed with prostate cancer during their lifetime (http://seer.cancer.gov/statfacts/html/prost.html). They also estimate that in 2013 there will be 238,590 new cases of prostate cancer in the United States and 29,720 deaths. It was shown in 1941 that prostate cancer is dependent on hormones and that surgical castration inhibited prostate cancer ${ }^{56}$. Amazingly, androgen deprivation therapy is still a major part of the treatment of prostate cancer today. However, this is accomplished using chemicals that interfere with the production or action of androgens. Luteinizing hormone releasing hormone (LHRH) agonists and antagonists are both used to block the signal to make more testosterone. Antiandrogens are used to directly interfere with the androgen receptor (AR), often in combination with an LHRH agonist ${ }^{57}$. Additionally, there is a third class of antiandrogens, primarily Abiraterone, that block production of androgens in the testes, adrenal glands and prostate tissue. This therapy has been shown to result in lower levels of androgens than LHRH agonists or antagonists ${ }^{58}$. These androgen deprivation therapies are typically combined with

prostatectomy surgery to take out as much of the cancer as possible ${ }^{59}$. Localized prostate cancer can be cured by prostatectomy. However, for disease that has spread, androgen deprivation therapy typically works for a short time, but always relapses. After relapse, it is called castration resistant prostate cancer (CRPC) due to its resistance to antiandrogen therapies. CRPC is often still dependent on the androgen receptor, even though it is deprived of its ligand. This is often 
due to AR gene amplification or mutation that makes it ligand independent or activatable by noncognate ligands ${ }^{60}$.

Like all cancers, prostate cancer is a genetic disease. Genetic alterations accumulate in cells over time, leading to inappropriate regulation over normal cell growth and behavior. Different types of cancers have different profiles of mutations. The mutation most unique to prostate cancer is a gene fusion between TMPRSS2 and the transcription factor ERG (ETSRelated Gene), which is found in about $50 \%$ of cases. This fusion attaches the TMPRSS2 promoter and a small 5' piece of TMPRSS2 to a truncated 3' piece of ERG. TMPRSS2 is a transcriptional target gene of the androgen receptor in prostate cells. Therefore, TMPRSS2-ERG fusions lead to inappropriate expression of truncated ERG in prostate cancer. The mechanism by which truncated ERG causes cancer and the relative prognosis of these tumors is not entirely clear $^{61}$. Another important gene in prostate cancer is the tumor suppressor Pten. One or more alleles of Pten are lost in up to $60 \%$ of primary tumors ${ }^{62}$ and mutations in the PI3K pathway as a whole are found in up to $100 \%$ of metastases ${ }^{63}$. Additionally, it has been shown that Pten null prostate cells can grow without androgen ${ }^{64}$. Pten is most often deleted via large deletions and rearrangements, but it has also been shown to be inactivated by point mutations and silenced by methylation ${ }^{62}$. Also, in cases where Pten is not lost, rare mutations have been published that activate downstream oncogenic members of the PI3K pathway, such as the kinases PIK3CA or Akt1 ${ }^{65}$.

\section{Section 1.11: The TGF- $\beta$ pathway in prostate cancer}

TGF- $\beta$ 's dual role of cancer inhibition and metastasis promotion makes the pathway a questionable target in cancer treatment. However, most alterations of TGF- $\beta$ genes in prostate cancer result in loss of pathway function, implying that TGF- $\beta$ 's main role in prostate cancer is as a tumor suppressor. Both TGF- $\beta$ receptors (TGFBR1 and TGFBR2) are deleted in prostate 
cancer and loss correlates with tumor grade ${ }^{66}$. In addition to reduced receptor expression, the SMAD4 gene was shown to be downregulated by methylation in prostate cancer with a direct correlation to advanced disease ${ }^{67}$. Furthermore, the TGF- $\beta$ pathway is downregulated in human prostate metastases to bone, especially the SMAD4 gene ${ }^{68}$. Additionally, the TGF- $\beta$ pathway is important because it has been shown to interact with a number of other pathways that are of crucial importance in prostate cancer. It was shown that the fusion gene TMPRSS2-ERG induces genes from the TGF- $\beta$ family, including Smad 2 and TGFBR $3{ }^{69}$. TGF- $\beta$ signaling also interacts with the androgen receptor pathway. It has been shown that Smad3 and AR interact and that they both repress each other's transcriptional activity ${ }^{70,71}$. Additionally, androgen was shown to inhibit TGF- $\beta$ induced apoptosis in prostate cells ${ }^{72}$. The TGF- $\beta$ pathway also interacts with the PI3K pathway. Some of the later stage pro-metastatic effects of TGF- $\beta$ are thought to be via activation of the Akt pathway ${ }^{73}$. Clearly, the TGF- $\beta$ pathway is important for understanding prostate cancer due not only to its intrinsic signaling, but also due to the multitude of important pathways that it interacts with.

\section{Section 1.12: The Wnt/APC/B-catenin pathway in prostate cancer}

The Wnt/APC/ $\beta$-catenin pathway has been show to be important in prostate cancer, but mutations in this pathway are relatively rare. In prostate cancer, activating mutations in $\beta$-catenin that prevent its destruction by the proteasome are seen only about $5 \%$ of the time. Mutation of the genes encoding AXIN1 and APC have been documented in prostate cancer, but they are also rare $^{53}$. However, it has been shown that APC gene expression is often decreased due to methylation ( $>27 \%$ of cases $)^{74}$. $\beta$-catenin signaling can still be important even if it is not mutated, due to its activation by other oncogenic pathways that are overexpressed. Akt may phosphorylate and inhibit GSK-3, leading to increased $\beta$-catenin protein, but this is not a universally accepted model ${ }^{53}$. Additionally, the ERG oncogene has been shown to induce the Wnt pathway, primarily through Frizzled-4 (FZD4). This led to an increase in the activity of the 
Wnt pathway, as shown by TCF/LEF reporter assays ${ }^{75}$. This was corroborated recently by another group who also showed that inhibition of Wnt signaling diminished cell growth and invasion induced by ERG ${ }^{76}$. Finally, it has been shown that $\beta$-catenin can bind to the androgen receptor and act as a co-activator. Importantly, the interaction of $\beta$-catenin with AR competes with the interaction of $\beta$-catenin with TCF/LEF-1. Therefore, in prostate cells where AR is expressed, $\beta$-catenin signaling switches from canonical TCF/LEF-1 signaling to AR transcriptional targets ${ }^{53}$. These results show that the APC pathway is important to prostate cancer and that an understanding of their function is necessary to truly understand AR signaling.

\section{Section 1.13: Mouse Models of Prostate Cancer}

Prostate cancer is often modeled using immortalized human cancer cell lines. However, these lines are made from advanced prostate cancers and are not very representative of most cancers. These cell lines can also be used in xenograft models, but they do not reconstitute the numerous types of cells and stroma within a prostate gland. Additionally, xenografts are made in immunodeficient mice, so these models lack the organism's immune response to tumors, a critical part of a cancer model. For these reasons many people have turned to using genetically modified mice to model human prostate cancer. Mice can be bred reasonably quickly and have an increasingly good genetic system that can be modified to one's specific needs. There are differences in the prostates of mice versus men though. First, the human prostate is a single contained lobe with different zones: peripheral (70\%), central (25\%) and transitional (5\%). Whereas the mouse prostate is composed of separate paired lobes: Anterior, dorsal, lateral and ventral. Additionally, mice do not secrete PSA or develop prostate cancer without genetic manipulation ${ }^{77}$. However, mice still allow modeling of prostate cancer that arises from cells within the prostate gland and goes through the stages of prostate cancer progression. Prostate glands in human and mice are composed of a single well organized layer of secretory luminal cells, surrounded by a layer of basal cells. Both layers of luminal and basal cells are epithelial. 
There are also rare neuroendocrine cells within the basal layer. These epithelial layers form a duct, which is then surrounded by stroma ${ }^{78}$. In prostate cancer progression the luminal cells start to expand in number and become less well organized. As these cells grow out into the duct lumen, this is known as Prostatic Intraepithelial Neoplasia (PIN) and progresses from low grade (LGPIN) to high grade (HGPIN). It is thought that HGPIN is the precursor to carcinoma, which starts in situ (within the duct) and then becomes invasive and eventually metastatic when it spreads to other organs ${ }^{79}$. In humans, prostate tumors are almost always composed of luminal cells ${ }^{80}$, therefore it would make sense that these tumors arise from the luminal layer. However, it is still being debated which cells initiate human tumors, luminal or basal, partially because basal cells are thought to contain the stem cells in the prostate. The Witte group showed that human basal cells can recapitulate whole prostate ducts with basal and luminal cells when transplanted into immunodeficient mice, while luminal cells cannot. They also showed that basal cells form pre-cancerous PIN lesions upon oncogenic stimulation with Akt, while luminal cells do not ${ }^{81}$. However, the Xin group showed in mice that both basal and luminal cells can form tumors upon loss of Pten, but luminal cells produce higher grade tumors and basal cells only become cancerous upon differentiating into luminal cells. Furthermore, Michael Shen's group argues prostate cancer stem cells come from luminal cells. They say the prostate cancer stem cell comes from a rare luminal cell that they term a CARN (castration-resistant Nkx3.1-expressing cell). They show that these cells can self renew and form prostate ducts in vivo and report that Nkx3.1 is required for preservation of stemness in these cells ${ }^{82}$.

The TRAMP (transgenic adenocarcinoma model mouse prostate) was once the most widely used mouse model of prostate cancer, but has become less popular due to its differences in physiology to humans. It consists of the SV40 T antigen driven by a section ( -426 to $+28 \mathrm{bp})$ of the rat probasin promoter, which drives expression in the dorso-lateral and ventral lobes of the mouse prostate. The SV40 T antigen transforms cells by disrupting $\mathrm{p} 53$ and $\mathrm{pRB}{ }^{83}$. The 
TRAMP model results in prostate cancer with metastases after 4-9 months. However, these tumors are composed of neuroendocrine cells, which are not the most common cell type in human tumors. Neuroendocrine differentiation often becomes more common after androgen deprivation therapy though ${ }^{84}$. However, given that this model is driven by a viral oncogene that is not present in human tumors, it is not as relevant as models built on disrupting signaling pathways that are found in human cancers.

Subsequently, other groups have tried to improve on the promoters used to express transgenes specifically in the prostate. The Matusik group started with a shorter piece of the rat probasin promoter $(-286$ to +28$)$ and added an additional two copies of the androgen response region (ARR) of the probasin promoter to the 5' end of the transgene promoter. They termed this the $\mathrm{ARR}_{2} \mathrm{~PB}$ promoter ${ }^{85}$. This promoter gives high level expression in the prostate epithelia, with a small level of nonspecific expression in the seminal vesicles and testes, and slight staining in the female ovary ${ }^{86}$. This $\mathrm{ARR}_{2} \mathrm{~PB}$ promoter was subsequently used to overexpress the oncogene c-Myc specifically in the prostate. These mice developed invasive carcinoma in 6 to 12 months, with tumors that appeared much like human cancer and were not composed of neuroendocrine cells. The tumors were also shown to be sensitive to castration. However, since the c-Myc transgene is driven by an androgen sensitive promoter, it is hard to determine the significance of this finding, since lack of androgen would presumably not stimulate expression of c-Myc ${ }^{87}$. Additionally, 6 to 12 months is fairly long for experiments and the mice did not develop metastases.

This $\mathrm{ARR}_{2} \mathrm{~PB}$ promoter is also widely used to express the Cre recombinase protein in mouse prostate, this transgene is called $\mathrm{Pb}-\mathrm{Cre} 4{ }^{86}$. Cre is a site specific DNA recombinase that excises DNA in-between loxP sites. Alleles of genes that have had LoxP sites inserted around them are called floxed (Flanked by loxP sites) alleles ${ }^{88}$. Expression of Cre using $\mathrm{Pb}-\mathrm{Cre} 4$ in combination with floxed alleles results in tissue specific knockouts in both the luminal and basal 
epithelial cells of the prostate, but not in the stroma ${ }^{89} . \mathrm{Pb}-\mathrm{Cre} 4$ has been used to create numerous prostate specific knockouts. Many are based on knockout of the Pten gene, with or without knocking out other genes. Prostate specific knockout of the Pten gene alone was published by the Wu group in 2003. They showed that Pten null mice develop PIN in the prostate by the time they are 6 weeks old. This then develops into invasive carcinoma, which is importantly comprised of secretory epithelial cells, not neuroendocrine cells. These mice also developed lymph node and lung metastases, and are resistant to castration ${ }^{90}$. The Pandolfi group also published a Pten prostate knockout with $\mathrm{Pb}-\mathrm{Cre} 4$. They reported a slower progression to cancer, more in line with our results, but they do not detail metastases or castration experiments in their paper ${ }^{91}$. As stated above, some groups have suggested that Pten dephosphorylates important targets other than PIP3. However, in mouse models of prostate cancer groups have shown that decreasing the dose of PDK1 (which activates Akt1) or knocking out Akt1 in a Pten heterozygous background is sufficient to reduce tumors in the prostate ${ }^{92,93}$. This suggests that the main tumor suppressive activity of Pten is via its ability to inhibit activation of Akt1. Accordingly, the Sellers group made a constitutively active Akt1 to model prostate cancer. This transgene is driven by a simple piece of the probasin promoter $(-421$ to +28$)$, which induces a myristolated Akt1 transcript. This myristolation of Akt1 tethers it to the cell membrane, which increases its phosphorylation by activating kinases, making it constitutively active. This transgene is mostly restricted to the ventral prostate and is not expressed well in the other prostate lobes. The Sellers group showed that expression of this transgene results in PIN in the majority of animals in the ventral prostate. However, these mice never develop invasive cancer; they even examined 41 mice greater than 78 weeks old ${ }^{94}$. This transgenic Akt has a milder phenotype than Pten loss, possibly due to low expression from the simple probasin promoter. Alternatively, the transgenic Akt could have a milder phenotype because Pten is doing more than just inhibiting Akt activity. 
A subsequent paper by the DePinho group used Pb-Cre4 to knockout Pten and Smad4. This resulted in a more aggressive phenotype that produced adenocarcinoma faster than Pten knockout alone. It also resulted in a higher frequency of metastases, with 25 of 25 mice showing lymph node metastases and 3 of 25 having lung metastases ${ }^{95}$. The same group subsequently published a paper with a triple knockout of Pten, Smad4 and p53 using Pb-Cre4. This resulted in even faster progression to adenocarcinoma, but more importantly, they saw bone metastases in 3 out of 24 mice ${ }^{68}$. Metastases to bone are an important part of a human prostate cancer model, because bone is a very common site of human prostate metastases.

The $\mathrm{Pb}-\mathrm{Cre} 4$ transgene has also been used to knockout $\mathrm{p} 53$ and $\mathrm{Rb}$ in the mouse prostate. This resulted in adenocarcinoma, but with some neuroendocrine differentiation and metastases to the lymph nodes, liver, lung and adrenal glands. The mice were shown to be resistant to castration also ${ }^{96}$. Surprisingly, the median survival of the $\mathrm{p} 53 / \mathrm{Rb}$ was 226 days, which is longer than for the Pten/Smad4 mice. Lastly, $\mathrm{Pb}$-Cre4 has been used to inactivate Apc in the mouse prostate. This knockout resulted in hyperplasia by 4.5 weeks and adenocarcinoma by 7 months old. They reported not seeing any metastases in these mice, even in mice that were kept for 12-15 months, when the mice had to be sacrificed for tumor burden. Interestingly, the resulting tumors regressed if the mice were castrated early in the progression of tumor formation (at 6 weeks old). When castrated mice were euthanized 32 weeks later the mice had metaplasia and hyperplasia, but not carcinoma. When these mice were castrated at 32 weeks however, they still developed adenocarcinoma in all lobes. Since these Apc null mice are castration sensitive early and become castration insensitive later these experiments seem to mimic human tumors better than other models ${ }^{97}$. The Apc null mice however, display squamous metaplasia, something that is very rare in human tumors, comprising less than $1 \%$ of cases ${ }^{98}$.

In summary, mouse models of prostate cancer have improved from using viral oncogenes not found in human cancers to modeling prostate cancer by deleting genes common in human 
cancer. This should improve the relevancy of these models to human treatment. Newer models based on deletion of Pten are completely penetrant and result in carcinoma fairly rapidly. However, none of the models above are perfect. First, mouse models using genetic deletion in the majority of the cells in the prostate do not mimic the spontaneous nature of human cancer. Second, none of them are a good model of the human progression of prostate cancer that is initially androgen dependent and then becomes androgen independent after treatment with androgen deprivation. Lastly, bone metastases are the most common site of metastases in humans and none of the current mouse models reliably results in bone metastases in a high proportion of animals. To make a mouse model more relevant for human research the most important attributes that are currently lacking are the progression from androgen dependent growth to androgen independent growth and metastases to bone. If new mouse models of prostate cancer could recapitulate these features it would be very helpful to prostate cancer research. 


\section{Chapter 2}

\section{Methods}




\subsection{Plasmids and oligonucleotides}

p15 reporter constructs were created in pGL2 or pGL3 (Promega) or in pGL2 basic into which a minimal TATA element from the adenovirus major late promoter (MLP) had been inserted. The E-cadherin-luc reporter contains sequences from $178 \mathrm{bp}$ upstream of the transcriptional start to +92 of mouse gene inserted into pGL2. The four-copy SBR2 and two-copy Meis/Pbx reporters are as described previously ${ }^{38}$ and ${ }^{99}$, respectively. Meis2, Pbx1, KLF, and Sp1 expression constructs were created in a modified pCMV5 with either a Flag or T7 epitope tag. KLF4 was expressed from within pCDNA3 for luciferase assays. Meis2 and Pbx1 mutants and deletion constructs are as described previously ${ }^{99}$. Pax3 and Etv1 luciferase reporters are as described previously ${ }^{100}$ and ${ }^{101}$.

\subsection{Cell culture and siRNA knockdown}

HepG2 (ATCC HB-8065), Mcf7 and HeLa cells were maintained in Dulbecco's modified Eagle medium (DMEM) with 10\% fetal bovine serum (FBS) and COS1 cells were grown in DMEM with $10 \%$ bovine growth serum (BGS). For knockdown, cells were plated in 12-well plates and transfected with Dharmacon SMARTpool oligonucleotides using DharmaFECT reagent 1, according to the manufacturer's instructions. RNA was isolated 60 hours after transfection. The control pool (mouse siGENOME nontargeting siRNA pool 3) was used for the nontargeting control. For EdU labeling, cells were labeled with $10 \mu \mathrm{M}$ EdU for $1 \mathrm{~h}$ at $37^{\circ} \mathrm{C}$, and after fixation in $4 \%$ paraformaldehyde, were permeabilized with Triton X-100 for $30 \mathrm{~min}$ at room temperature. EdU was detected with an Alexa Fluor 488 EdU detection kit (Click-iT EdU [Invitrogen]), according to the manufacturer's protocol and DNA was stained with Hoechst 33342. Images were captured on a Zeiss AxioObserver with Volocity.

\subsection{Immunoprecipitation and Western blotting}

COS1 cells were transfected using Lipofectamine (Invitrogen). Forty hours after transfection, cells were lysed by sonication in phosphate-buffered saline (PBS) with 1\% NP-40, $1 \mathrm{mM}$ 
dithiothreitol (DTT), and protease inhibitors (Roche cOmplete mini \#11836153001). Immunocomplexes were precipitated with Flag M2-agarose (Sigma). Following SDSpolyacrylamide gel electrophoresis, proteins were electroblotted to Immobilon-P (Millipore) and incubated with antisera specific for Flag (Sigma) or T7 (Novagen). Proteins were visualized with horseradish peroxidase-conjugated goat anti-mouse or anti-rabbit Ig (Pierce) and ECL (Pierce).

For testing dependence on DNA binding, ethidium bromide was added to a concentration of $1 \mu \mathrm{M}$ to cell lysates prior to precipitation.

\subsection{Western blotting on prostate tissue}

Ventral prostates of the indicated genotypes were placed in PBS + protease inhibitors (Roche cOmplete mini \#11836153001) and crushed with a pestle. 4X SDS loading buffer was added in the appropriate volume and samples were vortexed for 1 minute. They were then boiled for 5 minutes and centrifuged at 1,000g for 2 minutes. Lysates were then transferred to a new tube, away from any remaining intact tissue. Following SDS-polyacrylamide gel electrophoresis, proteins were electroblotted to Immobilon-P (Millipore). Primary antibodies were against phospho-Smad2 (Millipore AB3849), Smad4 (Millipore 04-1033), Tgfbr2 (Novus NBP1-19434) and $\gamma$-tubulin (Sigma T6557), $\beta$-catenin (BD biosciences 610153), phospho-Akt (Ser473, Cell Signaling 9277), AR (abcam ab133273). Proteins were visualized with horseradish peroxidaseconjugated goat anti-mouse or anti-rabbit Ig (Pierce) and ECL (Pierce).

\subsection{DNA affinity precipitation}

For isolation of protein complexes on double stranded DNA oligonucleotides, lysates were prepared from $75 \%$ of a confluent $15-\mathrm{cm}$ dish of COS1 cells for each condition, in MSLD (100 $\mathrm{mM} \mathrm{NaCl}, 20 \mathrm{mM}$ HEPES, pH 7.8, 10\% glycerol, $0.1 \%$ Tween $20 \& 1 \mathrm{mM}$ DTT) and protease inhibitors (Roche cOmplete mini \#11836153001). For each sample, $1 \mathrm{ml}$ of lysate was precleared with protein A-agarose (Pierce) and incubated with $100 \mathrm{ng}$ of biotinylated double-stranded oligonucleotides and $1 \mu \mathrm{g}$ poly $(\mathrm{dI}-\mathrm{dC})$. Complexes were isolated on streptavidin-agarose, washed 4 times with MSLD, and then subjected to analysis by SDS-PAGE and Western blotting. Sp1 
antibody was from Upstate (07-645), Meis2 was from Abnova (H00004212-M01) and Pbx1 was from Abnova (H00005087-M01).

\subsection{Luciferase assays - HepG2}

HepG2 cells were transfected using Exgen 500 (MBI Fermentas) according to the manufacturer's instructions. Cells were transfected with the indicated firefly luciferase reporters, a Renilla transfection control (phCMVRLuc [Promega]), and the indicated expression constructs. After 40 hours, firefly luciferase activity was assayed using firefly substrate (Biotium) and Renilla luciferase was assayed with $0.09 \mu \mathrm{M}$ coelenterazine (Biosynth) using a Berthold LB953 luminometer. Mithramycin was added to a final concentration of $200 \mathrm{nM}, 24$ hours prior to analysis, where indicated.

\subsection{Luciferase assays - Pbx1 repression}

LNCaP cells were transfected using Exgen 500 (MBI Fermentas) according to the manufacturer's instructions. Cells were transfected with the indicated $\mathrm{Pbx} 1$ promoter firefly luciferase reporters and a Renilla transfection control (phCMVRLuc [Promega]). 24 hours later they were changed into RPMI 1640 without phenol red + 5\% charcoal stripped FBS, with the indicated amount of synthetic androgen (R1881) or vehicle. 24 hours later, firefly luciferase activity was assayed using firefly substrate (Biotium) and Renilla luciferase was assayed with $0.09 \mu \mathrm{M}$ coelenterazine (Biosynth), using a Berthold LB953 luminometer.

\subsection{ChIP assays}

For transfected chromatin immunoprecipitation (ChIP) HeLa cells were transfected with Exgen 500 (Fermentas) in 60-mm dishes and $5 \mu \mathrm{g}$ of DNA. Two days after transfection, cells were washed with PBS, fixed in PBS $+1 \%$ formaldehyde for $15 \mathrm{~min}$, and then quenched with $0.125 \mathrm{M}$ glycine for $5 \mathrm{~min}$. Plates were washed twice with cold PBS, scraped into $1 \mathrm{ml}$ of cold radioimmunoprecipitation assay (RIPA) buffer (150 $\mathrm{mM} \mathrm{NaCl}, 1 \% \mathrm{NP}-40,0.5 \%$ deoxycholate, $0.1 \%$ SDS, $50 \mathrm{mM}$ Tris $\mathrm{pH} 8 \& 5 \mathrm{mM}$ EDTA) with protease inhibitors (Roche cOmplete mini \#11836153001) and sonicated 15 times for 10 seconds each. Lysates were centrifuged at 21,000 
relative centrifugal force $(\mathrm{RCF})$ for 15 min to remove cell debris and then precleared with protein G-agarose (Pierce) for 2 hours. Immunoprecipitation was carried out overnight with $15 \mu$ Flagagarose (in PBS $+1 \mathrm{mg} / \mathrm{ml}$ bovine serum albumin [BSA] \& $0.3 \mathrm{mg} / \mathrm{ml}$ salmon sperm DNA). Precipitates were washed twice with RIPA, 4 times with Szak's IP wash buffer (100 mM Tris$\mathrm{HCl}, \mathrm{pH} 8.5,500 \mathrm{mM} \mathrm{LiCl}, 1 \% \mathrm{NP}-40,1 \%$ deoxycholate), twice more with RIPA, and twice with cold $1 \mathrm{ml}$ Tris-EDTA (TE). Samples were aspirated down to $50 \mu 1$ and $100 \mu 1$ of $1.5 \mathrm{X}$ Talianidis elution buffer (70 mM Tris- $\mathrm{HCl}$ pH 8, 1 mM EDTA, $1.5 \%$ SDS \& $300 \mathrm{mM} \mathrm{NaCl}$ ) was added to precipitates (and $50 \mu \mathrm{l}$ of inputs) and samples were incubated at $65^{\circ} \mathrm{C}$ for 5 hours. Samples were treated with $10 \mu \mathrm{g}$ of proteinase $\mathrm{K}$ for $30 \mathrm{~min}$ at $45^{\circ} \mathrm{C}$ and DNA was isolated using QIAquick columns (Qiagen) in $100 \mu \mathrm{l}$ of water. Amounts of immunoprecipitated DNA were analyzed by qPCR on a Bio-Rad MyIQ cycler with Sensimix Plus SYBR green plus FITC mix (Quantace). Primer sequences for ChIP are listed in a table below. Signal was expressed as bound versus input by the $\triangle \triangle C T$ method. For endogenous ChIP, Mcf7 cells were fixed and harvested as described above. One 15-cm dish was used per sample. Immunoprecipitation was carried out overnight using $3 \mu \mathrm{g}$ of antibody and $15 \mu \mathrm{l}$ of protein G-agarose (Pierce) saturated with BSA and salmon sperm DNA, as described above. Antibody against Klf4 was from Santa Cruz (sc-20691) and Pbx1 was from Abnova (H00005087-M01). Immunoprecipitated fractions were washed and analyzed as described above.

\subsection{In silico site search}

Mouse and human genomic databases were searched using the Site Search program ${ }^{102}$ : http://www.sitesearch.mshri.on.ca/Genome/index.html. We searched $2 \mathrm{~kb}$ upstream of the predicted start site of each gene, for the combination of a Klf4 site (RRGGYSY) ${ }^{103}$ with both Meis and Pbx consensus sites (TGACA and CAATC) within 40 base pairs of either side of the Klf4 site. This combination had to be present in both mouse and human, and we then accepted only those in which the orientations were the same in both mouse and human. We then ranked the 
hits by the total difference in spacing between the sites between mouse and human, with a lower difference in spacing being better.

\subsection{Mice}

All animal procedures were approved by the Animal Care and Use Committee of the University of Virginia, which is fully accredited by the AAALAC. Conditional alleles of Tgfbr2 ${ }^{104}$ and Pten ${ }^{105}$ were combined with the $\mathrm{Pb}$-Cre4 transgene to drive prostate epithelium-specific deletion ${ }^{86}$. Mice with the prostate-specific Tg-Aktl transgene ${ }^{94}$ were obtained from the NCI MMHCC Repository. Apc floxed mice ${ }^{106}$ were also obtained from the NCI MMHCC. Experimental animals were maintained on a mixed C57BL/6 x FVB background. Significance testing for Kaplan Meier curves was performed using a log rank test (http://bioinf.wehi.edu.au/software/russell/logrank/). Castrations were performed by Marya Dunlap-Brown of the Molecular Assessments and Preclinical Studies (MAPS) Core Facility.

\subsection{DNA and RNA analyses}

Genomic DNA for genotype analysis was purified from ear punch (at P21) by HotShot ${ }^{107}$, and genotypes were determined by PCR. RNA was isolated and purified using Absolutely RNA kit (Stratagene). cDNA was generated using Superscript III (Invitrogen), and analyzed in triplicate by real time PCR using a BioRad MyIQ cycler and Sensimix Plus SYBRgreen plus FITC mix (Quantace), with intron spanning primer pairs, selected using Primer3 (http://frodo.wi.mit.edu/). Expression was normalized to Rpl4 and cyclophilin using the $(\Delta \Delta \mathrm{Ct})$ method.

\subsection{Histology, IHC and IF}

Immunohistochemistry (IHC), trichrome staining and most of the H\&E was performed by Sharon Birdsall of Dr. Henry Frierson's laboratory. Haematoxylin and eosin staining was performed by dewaxing in xylene, followed by rehydrating in descending percentages of $\mathrm{EtOH}(100 \%, 95 \%$, $90 \%, 70 \%$ ) and then washed with water. Slides were then stained in haematoxylin for 15 
minutes, differentiated in $70 \% \mathrm{EtOH}+1 \% \mathrm{HCl}$ for 30 seconds, washed in water and then stained in eosin for 5 minutes. Slides were then dehydrated in ascending alcohols (70\%, 90\%, 95\%, $100 \%$ ), incubated in xylene and then mounted with permount. Immunofluorescence (IF) was performed by dewaxing in xylene, followed by rehydrating in descending percentages of EtOH $(100 \%, 95 \%, 90 \%, 70 \%)$, then washed twice in TBS (Tris buffered saline). Slides were then boiled in sodium citrate $\mathrm{pH} 6.0$ (10mM sodium citrate, $0.05 \%$ Tween 20$)$ for 10 minutes, then allowed to cool to room temperature for 30 minutes. Slides were then washed in TBS and blocked for at least 1 hour in: M.O.M. Blocking Reagent (Vector laboratories MKB-2213) for mouse antibodies, TBS $+5 \%$ FBS for goat antibodies or TBS-T + 10\% NGS (Normal goat serum) for all other antibodies. Samples were then incubated in primary antibody overnight in blocking reagent and then washed 3 times with TBS-T. They were then incubated in fluorescently labeled secondary antibody for 1 hour. Slides were then washed with TBS-T, Hoechst stained for 15 minutes, washed 3 more times in TBS-T and mounted with Fluoro-Gel (EMS \#17985-10). Whole prostate images were taken with a Leica MZ16 stereomicroscope and QImaging 5.0 RTV digital camera. IF images were captured on a Zeiss AxioObserver or Nikon H600L and manipulated in Volocity, ImageJ or Adobe Photoshop. For analysis of $\mathrm{N}: \mathrm{C}$ ratios of phospho-Smad2, at least 40 cells per sample were chosen based on the DAPI image, and the mean fluorescence intensity in a fixed area of the nucleus and cytoplasm was determined using ImageJ. For quantification of Ki67 at least 58 cells were counted for each cell type in each condition per animal (average number of cells counted per sample was 485). The number of Ki67 cells was then divided by the total number of cells of that cell type counted for that sample. Antibodies for IF and IHC were against: phospho-Smad2 (Millipore AB3849), Smad4 (Millipore 04-1033), Tgfbr2 (Novus NBP1-19434), phospho-Akt (Ser473, Cell Signaling 9277), Cyclin D (Santa Cruz sc-753), p27 (BD Transduction Labs 610242), Ki-67 (DakoCytomation M7249), $\beta$ catenin (BD Biosciences 610153), CollagenIV (AbD Serotec 2150-1470), FoxA1 (Everest 
Biotech EB05999), SMA (Epitomics 1184-1), Keratin 5 (Covance PRB-160P), Keratin 8

(Covance MMS-162P), Keratin 18 (Abcam ab32118) and CD44 (BD Biosciences 550538).

\section{$2.13 \beta$-galactosidase staining}

$\beta$-galactosidase staining was done as in Sundararajan et al. ${ }^{108}$. Ventral prostates were dissected and fixed for 20 minutes in PBS $+4 \%$ paraformaldehyde. They were then washed 3 times in detergent wash (100mM phosphate buffer ph 7.4, 2mM MgCl2, $0.01 \%$ sodium deoxycholate and $0.02 \%$ NP-40). Whole prostates were then stained overnight at 37 degrees celsius in detergent wash $+5 \mathrm{mM}$ potassium ferricyanide, $5 \mathrm{mM}$ potassium ferrocyanide, $1 \mathrm{mg} / \mathrm{ml} \mathrm{X}$-gal and $20 \mathrm{mM}$ Tris $\mathrm{pH}$ 7.5. After staining overnight they were postfixed in $4 \%$ paraformaldehyde overnight at 4 degrees celsius. They were then dehydrating in ascending EtOH $(70 \%, 80 \%, 90 \%, 95 \%, 100 \% \mathrm{x}$ 2), washed twice in xylene for 30 minutes, washed in 50\% xylene/50\% wax for 1 hour, washed in liquid wax for 1 hour and then incubated overnight in liquid wax. Blocks were sectioned and sections were counterstained with eosin as per the haematoxylin and eosin protocol, without the haematoxylin and acid alcohol steps.

\subsection{Primers used in this study:}

\begin{tabular}{|l|l|l|l|}
\hline Human primers for qRT-PCR & & \\
\hline Meis2 Forward & GGAGTTTATTGGAGCGCAGA & Meis2 Reverse & GTGAGGGTCTCCGTACATGG \\
\hline Pbx1 Forward & AGGAAGCAGGACATTGGAGA & Pbx1 Reverse & AAGGCAGGCTTCATTCTGTG \\
\hline p15 Forward & GATCCCAACGGAGTCAACC & p15 Reverse & GTGAGAGTGGCAGGGTCT \\
\hline $\begin{array}{l}\text { E-cadherin } \\
\text { Forward }\end{array}$ & GCCGAGAGCTACACGTTCAC & $\begin{array}{l}\text { E-cadherin } \\
\text { Reverse }\end{array}$ & ACTTTGAATCGGGTGTCGAG \\
\hline p21 Forward & CTCTCAGGGTCGAAAACG & p21 Reverse & CGGATTAGGGCTTCCTCTT \\
\hline Ccna1 Forward & GTTGTGCTGGCTACAGTGG & Ccna1 Reverse & CCTGCTCTAGTTCATCCATGTA \\
\hline Orc1 Forward & GCTGCAGCAGATCCTAAGGT & Orc1 Reverse & GTGCATCTCCAGACAGTGCT \\
\hline Klf4 Forward & ATGCCACCCGGTTCCTGCAT & Klf4 Reverse & GGTTTCTCACCTGTGTGGGTTCGC \\
\hline PLZF Forward & CTACGAGTGCAATGGCTGTG & PLZF Reverse & GTTGTGCGTTCTCAGGTGCT \\
\hline Mouse primers for qRT-PCR & & \\
\hline Tgfb1 Forward & ATGACATGAACCGGCCCTTCCT & Tgfb1 Reverse & TGCCGCACACAGCAGTTCTTCTC \\
\hline Tgfbr1 Forward & AACCGCACTGTCATTCACCACCG & Tgfbr1 Reverse & TCGCCAAACTTCTCCAAACCGACC \\
\hline Tgfbr2 Forward & CTTGCGACAACCAGAAGTCC & Tgfbr2 Reverse & GGCATCTTCCAGAGTGAAGC \\
\hline Smad2 Forward & ACACAGGCTCTCCGGCTGAACT & Smad2 Reverse & AGGGCTGTGACGCATGGAAGGT \\
\hline Smad3 Forward & ACCACAGCATGGACGCAGGTTC & Smad3 Reverse & TCATGGATGGCTGTGAGGCGTG \\
\hline Smad4 Forward & AGCGGGTTGTCTCACCTGGAA & Smad4 Reverse & ACGTCTCCGTTGATGCGCGAT \\
\hline $\begin{array}{l}\text { Cyclophilin } \\
\text { Forward }\end{array}$ & GGAGATGGCACAGGAGGAA & $\begin{array}{l}\text { Cyclophilin } \\
\text { Reverse }\end{array}$ & GCCCGTAGTGCTTCAGCTT \\
\hline Rp14 Forward & GGTCATCGTATTGAGGAGGTTC & Rp14 Reverse & CCTTGCCAGCTCTCATTCTC \\
\hline
\end{tabular}




\begin{tabular}{|l|l|l|l|}
\hline ChIP Primers & & & \\
\hline p15 -1265 Forward & AGCCCTAACCAGCACTTC & $\begin{array}{l}\text { p15 -1265 } \\
\text { Reverse }\end{array}$ & GGATACCTTAGCTCTGACTCC \\
\hline p15 -56 Forward & CATGCGTCCTAGCATCTT & p15 -56 Reverse & TCGCGGAGTCCTCACTGC \\
\hline p15 3' Forward & CCTTTCTAGGGAAGCATACCAC & p15 3' Reverse & AATTTTGTAGACCTGGAGCTGA \\
\hline $\begin{array}{l}\text { E-cadherin } \\
\text { Forward }\end{array}$ & CTGATCCCAGGTCTTAGTGAGC & $\begin{array}{l}\text { E-cadherin } \\
\text { Reverse }\end{array}$ & GCTGATTGGCTGAGGGTTC \\
\hline
\end{tabular}




\section{Chapter 3}

\section{Meis2 and Pbx1 Cooperate with Klf4 to}

Activate Gene Transcription 


\subsection{Introduction}

Our lab is primarily interested in the transcription factor TGIF (5' -TG-3' Interacting Factor), which principally binds to Smads and functions as a co-repressor. However, TGIF can also bind to DNA directly at the sequence CTGTCA. This is the same DNA sequence as TALE family members Meis1 and Meis2 also bind to. The Mouradian group published that Meis2 and TGIF can compete for binding to a site in the Dopamine $\mathrm{D}_{1 \mathrm{~A}}$ promoter ${ }^{12}$. Additionally, it has been published that the gene $\mathrm{p} 15(\mathrm{CDKN} 2 \mathrm{~B})$ is regulated by Smad proteins ${ }^{38}$. p15 is an important inhibitor of cell division and a well described tumor suppressor ${ }^{39}$. Therefore, we hypothesized that Meis proteins could regulate transcription of the p15 gene. I describe in this chapter that Meis2 and $\mathrm{Pbx} 1$ do activate transcription of the p15 gene along with activation of the gene for E-cadherin. Furthermore, knockdown of Meis2 and Pbx1 increased cellular proliferation in HepG2 cells. This activation of transcription by Meis 2 and Pbx1 is via a novel interaction with the transcription factor Klf4. The components of the transcription complexes formed were analyzed in detail, and these details were used in a bioinformatics approach to find new genes regulated cooperatively by these factors. Since Meis 2 and $\mathrm{Pbx} 1$ activate well characterized tumor suppressors (p15 and E-cadherin) we hypothesized that they would be decreased in cancer. Consequently, we show that expression of Meis 2 and $\mathrm{Pbx} 1$ are decreased in prostate cancer. As such, this work furthers the knowledge of the transcription factors Meis 2 and Pbx1 in both development and cancer. I also helped finish another paper that examined the domain structure of Meis2 and how it interacted with other homeodomain proteins Pbx1 and HoxB1, which was published in the journal FEBS ${ }^{99}$, but I have not included that work in this dissertation. 


\subsection{Results}

\subsubsection{Meis2 and Pbx1 activate $p 15$ and E-cadherin}

The CDK inhibitor (CKI) p15 $5^{\mathrm{INK} 4 \mathrm{~B}}(\mathrm{CDKN} 2 \mathrm{~B})$ is a well known target gene of TGF- $\beta$, and it has been shown that Smads activate the gene via the SBR2 (Smad Binding Region) ${ }^{38}$. We examined whether Meis2 and TGIF could compete for activation or repression of the p15 promoter, but did not find any conclusive evidence of competition. However, we did discover that Meis2 regulates activation of p15 in conjunction with its homeodomain binding partner Pbx1. Assays of promoter activity were done using luciferase assays, which use a plasmid containing the promoter of the gene of interest to drive expression of luciferase. Luciferase assays shown in this dissertation were always done with a renilla luciferase control. This allows normalization for transfection efficiency relative to renilla luciferase, which is expressed from a constitutively active promoter. Results of luciferase assays are shown as activity relative to renilla, with basal activity set arbitrarily at 100 . Using a transfected luciferase reporter in HepG2 cells corresponding to the $-967 \mathrm{bp}$ to $+78 \mathrm{bp}$ region of the 15 promoter we showed Meis $2 \mathrm{~d}$ and $\mathrm{Pbx} 1 \mathrm{a}$ activate the p15 promoter 16.4 fold (Figure 1A). Initially, it was presumed that activation by Meis2d would be via the SBR2. However, we showed that mutating this MEIS/TGIF site actually increased activation to 20 fold (Figure 1A). We then made 5' deletions of the luciferase reporter and showed that full activation by Meis2d and Pbx1a can be seen with just base pairs 113 to +78 of the p15 promoter, which contains a pair of GC boxes (Figure 1A). It was shown previously that $\mathrm{Sp} 1$ can bind to these GC boxes and activate transcription of $\mathrm{p} 15^{26}$. We also made 3' deletions of the p15 promoter that were placed in a luciferase reporter with a basic TATA box. Once again, full activation by Meis2d and Pbx1a was only seen when the region containing the GC boxes was within the reporter (Figure 1A). 
Figure 1. p15 and E-cadherin respond transcriptionally to Meis2d and Pbx1a. A) A schematic of the 15 promoter is shown with Meis/TGIF sites, the Smad Binding Region (SBR2) and $\mathrm{Sp} 1$ sites as indicated. Below are the reporters used with their size in base pairs relative to the transcription start site shown and their fold induction upon stimulation with Meis $2 \mathrm{~d}$ and Pbx1a. The fold induction for the (SBR2) $)_{4}$-luc is shown in parentheses because Pbx 1 addition did not further increase its fold induction. B) HepG2 cells were transfected with long and short constructs of the p15 promoter and normalized to baseline Renilla activity. The addition of Meis2d and Pbx1a is shown on the bottom and numbers are presented as the mean + SD of duplicate transfections. C) The effect of Meis $2 \mathrm{~d}$ and Pbx1a is shown on 4 luciferase promoters which contain Sp1 sites, with the numbers presented as in B. D \& E) HepG2 cells were transfected with control, Meis2 or Pbx1 siRNAs and mRNA level quantified by quantitative RTPCR. F) HepG2 cells were transfected with control, Meis2 or Pbx1 siRNAs and after 60 hours incubated with EdU for 1 hour. Cells were then fixed and the percent of cells with incorporated EdU were quantified by fluorescent microscopy. Numbers are presented as average percent + SD of triplicates, with significance calculated by Student's t test: $*=\mathrm{P}<0.05, * *=\mathrm{P}<0.01$, $* * *=\mathrm{P}<0.001$. Panels A, B \& C were done by Cathy Hyman-Walsh. 


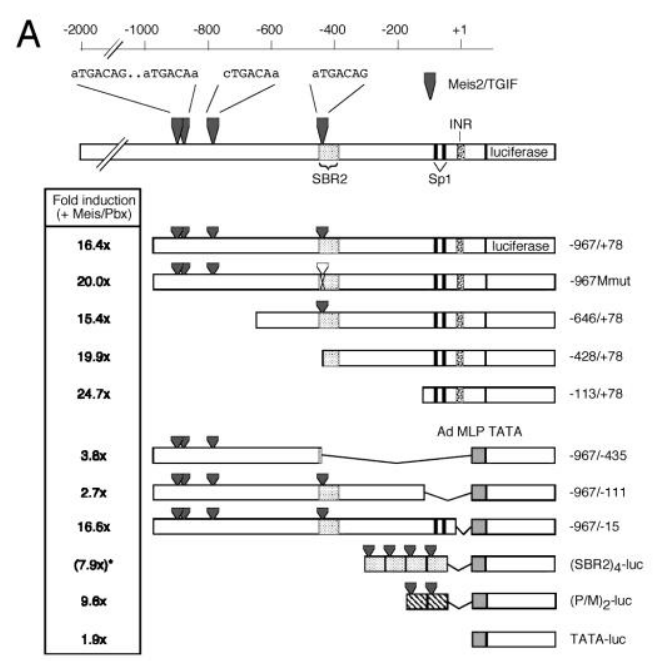

D

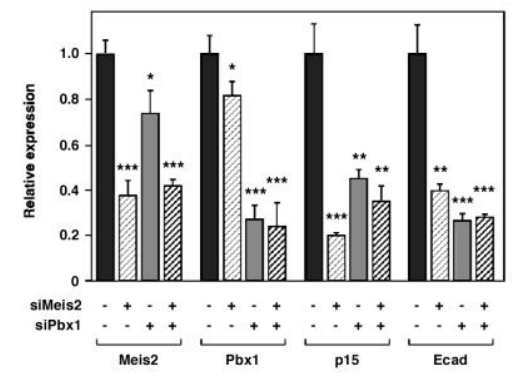

B

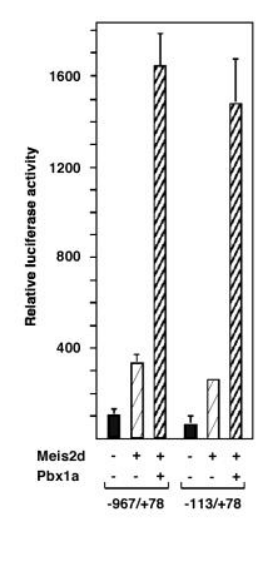

C

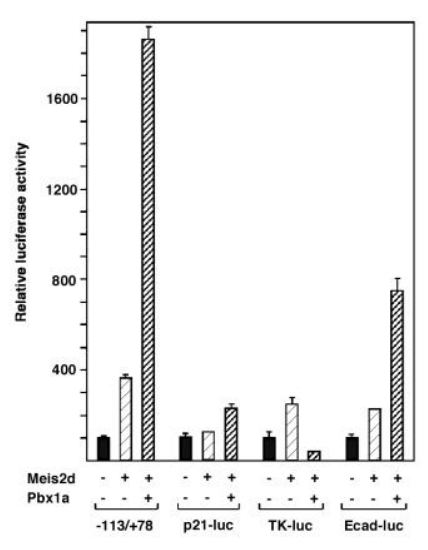

F

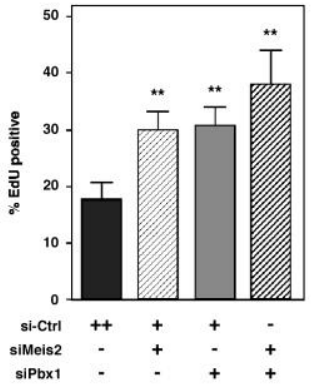


As a control, we used a reporter with 4 copies of the SBR2 region of p15 placed in the TATAluciferase reporter ((SBR2) $)_{4}$-luc), which was activated 7.9 fold by Meis2d and co-transfection of $\mathrm{Pbx} 1$ did not further activate the luciferase. We also put two copies of a consensus $\mathrm{Pbx} / \mathrm{Meis}$ site into the TATA luciferase reporter to make $(\mathrm{P} / \mathrm{M})_{2}$-luc, which is activated 9.6 fold by Meis $2 \mathrm{~d}$ and Pbx1a. As a negative control, the TATA-luc vector without any inserts is minimally activated (Figure 1A).

Figure 1B displays equal activation of the long (-967/+78) and short (-113/+78) p15 promoters with: no expression vectors added, just Meis2d added or Meis2d and Pbx1a added. Meis2d alone activates about 3 fold on both reporters, but when both Meis2d and Pbx1a are added, activation increases to 16 fold. Pbxla alone is not shown because by itself it does not activate the reporters. To examine whether Meis2d and Pbx1a could activate all GC boxes or whether there was something specific about the p15 promoter, HepG2 cells were transfected with 4 luciferase reporters that contain GC boxes in their promoters: p15 (-113/+78)-luciferase, p21luciferase (the promoter of CDKN1A), TK-luciferase (Thymidine Kinase) and E-cadherinluciferase. This was done with expression constructs for Meis2d alone and with Meis $2 \mathrm{~d}$ and Pbx1a, as shown in Figure 1C. This assay showed that not all GC boxes could be activated by Meis2d and Pbx1a, as evidenced by the lack of activation of the $\mathrm{p} 21$ and TK promoters. Additionally, we learned that E-Cadherin could be activated by Meis2d and Pbx1a. As it turned out, the E-cadherin promoter is fairly similar to the p15 promoter, as shown in figure 3D.

To make sure that Meis2 and Pbx1's activation of the p15 and E-cadherin promoters was not an artifact of the luciferase assay, I transfected HepG2 cells with sets of Dharmacon siRNAs: A non-targeting control, siRNAs to Meis2, siRNAs to Pbx1 or siRNAs to both Meis2 and Pbx1. The cells were then harvested 60 hours later and mRNA levels were analyzed by quantitative reverse transcription PCR (qRT-PCR). As shown in figure 1D, this resulted in mRNA knockdown to approximately $40 \%$ and $30 \%$ of normal for Meis 2 and $\mathrm{Pbx} 1$, respectively. 
Additionally, mRNA levels of p15 and E-cadherin decreased significantly in both of the single knockdowns and the double knockdown. The decrease of p15 and E-cadherin in the single knockdowns fits with published data saying that Meis and Pbx regulate each other's protein stability. Therefore, if one is knocked down, the protein level of the other most likely decreases also ${ }^{19}$. I also examined the levels of other important cell cycle genes by qRT-PCR, as shown in figure 1E. The mRNA level of p21 decreased significantly upon knockdown of Meis2 and Pbx1, but not to the level seen for 15 or E-cadherin. This is consistent with the slight activation of the p21-luciferase by Meis2d and Pbx1a shown in figure 1C. I also examined other important cell cycle genes: CCNA2 (Cyclin A2), CCND1 (Cyclin D1) and ORC1 (Origin recognition complex, subunit 1). As shown in figure $1 \mathrm{E}$, the mRNA level of these genes mostly did not change significantly, except for the mRNA level of CCNA2 increased with Meis2 knockdown. This shows that Meis 2 and $\mathrm{Pbx} 1$ are specifically acting at the p15 locus. Next, to examine the effect of Meis2 and Pbx1 knockdown on the cell cycle I transfected HepG2 cells with siRNAs targeting each of them individually or both of them together and 60 hours later I incubated the cells with EdU (5-ethynyl-2'-deoxyuridine) for 1 hour. When present, EdU is incorporated into DNA during S-phase while the cell is synthesizing DNA. It is therefore used as a marker of cell proliferation. I then visualized the cells that had incorporated EdU fluorescently using an Invitrogen Click iT kit. The results of EdU incorporation are shown in figure 1F. When transfected with siRNAs against Meis2 or Pbx1 alone cell proliferation increased from less than 20 percent up to around 30 percent. The EdU incorporation further increased to $38 \%$ of the cells when both Meis2 and Pbx1 were knocked down. These results clearly show that not only are Meis 2 and Pbx1 capable of activating p15 and E-cadherin, but also that this is a meaningful effect, as shown by an increase in the percent of cells with EdU incorporation. 


\subsubsection{Activation of p15 and E-cadherin requires the interaction between Meis2 and Pbx1, DNA binding and Meis2's transcription activation domain}

Next we wanted to determine what regions and interactions of Meis2 and Pbx1 were required for activation of p15 and E-cadherin. To examine this we made truncations of Meis2 and Pbx1 that do not interact with each other (Meis2 98-470 and Pbx1 $\Delta 90$ ), DNA binding mutants of both proteins (Meis2d R332M and Pbx1a N286S) and a version of Meis2d that lacks the transcription activation domain (Tx AD) as shown in figure 2A. These were then used in luciferase assays on various reporters to test the necessity of the Meis2-Pbx1 interaction, DNA binding by both proteins and Meis2d's transcription activation domain. A luciferase reporter containing a perfect $\mathrm{Pbx} / \mathrm{Meis}$ site, $(\mathrm{P} / \mathrm{M})_{2}$-TATA-luciferase, was used as a positive control. Using a DNA sequence specific to a Pbx-Meis dimer we found that the Meis-Pbx interaction, DNA binding by both members and Meis2d's transcription activation domain are all required for activation (Figure 2B). Both the p15-luciferase and E-cadherin-luciferase, figures 2C and 2D respectively, showed a requirement for Meis2d-Pbx1a interaction, Meis2d binding to DNA and for Meis2d's transcription activation domain. However, they had less dependence on Pbx1a binding to DNA, suggesting at least 3 possibilities: Pbx 1 may not bind these sites well due to the sequence, or Pbx1 may not be directly contacting DNA in these complexes, or that there may be additional proteins in this complex that recruit and stabilize $\mathrm{Pbx} 1$.

\subsubsection{Meis2 and Pbx1 regulate p15 through the proximal GC box}

Since the region that we had narrowed Meis2d and Pbx1a activation to contains GC boxes and has been shown to be activated by Sp1 we examined whether Sp1 was helping recruit Meis2d and Pbx1a to DNA. To do this we used a small molecule called mithramycin that binds to GC rich regions of DNA and has been shown to interrupt activation by $\mathrm{Sp} 1{ }^{109}$. 
Figure 2. Requirements of Meis2d and Pbx1a domains on gene activation. A) A Schematic of Meis2d and Pbx1a expression constructs used is shown along with a summary of their known interactions and whether they contain a transcription activation domain (Tx AD). B-D) Luciferase assays in HepG2 cells with the indicated reporters are shown normalized to Renilla control. Expression constructs were added as denoted for Meis2d and Pbx1a. Results are shown in relative units as the average of duplicate transfections + standard deviation. B) Results of luciferase assays for the (Pbx/Meis) ${ }_{2}$-TATA promoter. C) Results of luciferase assays for the p15 $(-113 /+78)$ promoter. D) Results of luciferase assays for the E-cadherin promoter. All panels in this figure were done by Cathy Hyman-Walsh. 
A

\begin{tabular}{|c|c|c|c|c|c|c|c|}
\hline & $\begin{array}{c}100 \\
1\end{array}$ & 200 & $\begin{array}{r}300 \\
1\end{array}$ & 400 & Pbx int & $T \times A D$ & DNA bind \\
\hline Meis2d & & & HD & & + & + & + \\
\hline Meis2d(2-345) & & & HD & & + & - & + \\
\hline eis2d(R332M) & & & HD & & + & + & - \\
\hline eis2d(98-470) & & & HD & & - & + & + \\
\hline
\end{tabular}

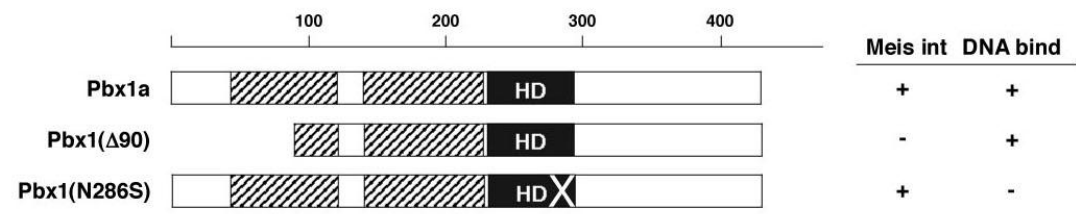

B
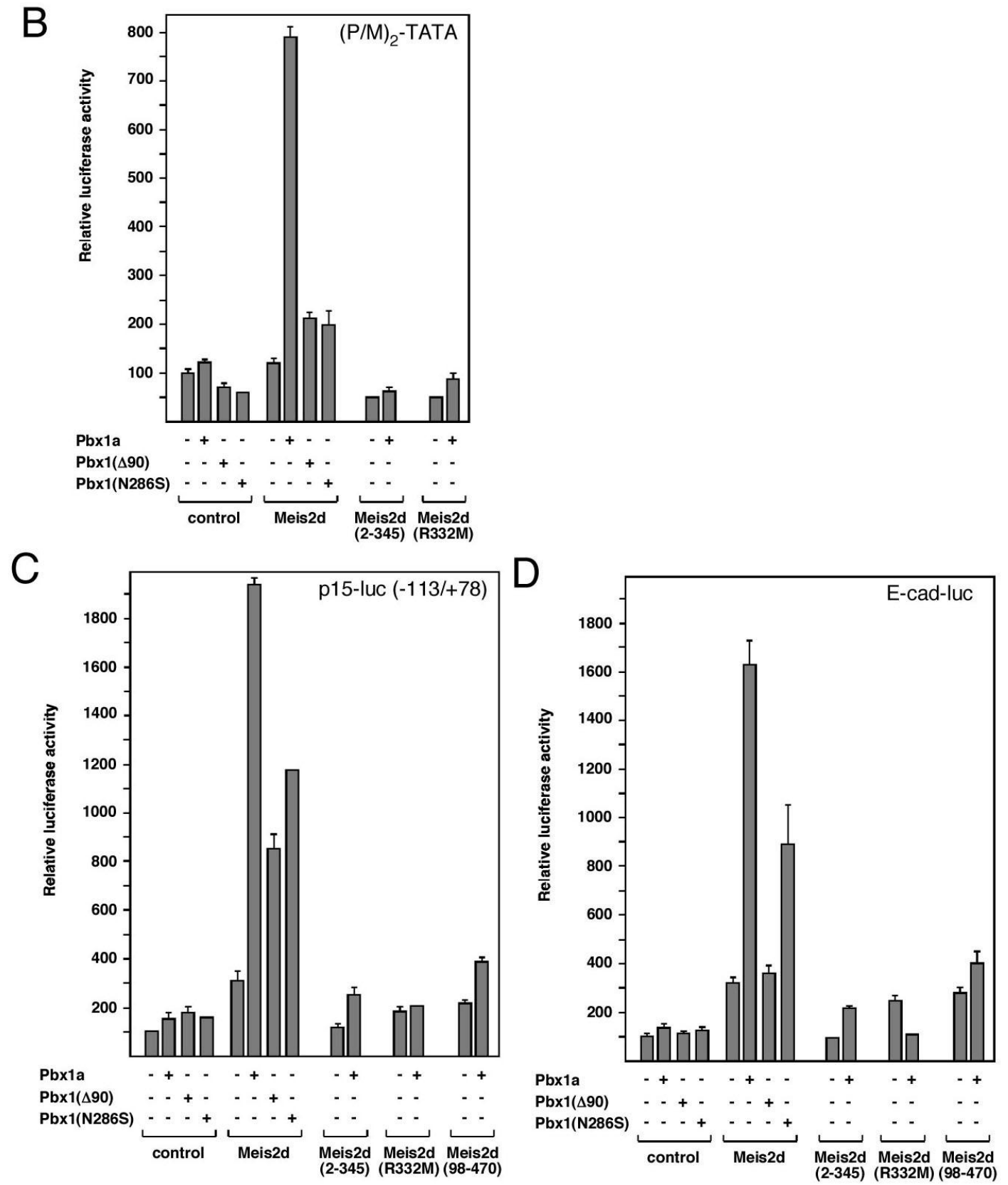
As shown in figure $3 \mathrm{~A}$, mithramycin severely inhibited activation by Meis $2 \mathrm{~d}$ and $\mathrm{Pbx} 1 \mathrm{a}$ on both the long (-967/+78) and short (-113/+78) p15 luciferase reporters and the E-cadherin reporter, without any additional Sp1 transfected. Additionally, mithramycin did not have an effect on the $(\mathrm{P} / \mathrm{M})_{2}$-TATA-luciferase reporter, which lacks GC boxes. This suggests that a significant amount of activation by Meis $2 \mathrm{~d}$ and $\mathrm{Pbx} 1$ is through the GC boxes. To examine this further I did DNA pulldowns with biotinylated oligos made with the same sequence as the p15 promoter. Doing this experiment with biotinylated oligos allowed me to make mutations in the sequence and examine the sequence necessary for binding of each protein. The wild type sequence of p15 and the mutations made in the biotinylated oligos are shown in figure 3E. I incubated biotinylated oligos in COS1 cell lysates, affinity purified the oligos with streptavidin agarose and performed western blots on the pulldown lysates to look for proteins of interest that bound to the oligos. As shown in figure 3B, Sp1, Meis2 and Pbx1 all bind to the wild type sequence of p15 and not to the nonspecific DR5 oligo. Lysate (Lys) is shown as a control for protein presence. Interestingly, binding of all three is lost when just the GC box is mutated. DNA pulldowns were then performed again with additional mutations of this oligo: two putative Meis site mutations (M1 \& $\mathrm{M} 2$ ) and a Pbx site mutation (P1), as shown in figure 3E. Consistent with the earlier result, the only mutation that interrupted binding of $\mathrm{Sp} 1$ was the mutation of the GC box (figure 3C). In contrast, binding of Meis2 was interrupted by the GC, M1 and P1 mutations. These results suggest that Sp1 is binding only to the GC box, but Meis2 binding requires the GC box, the Meis site that is mutated by the M1 mutation and the Pbx site. To examine whether Meis2 and Pbx1 are present at the p15 promoter in the context of a cell I performed chromatin immunoprecipitation (ChIP) assays using Flag epitope tagged proteins. I transfected HeLa cells with either Flag-Meis2d, or Flag-Meis2e as a control because it does not bind DNA. I then fixed the cells with $1 \%$ formaldehyde, lysed them with RIPA, sonicated them and immunoprecipitated half of the lysate with anti-Flag agarose and half of the lysate with anti-Glu-Glu agarose as a negative control. 
Figure 3. Meis2 and Pbx1 regulation of the p15 promoter through the proximal GC box.

A) HepG2 cells were transfected with the indicated luciferase reporters, with or without Meis2d and Pbx1. 24 hours after transfection samples were treated with mithramycin as indicated and then assayed 24 hours later. Results are shown relative to renilla as averages of duplicates + SD. B \& C) Biotinylated DNA pulldowns are shown with control nonspecific DR5, p15 wild type, GC box mutant, two different MEIS site mutations and a Pbx site mutation, as shown in E. COS1 cell lysates were incubated with biotin labeled oligos as indicated and western blotted for proteins pulled down. Results are shown below as compared to protein lysates (Lys). D) A comparison of the regions of interest between the p15 and E-cadherin promoters is shown. E) Oligos used in B $\& \mathrm{C}$ are shown with colons representing unchanged residues and letters indicating mutated residues. F) Schematic of the p15 promoter with the transcription start site, exons $1 \& 2$, Meis/TGIF sites, Sp1 sites and ChIP primers used. G) HeLa cells were transfected with FlagMeis2d or Flag-Meis2e as indicated and subjected to ChIP with anti-Flag agarose or anti-Glu-Glu agarose as a negative control. The indicated regions of p15 were then assayed by real time PCR. H) ChIP was done as in G with Flag-Meis2d and/or T7-Pbx1a as indicated. Relative ChIP signal is shown as mean $+\mathrm{SD}$ of triplicates. Significance calculated by Student's t test: $*=\mathrm{P}<0.05$, $* * *=\mathrm{P}<0.001$. Panel A was done by Cathy Hyman-Walsh. 
A
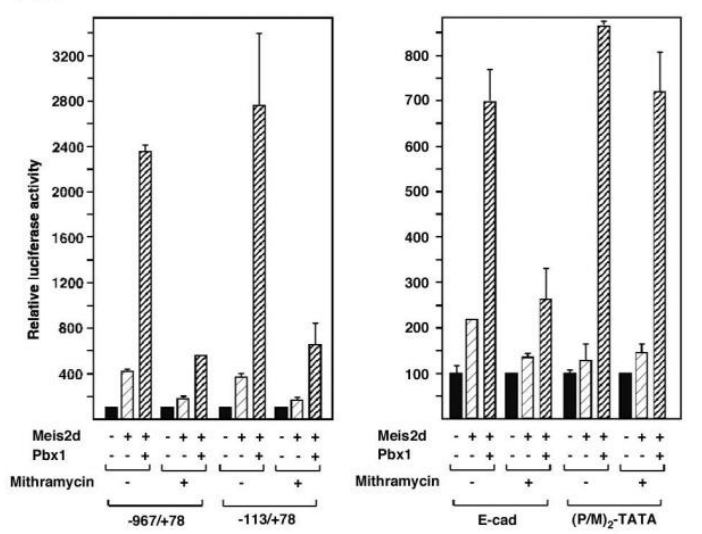

B

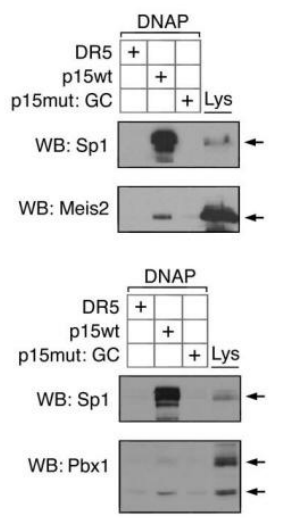

C

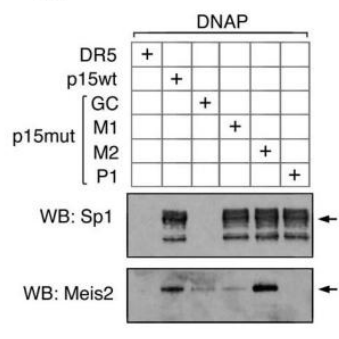

D

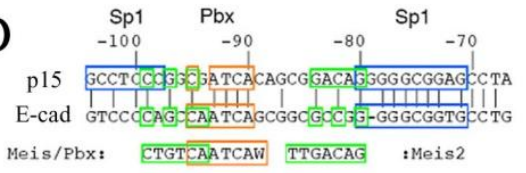

E

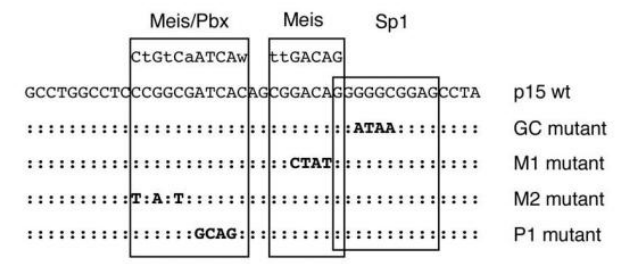

F

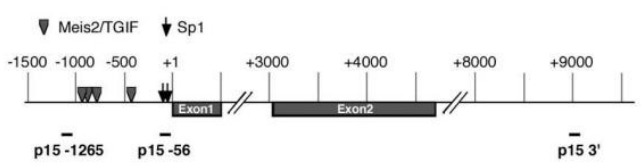

G

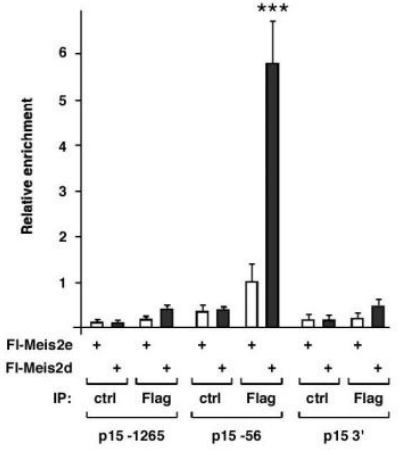

$\mathrm{H}$

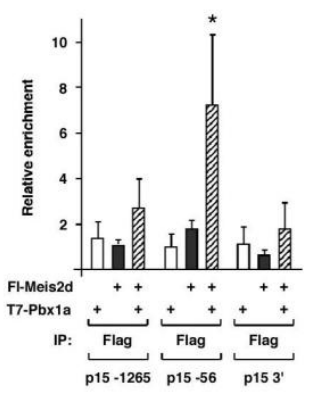


The resulting DNA was then assayed by qPCR with primers for 3 locations on the p15 promoter. Figure $3 \mathrm{~F}$ shows a diagram of the primer locations on $\mathrm{p} 15$ used for ChIP. The primer pair p15 56 is centered at base pair -56 of the p15 promoter and is around the GC boxes. The primer pairs p15 -1265 and p15 3' are further away from the GC boxes of interest in the proximal promoter and serve as negative controls. As shown in figure 3G, when lysates were immunoprecipitated with anti-Glu-Glu agarose, there is little enrichment of chromatin. Also, Meis2e does not show enrichment at any of the locations. However, when immunoprecipitated with anti-Flag agarose for Flag-Meis2d there is a clear enrichment around base pairs -56 of the p15 promoter.

Furthermore, to test whether the addition of Pbx1a increased Meis2d binding, I transfected FlagMeis2d alone, T7-Pbx1a alone or both Flag-Meis2d and T7-Pbx1a. ChIPs were then performed on these lysates with anti-Flag agarose and interrogated by PCR as above. This experiment showed a synergy between Meis2 and Pbx1 only at the p15 -56 region (Figure 3H). However, I do not know why Meis2d alone did not bind by itself in this assay. These experiments show that the GC boxes proximal to the $\mathrm{p} 15$ transcription start site are important for activation of $\mathrm{p} 15$ by Meis2 and Pbx1. Additionally, they show that Meis2 and Pbx1 bind to this area in a manner dependent on the GC boxes in the proximal promoter.

\section{Section 3.2.4 Meis2 and Pbx1 interact with Sp1 in a DNA dependent manner and Klf4 in a DNA independent manner}

Next, due to results suggesting that a GC box binding protein recruited Meis2 and Pbx1 to DNA, I assayed for an interaction between Meis2 and Sp1. To do this I performed a number of transfected co-immunoprecipitation (co-IP) experiments in COS1 cells. Using T7 epitope tagged Sp1 and Sp3, I looked for an interaction with Flag epitope tagged Meis2d, Meis2e and Pbx1a as shown in figure 4A. This experiment showed interactions between both $\mathrm{Sp} 1$ and Sp3 with Meis2d and Pbx1a, but not Meis2e, which cannot bind DNA. This suggested the interaction may be DNA dependent. Therefore, I did a co-IP between Meis2d and Sp1 with and without Ethidium 
Bromide $(\mathrm{EtBr})$ as shown in figure 4B. Ethidium bromide prevents proteins from binding DNA and is therefore used in immunoprecipitations (IPs) to examine if an interaction is DNA independent ${ }^{110}$. In this case, EtBr inhibited the interaction between Sp1 and Meis2d, suggesting that the two proteins may have been binding DNA adjacent to each other and not truly interacting. I also performed a co-IP between Sp1 and the DNA binding mutant of Meis2d (R332M), which showed no interaction (Data not shown). Using published mutations of a related zinc finger protein, Zif268 ${ }^{111}$, I made mutations in key amino acids of Sp1 to make a DNA binding mutant. This mutant version of Sp1 also did not interact with Meis2d (Data not shown). Additionally, in a number of luciferase assays, Sp1 did not activate transcription of p15 (Data not shown). This led us to believe that Sp1 was not the true protein that was recruiting Meis2 and Pbx1to the GC boxes in the p15 promoter.

This led us to examine other Klf family members, since they all bind to GC boxes. I performed co-IPs between T7 epitope tagged Klf3 or Klf4 and Flag epitope tagged Pbx1 or Pbx1 (N286S) which does not bind to DNA (Figure 4C). This showed an interaction between Klf4 and Pbx1 that was DNA binding independent. Additionally, there was no interaction between Klf3 and Pbx1. Next, I did a set of co-IPs with T7 epitope tagged Klf4 and Flag epitope tagged Meis2d or Pbx1, with and without the addition of ethidium bromide. This experiment revealed interactions between Klf4 and both Meis2d and $\mathrm{Pbx} 1$, although the interaction with $\mathrm{Pbx} 1$ appears stronger. Importantly, both of these interactions were DNA independent because the addition of ethidium bromide did not inhibit the co-immunoprecipitation. We next performed assays to determine which domain of Pbx1 interacts with Klf4. Therefore, I did co-IPs with a number of Flag-Pbx1 mutants and T7-Klf4 to examine which domain of Pbx1 interacted with Klf4. As shown in figure 4E, T7-Klf4 interacted with wild type Pbx1, Pbx1 (N286S) and the aminoterminal portion of $\mathrm{Pbx} 1$ up to the homeodomain (2-233). 
Figure 4. Meis2 and Pbx1 interact with Sp1 in a DNA dependent manner and Klf4 in a DNA independent manner. Klf4 cooperates with Meis2 and Pbx1 at the p15 promoter. A) COS1 cells were transfected with the indicated expression constructs for T7-Sp1 or T7-Sp3, and Flag-Meis2d, Flag-Meis2e or Flag-Pbx1a. Cells were lysed and co-immunoprecipitated with anti-Flag agarose and western blotted with anti-T7 antibody. B) COS1 cells were transfected with T7-Sp1 + Flag-Meis2d and then treated with ethidium bromide as indicated and coimmunoprecipitated as in A. C) COS1 cells were transfected with T7-Klf4, Flag-Meis2d or Flag$\mathrm{Pbx} 1$, treated with ethidium bromide as indicated and then co-immunoprecipitated as in A. D) COS1 cells were transfected with T7-Klf3 or T7-Klf4 and Flag-Pbx1 or Flag-Pbx1 (N286S) as indicated and then co-immunoprecipitated as in A. E) COS1 cells were transfected with T7-Klf4 or Flag-Pbx1 mutations as indicated and then co-immunoprecipitated as in A. F) HepG2 cells were transfected with the p15 (-113/+78) luciferase construct, with or without Meis2d and Pbx1a, and increasing amounts of Klf4. Luciferase is shown as relative units normalized to renilla, as average signal + SD of triplicates. G) HeLa cells were transfected with Flag epitope tagged expression constructs for Klf4 or Sp1 and subjected to ChIP with anti-flag agarose as in Figure 3H. H) HepG2 cells were transfected with siRNAs to KLF4 or a control siRNA pool as indicated. Genes of interest when then quantified by qRT-PCR. Results are shown as averages relative to control of triplicates $+\mathrm{SD}$. Significance calculated by Student's t test: $*=\mathrm{P}<0.05, * *=$ $\mathrm{P}<0.01, * * *=\mathrm{P}<0.001$. 
A
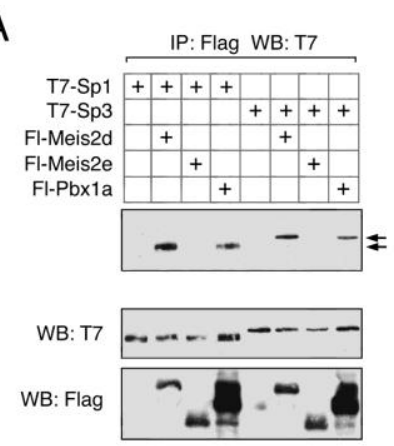

B

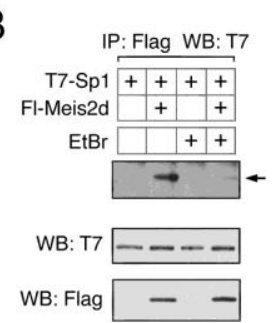
WB: Flag $-\quad-$

E

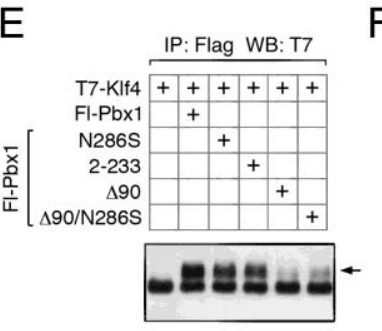

WB: T7

Denee

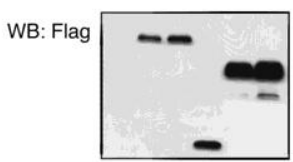

F

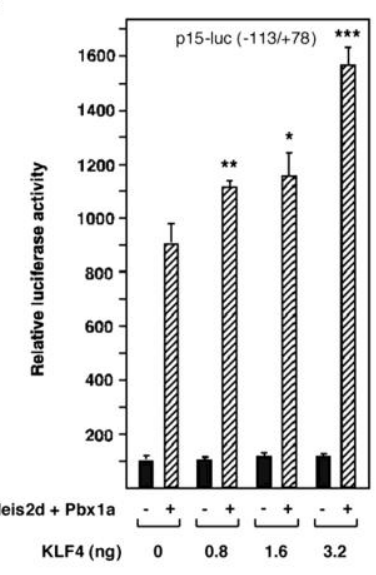

C
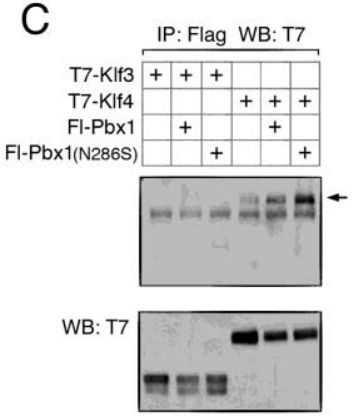

WB: Flag $-\infty$

G

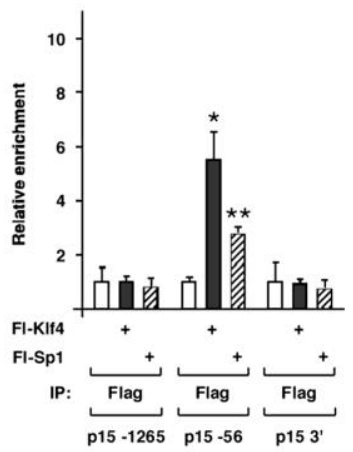

D
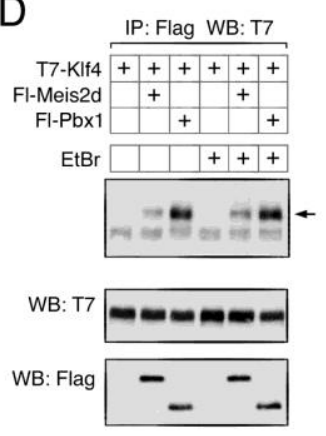

$\mathrm{H}$

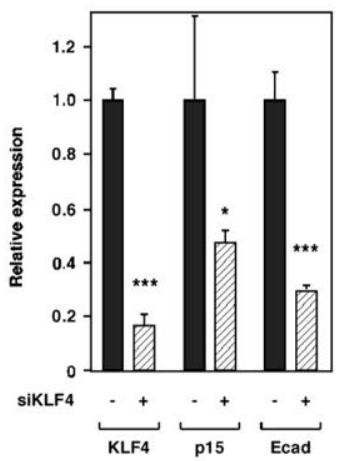


However, T7-Klf4 did not interact with Flag-Pbx1 missing the first 90 amino acids $(\Delta 90)$ or the double mutant ( $\Delta 90 / \mathrm{N} 286 \mathrm{~S})$. This suggests that Pbx1 binds to Klf4 via the PBC-A domain at its amino-terminus.

\subsubsection{Klf4 cooperates with Meis/Pbx to activate the $\mathrm{p} 15$ promoter}

I next examined activation of the p15 promoter by Klf4. Using the short reporter for p15luciferase (-113/+78), I transfected HepG2 cells with Meis2d-Pbx1a and increasing amounts of Klf4. Klf4 by itself had no effect, but increasing amounts of Klf4 from 0.8 to 3.2 nanograms synergized with Meis2d-Pbx1a, increasing activation from 9 fold up to about 16 fold (figure 4F). Subsequently, I examined whether Klf4 was present at the p15 promoter by transfected ChIP. I transfected Flag-Klf4 or Flag-Sp1 into HeLa cells and performed a ChIP. I then again assayed the immunoprecipitated chromatin for the same locations of p15 as earlier. Both Klf4 and Sp1 showed a significant enrichment only at the -56 region of the p15 promoter (figure $4 \mathrm{G}$ ). To show that Klf4 regulated the p15 and E-cadherin promoters at the endogenous level, I used Dharmacon siRNAs to knockdown Klf4 in HepG2 cells. As shown in figure 4H, Klf4 was knocked down to less than $20 \%$ of normal by qRT-PCR. This reduction in Klf4 caused a $50 \%$ reduction in p15 mRNA levels and about a 70\% reduction in E-cadherin levels. Taken together this data indicates that Klf4 is a true binding partner of Meis 2 and Pbx1 and that it regulates p15 and Ecadherin at the endogenous level.

\subsubsection{Klf4 and Pbx1 also regulate p15 and E-cadherin in MCF7 cells}

I next assayed whether Meis/Pbx and Klf4 regulated p15 and E-cadherin in other cell lines. It had been published that Klf4 is recruited to the E-cadherin promoter in breast cancer cells ${ }^{112}$, so we decided to look at the effect of Meis2 and Pbx1 in MCF7 cells. Meis2, Pbx1 and Klf4 were knocked down with Dharmacon siRNA oligos and the knockdown was verified by qRT-PCR, as shown in figure 5A. Meis2 knockdown had little effect, so it is not shown. Pbx1 
and Klf4 were knocked down to about $30 \%$ of normal and this decrease was also verified by western blot, as shown in the right panel of figure 5A. I then assayed the levels of p15 and Ecadherin mRNA upon knockdown of Pbx1 and Klf4 by qRT-PCR. The mRNAs for p15 and Ecadherin both showed a small, but significant decrease. Next, to verify that Pbx1 and Klf4 are present at the p15 and E-cadherin promoters I performed a ChIP assay with the endogenous proteins. MCF7 cells were fixed and sonicated and then probed with antibodies to Pbx1 or Klf4. The resulting chromatin pulled down was analyzed by PCR using the same primers as above for p15 and a primer set designed around the GC boxes of the E-cadherin promoter. As shown in figure 5C, $\mathrm{Pbx} 1$ was present at the E-cadherin promoter and the p15 -56 regions, but not at the negative control p15 3' region. Klf4 was also present at the E-cadherin and p15 -56 regions, but not at the p15 3' region. Input DNA is shown for each primer set as a control. These results show that Pbx1 and Klf4 regulate p15 and E-cadherin in another cell line and that Pbx1 and Klf4 are present at their promoters at the endogenous level.

\subsubsection{Analysis of promoter sites necessary for activation by Meis2d, Pbx1 and Klf4}

We next wanted to know how much of the effect on the p15 promoter is mediated by the proximal region containing the GC boxes and imperfect Meis/Pbx sites. In the context of the longer $(-967 /+78)$ p 15 promoter, mutations were made in the proximal GC boxes or the proximal Meis and Pbx sites. HepG2 cells were then transfected with each of these reporters and combinations of Pbx1a/Meis2d, Klf4 or both Pbx1a/Meis2d and Klf4. As shown in figure 6A, Pbx1a and Meis2d induced the wild type (-967/+78) p15 reporter synergistically, similar to previous data. However, mutation of the GC boxes increased the basal activity of the reporter, but did not change the maximum activation level. This resulted in less induction of the reporter, as shown in figure 6C. Additionally, the addition of Klf4 on the GC mutant did not increase the induction. The p15 luciferase reporter with mutant Meis and Pbx sites was induced at about the same level by Meis2d and Pbx1, and then induced more by Klf4 (Figure 6A). 
Figure 5. Klf4 and Pbx1 also regulate p15 and E-cadherin in MCF7 cells. A) siRNAs for a non-targeting control, Pbx1 or Klf4 were transfected as shown into MCF7 cells and knockdown was quantified at the RNA level using quantitative RT-PCR and assayed at the protein level by western blot. B) MCF7 cells were transfected as in A and the indicated genes were assayed by quantitative RT-PCR. C) MCF7 cells were fixed with formaldehyde and subjected to ChIP with IgG control, or antibodies to $\mathrm{Pbx} 1$ and $\mathrm{Klf} 4$ as indicated. Immunoprecipitated chromatin was then analyzed using PCR for the specified regions of E-cadherin, p15 proximal promoter ( $\mathrm{p} 15$ 56) or as a negative control the p15 3' region (p15 3'). As a positive control, PCR with the specified primers on input DNA is shown on the right. 
A
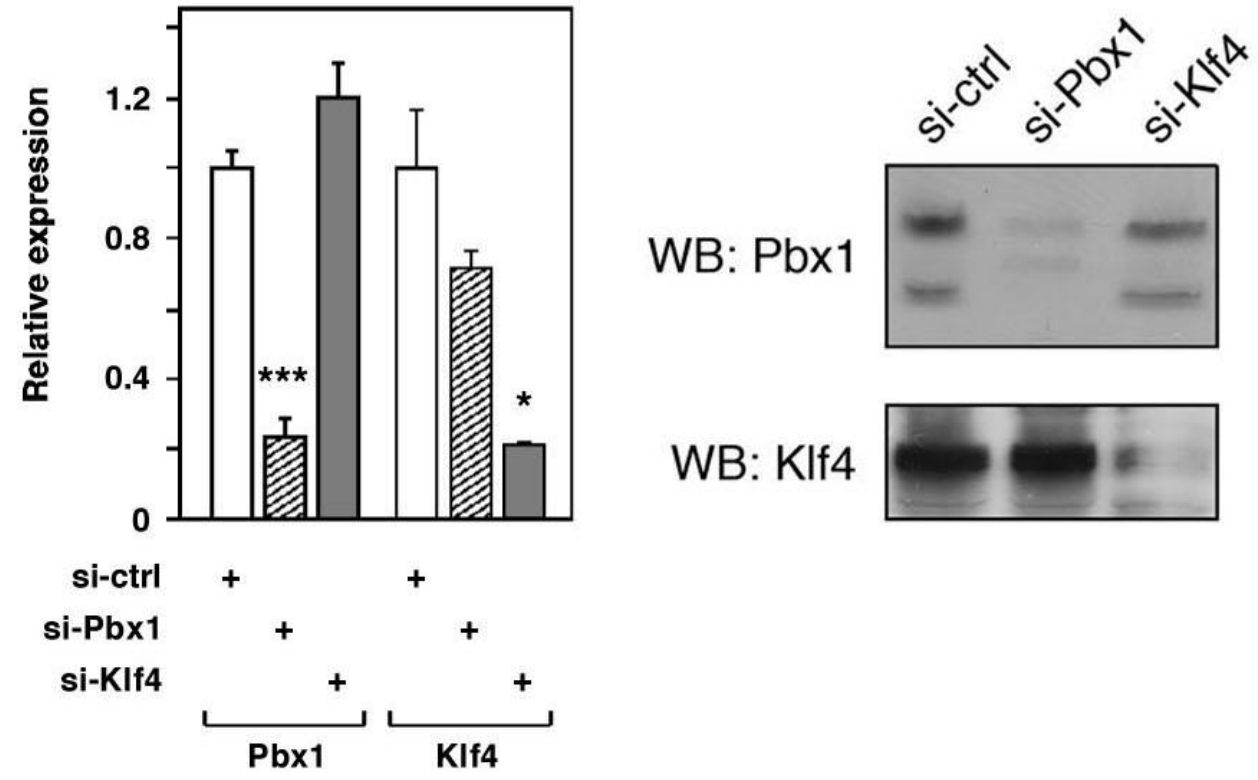

WB: Klf4

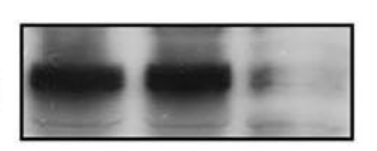

B

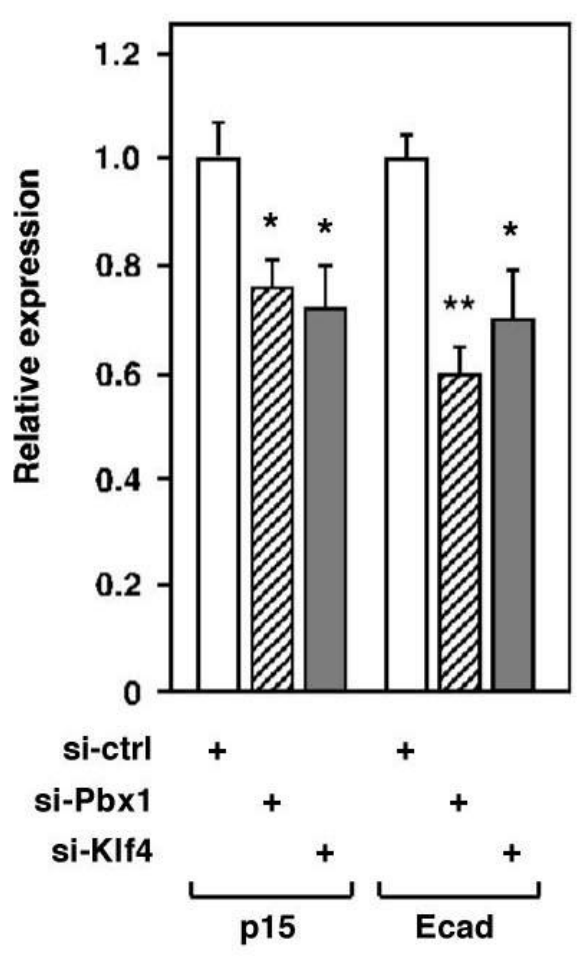

C

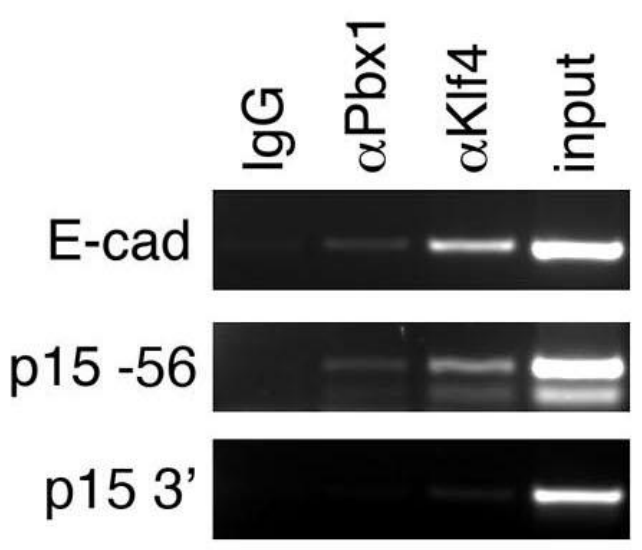


This is most likely because Meis2d and Pbx1a are partially recruited by the GC box, and they retain some binding activity even without the Meis and $\mathrm{Pbx}$ binding sites. Importantly, the induction by Klf4 was retained. Also, since these mutations were made in the longer promoter, there could be additional sites that Meis2, Pbx1 and Klf4 bind to. Similar mutations were made in the E-cadherin promoter, as shown in figure 6B. However, the E-cadherin does not have a good Meis binding site, so only the Pbx site was mutated. The wild type E-cadherin promoter was induced by Meis2, Pbx1 and Klf4, similar to p15. However, for the E-cadherin promoter significant activity was lost when the GC box or the Pbx site was mutated. The GC box mutant was still induced as well or better than the wild type, but the Pbx mutant reporter showed lower induction than the wild type (Figure 6C). This may indicate that for transcriptional activation of the E-cadherin promoter the Pbx site is more important and for p15 the GC box is more important.

\subsubsection{Additional genes activated by Meis2, Pbx1 and Klf4 identified by Site Search}

We next wanted to see if we could identify additional targets that are regulated in a similar manner to p15 and E-cadherin by complexes of Meis, Pbx and Klf4. This was done using a web based program called Site Search (http://www.sitesearch.mshri.on.ca/Genome/index.html)

102. This program identifies combinations of transcription factor binding sites (that can be degenerate) that are located within a defined distance from the transcription start site. Searches were performed to locate degenerate GC boxes for Klf4 (RRGGYSY, where R is A/G, Y is C/T and $\mathrm{S}$ is $\mathrm{C} / \mathrm{G}$ ) with sites for Meis (TGACA) and Pbx (CAATC) within 40 base pairs of the GC box. These sites had to be located within $2 \mathrm{kp}$ upstream of a transcription start site. Exact matches to Meis and Pbx sites had to be used because they are so short. Using degenerate sites did not give enough specificity. Restricting this to sites that are present in mice and humans resulted in 484 hits. Hits that retained the relative positions of the three sites were then selected, resulting in 142 hits. 
Figure 6. Analysis of promoter sites necessary for activation by Meis2d, Pbx1 and Klf4. A) HepG2 cells were transfected with luciferase reporters for p15 (-967/+78): Wild type, GC mutant or Meis/Pbx mutant. Additionally, Pbx1a-Meis2d and Klf4 were transfected as indicated. Luciferase activity is shown relative to renilla as average $+\mathrm{SD}$ of duplicate transfections. B) HepG2 cells were transfected as in A, but with E-cadherin wild type, GC mutant or Pbx mutant luciferase reporters as indicated. C) Fold induction is shown for panels A and B for each sample with Meis2d/Pbx1a divided by without addition of Meis2d/Pbx1a. D) A schematic of the site search protocol is outlined with the number of hits matching each sequential step displayed to the right. E \& F) HepG2 cells were transfected with a Pax3 promoter luciferase construct (E) or an Etv1 promoter luciferase construct (F) and the specified expression constructs of Meis2d, Pbx1a and Klf4. Luciferase is shown relative to renilla control as average of triplicate transfections + SD. Maximum relative activation is shown above each set. In E \& F triangles represent increasing amounts of expression plasmids transfected for Meis2d and Pbx1a, and represent 25, 50, and $100 \mathrm{ng}$ per triplicate and for Klf4 plus and double-plus symbols represent 2.5 and $5 \mathrm{ng}$ per triplicate. Significance (Student's t test $\mathrm{P}<0.05$ ) is shown by a \# for comparisons of Meis $2 / \mathrm{Pbx} 1$ to control and a * for comparisons of each amount of KLF4 relative to its Meis2/Pbx1 amount without KLF4. 
A

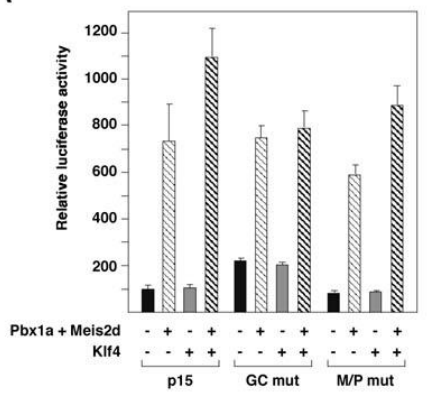

D

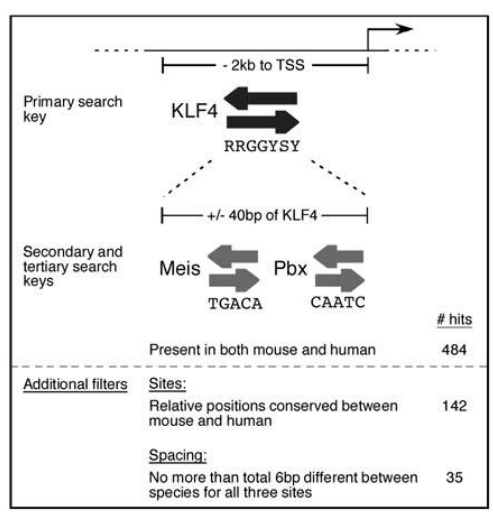

B

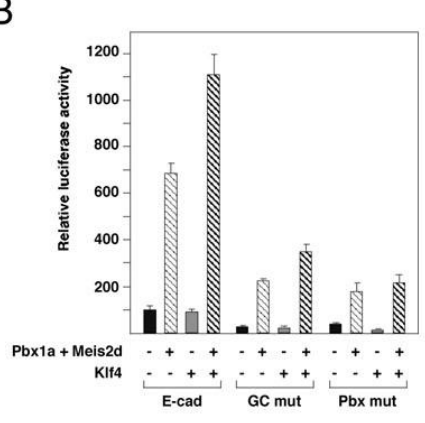

E

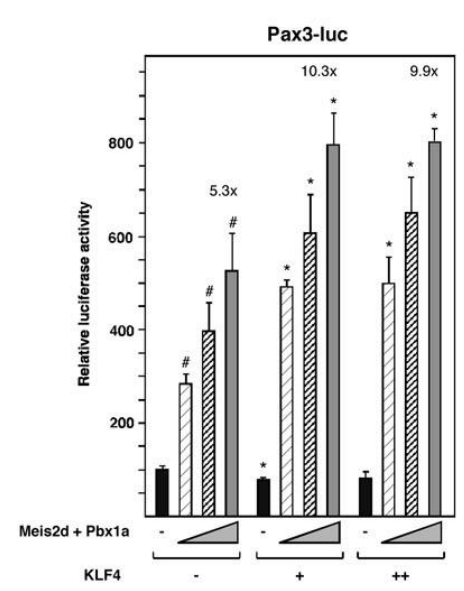

C

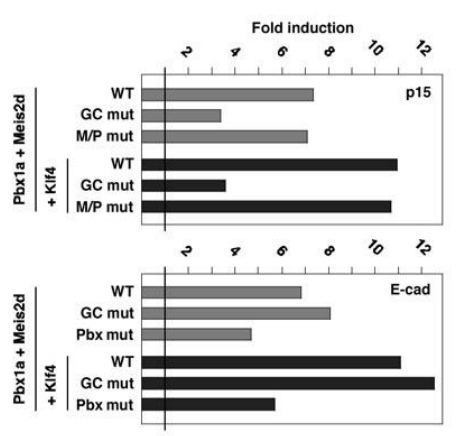

F

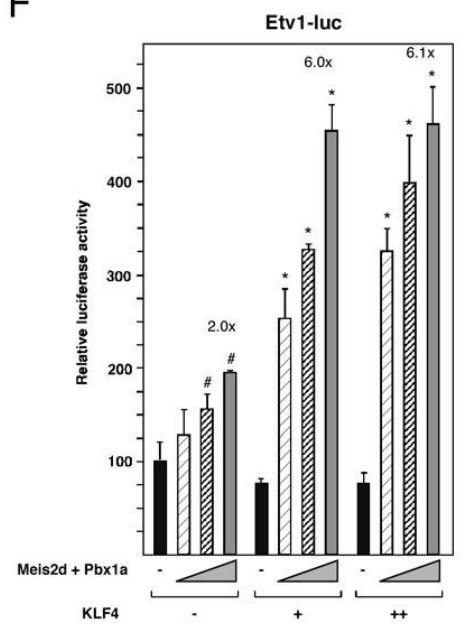


Sites that changed by more than 6 base pairs between mice and humans were discarded and this brought the number of hits down to 35. This Site Search protocol is shown in figure 6D. The additional filters of site orientation and spacing were done in Microsoft Excel. Of these 35 most stringent hits, two of them had published luciferase reporters. A Pax3 luciferase reporter has been published to respond to activation by Meis and $\mathrm{Pbx}{ }^{100}$ and another group had published a luciferase reporter for Etv1 ${ }^{101}$. These reporters were obtained from the groups who published them and assayed in luciferase assays to examine whether they responded to activation by Meis $2 \mathrm{~d}$ and Pbx1a in combination with Klf4. As shown in figure 6E, the Pax3-luciferase reporter was activated by increasing amounts Meis2d and Pbx1a. Klf4 by itself did not activate the reporter. However, when Klf4 was added in addition to Meis2d and Pbx1a, this resulted in synergistic activation of the Pax3 reporter, increasing activation of the highest amount of Meis2 and Pbx1 from 5.3 fold to greater than 10 fold. Synergistic activation of the Etv1 luciferase reporter was even greater. As shown in Figure 6F, the highest amount of Meis2d and Pbx1 activated only 2 fold, but when Klf4 was added, this increased to 6 fold. These results show that synergistic activation by Meis, Pbx and Klf4 is not just limited to p15, but rather that these complexes also activate E-cadherin, Pax2 and Etv1. Also, Etv1 was shown to be a novel target gene of Meis and Pbx alone. The preceding data was published in the journal Molecular and Cellular Biology in $2011^{113}$.

\subsubsection{Meis2 and Pbx1 are downregulated in human prostate cancer}

Due to Meis2 and Pbx1's ability to activate p15 and E-cadherin (known tumor suppressors), we next wanted to see if they were decreased in cancer. There is a website called Oncomine.com that provides an easy way to examine the results of many microarray experiments with different cancers and can be searched for individual genes ${ }^{114}$. On Oncomine we found that mRNA levels of both Meis2 and Pbx 1 decreased in microarray datasets during the progression of prostate cancer. The results of one microarray dataset for Meis2 and Pbx1 are shown in figure 
7A, these results come from a paper by the Chinnaiyan group (Tomlins et al., 2007). It shows a decrease in expression level for both Meis 2 and $\mathrm{Pbx} 1$ in the progression from normal prostate and benign prostatic hyperplasia to prostatic intraepithelial neoplasia and prostate carcinoma.

Therefore, luciferase assays using the p15 and E-cadherin promoters with expression of Meis2 and $\mathrm{Pbx} 1$ were performed in the prostate cancer derived LNCaP cell line. However, transcriptional activation of p15 and E-cadherin by Meis2 and Pbx1 was not seen in LNCaPs (data not shown).

\subsubsection{Pbx1 is repressed by androgen}

While we were working with LNCaP cells we noticed in published microarray data for androgen regulated genes that $\mathrm{Pbx} 1$ was repressed by treatment with androgen (such as GEO accession \#GSE846) ${ }^{116}$. I verified the repression of Pbx1 by androgens by treating LNCaP cells with 2 amounts of synthetic androgen (R1881) for 24 hours and then quantifying the level of Pbx1 mRNA by qRT-PCR as shown in figure 7B. We also found that the Meis 2 and Pbx 1 target gene E-cadherin was decreased by androgen treatment. Therefore, we decided to make a luciferase reporter for the human $\mathrm{Pbx} 1$ promoter. I cloned the human $\mathrm{Pbx} 1$ promoter from genomic DNA and placed a fragment from -2654 to +34 into the luciferase reporter pGL3-basic. I transfected this reporter into LNCaP cells, waited 24 hours and then treated with synthetic androgen R1881 for 24 hours. As shown in figure 8A, this reporter was suppressed $>5$ fold. I then made 5' deletions of this reporter to map the repressive activity of androgens. As shown in figure 8A, basal activity of the reporter was decreased when the 5' end was cropped down to -1381 and then -688 , but the repression of the reporter was mostly retained. Figure $8 \mathrm{~B}$ shows the same data as

$8 \mathrm{~A}$, but normalized to 1 for each reporter so the amount of repression is more apparent. However, when the promoter was cropped down to -425 , activity and repression were both lost. This area of the promoter is highly repetitive and without activity, it was impossible to see repression. 
Figure 7. MEIS2 and PBX1 transcripts levels are decreased during prostate cancer progression. A) Data from Oncomine showing the expression level of MEIS2 (Top) and PBX1 (Bottom) in the progression from normal prostate, benign prostatic hyperplasia, prostatic intraepithelial neoplasia and prostate carcinoma, shown in order from left to right. The bar in the middle of the box plots represents the median, the boxes represent the $25^{\text {th }}$ and $75^{\text {th }}$ percentiles and the error bar lines represent the $10^{\text {th }}$ and $90^{\text {th }}$ percentiles. The data shown is from one microarray set, published by Tomlins et al. B) The mRNA expression levels of E-cadherin and PBX1 in LNCaPs were quantified by qRT-PCR after a 24 hour treatment with: vehicle, $0.1 \mathrm{nM}$ R1881 and $1 \mathrm{nM}$ R1881. 

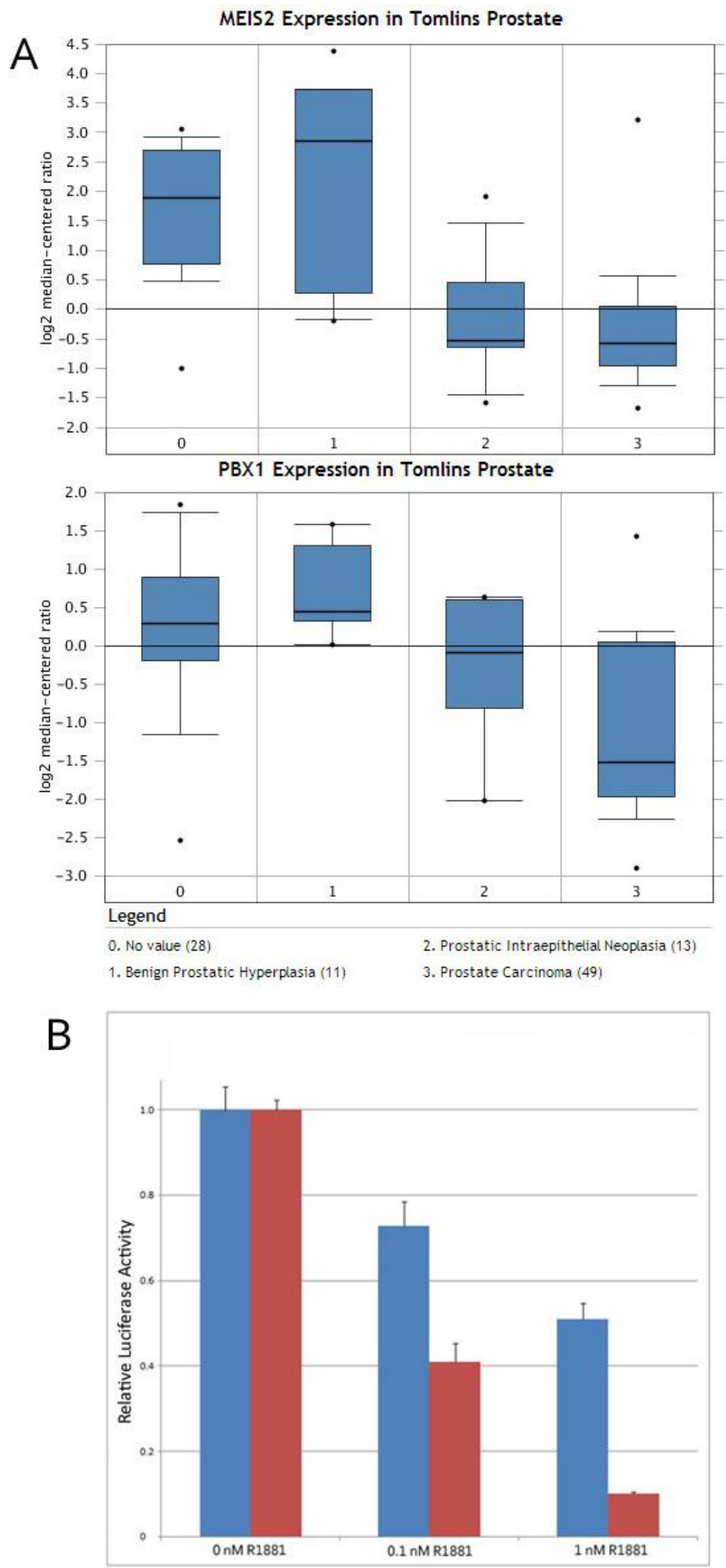

E-cadherin $\mathrm{PBX1}$ 
Figure 8. Repression of the Pbx1 promoter and expression of PLZF. A) LNCaP cells were transfected with 5' deletions of a $\mathrm{Pbx} 1$ promoter luciferase reporter. 24 hours later they were treated with $1 \mathrm{nM}$ R1881 for 24 hours and then assayed for luciferase activity. Results are shown as the average $+\mathrm{SD}$ of luciferase activity relative to renilla control, with the first sample normalized to 1 . B) The same data is presented as in A, but with each reporter normalized to 1 so the repression is more easily visualized. C) $\mathrm{LNCaP}$ cells were treated with vehicle, $0.1 \mathrm{nM}$ R1881 or 1.0 nM R1881 for 24 and 48 hours. PLZF mRNA levels were then quantified by qRTPCR. 

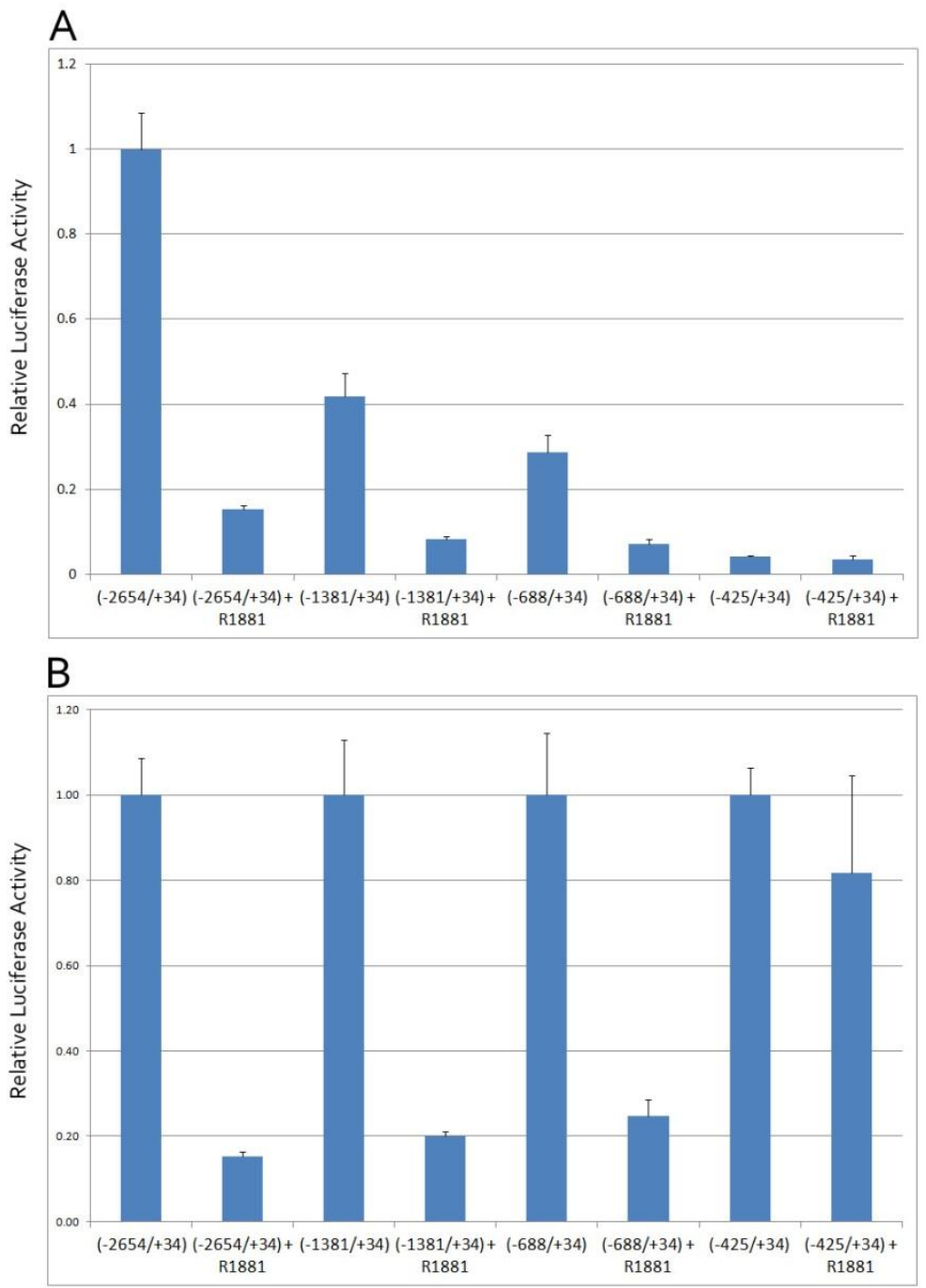

C
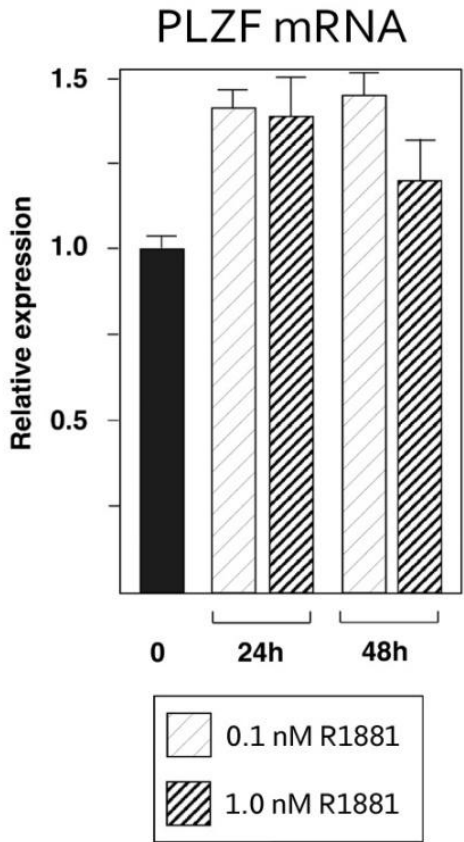
We tried attaching the 5 , end of the promoter to the proximal $-425 /+34$ piece to give the reporter higher activity and placing the proximal $-425 /+34$ piece in pGL3-enhancer or pGL3-control to try and increase the activity, but the activity of the reporter was still too low (data not shown).

Additionally, when we started this $\mathrm{Pbx} 1$ repression project we had a reasonable hypothesis as to the mechanism. The Wang group published that a zinc finger transcription factor, named PLZF, was induced by androgen ${ }^{117}$. Also, the Higashiyama group published that PLZF represses Pbx1 transcription $^{118}$. However, in luciferase assays, expression of PLZF did not result in repression of the Pbx1 promoter (data not shown). Further, PLZF was not induced much by androgen in LNCaP cells, as shown in figure 8C. Therefore, we did not know what to do about losing activity of the $\mathrm{Pbx} 1$ promoter, because without activity we could not see repression. In conclusion, these data indicate that Meis 2 and $\mathrm{Pbx} 1$ are down in prostate cancer and that androgens repress Ecadherin and $\mathrm{Pbx} 1$ via an unknown mechanism.

\subsection{Discussion}

In the preceding chapter we showed that Meis2 and $\mathrm{Pbx} 1$ regulate the $\mathrm{p} 15$ and E-cadherin genes in HepG2 and MCF7 cells. It was also shown that Meis2 and Pbx1 regulate the cell cycle in HepG2 cells, presumably through their regulation of p15 and possibly to a lesser extent p21. We also showed this regulation of p15 and E-cadherin requires DNA binding by Meis2 and Pbx1, the Meis-Pbx interaction and Meis2's activation domain. This regulation of p15 was mapped to a pair of GC boxes in the p15 proximal promoter that had been shown to bind Sp1. However, I showed that Meis2 and $\mathrm{Pbx} 1$ cooperate with another Klf family member, Klf4 to activate transcription. Additionally, on these promoters Klf4 did not activate reporter activity by itself; it was dependent on Meis2's activation domain. Both the finding that Klf4 regulates the p15 gene and that Klf4 interacts with Pbx1 and Meis2 were novel. Additionally, we identified new genes, Pax 3 and Etv1 that are activated synergistically by this complex. In the p15 and E-cadherin promoters the Meis and Pbx sites do not match the exact known sites. Therefore, in the context 
of a larger Meis/Pbx/Klf4 complex binding probably does not require perfect sites. When we did our Site Search we used exact matches for Meis and Pbx sites because they are only 5 base pair sites and relaxing the site requirement would not provide any specificity. Therefore, it seems plausible that there could be many more sites where these complexes could form.

These complexes of homeodomain proteins are clearly very context dependent. There are many homeodomain proteins that Meis, $\mathrm{Pbx}, \mathrm{Hox}$ and their paralogs can interact with and they have been shown to interact with non-homeodomain proteins also ${ }^{3}$. The multitude of interactions could help explain the seemingly contradictory result of our study compared to other studies. We showed that Meis2 functions to activate p15, which is contrary to Meis1's links to the cancer AML. However, after we published our paper another group published in Nature that Meis1 activates cell cycle arrest in cardiomyocytes via p15, p16 and p21 ${ }^{119}$. We also found that the transcript levels of Meis 2 and $\mathrm{Pbx} 1$ are decreased in prostate cancer and that $\mathrm{Pbx} 1$ and $\mathrm{E}$ cadherin are repressed by androgen. We propose that expression of Meis 2 and Pbx 1 are decreased because of their ability to activate the tumor suppressors p15 and E-cadherin, but more work needs to be done on this. Repression of Pbx1 by androgen signaling is interesting because the androgen receptor is usually thought of as an activator. However, we were unable to determine the method due to loss of activity of the reporter, and our hypothesis as to the method of the repression did not work out. It has also been shown that $\mathrm{Pbx}$ induces activation of HoxC8, which inhibits androgen receptor signaling ${ }^{120}$. Therefore the repression of Pbx may be a feedback loop, or loss of Pbx in prostate cancer may be a way for cancer cells to boost androgen receptor signaling, which is common in later stages of prostate cancer. 


\title{
Chapter 4
}

\section{Loss of Tgfbr2 in Addition to Pten Speeds}

\section{Progression to Invasive Cancer in Murine}

\author{
Prostate
}




\subsection{Introduction}

According to the National Cancer Institute, prostate cancer is the second most frequent cancer in men and the second leading cause of cancer deaths in men in the USA (http://seer.cancer.gov/statfacts/html/prost.html). Animal models of prostate cancer are necessary for study of the disease, both for determining what drives cancer and for testing treatments. Current animal models of prostate cancer lack a few key attributes of human prostate cancer. First, some of the current widely used models, such as the Tramp model, are based on viral oncogenes that are not found in human cancers. Secondly, the majority of human prostate cancers metastasize to bone, which no animal models recapitulate at a reasonable rate. Lastly, an animal model of prostate cancer needs to proceed quickly enough that it is feasible to work with. Since TGF- $\beta$ has a tumor suppressive role early in cancer and numerous components of the TGF$\beta$ pathway are lost in the progression of prostate cancer, we hypothesized that prostate specific knockout of the Pten gene and the TGF- $\beta$ receptor type II receptor $(T g f b r 2)$ would result in a rapid progression to prostate cancer in mice. Additionally, since both of these pathways are commonly lost in prostate cancer, we hypothesized that this model would be highly relevant to human cancers. Therefore, we combined floxed alleles of both Pten and Tgfbr2 along with the $\mathrm{Pb}-\mathrm{Cre} 4$ transgene to express Cre recombinase specifically in the prostate epithelium. We used Pten recombination because it reliably gives a PIN phenotype at an early age, but the phenotype only slowly progresses to poorly differentiated adenocarcinoma. Recombination of Pten was combined with the additional loss of Tgfbr2 to determine whether the double knockout would speed the progression to cancer. There is also a large volume of research that has been done on the TGF- $\beta$ pathway and bone metastases, where TGF- $\beta$ is thought to promote metastases to bone 121. This effect of TGF- $\beta$ signaling is specific to advanced cancers, after tumors have overcome the growth suppression of the TGF- $\beta$ pathway. However, after we started this project, the DePinho group showed that loss of Smad4 is correlated with an increase in bone metastases ${ }^{68}$. 
Therefore, we also wanted to analyze what effect loss of Tgfbr2 would have on the ability of prostate cancer cells to metastasize to bone.

In this chapter I show that deletion of Pten and Tgfbr2 in the prostate results in a rapid progression to cancer. These tumors were poorly differentiated and metastatic to the lumbar lymph nodes and lungs. Additionally, the TGF- $\beta$ pathway was activated in prostate ducts with the PIN phenotype. Furthermore, this activation of the TGF- $\beta$ pathway was shown to be downstream of the oncogenic kinase Akt. We think this activation of the TGF- $\beta$ pathway functions as a tumor suppressor feedback mechanism to protect against activation of Akt.

\subsection{Results}

\subsubsection{Loss of Tgfbr2 in addition to Pten leads to an early onset of prostate cancer}

We obtained the $\mathrm{Pb}-\mathrm{Cre} 4$ transgene from the $\mathrm{NCI}$, which came on a $\mathrm{C} 57 \mathrm{BL} / 6 \mathrm{~N}$ background. We obtained the Pten floxed allele made by the Mak group ${ }^{105}$ from a colleague at UVa, which was on an FVB background. We already had the floxed allele of $T g f b r 2$, which was

made by the Moses group ${ }^{104}$. These mice were intercrossed to make each combination of alleles and then kept on a mixed strain background. As part of this project we collaborated with a pathologist at UVa, Dr. Henry Frierson. His technician, Sharon Birdsall, did the majority of the specimen embedding, sectioning, H\&E staining and IHC shown in the rest of this dissertation. To confirm the tissue specific knockout worked as expected, wild type and Tgfbr $2^{\mathrm{r} / \mathrm{r}}$ prostate sections were stained by IHC as shown in figure 9A. To verify recombination of Pten worked as expected we stained wild type and $\operatorname{Pten}^{\mathrm{r} / \mathrm{r}}$ prostate sections for phospho-Akt(Ser473) as a marker of Pten loss (figure 9A). As shown in figure 9B, the $\operatorname{Pten}^{\mathrm{r} / \mathrm{r}} ; \mathrm{Tgfbr}^{\mathrm{r} / \mathrm{r}}$ mice develop prostate cancers with astonishing speed. These mice need to be euthanized for tumor burden at a median age of 88 days ( 12 weeks $\& 4$ days) and none of them survive past 20 weeks. The Pten ${ }^{\mathrm{r} / \mathrm{r}} ;$ Tgfbr $^{\mathrm{r} / \mathrm{r}}$ mice get sick from bladder obstruction and have hydronephrotic kidneys (data not shown). The 
$\operatorname{Pten}^{\mathrm{r} / \mathrm{r}}$ cohort is fully viable within the range of the double nulls and they survive to a median age of 446 days old. In contrast, Tgfbr $2^{\mathrm{r} / \mathrm{r}}$ mice do not develop an abnormal phenotype, even out to 70 weeks old. Therefore, we believe that Pten loss initiates the tumors and that loss of Tgfbr2 allows rapid progression. I also bred a set of mice that were heterozygous for Pten recombination and combined with: wild type Tgfbr 2, Tgfbr $2^{+/ r}$ or Tgfbr $2^{\mathrm{r} / \mathrm{r}}$. As shown in figure $9 \mathrm{C}, \mathrm{Pten}^{+/ \mathrm{r}}$ mice and $\mathrm{Pten}^{+/ \mathrm{r}} ; \mathrm{Tgfbr}^{+/ \mathrm{r}}$ mice all survive to 70 weeks. However, most of the $\operatorname{Pten}^{+/ \mathrm{r}} ; \mathrm{Tgfbr}^{\mathrm{r} / \mathrm{r}}$ mice developed tumors and had to be euthanized at a median of age of 343 days. It has been shown that Pten heterozygotes often lose expression of Pten during the progression to cancer ${ }^{122}$. Therefore, if Pten heterozygous and Tgfbr2 null tumors lose the other allele of Pten they could be very similar to the double null tumors, but we did not examine the status of the intact Pten allele in our Pten heterozygous mice. Figure 9D shows a table of the survival data for all the intermediate Pten and Tgfbr2 genotypes. Another interesting genotype is mice that were recombined for Pten and heterozygous for Tgfbr2 in the prostate. These mice show similar survival to the Pten heterozygous and Tgfbr2 null mice, however, are highly metastatic, as shown later in figure 12.

\subsubsection{Histology of tumors}

We next wanted to characterize the tumors that formed. To do this we H\&E stained prostate sections of each genotype. As shown in figure 10, wild type prostate ducts consist mainly of one layer of epithelial cells and do not have much stroma (Human prostates have much more fibromuscular stroma). Tgfbr $2^{\mathrm{r} / \mathrm{r}}$ prostates look similar to wild type, an example of an 18 week old Tgfbr $2^{\mathrm{r} / \mathrm{r}}$ is shown in figure 10 . We also stained 8 week old and 14 week old Pten $^{\mathrm{r} / \mathrm{r}}$ and $\operatorname{Pten}^{\mathrm{r} / \mathrm{r}} ;$ Tgfbr $^{\mathrm{r} / \mathrm{r}}$ mice to look at progression. At 8 weeks old both the Pten ${ }^{\mathrm{r} / \mathrm{r}}$ and the $\operatorname{Pten}^{\mathrm{r} / \mathrm{r}} ;$ Tgfbr $^{\mathrm{r} / \mathrm{r}}$ mice had PIN (Prostatic Intraepithelial Neoplasia) as shown in figure 10. This is characterized by the epithelial cells mostly filling in the prostate ducts. 
Figure 9. Loss of Tgfbr 2 in addition to Pten leads to an early onset of prostate cancer. (A) Prostates of the indicated genotypes (Tgfbr $2^{\mathrm{r} / \mathrm{r}}$ and $\mathrm{Pten}^{\mathrm{r} / \mathrm{r}}$ indicate prostate specific recombination of the indicated gene) were analyzed by IHC for Tgfbr2 and Akt phosphorylated on serine 473 (pAkt). (B) Kaplan-Meier plot for mice with Pten, Tgfbr2 and Pten/Tgfbr2 homozygous prostate recombination. The P-value (log-rank test) is shown for $\operatorname{Pten}^{\mathrm{r} / \mathrm{r}} ; \mathrm{Tgfbr}^{\mathrm{r} / \mathrm{r}}$ versus $\operatorname{Pten}^{\mathrm{r} / \mathrm{r}}$. (C) Kaplan-Meier plot for mice with heterozygous recombination of Pten in combination with: wild type $\left(\mathrm{Tgfbr} 2^{+/+)}\right.$, heterozygous recombination of Tgfbr2 $\left(\mathrm{Tgfbr} 2^{+/ r}\right)$ or homozygous recombination of Tgfbr2 $\left(\operatorname{Tgfbr}^{\mathrm{r} / \mathrm{r}}\right)$. The P-value shown is for Pten ${ }^{+/ \mathrm{r}} ; \operatorname{Tgfbr}^{\mathrm{r} / \mathrm{r}}$ versus Pten ${ }^{+/ \mathrm{r}} ; \operatorname{Tgfbr}^{+/ \mathrm{r}}$. (D) A summary of the tumor-free survival data for animals of the indicated genotypes is shown. Genotypes refer to prostate-specific recombination of the indicated genes. Only mice that survived up to 70 weeks (490) days or that had to be euthanized due to tumor burden are included in this analysis. 

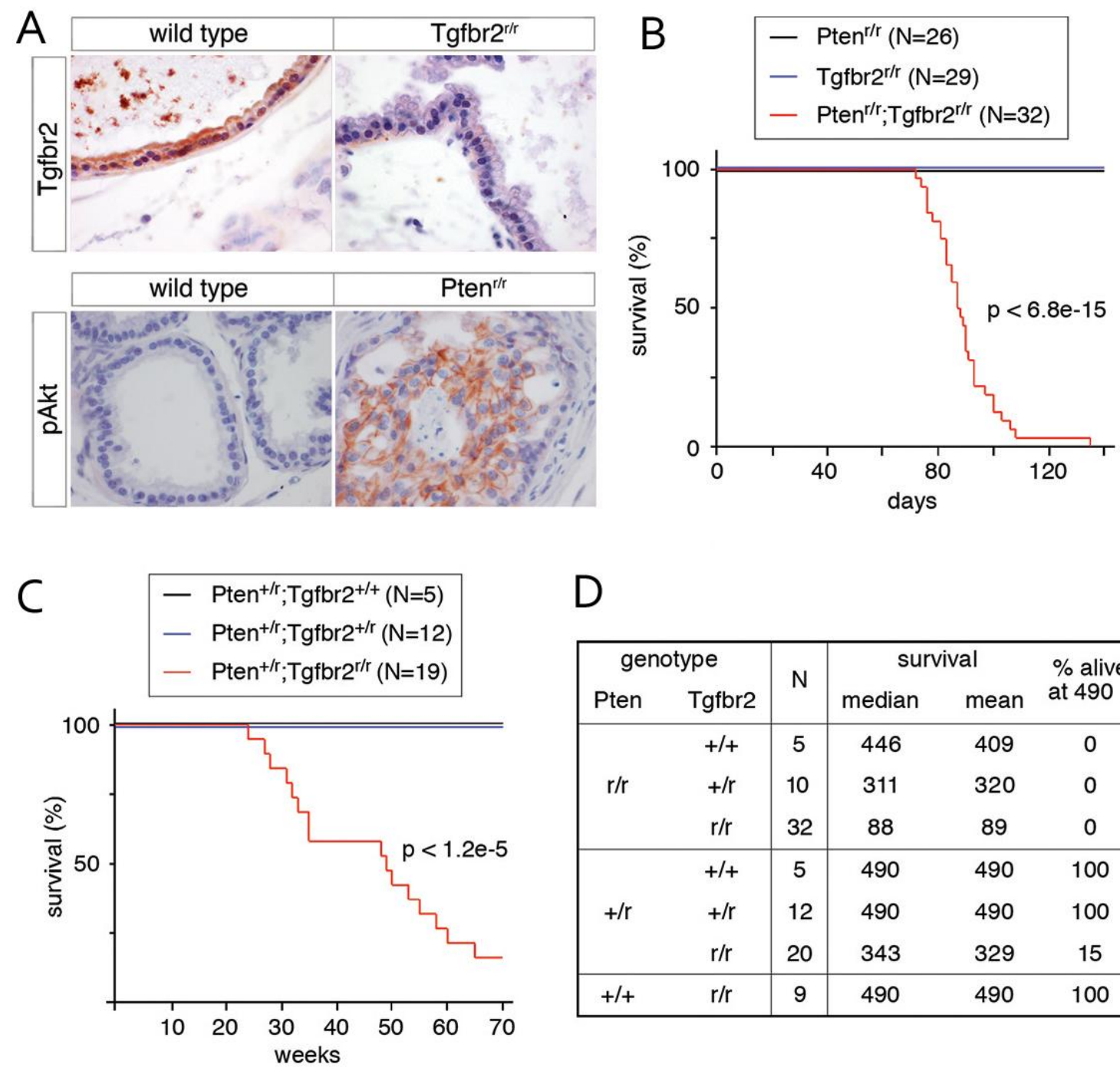

D

\begin{tabular}{|cc|c|ccc|}
\hline \multicolumn{2}{|c|}{ genotype } & \multirow{2}{*}{$\mathrm{N}$} & \multicolumn{2}{c|}{ survival } & \% alive \\
Pten & Tgfbr2 & & median & mean & at 490 d \\
\hline \multirow{3}{*}{$r / r$} & $+/+$ & 5 & 446 & 409 & 0 \\
& $+/ r$ & 10 & 311 & 320 & 0 \\
& $r / r$ & 32 & 88 & 89 & 0 \\
\hline \multirow{2}{*}{$+/ r$} & $+/+$ & 5 & 490 & 490 & 100 \\
& $+/ r$ & 12 & 490 & 490 & 100 \\
& $r / r$ & 20 & 343 & 329 & 15 \\
\hline$+/+$ & $r / r$ & 9 & 490 & 490 & 100 \\
\hline
\end{tabular}




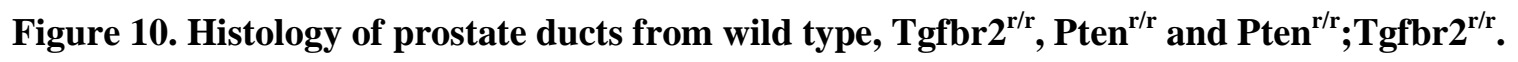
Haematoxylin and eosin (H\&E) stained sections are shown at two magnifications for wild type, Tgfbr $^{\mathrm{r} / \mathrm{r}}, \operatorname{Pten}^{\mathrm{r} / \mathrm{r}}$ and $\operatorname{Pten}^{\mathrm{r} / \mathrm{r}} ; \mathrm{Tgfbr}^{\mathrm{r} / \mathrm{r}}$ at the indicated ages. 

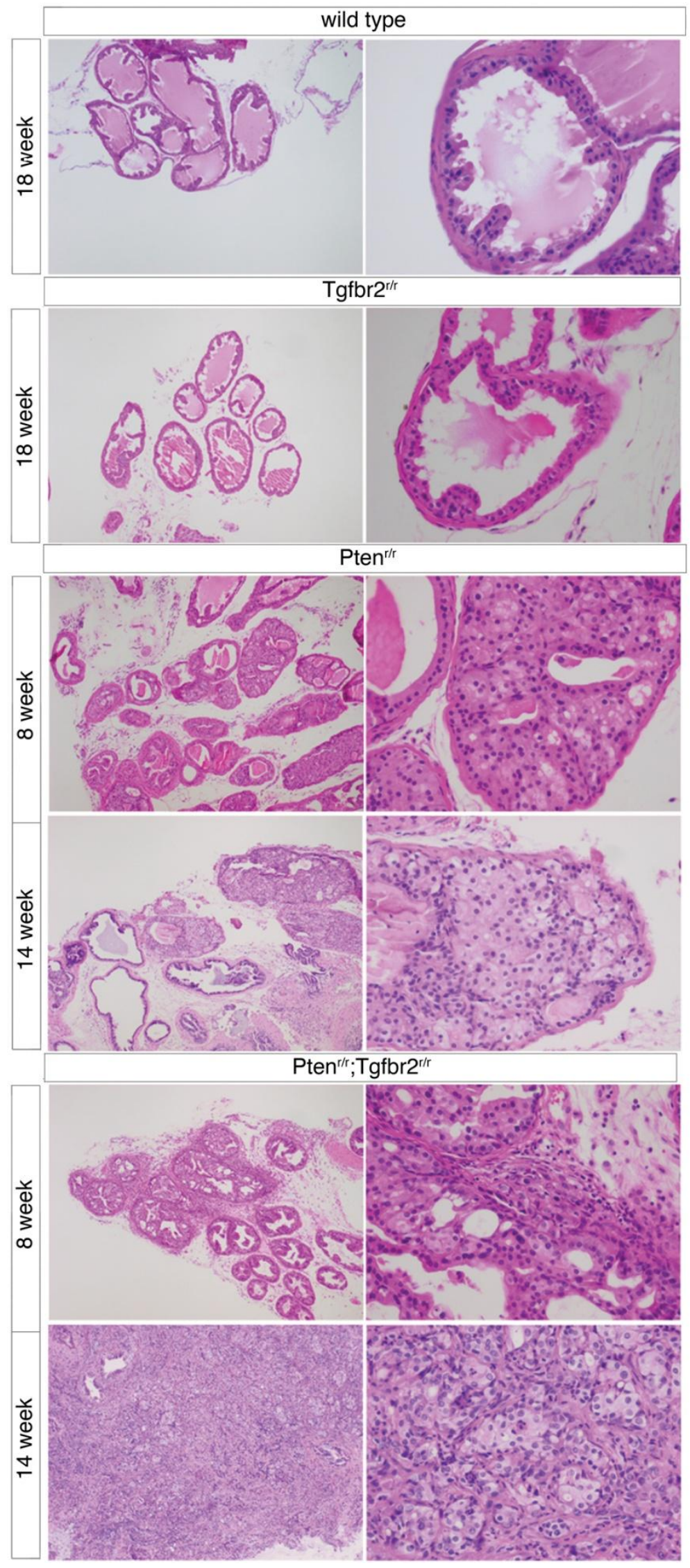
However, at 14 weeks old the Pten ${ }^{\mathrm{r} / \mathrm{r}}$ mice are still at the PIN phase, while Pten ${ }^{\mathrm{r} / \mathrm{r}}$ Tgfbr ${ }^{\mathrm{r} / \mathrm{r}}$ mice have progressed to poorly differentiated adenocarcinoma (PDA) and have lost almost all organization of their prostate ducts.

\subsubsection{Higher proliferation and loss of p27 in the progression from Pten null to Pten/Tgfbr2} double null

We further characterized these tumors proliferation by immunohistochemistry (IHC). Sections from wild type, $\operatorname{Pten}^{\mathrm{r} / \mathrm{r}}$ and $\mathrm{Pten}^{\mathrm{r} / \mathrm{r}} ; \mathrm{Tgfbr}^{\mathrm{r} / \mathrm{r}}$ mice were stained for cyclin $\mathrm{D}$ as shown in figure 11A. There was an apparent increase in cyclin D during the progression from wild type to $\operatorname{Pten}^{\mathrm{r} / \mathrm{r}}$ to $\operatorname{Pten}^{\mathrm{r} / \mathrm{r}} ; \mathrm{Tgfbr}^{\mathrm{r} / \mathrm{r}}$. To verify this increase in cyclin $\mathrm{D}$, the percent of cyclin D positive cells was quantified by Dr. Frierson for each genotype. Additionally, he counted the different phenotypes (PIN versus PDA) separately in the $\mathrm{Pten}^{\mathrm{r} / \mathrm{r}} ; \mathrm{Tgfbr}^{\mathrm{r} / \mathrm{r}}$. As shown in figure 11B wild type and Tgfbr $2^{\mathrm{r} / \mathrm{r}}$ mice have similarly low levels of cyclin D. The percent of cyclin D positive cells rises in $\operatorname{Pten}^{\mathrm{r} / \mathrm{r}}$ mice, which just have PIN, and is similar to PIN in the $\operatorname{Pten}^{\mathrm{r} / \mathrm{r}} ; \operatorname{Tgfbr}^{\mathrm{r} / \mathrm{r}}$. However, the percent of cyclin D positive cells increases dramatically in PDA of $\operatorname{Pten}^{\mathrm{r} / \mathrm{r}} ; \mathrm{Tgfbr}^{\mathrm{r} / \mathrm{r}}$. We did the same experiment with another proliferation marker Ki-67, which is shown in figure 11C. The increase in proliferation from PIN to PDA seems to indicate that proliferation is more dependent on the phenotype than the genotype. We also stained sections of wild type, $\mathrm{Pten}^{\mathrm{r} / \mathrm{r}}$ and $\operatorname{Pten}^{\mathrm{r} / \mathrm{r}} ; \mathrm{Tgfbr}^{\mathrm{r} / \mathrm{r}}$ prostates by IHC for the CDK inhibitor p27 (CDKN1B or Kip1). As shown in figure 11D, p27 levels increase in the $\operatorname{Pten}^{\mathrm{r} / \mathrm{r}}$ and then decrease in PDA of the Pten ${ }^{\mathrm{r} / \mathrm{r}} ; \operatorname{Tgfbr}^{\mathrm{r} / \mathrm{r}}$. This apparent increase and decrease also appeared to be phenotype dependent. As shown in figure 11E, we stained serial sections of a $\operatorname{Pten}^{\mathrm{r} / \mathrm{r}} ; \mathrm{Tgfbr}^{\mathrm{r} / \mathrm{r}}$ prostate for cyclin D and $\mathrm{p} 27$. This showed minimal cyclin D in the normal duct on the left with increased amounts in the PDA to the right. The opposite is seen for $\mathrm{p} 27$, with the cells in the duct expressing $\mathrm{p} 27$, but the cells in the neighboring PDA not expressing it. These results show a clear gain in proliferation in PDA of the double null mice, with an associated decrease in the CDK inhibitor p27. 
Figure 11. Higher proliferation and loss of CDK inhibitor p27 in the progression from Pten null to Pten/Tgfbr2 double null. (A) IHC for Cyclin D is shown for the indicated genotypes. (B \& C) Quantification of IHC for Cyclin D (B) and Ki-67 (C) is shown for the indicated genotypes as the average percent of cells which stained positive for three mice plus the standard deviation. In the Pten;Tgfbr2 null, the different phenotypes of PIN and PDA were counted separately.

Significance (by Student's t-test) is shown for each genotype compared to wild type and for PDA compared to PIN in the Pten; Tgfbr2. * $=\mathrm{P}<0.05$, ** $=\mathrm{P}<0.01, * * *=\mathrm{P}<0.001$. (D) IHC for $\mathrm{p} 27$ is shown for the indicated genotypes. (E) Serial sections of a $\operatorname{Pten}^{\mathrm{r} / \mathrm{r}} ; \operatorname{Tgfbr}^{\mathrm{r} / \mathrm{r}}$ prostate are shown stained by IHC for Cyclin D and p27. The left part of the sections shows a more normal duct, with PDA visible on the right. 
A

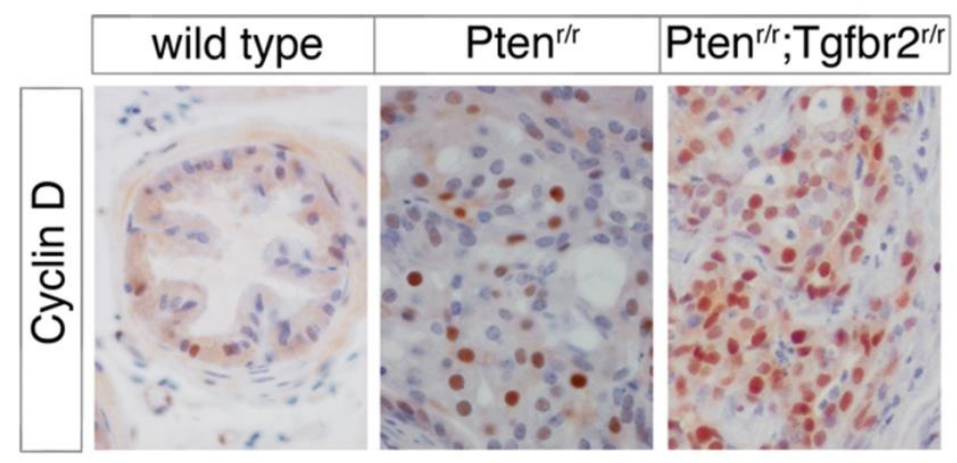

D
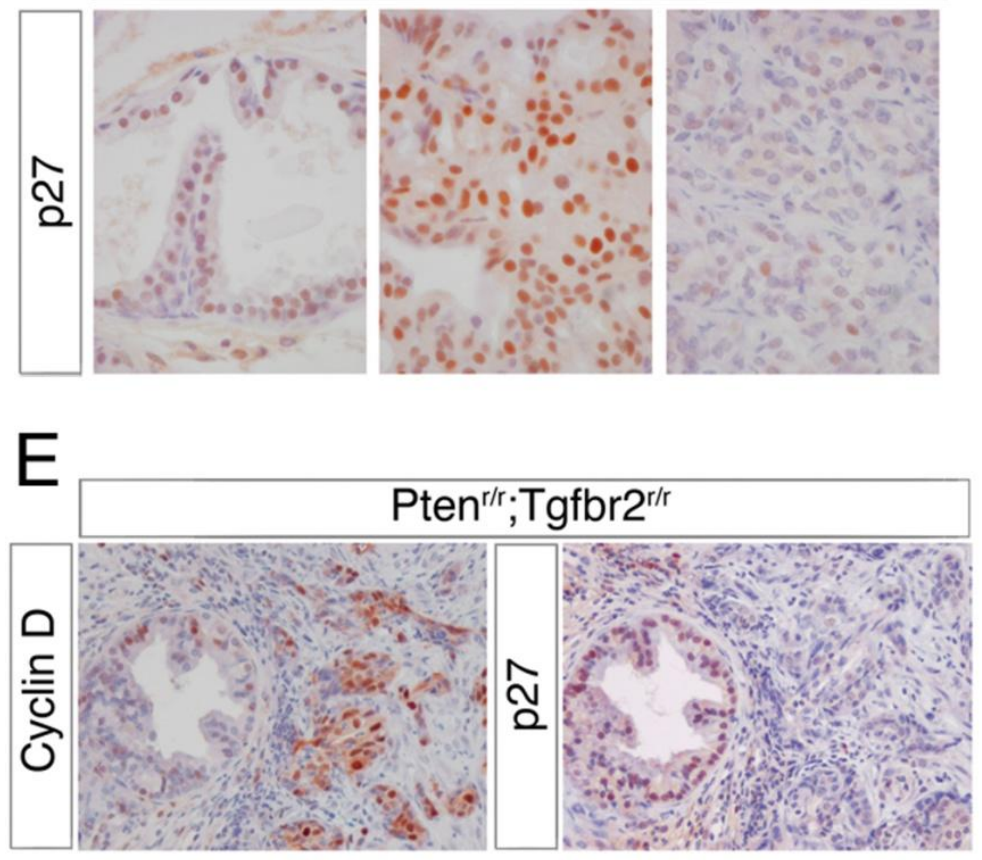

B

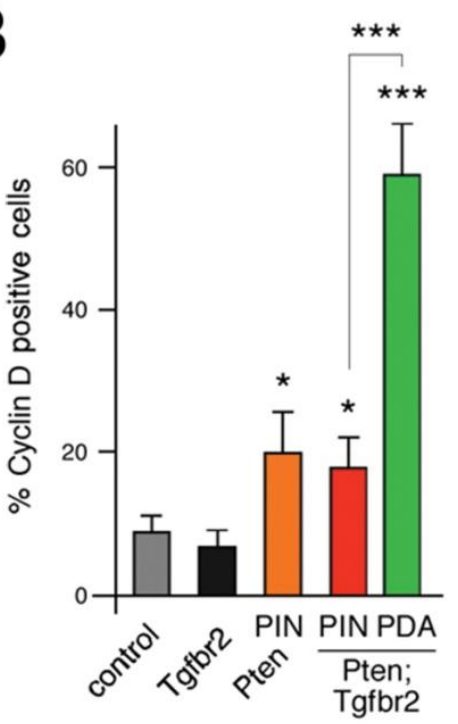

C

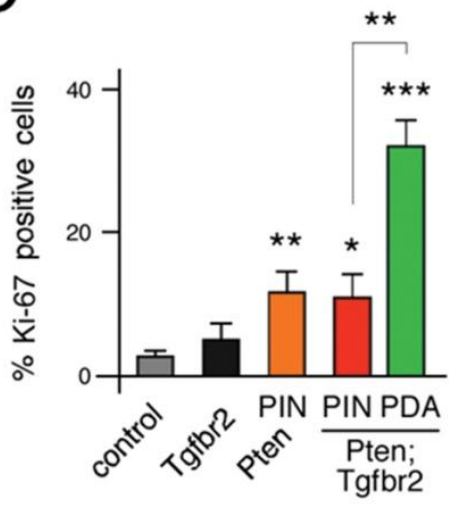


It has been published that TGF- $\beta$ stabilizes p27 through the degradation of Skp2, part of a ubiquitin ligation complex that targets p27 for destruction ${ }^{123}$. Therefore, the levels of Skp2 were examined by western blot, but no change was seen (Data not shown). Consequently, we do not think loss of p27 is via this mechanism.

\subsubsection{Pten/Tgfbr2 null prostate tumors are metastatic to lymph nodes and lung}

We next wanted to know if our prostate cancer models were developing metastases to distant organs. Any mice that might have had carcinoma were examined for metastases to the lumbar lymph nodes, as this is the first place that prostate cancer in mice usually metastasizes to. As shown in figure $12 \mathrm{~A}$, lymph nodes from $35 \mathrm{Pten}^{\mathrm{r} / \mathrm{r}} ; \mathrm{Tgfbr}^{\mathrm{r} / \mathrm{r}}$ mice were analyzed and 23 of them had metastases present, which is $65.7 \%$. Six $\operatorname{Pten}^{\mathrm{r} / \mathrm{r}}$ mice were maintained long enough that they might develop metastases and a lymph node metastasis was found in only 1 of them. However, in the set of $9 \mathrm{Pten}^{\mathrm{r} / \mathrm{r}} ; \mathrm{Tgfbr}^{+/ \mathrm{r}}$ mice, lymph node metastases were found in all of them. Additionally, in a set of $11 \mathrm{Pten}^{+/ \mathrm{r}} ; \mathrm{Tgfbr}^{\mathrm{r} / \mathrm{r}}$ mice lymph node metastases were found in four of them. In double null $\operatorname{Pten}^{\mathrm{r} / \mathrm{r}} ; \operatorname{Tgfbr}^{\mathrm{r} / \mathrm{r}}$ mice that had been castrated we saw fewer lymph node metastases ( 5 out of $14,35.7 \%$ ), but with the lower number of mice examined, it is hard to know if this is a real difference. Not only do the $\operatorname{Pten}^{\mathrm{r} / \mathrm{r}} ; \operatorname{Tgfbr}^{+/ \mathrm{r}}$ mice have the highest rate of metastases, but they had the largest metastases we observed. Figure 12B shows a rather large lymph node metastasis from a Pten ${ }^{\mathrm{r} / \mathrm{r}} ; \mathrm{Tgfbr}^{+/ \mathrm{r}}$ mouse. Most of the lymph node metastases that we observed in $\operatorname{Pten}^{\mathrm{r} / \mathrm{r}} ; \operatorname{Tgfbr}^{\mathrm{r} / \mathrm{r}}$ mice were only a handful of cells, as shown in figure $12 \mathrm{C}$. This

figure shows an H\&E stained lymph node metastasis and the same lymph node stained for keratin 18 by IHC to confirm that these were epithelial cells. We also examined lung tissue in transgenic mice for metastases. As shown in figure 12D, lung metastases were found in 14 of 31 $\operatorname{Pten}^{\mathrm{r} / \mathrm{r}} ;$ Tgfbr $^{\mathrm{r} / \mathrm{r}}$ mice. Four Pten ${ }^{\mathrm{r} / \mathrm{r}} ;$ Tgfbr $^{+/ \mathrm{r}}$ mice were examined for lung metastases and all four of them had metastases to the lungs. Most of the lung metastases for $\operatorname{Pten}^{\mathrm{r} / \mathrm{r}} ; \operatorname{Tgfbr}^{\mathrm{T} / \mathrm{r}}$ mice were small, with only a handful of cells, such as the one shown in figure 12E stained with H\&E. 
$\operatorname{Pten}^{\mathrm{r} / \mathrm{r}} ; \mathrm{Tgfbr}^{+/ \mathrm{r}}$ mice typically had larger lung metastases than double null tumors, and one mouse had visible nodules on his lungs upon dissection. A section of this lung metastasis stained with $\mathrm{H} \& \mathrm{E}$ is shown in figure $12 \mathrm{~F}$. We also examined liver in a number of mice, but never found any metastases. These data indicate that our Pten/Tgfbr2 null model can readily metastasize to not only the local lymph nodes, but the lungs also. This is interesting because we knocked out TGF- $\beta$ signaling, which later in cancer is pro-metastasis. It is also interesting to note that the most metastatic mice were the ones with a half a dose of Tgfbr2.

\subsubsection{Pten/Tgfbr2 null prostate tumors are resistant to castration}

Since androgen deprivation is a common treatment for prostate cancer, we next wanted to know whether the tumors of our Pten ${ }^{\mathrm{r} / \mathrm{r}} ; \mathrm{Tgfbr}^{\mathrm{r} / \mathrm{r}}$ mice were sensitive or resistant to castration. Hong Wu's group published that their prostate specific Pten knockout mice are resistant to castration. Specifically, they showed that $P \operatorname{ten}^{\mathrm{r} / \mathrm{r}}$ mice castrated at 16 weeks old still had carcinoma 10 weeks later ${ }^{90}$. However, they did not show a direct comparison to un-castrated $\operatorname{Pten}^{\mathrm{r} / \mathrm{r}}$, so it is unknown how complete the castration resistance is. Experiments using castration of mice utilizing the $\mathrm{Pb}$-Cre4 transgene are potentially difficult to analyze, due to the dependence on androgen for expression of the Cre transgene. The worry is if the mice are castrated too early (removing androgen), Cre will not be expressed well and the floxed alleles will not recombine.

Therefore, we had to be careful to not castrate the mice too early. However, the group who made the $\mathrm{Pb}-\mathrm{Cre} 4$ transgene showed that it is expressed well by the time the mice are 1 to 2 weeks old ${ }^{86}$. Two groups of $\operatorname{Pten}^{\mathrm{r} / \mathrm{r}} ; \mathrm{Tgfbr}^{\mathrm{r} / \mathrm{r}}$ mice were castrated, one group at 6 weeks of age and one group at 9-11 weeks of age. These mice were allowed to develop as normal for $\operatorname{Pten}^{\mathrm{r} / \mathrm{r}} ; \mathrm{Tgfbr}^{\mathrm{r} / \mathrm{r}}$ mice and euthanized when they showed significant tumor burden. The set castrated at 6 weeks old and the set castrated at 9-11 weeks old showed no difference in survival and the data for the two groups was combined together. 
Figure 12. Analysis of metastasis and castration resistance. (A) A summary of the lymph node metastases seen in the indicated genotypes with the total mice analyzed shown and the percent with metastases. Also shown at the bottom is the same summary for $\operatorname{Pten}^{\mathrm{r} / \mathrm{r}} ; \operatorname{Tgfbr}^{\mathrm{r} / \mathrm{r}}$ mice that had been castrated between the ages of 6-11 weeks. (B) A lymph node metastasis from a 49 week old Pten ${ }^{\mathrm{r} / \mathrm{r}}$;gfbr $2^{+/ \mathrm{r}}$ mouse is shown stained by H\&E. (C) A lymph node micrometastasis from an 88 day old $\operatorname{Pten}^{\mathrm{r} / \mathrm{r}} ; \mathrm{Tgfbr}^{\mathrm{r} / \mathrm{r}}$ is shown stained by H\&E and by IHC for Keratin 18. (D) The number and frequency of lung metastases is shown for $\operatorname{Pten}^{\mathrm{r} / \mathrm{r}} ; \operatorname{Tgfbr}^{+/ \mathrm{r}}$ and $\operatorname{Pten}^{\mathrm{r} / \mathrm{r}} ; \operatorname{Tgfbr}^{\mathrm{r} / \mathrm{r}}$ mice. (E) An example of an H\&E stained lung metastasis is shown for an 88 day old Pten $^{\mathrm{r} / \mathrm{r}} ; \mathrm{Tgfbr}^{\mathrm{T} / \mathrm{r}}$ mouse. (F) A large lung metastasis is shown for a 54 week old Pten $^{\mathrm{r} / \mathrm{r}} ; \mathrm{Tgfbr}^{+/ \mathrm{r}}$ mouse, stained by H\&E. (G) Kaplan-Meier plots comparing the survival of $\operatorname{Pten}^{\mathrm{r} / \mathrm{r}} ; \operatorname{Tgfbr}^{\mathrm{r} / \mathrm{r}}$ mice that were castrated at 6-11 weeks to mice of the same genotype which were not castrated. 


\begin{tabular}{|c|c|c|c|c|}
\hline \multicolumn{2}{|c|}{ genotype } & \multirow{2}{*}{ Total } & \multicolumn{2}{|c|}{ LN mets } \\
\hline Pten & Tgfbr2 & & $\mathrm{N}$ & $\%$ \\
\hline \multirow{3}{*}{$r / r$} & $+/+$ & 6 & 1 & 16.7 \\
\hline & $+/ r$ & 9 & 9 & 100 \\
\hline & $r / r$ & 35 & 23 & 65.7 \\
\hline$+/ r$ & $r / r$ & 11 & 4 & 36.4 \\
\hline \multicolumn{5}{|c|}{ castrated } \\
\hline$r / r$ & $r / r$ & 14 & 5 & 35.7 \\
\hline
\end{tabular}

B

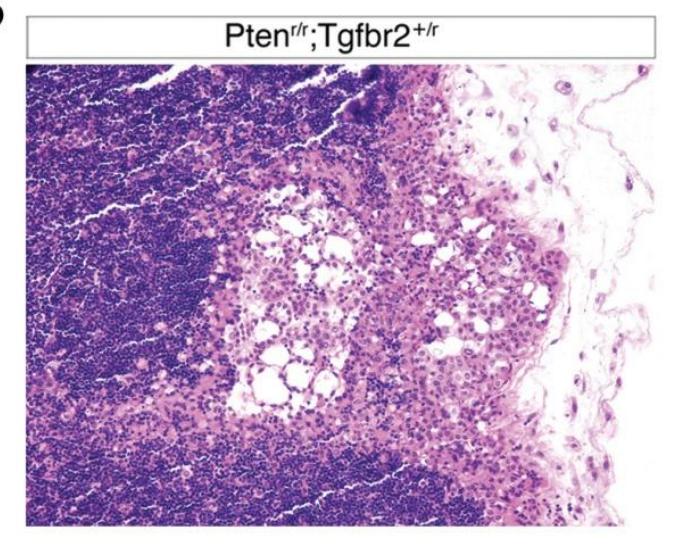

C

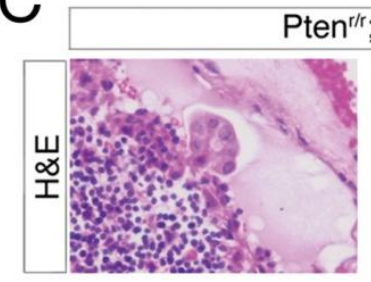

D

\begin{tabular}{|cc|c|cc|}
\hline \multicolumn{2}{|c|}{ genotype } & \multirow{2}{*}{ Total } & \multicolumn{2}{|c|}{ Lung mets } \\
Pten & Tgfbr2 & & $\mathrm{N}$ & $\%$ \\
\hline $\mathrm{r} / \mathrm{r}$ & $+/ \mathrm{r}$ & 4 & 4 & 100 \\
& $\mathrm{r} / \mathrm{r}$ & 14 & 31 & 45 \\
\hline
\end{tabular}

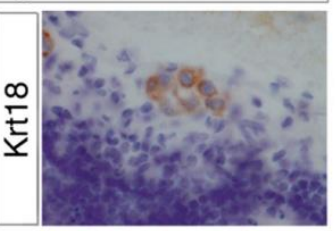

E

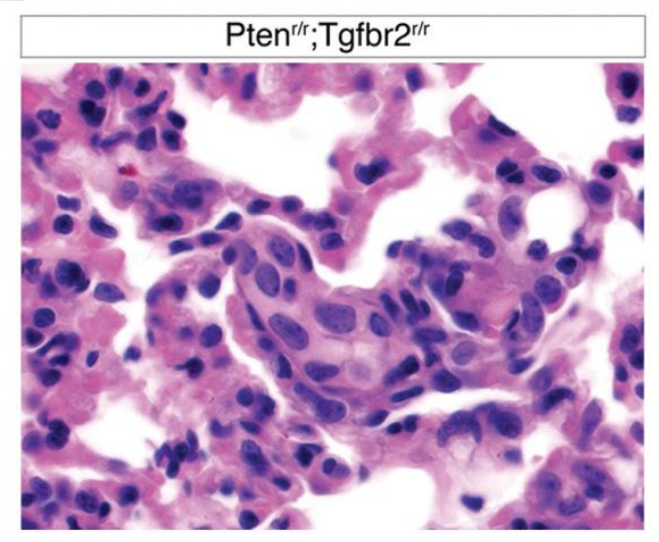

F

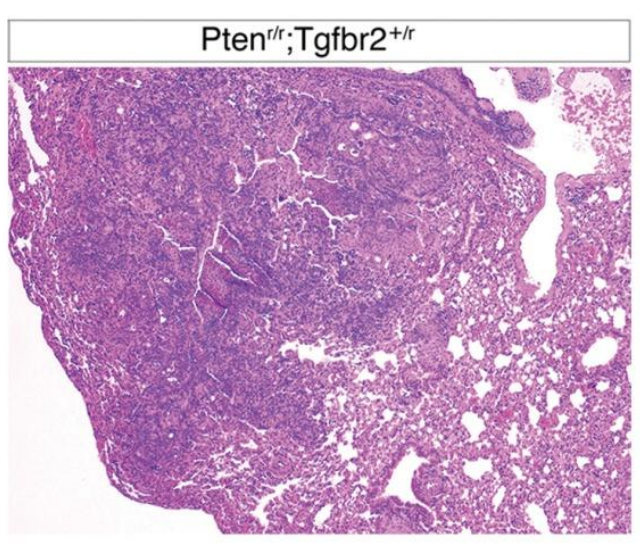

G

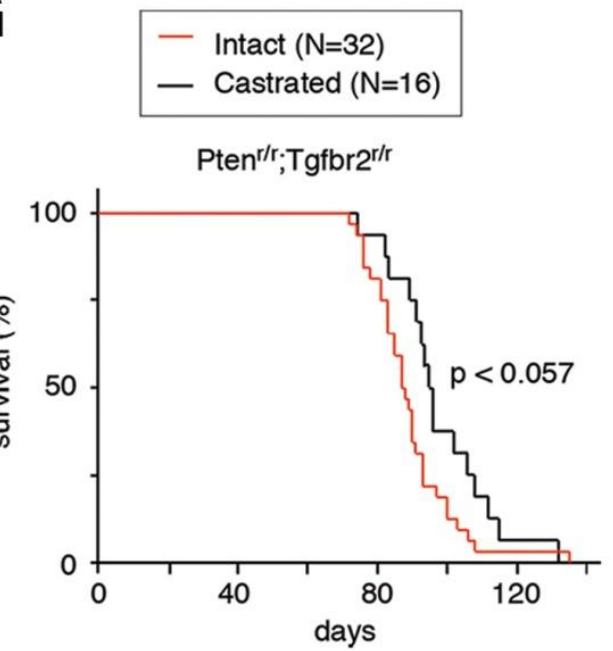


A Kaplan-Meier survival curve for castrated versus intact Pten ${ }^{\mathrm{r} / \mathrm{r}} ; \operatorname{Tgfbr}^{\mathrm{r} / \mathrm{r}}$ mice is shown in figure 12G. There may be a minimal increase in survival of castrated $\operatorname{Pten}^{\mathrm{r} / \mathrm{r}} ; \mathrm{Tgfbr}^{\mathrm{r} / \mathrm{r}}$ mice as compared to un-castrated, but the $\mathrm{p}$-value was not significant $(\mathrm{p}<0.057)$. Therefore, we believe our double null Pten/Tgfbr2 mice to already be androgen independent.

\subsubsection{The TGF- $\beta$ pathway is activated in the Pten null}

While we were working on this project, the DePinho group published a similar study with a prostate specific Pten and Smad4 knockout ${ }^{95}$. In this study they showed a western blot for Smad4 with an increase in protein level from wild type to Pten knockout. This gave us the idea that the TGF- $\beta$ pathway may be increased in the $\operatorname{Pten}^{\mathrm{r} / \mathrm{r}}$ as a protective tumor suppressive mechanism against the loss of Pten. Therefore, we decided to assay important components of the TGF- $\beta$ pathway to see if they are increased in $\operatorname{Pten}^{\mathrm{r} / \mathrm{r}}$ mice. As shown in figure $13 \mathrm{~A}$, both Tgfbr2 and Smad4 protein levels were increased in the Pten ${ }^{\mathrm{r} / \mathrm{r}}$, as shown by IHC. Additional components of the TGF- $\beta$ pathway were increased at the mRNA level as assessed by qRT-PCR in the Pten ${ }^{\mathrm{r} / \mathrm{r}}$ prostates. As shown in figure 13B, the ligand (Tgfb1), both receptors (Tgfbr1 and Tgfbr2) and Smads 2, 3 and 4 (although Smad2 was not significant) were increased at the transcript level. The protein levels for both Tgfbr2 and Smad4 were also assayed by western blot. As shown in figure 13C, both Tgfbr2 and Smad4 protein levels are increased in the Pten ${ }^{\mathrm{r} / \mathrm{r}}$ as compared to wild type. As a marker of pathway activation I western blotted for phospho-Smad2 (Ser465/467), which was increased in the $\operatorname{Pten}^{\mathrm{r} / \mathrm{r}}$ also. This is a good readout for pathway activity, since simple upregulation of the components of the TGF- $\beta$ pathway does not mean that the pathway is more active. Additionally, I stained sections for each genotype wild type, Tgfbr $2^{\mathrm{r} / \mathrm{r}}, \mathrm{Pten}^{\mathrm{r} / \mathrm{r}}$ and $\operatorname{Pten}^{\mathrm{r} / \mathrm{r}} ;$ Tgfbr $^{\mathrm{r} / \mathrm{r}}$ for phosho-Smad2 by immunofluorescence. The results are shown in figure 13D with the DAPI staining for each shown below. There appeared to be an increase in the phosphoSmad2 staining in the $\operatorname{Pten}^{\mathrm{r} / \mathrm{r}}$ and a decrease in the $\operatorname{Pten}^{\mathrm{r} / \mathrm{r}} ; \operatorname{Tgfbr}^{\mathrm{r} / \mathrm{r}}$. 
Figure 13. Expression of the TGF- $\beta$ pathway in Pten null mouse prostates. (A) IHC for Tgfbr 2 and Smad4 is shown for wild type and Pten ${ }^{\mathrm{r} / \mathrm{r}}$ prostates. (B) The mRNA expression levels for the indicated TGF- $\beta$ genes is shown for wild type and $\mathrm{Pten}^{\mathrm{r} / \mathrm{r}}$ prostates, as quantified by qRT-PCR. Relative expression is shown with the wild type normalized to 1 as the mean plus standard deviation. P-values were determined by Student's t-test $*=\mathrm{P}<0.05$, $* *=\mathrm{P}<0.01$. (C) Expression of Tgfbr2, Smad4, phospho-Smad2 (Ser465/467) and tubulin from 3 different animals of each genotype are shown by western blot on wild type and Pten ${ }^{\mathrm{r} / \mathrm{r}}$ prostates. (D) Prostate sections from the indicated genotypes were analyzed by IF for phospho-Smad2 as a marker of Smad activation. The nuclear DAPI stain is shown below for each. (E) Quantification of phospho-Smad2 IF staining is shown for the indicated genotypes as the nuclear intensity divided by the cytoplasmic intensity as selected by DAPI stain. Data are shown as box plots (median, 5th, 25th, 75th and 95th percentiles), with the P-values (determined by Student's t-test) for comparison of Pten null to control and Pten null to double null. 

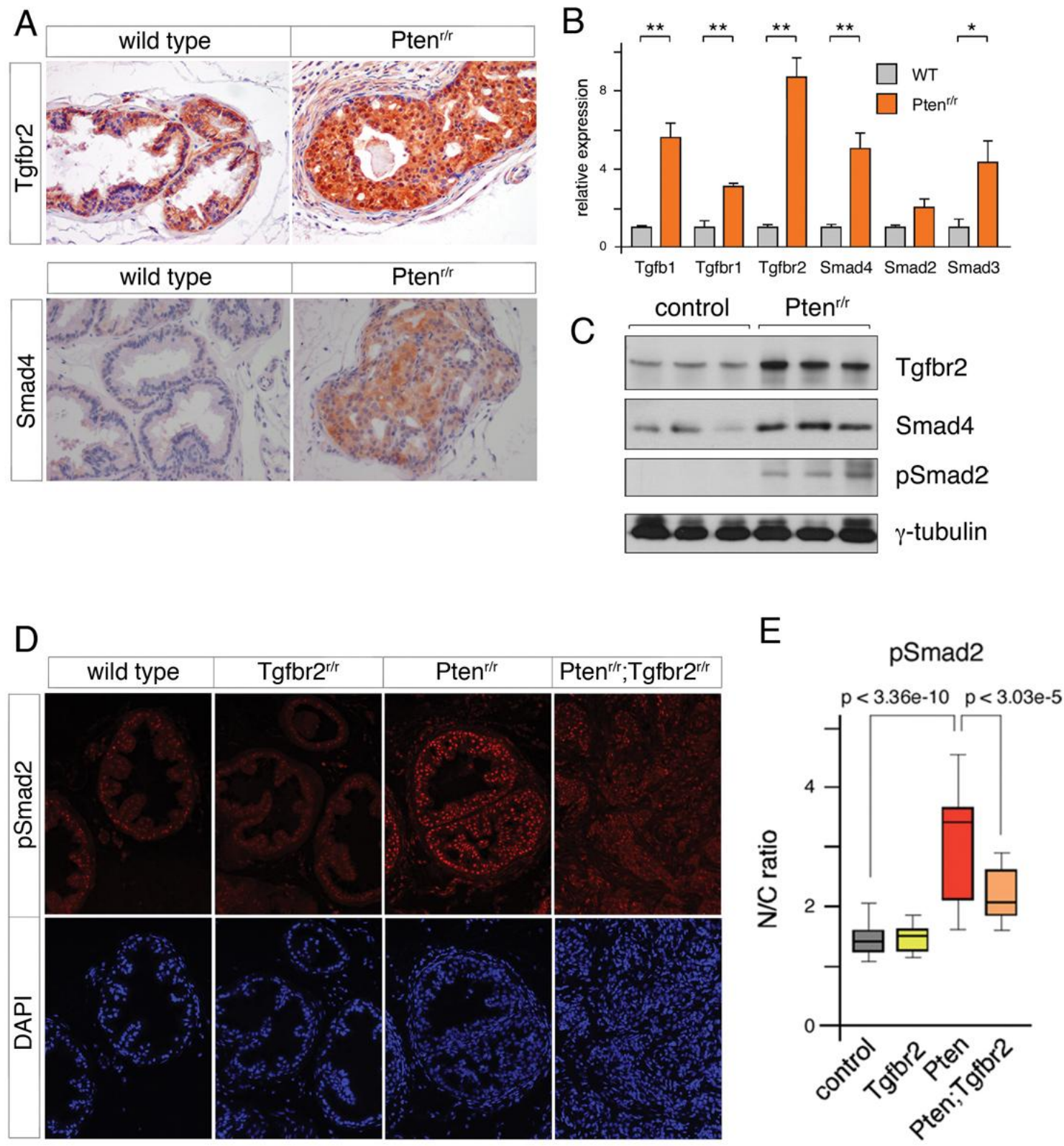
To verify this result, the mean nuclear intensity divided by the mean cytoplasmic intensity (N/C ratio) was quantified for each sample. The results are shown in figure 13E. In wild type and $\operatorname{Tgfbr} 2^{\mathrm{r} / \mathrm{r}}$ prostates there is low level staining, which is presumably background staining for the antibody, since there should not be any staining in the Tgfbr $2^{\mathrm{r} / \mathrm{r}}$. In the $\operatorname{Pten}^{\mathrm{r} / \mathrm{r}}$ there is a significant increase in the N/C ratio of $\mathrm{pSmad} 2$, as seen by western blot. As expected, the N/C ratio decreased in the Pten ${ }^{\mathrm{r} / \mathrm{r}} ; \operatorname{Tgfbr}^{\mathrm{r} / \mathrm{r}}$, however not down to the level seen in control or Tgfbr $2^{\mathrm{r} / \mathrm{r}}$ alone. This may be due to related receptors in the TGF- $\beta$ family that can still phosphorylate Smad2.

\subsubsection{The TGF- $\beta$ pathway is activated downstream of Akt}

Subsequently, we wanted to know whether loss of Tgfbr2 would accelerate a weaker oncogenic stimulus and whether the activation of the TGF- $\beta$ pathway was downstream of the important mediator of Pten deletion, Akt. Therefore, we utilized a transgenic line that uses the probasin promoter to drive expression of a myristoylated version of human Akt1 in the mouse prostate. This myristoylation tethers Akt1 to the membrane, leading to its constitutive activation by PDK-1. We refer to it as Tg-Akt in our paper, but the group that made it called it MPAKT (murine prostate restricted Akt kinase transgenic) ${ }^{94}$. We combined the Tg-Akt with $\mathrm{Pb}-\mathrm{Cre} 4$ mediated knockout of the Tgfbr2 floxed allele as used earlier. First, we examined the activation status of the TGF- $\beta$ pathway in the Tg-Akt only mice. As shown in figure 14A, Smad4 was upregulated at the protein level, as demonstrated by IHC. The Tg-Akt transgenic is not fully penetrant and some of the mice did not have significant activation of Akt or a phenotype. As shown in figure 14B, the Tg-Akt displayed in the left panel did not have significant activation of Akt, as shown by IHC for phospho-Akt(Ser473). This mouse also showed no upregulation of Smad4. However, shown in the right panel is a mouse that had significant activation of phosphoAkt and also upregulation of Smad4. I also did western blots for pathway components Tgfbr2, Smad4 and phospho-Smad2 as shown in figure 14C, all of which were elevated in the Tg-Akt as compared to the wild type. 
Figure 14. Induction of the TGF- $\beta$ pathway downstream of activated Akt. (A) IHC for Smad4 in a wild type and a Tg-Akt1 prostate. (B) IHC for Smad4 and phospho-Akt 473 are shown on a Tg-Akt1 without a phenotype (left) and with PIN phenotype (right). (C) Protein levels for Tgfbr2, Smad4, phospho-Smad2 and tubulin are shown by western blot on wild type and Tg-Akt1 prostates. (D) Quantification of IF for phospho-Smad2 is shown as the nuclear intensity divided by the cytoplasmic intensity for the indicated genotypes. Data are shown as box plots (median, 5th, 25th, 75th and 95th percentiles), with the P-values (determined by Student's ttest) shown for each one compared to wild type. (E) A Kaplan-Meier plot for Tg-Akt1 mice compared to Tg-Akt1; Tgfbr2 ${ }^{\mathrm{r} / \mathrm{r}}$ mice is shown with the P-value. (F) Tg-Akt1 and TgAkt1; $\operatorname{Tgfbr}^{\mathrm{r} / \mathrm{r}}$ ventral prostates were stained with H\&E (top) and by IHC for cyclin D (bottom). Two examples of Tg-Akt1;Tgfbr $2^{\mathrm{r} / \mathrm{r}}$ prostates are shown: one (right) shows invasive cancer and the other (center) has only HGPIN and is similar to the Tg-Akt1. (G) The phenotypes of Tgfbr ${ }^{\mathrm{r} / \mathrm{r}}$, Tg-Akt1 and Tg-Akt1;Tgfbr ${ }^{\mathrm{r} / \mathrm{r}}$ mice are shown grouped by age. Ventral prostates were stained by $H \& E$ and scored as normal, PIN, or invasive cancer. 


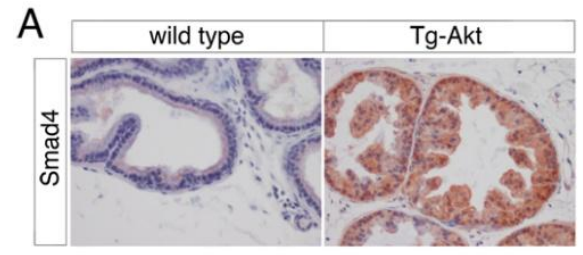

C

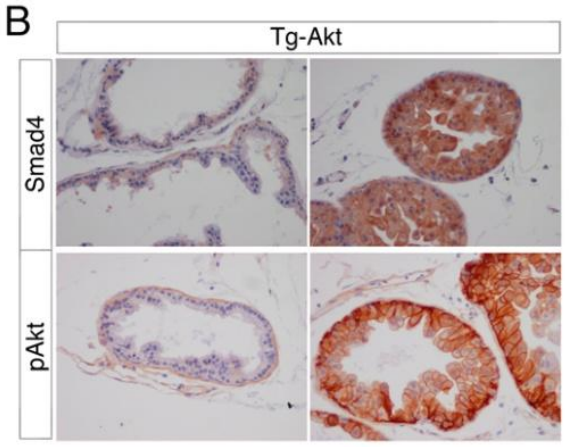

control Tg-Akt
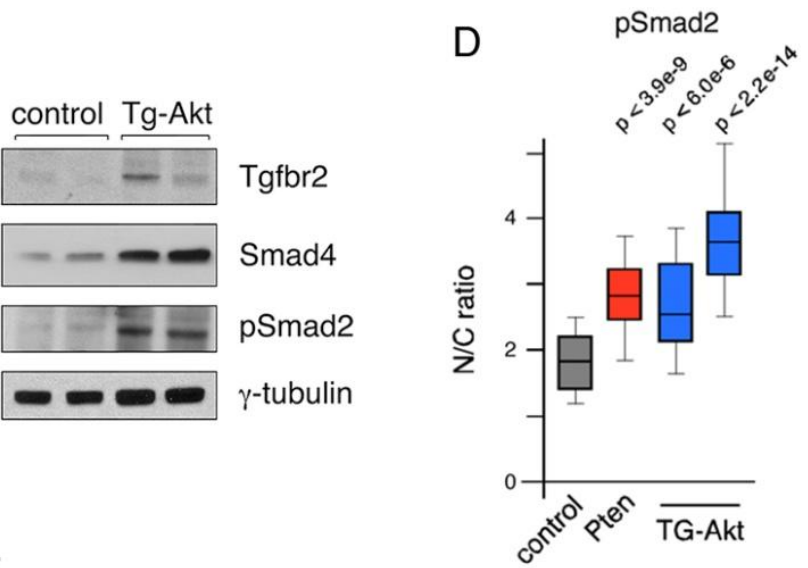

F
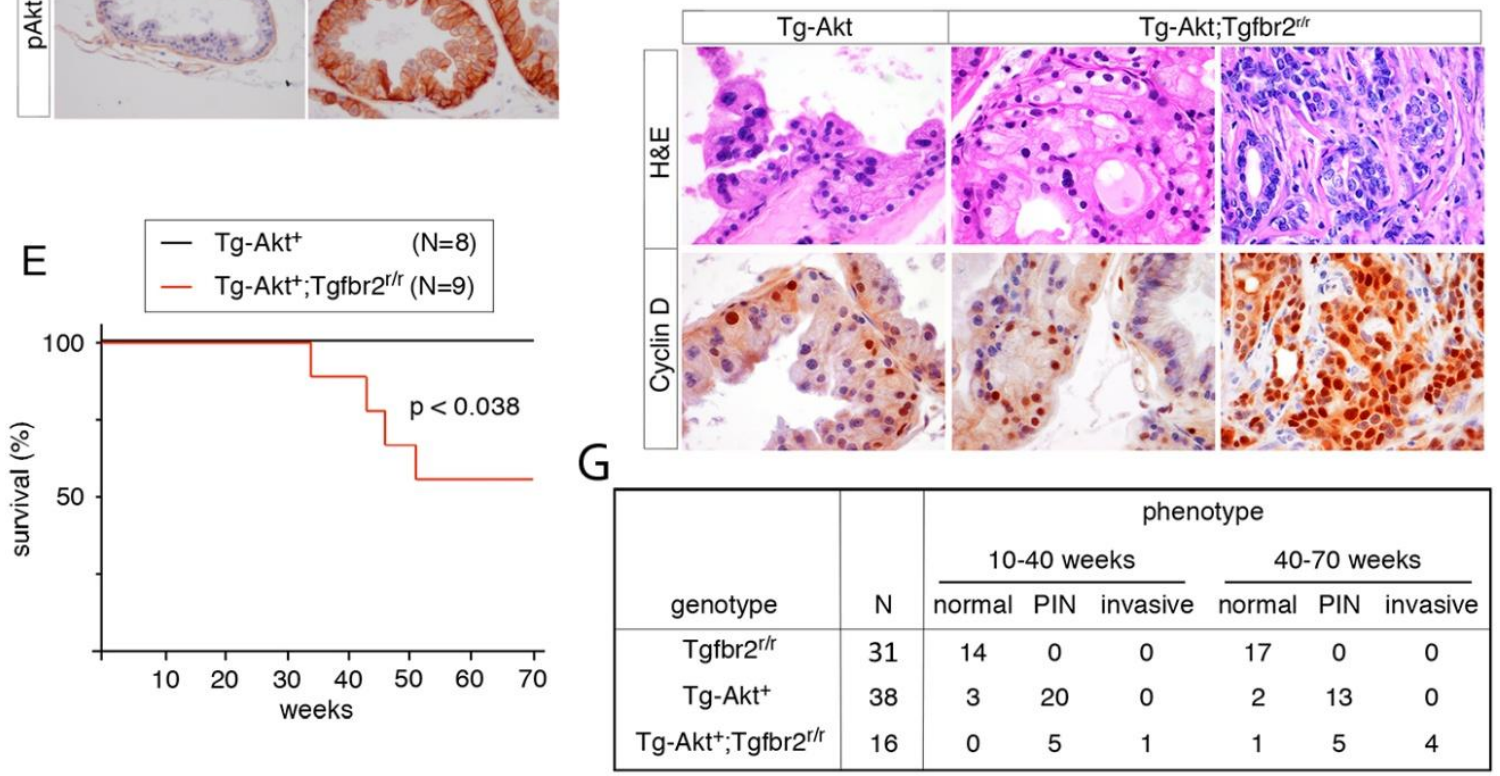
Immunofluorescence was also performed for phospho-Smad2 as described earlier for the Pten ${ }^{\mathrm{r} / \mathrm{r}}$ prostates. Again, I quantified the average nuclear to cytoplasmic intensity for each of $2 \mathrm{Tg}$-Akt and $\operatorname{Pten}^{\mathrm{r} / \mathrm{r}}$ as a positive control and compared them to wild type. Both of the Tg-Akts quantified had statistically significant elevated signal of phospho-Smad2 as compared to wild type, as shown in figure $14 \mathrm{D}$. This suggests that TGF- $\beta$ pathway components are also elevated in the Tg-Akt and the pathway is more active due to the phosphorylation of Smad2.

\subsubsection{Loss of Tgfbr2 cooperates with activated Akt to cause cancer}

The activated Akt transgenic is published to only result in the PIN phenotype ${ }^{94}$. As shown in figure 14E, eight Tg-Akt mice were maintained out to 70 weeks old and none of them needed to be euthanized for tumor burden. However, when recombination of Tgfbr2 is combined with the Tg-Akt, $44 \%$ of the mice needed to be euthanized before 70 weeks old. This clearly indicates that the combination of $\mathrm{Tg}-\mathrm{Akt}$ and $\mathrm{Tgfbr} 2$ recombination results in a more severe tumor phenotype than Tg-Akt alone.

We next characterized the tumors formed in Tg-Akt; Tgfbr $2^{\mathrm{r} / \mathrm{r}}$ mice versus Tg-Akt alone. Figure 14F shows H\&E stained sections for Tg-Akt alone and two different Tg-Akt; Tgfbr2 ${ }^{\text {r/r }}$ mice. The Tg-Akt;Tgfbr $2^{\mathrm{r} / \mathrm{r}}$ on the left only showed HGPIN and was similar to Tg-Akt. The TgAkt; Tgfbr $2^{\mathrm{r} / \mathrm{r}}$ shown on the right displays invasive cancer. Below the H\&E is IHC for cyclin D on sections from the same mice. The Tg-Akt and the Tg-Akt; Tgfbr $2^{\mathrm{r} / \mathrm{r}}$ with HGPIN look similar, but the Tg-Akt; Tgfbr ${ }^{\mathrm{r} / \mathrm{r}}$ with invasive cancer clearly has more cells that are cyclin D positive. Figure $14 \mathrm{G}$ shows a table of the number of mice with a given phenotype for each genotype and is also broken down further by age into younger (10-40 week) and older mice (40-70 week). All Tgfbr2 mice were normal, regardless of age. The majority of Tg-Akt mice had PIN at either age, but none had invasive cancer. In contrast, 1 of 6 younger Tg-Akt;Tgfbr $2^{\mathrm{r} / \mathrm{r}}$ developed invasive cancer at 33 weeks old and 4 out of 10 older Tg-Akt;Tgfbr $2^{\mathrm{r} / \mathrm{r}}$ had invasive cancer. These data 
clearly show that activation of the TGF- $\beta$ pathway is downstream of Akt and that in many cases, loss of Tgfbr2 is sufficient to change the phenotype of these mice from PIN to invasive cancer.

\subsubsection{Loss of Smad2 does not worsen the $\operatorname{Pten}^{\mathrm{r} / \mathrm{r}}$ phenotype}

I also bred mice for another prostate specific double knockout: Pten and Smad2. This was done again using the $\mathrm{Pb}-\mathrm{Cre} 4$ transgene to recombine floxed alleles of Pten and $\mathrm{Smad} 2$ in the prostate. We created these mice because the Pten \& Smad4 knockout has a phenotype similar to our Pten ${ }^{\mathrm{r} / \mathrm{r}} ; \operatorname{Tgfbr}^{\mathrm{r} / \mathrm{r} 95}$ and activation of Smad2 is seen downstream of Pten loss (as shown in figure 13C). Therefore, we believed that $\mathrm{Smad} 2$ was important for restraining tumor progression downstream of activated Akt. $18 \operatorname{Pten}^{\mathrm{r} / \mathrm{r}} ; \mathrm{Smad}^{\mathrm{r} / \mathrm{r}}$ mice were bred and then euthanized at time points where they could be compared to the $\operatorname{Pten}^{\mathrm{r} / \mathrm{r}}$. As shown in figure 15, the ratio of mice with PIN versus invasive cancer was approximately the same for $\operatorname{Pten}^{\mathrm{r} / \mathrm{r}}$ and $\operatorname{Pten}^{\mathrm{r} / \mathrm{r}} ; \operatorname{Smad}^{\mathrm{r} / \mathrm{r}}$. Additionally, ten $\mathrm{Smad}^{\mathrm{r} / \mathrm{r}}$ mice were bred and analyzed at 41-52 weeks old and they were all diagnosed as normal, which is similar to the Tgfbr $2^{\mathrm{r} / \mathrm{r}}$. We did not pursue examining these mice any further, because the additional loss of Smad2 did not seem to be causing an additional phenotype worth investigating.

\subsubsection{Proposed model of progression in $\operatorname{Pten}^{\mathrm{r} / \mathrm{r}} ; \operatorname{Tgfbr}^{\mathrm{r} / \mathrm{r}}$}

Figure 16 shows our model of how we hypothesize loss of Pten and TGF- $\beta$ signaling are cooperating to cause tumor progression in prostate cancer. Pten restrains Akt activity and possibly other factors (because the Pten ${ }^{\mathrm{r} / \mathrm{r}}$ phenotype is worse than activated Akt) that cause cell growth that progresses to PIN. However, Akt also activates TGF- $\beta$ signaling which restricts the progression from PIN to invasive cancer. If TGF- $\beta$ signaling growth restraint is lost, then PIN progresses to invasive cancer much more rapidly. There is also an arrow from PIN to TGF- $\beta$ signaling because we cannot rule out that the PIN phenotype itself activates TGF- $\beta$ signaling. 


\begin{tabular}{|c|c|cccc|}
\hline & & \multicolumn{4}{|c|}{ Phenotype } \\
Genotype & N & $\frac{31-40 \text { Weeks }}{\text { PIN }}$ & invasive & PI-70 Weeks \\
\hline Pten r/r & 18 & 3 & 3 & 7 & 5 \\
Pten r/r; Smad2 r/r & 18 & 2 & 2 & 12 & 2 \\
\hline
\end{tabular}

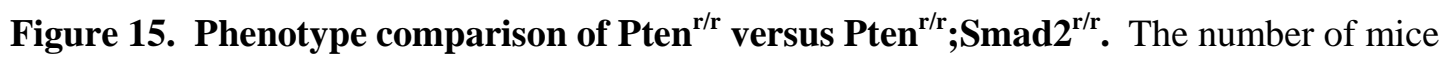
with each phenotype is shown by genotype and age for each $\operatorname{Pten}^{\mathrm{r} / \mathrm{r}}$ and $\operatorname{Pten}^{\mathrm{r} / \mathrm{r}} ; \operatorname{Smad}^{\mathrm{r} / \mathrm{r}}$. 
Figure 16. Diagram of proposed progression in our model. A proposed model is shown for our prostate cancer models whereby Pten loss efficiently initiates growth, which quickly become PIN. However, at this state some factor inhibits progression beyond PIN. We propose that Akt activates TGF- $\beta$ signaling, which keeps the cells from progressing to invasive cancer. If TGF- $\beta$ signaling is subsequently lost, the cells become cancerous. However, with our data we cannot rule out that the activation of the TGF- $\beta$ pathway is downstream of the PIN phenotype. 


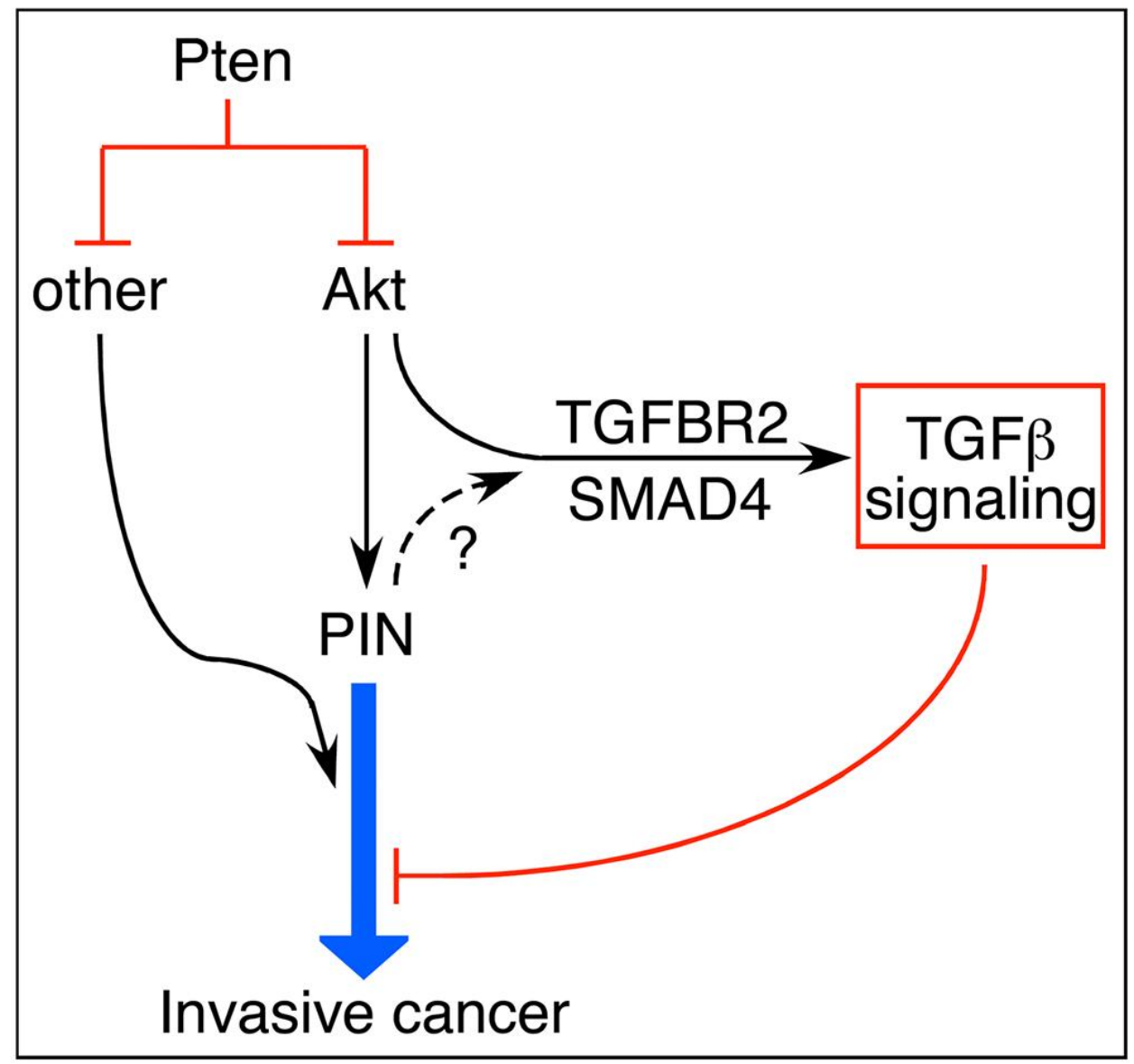




\subsection{Discussion}

I described above a novel model of prostate cancer that rapidly and reliably results in poorly differentiated prostate adenocarcinoma. Additionally, it does so with loss of only 2 endogenous genes. To the best of my knowledge, this mouse model of prostate cancer is the most rapid progression published. Our mice needed to be euthanized at a median of 88 days. Pten/Smad4 knockout mice had to be euthanized at a median of 160 days and even Pten/Smad4/p53 knockout mice survive to a median age of 119 days ${ }^{68}$. Additionally, our model resulted in lung metastases $45 \%$ of the time, while the Pten/Smad4 knockout had lung metastases $12 \%$ of the time (Admittedly, a lot of our lung metastases were quite small). Since our mice need to be euthanized for bladder obstruction, we think our model would be more metastatic if the mice survived longer. It is also interesting to note that that Pten null, Tgfbr2 heterozygotes are the most metastatic. This may be because the lower level of the TGF- $\beta$ signaling allows them to escape cell cycle blockade, but still gives them some metastatic advantage. This is not without precedent as a group published that a half dose of Smad3 allows breast cancer cells to escape from the cytostatic control of TGF- $\beta$ and made them more metastatic ${ }^{124}$. However, since the Pten null, Tgfbr2 heterozygotes survive much longer, it may just be that the cancer cells have longer to metastasize. Since researchers usually look for genes that are mostly or completely lost when looking for tumor suppressors, it is an interesting idea that it may be worse for patients to have a half dose of TGF- $\beta$ signaling than to lose it completely (since it is metastases that are usually deadly). Our model also indicates that loss of Tgfbr2 is not a cancer initiating event, because the $\operatorname{Tgfbr} 2^{\mathrm{r} / \mathrm{r}}$ animals are normal out to 70 weeks old. The acceleration of the Pten null phenotype by the loss of Tgfbr2, which has no phenotype by itself, is very interesting. Similarly, it has been shown that loss of p53 in the prostate has the same phenotype. Prostate specific p53 null mice up to 18 months old are indistinguishable from wild type. However, when combined in the prostate with loss of Pten, the loss of p53 greatly accelerates how quickly the mice develop 
tumors ${ }^{125}$. Therefore, Tgfbr2 and p53 presumably can only restrain tumors when there is a stimulus towards growth, such as upon loss of Pten.

Interestingly, our model varies from the Pten/Smad4 model in an overlooked way: our model should not be able to activate the TGF- $\beta$ type I receptor (since it is activated by Tgfbr2), while their model should still be capable of activating the type I receptor. This is important because a number of the oncogenic functions of the TGF- $\beta$ pathway are through the type I receptor and not Smads. Activated Tgfbr1 can phosphorylate ShcA, causing the downstream activation of Ras, which activates Erk. Erk is an important mediator of TGF- $\beta$ induced EMT ${ }^{44}$. Additionally, Tgfbr1 can activate the important mediators of MAPK signaling p38 and JNK. It does this through TAK1 (TGF- $\beta$ activated kinase 1). These factors play an important role in TGF- $\beta$ induced EMT and the regulation of apoptosis. Additionally, it is thought that TGF- $\beta$ signaling can activate the important mediators of cell movement RhoA and cdc42. The mechanism of this activation is less clear, but it was also shown to be Smad independent ${ }^{44}$.

Our Pten/Tgfbr2 null mice are already castration resistant, which may be attributable to the loss of Pten. However, many mouse models of prostate cancer use Pten knockout, and therefore would also already be resistant to castration. Consequently, any mouse model based on loss of Pten would not be useful to study the progression of prostate cancer to androgen independence. Also, any model with overexpression of an oncogene from an androgen responsive promoter cannot be used for castration experiments (such as Tg-Akt1), since loss of androgen will cause loss of transgene expression. A good model for the progression from androgen dependence to independence is still a necessity in the field of prostate cancer.

Finally, we proposed a novel feedback mechanism whereby loss of Pten induces the TGF- $\beta$ pathway to keep growth in check. This mechanism is based on our data showing upregulation of multiple components of the TGF- $\beta$ pathway and upregulation of activated Smad2 
in the Pten ${ }^{\mathrm{r} / \mathrm{r}}$. This model is also consistent with the loss of Pten effectively initiating tumors, but then progressing slowly from HGPIN to invasive cancer. Furthermore, we show that activation of the TGF- $\beta$ pathway is downstream of Akt1. This adds more justification to TGF- $\beta$ 's role as a tumor suppressor if it can respond to oncogenic stimuli and inhibit growth. However, our data do not rule out the possibility that activation of TGF- $\beta$ is due to the PIN phenotype. 


\section{Chapter 5}

\section{Loss of Tgfbr2 Also Promotes Rapid}

\section{Tumor Progression in Combination With}

Apc Knockout 


\subsection{Introduction}

We next examined whether loss of $T g f b r 2$ would cause prostate cancer in combination with another oncogenic stimulus. We chose Apc knockout because Wnt/ $\beta$-catenin signaling is important in many types of cancer, including prostate cancer, as discussed in the introduction. Additionally, we wanted to use an endogenous gene, not something exogenous, such as a viral oncogene. Furthermore, neoplasias in the $\mathrm{Apc}^{\mathrm{r} / \mathrm{r}}$ model regress upon castration when done before the mice develop advanced tumors ${ }^{97}$. We hypothesized that recombination of $T g f b r 2$ in addition to Apc would cause faster tumor growth. Additionally, we hypothesized that the further loss of $T g f b r 2$ would make the tumors metastatic. We obtained mice with an Apc floxed allele from the $\mathrm{NCI}$, which have loxP sites surrounding exon 14 of the $A p c$ gene. I crossed these mice to $\mathrm{Pb}$ $\mathrm{Cre}^{+} ; \mathrm{Tgfbr} 2^{\mathrm{f} / \mathrm{f}}$ mice and then intercrossed the offspring to make both $\mathrm{Pb}-\mathrm{Cre} 4^{+} ; \mathrm{Apc}{ }^{\mathrm{f} / \mathrm{f}}$ and $\mathrm{Pb}-$ $\mathrm{Cre}^{+} ; \mathrm{Apc}^{\mathrm{f} / \mathrm{f}} ; \mathrm{Tgfbr}^{\mathrm{f} / \mathrm{f}}$ mice. I show in this chapter that $\mathrm{Apc}^{\mathrm{r} / \mathrm{r}} ; \mathrm{Tgfbr}^{\mathrm{r} / \mathrm{r}}$ mice develop a rapid progression to adenosquamous carcinoma and that these tumors are metastatic to the lumbar lymph nodes and lungs. These cancers have increased cytoplasmic localization of $\beta$-catenin and lose almost all normal secretory duct organization. Similar to the $\operatorname{Pten}^{\mathrm{r} / \mathrm{r}} ; \mathrm{Tgfbr}^{\mathrm{r} / \mathrm{r}}$, the tumors also have increased staining for cyclin D and decreased staining for $\mathrm{p} 27$. Additionally, both the $\mathrm{Apc} \mathrm{c}^{\mathrm{r} / \mathrm{r}}$ and the $\operatorname{Pten}^{\mathrm{r} / \mathrm{r}}$ mice appear to be restrained by cellular senescence, which is bypassed in both of the double null tumors upon loss of $T g f b r 2$. This work shows that loss of $T g f b r 2$ causes a rapid progression to cancer with another oncogenic stimulus in addition to Akt activation. It also suggests that cellular senescence may be the mechanism by which $T g f b r 2$ is keeping tumor growth in check. 


\subsection{Results}

\subsubsection{Loss of Tgfbr2 cooperates with loss of Apc to cause invasive cancer}

As shown in figure $17 \mathrm{~A}, \mathrm{Apc}^{\mathrm{r} / \mathrm{r}}$ mice are viable out to 52 weeks, as previously published ${ }^{97}$. The majority of $\mathrm{Apc}^{\mathrm{r} / \mathrm{r}}$ mice up to 52 weeks old only develop HGPIN and not carcinoma (data not shown). However, the $\mathrm{Apc}^{\mathrm{r} / \mathrm{r}} ; \mathrm{Tgfbr}^{\mathrm{r} / \mathrm{r}}$ mice develop large tumors from their lateral and ventral prostate lobes and need to be euthanized before 30 weeks old. Figure 17A shows a comparative Kaplan-Meier plot for $\operatorname{Apc}^{\mathrm{r} / \mathrm{r}}, \operatorname{Pten}^{\mathrm{r} / \mathrm{r}}, \mathrm{Apc}^{\mathrm{r} / \mathrm{r}} ; \operatorname{Tgfbr}^{\mathrm{T} / \mathrm{r}}$ and Pten ${ }^{\mathrm{r} / \mathrm{r}} ; \operatorname{Tgfbr}^{\mathrm{r} / \mathrm{r}}$ mice. The $\mathrm{Apc}^{\mathrm{r} / \mathrm{r}} ; \mathrm{Tgfbr}^{\mathrm{r} / \mathrm{r}}$ take a little less than twice as long as the $\mathrm{Pten}^{\mathrm{r} / \mathrm{r}} ; \mathrm{Tgfbr}^{\mathrm{r} / \mathrm{r}}$ to develop carcinoma, which would be expected, since the $\operatorname{Pten}^{\mathrm{r} / \mathrm{r}}$ have a more aggressive phenotype than the $\mathrm{Apc}^{\mathrm{r} / \mathrm{r}}$ alone. Figure 17B shows the gross phenotype of the prostate for each genotype at the following ages: wild type (18 weeks), $\operatorname{Pten}^{\mathrm{r} / \mathrm{r}}\left(18\right.$ weeks), $\operatorname{Pten}^{\mathrm{r} / \mathrm{r}} ; \operatorname{Tgfbr}^{\mathrm{r} / \mathrm{r}}\left(12.6\right.$ weeks), two ages of $\mathrm{Apc}^{\mathrm{r} / \mathrm{r}}$

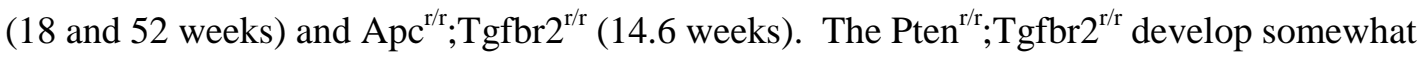
smaller, hard tumors, while the $\mathrm{Apc}^{\mathrm{r} / \mathrm{r}}$; $\mathrm{Tgfbr}^{\mathrm{r} / \mathrm{r}}$ develop larger, softer tumors. Figure $17 \mathrm{C}$ shows the median and mean survival, and the number and percentage of lymph node (LN) and lung metastases found. We saw a lower frequency of both lymph node and lung metastases in the $\mathrm{Apc}^{\mathrm{r} / \mathrm{r}} ;$ Tgfbr $^{\mathrm{r} / \mathrm{r}}$ compared to the Pten ${ }^{\mathrm{r} / \mathrm{r}} ; \mathrm{Tgfbr}^{\mathrm{r} / \mathrm{r}}$. These data show that loss of $T g f b r 2$ also causes a rapid progression to cancer in an $A p c$ null background. In addition, loss of $T g f b r 2$ makes these tumors metastatic, as the Williams group reported not finding any metastases in their publication on $A p c$ knockout in the mouse prostate ${ }^{97}$.

\subsubsection{Comparative histology between Pten null and Apc null based models}

Next we examined the histology of the $\mathrm{Apc}^{\mathrm{r} / \mathrm{r}}$ and $\mathrm{Apc} \mathrm{c}^{\mathrm{r} / \mathrm{T}} ; \mathrm{Tgfbr}^{\mathrm{r} / \mathrm{r}}$ as compared to the $\operatorname{Pten}^{\mathrm{r} / \mathrm{r}}$ based model. As shown in figure $18, \mathrm{Apc}^{\mathrm{r} / \mathrm{r}}$ prostates also display HGPIN, but at a later age (the one shown was from a 36 week old mouse). However, the $\mathrm{Apc}^{\mathrm{r} / \mathrm{r}} \mathrm{HGPIN}$ differs from the $\operatorname{Pten}^{\mathrm{r} / \mathrm{r}}$, as it displays adenosquamous differentiation, in line with previously published data. 
Figure 17. Tgfbr2 knockout accelerates prostate cancer progression in an Apc knockout background. (A) A Kaplan-Meier survival curve is shown for each genotype as indicated. The number of animals for each is shown on the right. The $\mathrm{p}$-value is shown for $\mathrm{Apc}^{\mathrm{r} / \mathrm{r}} ; \mathrm{Tgfbr}^{\mathrm{r} / \mathrm{r}}$ versus $\operatorname{Pten}^{\mathrm{r} / \mathrm{r}} ; \mathrm{Tgfbr}^{\mathrm{r} / \mathrm{r}}$ and for $\mathrm{Apc}^{\mathrm{r} / \mathrm{r}} ; \operatorname{Tgfbr}^{\mathrm{r} / \mathrm{r}}$ and $\mathrm{Pten}^{\mathrm{r} / \mathrm{r}} ; \mathrm{Tgfbr}^{\mathrm{r} / \mathrm{r}}$ relative to each one's single knockout without Tgfbr2, as calculated by log-rank test. (B) Gross anatomy of the prostate tumors is shown for each at the following ages: WT (18 weeks), Pten ${ }^{\mathrm{r} / \mathrm{r}}(18$ weeks),

$\operatorname{Pten}^{\mathrm{r} / \mathrm{r}} ; \operatorname{Tgfbr}^{\mathrm{r} / \mathrm{r}}$ (12.6 weeks), Apc ${ }^{\mathrm{r} / \mathrm{r}}$ (18 weeks), Apc ${ }^{\mathrm{r} / \mathrm{r}}$ (52 weeks) and $\mathrm{Apc}^{\mathrm{r} / \mathrm{r}} ; \operatorname{Tgfbr}^{\mathrm{r} / \mathrm{r}}(14.6$ weeks). (C) The survival data for each of the double nulls is shown, along with a summary of metastases to lumbar lymph nodes (LN) and lung. 

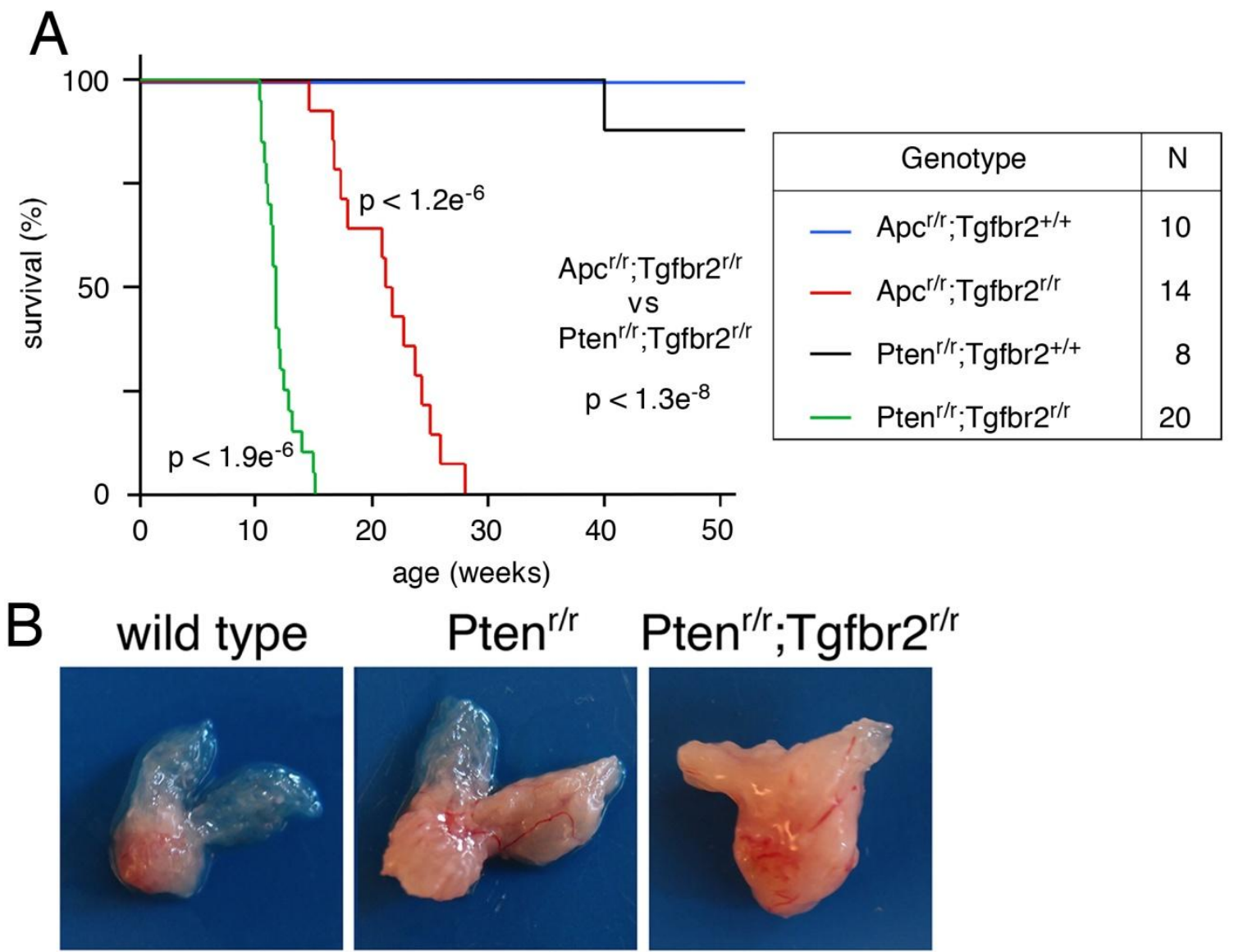

Pten $^{r / r} \quad$ Pten $^{r / r} ;$ Tgfbr2 $^{r / r}$

$\mathrm{Apc}^{\mathrm{r} / \mathrm{r}}$
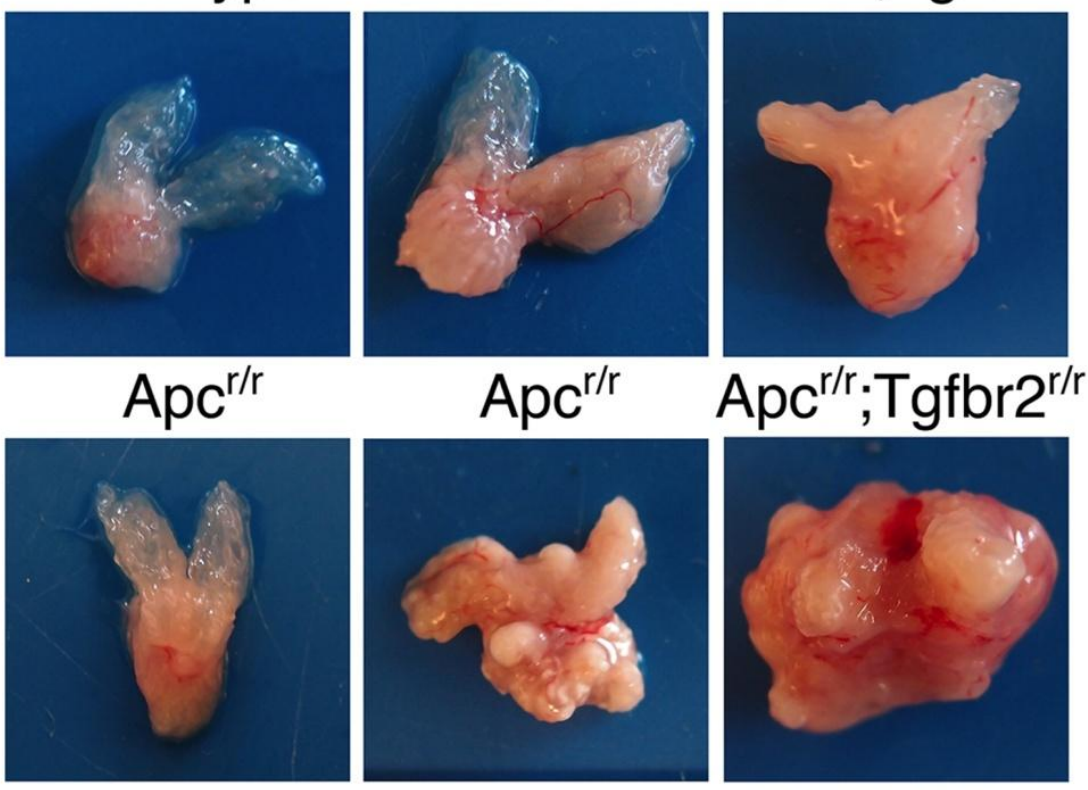

$\mathrm{Apc}^{\mathrm{r} / \mathrm{r}} ; \mathrm{Tgfbr}^{\mathrm{r} / \mathrm{r}}$

C
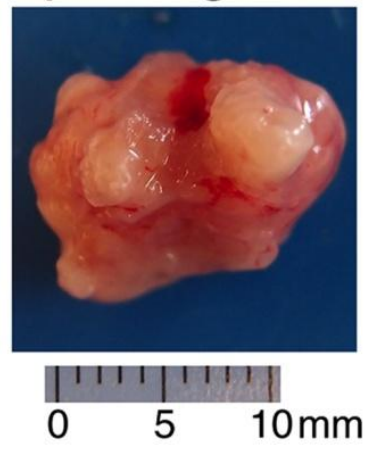

\begin{tabular}{|c|c|cc|cc|}
\hline \multicolumn{2}{|c|}{} & \multicolumn{2}{c|}{ Survival (days) } & \multicolumn{2}{c|}{ Metastases } \\
\hline Genotype & N & Median & Mean (sd) & LN & Lung \\
\hline Apc $^{r / r} ;$ Tgfbr2 $^{r / r}$ & 15 & 151 & $149(26)$ & $3(20 \%)$ & $1(7 \%)$ \\
Pten $^{r / r} ;$ Tgfbr2 $^{r / r}$ & 20 & 82 & $83(9)$ & $12(60 \%)$ & $8(40 \%)$ \\
\hline
\end{tabular}


Histology of the $\mathrm{Apc}^{\mathrm{r} / \mathrm{r}}$; $\mathrm{Tgfbr}^{\mathrm{r} / \mathrm{r}}$ shows clear loss of almost any organization in the prostate and carcinoma. However, whereas the $\operatorname{Pten}^{\mathrm{r} / \mathrm{r}} ; \operatorname{Tgfbr}^{\mathrm{r} / \mathrm{r}}$ carcinoma was classified as poorly differentiated, Dr. Frierson classified the $\mathrm{Apc}^{\mathrm{r} / \mathrm{r}} ; \mathrm{Tgfbr}^{\mathrm{r} / \mathrm{r}}$ as adenosquamous carcinoma, in line with the adenosquamous differentiation of the $\mathrm{Apc}^{\mathrm{r} / \mathrm{r}}$ alone. Therefore, neoplasia in both the $\operatorname{Pten}^{\mathrm{r} / \mathrm{r}}$ and the $\mathrm{Apc}^{\mathrm{r} / \mathrm{r}}$ can be accelerated by loss of Tgfbr2, but interestingly they result in different histological presentations, due to the squamous differentiation seen upon loss of Apc.

\subsubsection{Trichrome staining of Pten null and Apc null based models}

Next, sections from each genotype were analyzed by Masson's trichrome staining. Trichrome is a series of dyes that stains collagen blue and all other cellular components red. It is used to examine the amount of stroma within tumors. As shown in figure 19, wild type mouse prostates do not have much stroma and Tgfbr $2^{\mathrm{r} / \mathrm{r}}$ may increase the amount of stroma slightly. In both $\operatorname{Pten}^{\mathrm{r} / \mathrm{r}}$ and $\mathrm{Apc}^{\mathrm{r} / \mathrm{r}}$ mice there is an increase in the amount of blue staining in the stroma, indicating increased collagen, but it is clear that the ducts are still intact. However, in both of the double nulls, there is a clear comingling of the epithelial and stromal layers. The increase in stroma interaction is certainly interesting and is most likely changing signaling to the epithelial tumor cells. However, we have not yet examined what effect this may be having.

\subsubsection{Characterization of $\beta$-catenin and CollagenIV in Pten null and Apc null based models}

We also examined other important components of tumor progression in conjunction with stroma markers. Figure 20 shows immunofluorescence for $\beta$-catenin (green) and CollagenIV (red). $\quad \beta$-catenin is not known as an epithelial marker, but from our staining, appears to be mainly in the epithelial cells. We stained for $\beta$-catenin because it is an important driver of cancer progression, especially in the $\mathrm{Apc}^{\mathrm{r} / \mathrm{r}}$. 
Figure 18. Comparative histology of Pten null and Apc null models. H\&E stained sections are shown for all of the six genotypes. Ages for each are as follows: Wild type- 21 weeks old, Pten $^{\mathrm{r} / \mathrm{r}}-22$ weeks old, APC ${ }^{\mathrm{r} / \mathrm{r}}-36$ weeks old, Tgfbr $2^{\mathrm{r} / \mathrm{r}}-70$ weeks old, $\operatorname{Pten}^{\mathrm{r} / \mathrm{r}} ; \operatorname{Tgfbr}^{\mathrm{r} / \mathrm{r}}-11$ weeks old, $\mathrm{Apc}^{\mathrm{r} / \mathrm{r}} ; \mathrm{Tgfbr}^{\mathrm{r} / \mathrm{r}}-17$ weeks old. 


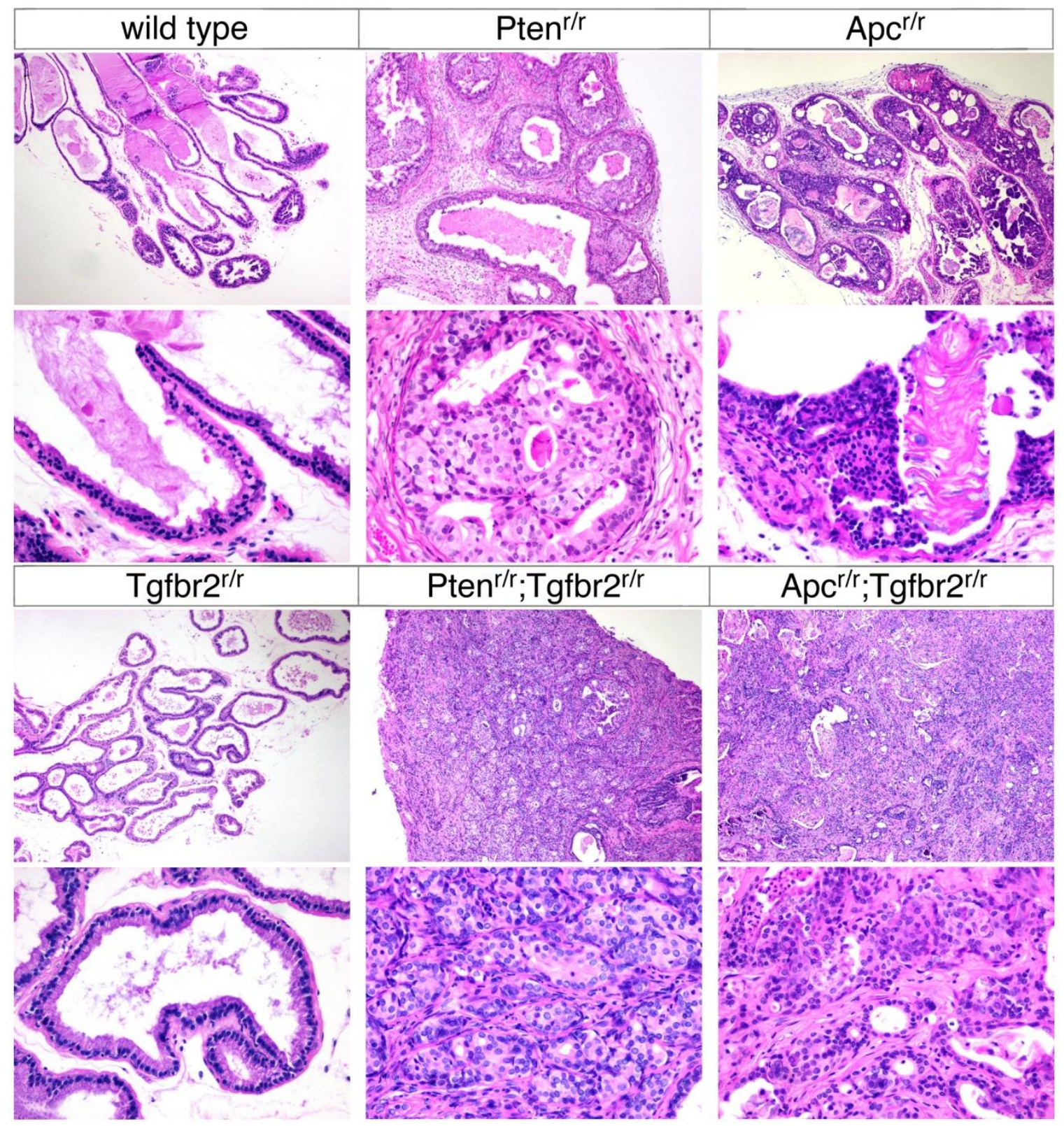


Figure 19. Trichrome staining on the set of 6 genotypes. Trichrome staining was performed on the set of 6 genotypes to examine the epithelial and stromal structure. Ages for each section are as follows: Wild type- 25 weeks old, Tgfbr $2^{\mathrm{r} / \mathrm{r}}-18$ weeks old, Pten $^{\mathrm{r} / \mathrm{r}}-18$ weeks old, $\operatorname{Pten}^{\mathrm{r} / \mathrm{r}} ; \operatorname{Tgfbr}^{\mathrm{r} / \mathrm{r}}-12$ weeks old, APC ${ }^{\mathrm{r} / \mathrm{r}}-36$ weeks old, $\mathrm{Apc}^{\mathrm{r} / \mathrm{r}} ; \operatorname{Tgfbr}^{\mathrm{r} / \mathrm{r}}-17$ weeks old. 


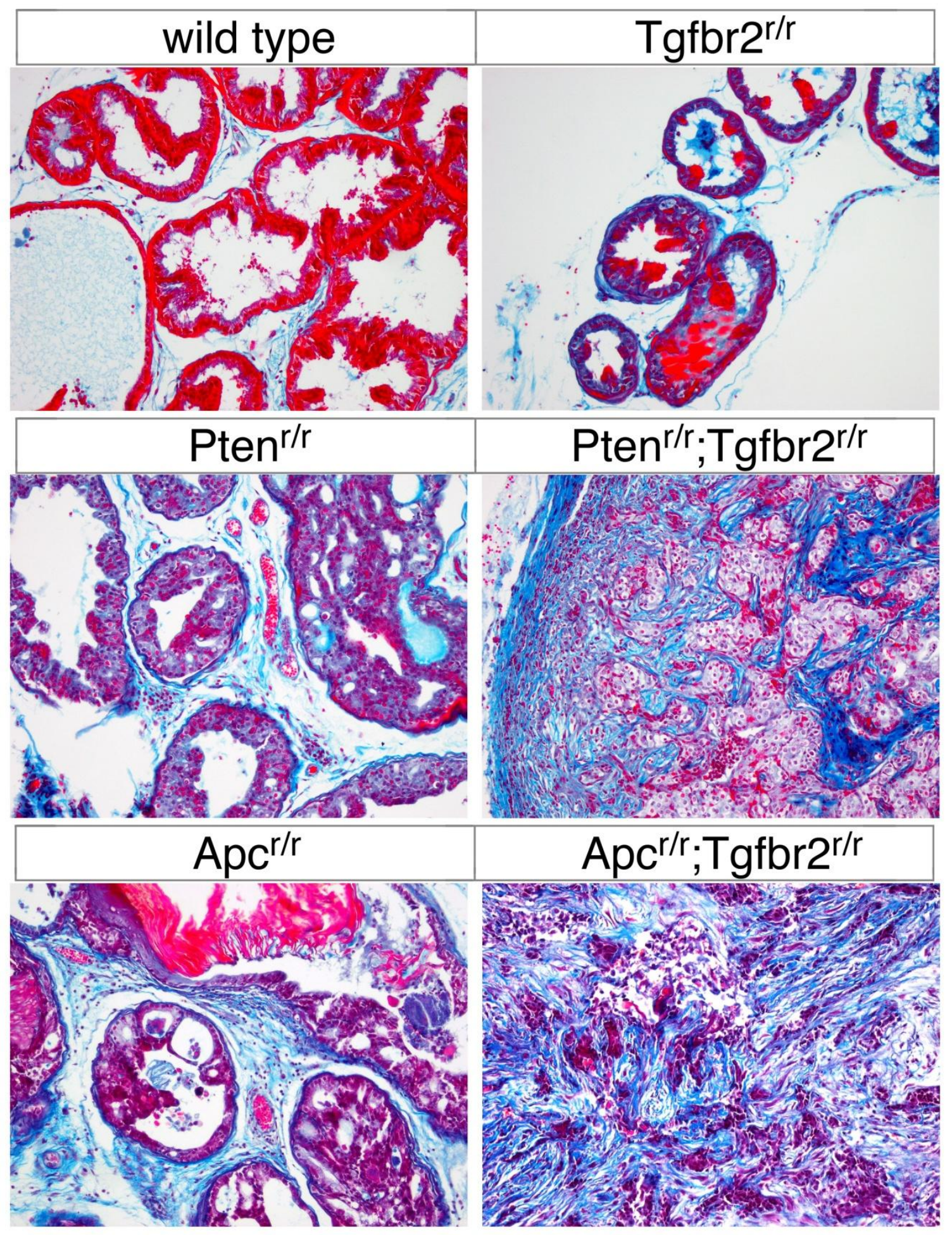


In the Pten ${ }^{\mathrm{r} / \mathrm{r}}$ and $\mathrm{Pten}^{\mathrm{r} / \mathrm{r}} ; \mathrm{Tgfbr}^{\mathrm{r} / \mathrm{r}}$ samples, $\beta$-catenin is well localized to the cell membrane and may be increased in the $\operatorname{Pten}^{\mathrm{r} / \mathrm{r}}$ (also shown by western blot in figure 22) and the $\operatorname{Pten}^{\mathrm{r} / \mathrm{r}}$ Tgfbr $2^{\mathrm{r} / \mathrm{r}}$. In the $\mathrm{Apc}^{\mathrm{r} / \mathrm{r}}$ and $\mathrm{Apc}^{\mathrm{r} / \mathrm{r}} ; \mathrm{Tgfbr}^{\mathrm{r} / \mathrm{r}}$ samples, $\beta$-catenin levels appear to be increased and in most of the cells it is not well localized to the cell membrane. Collagen IV staining marks a clear boundary around the epithelial layer in wild type, Tgfbr2 $2^{\mathrm{r} / \mathrm{r}}, \mathrm{Pten}^{\mathrm{r} / \mathrm{r}}$ and $\mathrm{Apc}^{\mathrm{r} / \mathrm{r}}$. However, in the $\operatorname{Pten}^{\mathrm{r} / \mathrm{r}} ; \operatorname{Tgfbr}^{\mathrm{r} / \mathrm{r}}$ and $\mathrm{Apc}^{\mathrm{r} / \mathrm{r}} ; \operatorname{Tgfbr}^{\mathrm{r} / \mathrm{r}}$, it is again apparent from the CollagenIV staining how much breakdown of the basement membrane there is and how much stroma becomes mixed in with the carcinoma cells. These data show that $\beta$-catenin is upregulated by Apc loss, and that it becomes mislocalized from cell membrane. It also reaffirms previous data that the boundary between the epithelial layer and the stroma is being broken down.

\subsubsection{Characterization of FoxA1 and Sma in Pten null and Apc null based models}

As shown in figure 21, we next examined Foxa1 (shown in red) along with smooth muscle action (Sma, shown in green), by immunofluorescence. Foxa1 is a known epithelial marker of prostate ducts, which we combined with Sma, a marker of the smooth muscle layer that surrounds each prostate duct. Wild type and $\mathrm{Tgfbr} 2^{\mathrm{r} / \mathrm{r}}$ prostate ducts are formed of a layer of epithelial cells, marked by Foxa1, surrounded completely by a layer of smooth muscle, shown by Sma. However, the Foxa1 antibody may not be entirely specific because it does appear to mark some cells in the stroma. In Pten ${ }^{\mathrm{r} / \mathrm{r}}$ prostates the Sma staining does not surround the duct as completely and there is slight staining within the duct. Within PDA in the $\operatorname{Pten}^{\mathrm{r} / \mathrm{r}} ; \operatorname{Tgfbr}^{\mathrm{r} / \mathrm{r}}$ there is almost complete loss of Sma staining. The image shown has slight staining around a duct still,

but most of the PDA is devoid of Sma. The bottom left panel shows $\mathrm{Apc}^{\mathrm{r} / \mathrm{r}}$ ducts, which also have less Sma, and some areas of the ducts have lost complete enclosure. Similarly to the Pten/Tgfbr2 double null, the $\mathrm{Apc}^{\mathrm{r} / \mathrm{r}} ; \mathrm{Tgfbr}^{\mathrm{r} / \mathrm{r}}$ carcinomas completely lose the smooth muscle layer that encompasses ducts. 
Figure 20. Immunofluorescence for $\beta$-catenin and CollagenIV in 6 genotypes.

Immunofluorescence is shown for $\beta$-catenin (green) and CollagenIV (red) on sections of each of the 6 genotypes. Ages are as follows: Wild type- 21 weeks old, Tgfbr $2^{\mathrm{r} / \mathrm{r}}-44$ weeks old, Pten ${ }^{\mathrm{r} / \mathrm{r}}-$ 21 weeks old, Pten $^{\mathrm{r} / \mathrm{r}} ; \mathrm{Tgfbr}^{\mathrm{r} / \mathrm{r}}-11$ weeks old, $\mathrm{APC}^{\mathrm{r} / \mathrm{r}}-36$ weeks old, $\mathrm{Apc}^{\mathrm{r} / \mathrm{r}} ; \mathrm{Tgfbr}^{\mathrm{r} / \mathrm{r}}-24$ weeks old. Done with the help of Karolina Pietrzak. 
wild type

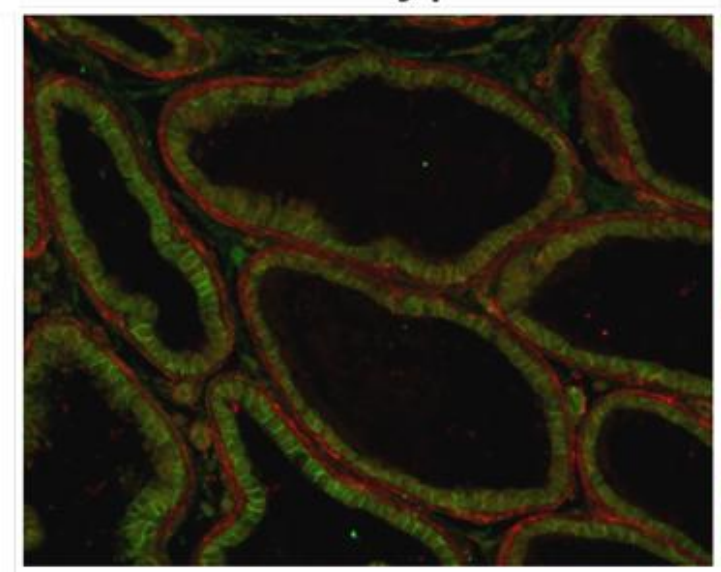

Pten $^{r / r}$

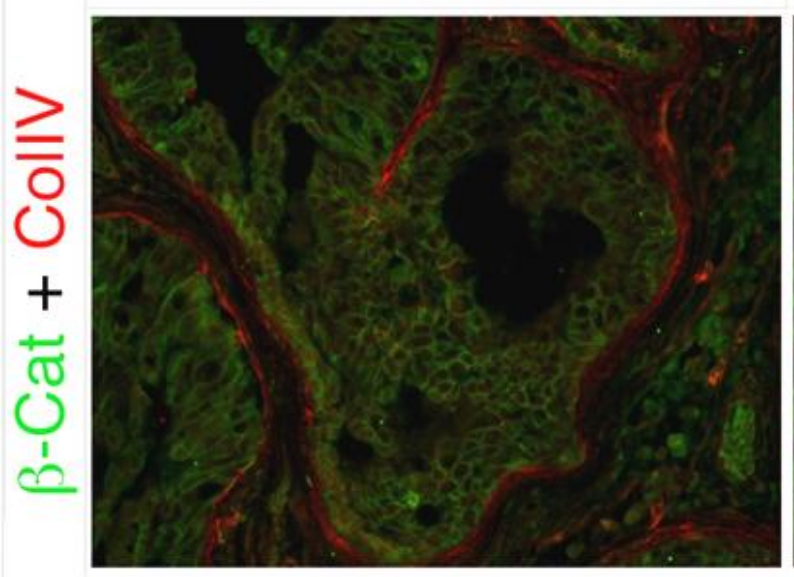

$\mathrm{Apc}^{\mathrm{r} / \mathrm{r}}$

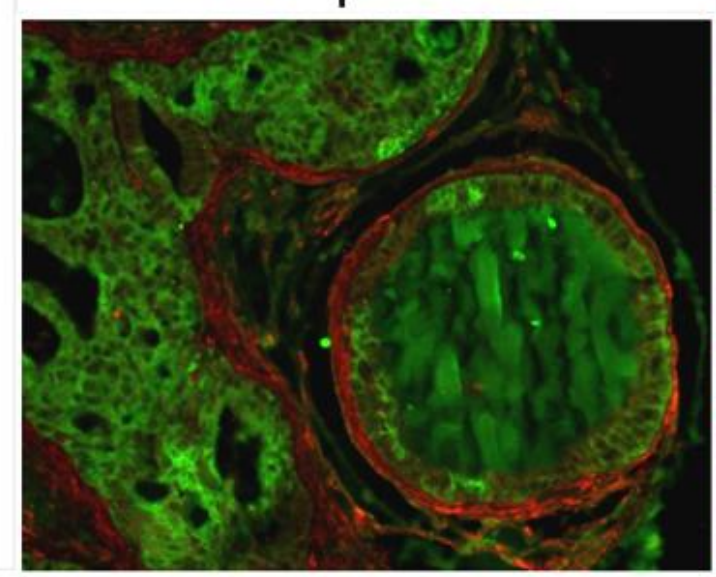

Tgfbr2 $^{r / r}$

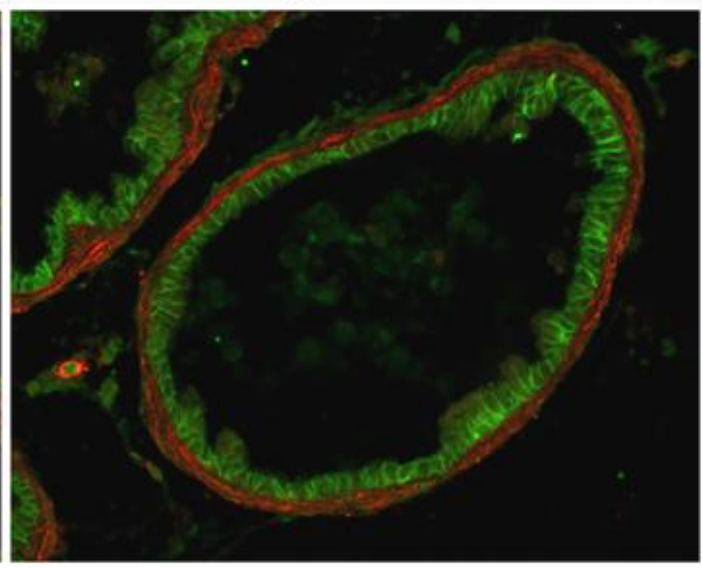

Pten $^{r / r} ;$ Tgfbr2 $^{r / r}$

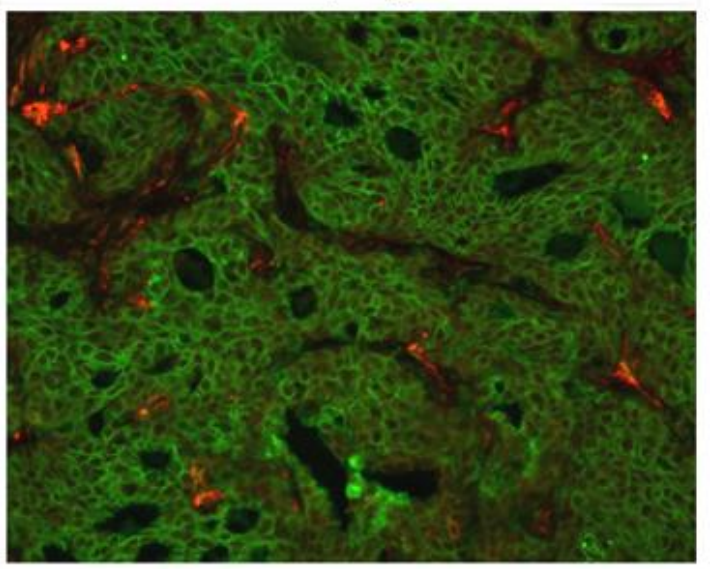

$\mathrm{Apc}^{\mathrm{r} / \mathrm{r}} ; \mathrm{Tgfbr}^{\mathrm{r} / \mathrm{r}}$

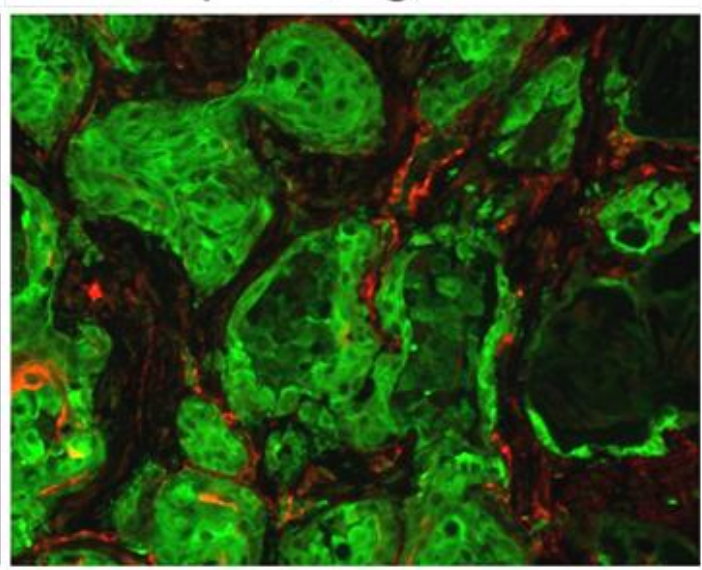


Figure 21. Immunofluorescence for FoxA1 and Sma (Smooth muscle actin) in 6 genotypes.

FoxA1 (red) and Sma (green) staining is shown by immunofluorescence on each of the 6 genotypes. Ages are as follows: Wild type- 21 weeks old, Tgfbr $2^{\mathrm{r} / \mathrm{r}}-44$ weeks old, Pten $^{\mathrm{r} / \mathrm{r}}-21$ weeks old, Pten ${ }^{\mathrm{r} / \mathrm{r}} ; \mathrm{Tgfbr}^{\mathrm{r} / \mathrm{r}}-11$ weeks old, $\mathrm{Apc}^{\mathrm{r} / \mathrm{r}}-36$ weeks old, $\mathrm{Apc}^{\mathrm{r} / \mathrm{r}} ; \mathrm{Tgfbr}^{\mathrm{r} / \mathrm{r}}-24$ weeks old. Done with the help of Karolina Pietrzak. 


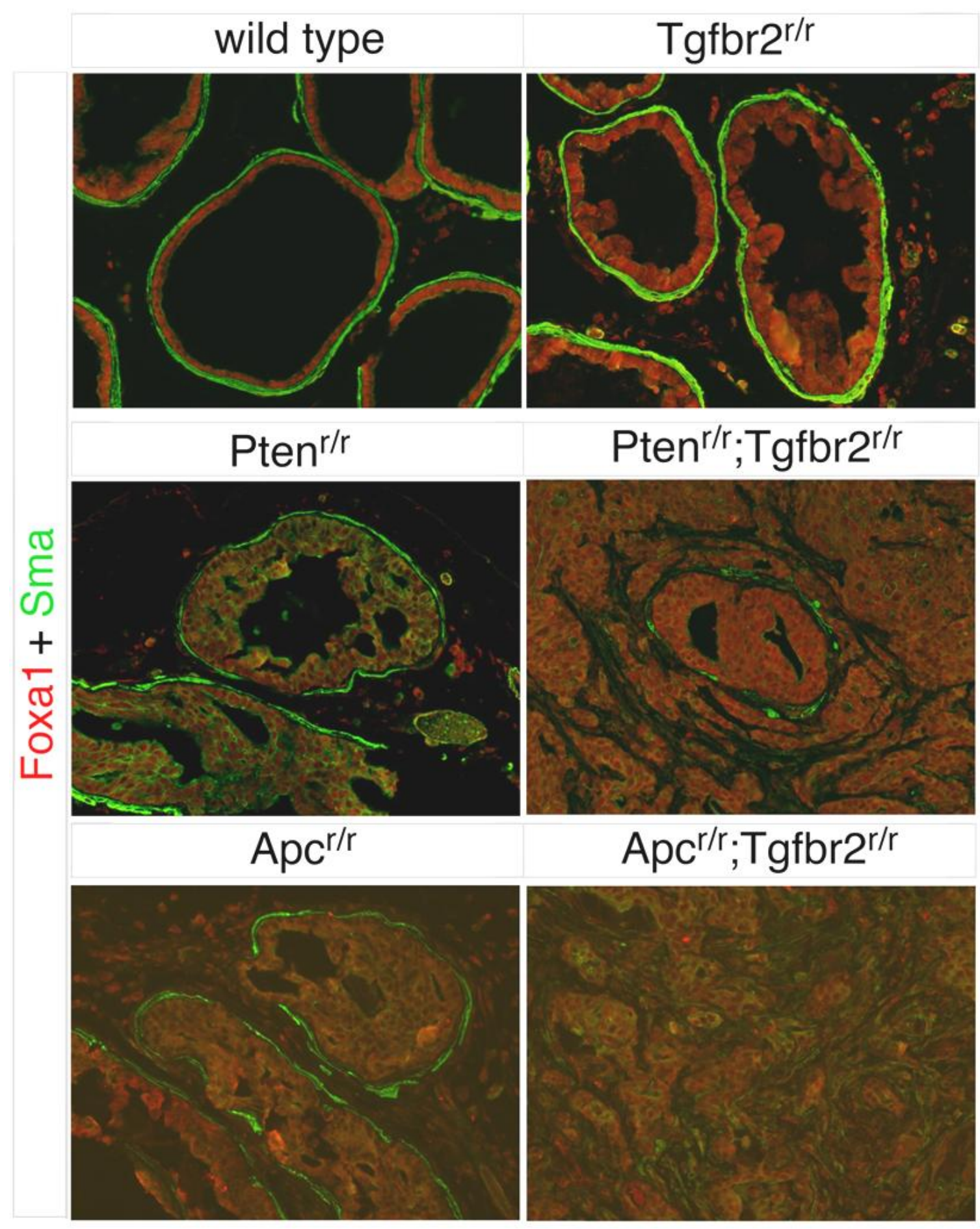


Together, these data show the tumors from both Apc and Pten double nulls lose their epithelial structure and their smooth muscle layer. Both of these traits are indicative of advanced disease and reliably occur in these models.

\subsubsection{Comparison of protein levels for key components of the Apc, Pten and TGF- $\beta$ pathways}

Next, protein expression was analyzed for components important for tumor progression in the $\mathrm{Apc}^{\mathrm{r} / \mathrm{r}}$ and $\mathrm{Pten}^{\mathrm{r} / \mathrm{r}}$. This was done by western blot on the ventral prostates of 3 wild type, 3 $\mathrm{Apc}^{\mathrm{r} / \mathrm{r}}$ and $3 \operatorname{Pten}^{\mathrm{r} / \mathrm{r}}$. $\beta$-catenin was assayed because it should be increased in the Apc $\mathrm{Ac}^{\mathrm{r} / \mathrm{r}}$. Also, it has been published that Akt phosphorylates GSK-3 and inhibits it ${ }^{48}$, so we wondered whether $\beta$ catenin protein levels would be increased in the $\operatorname{Pten}^{\mathrm{r} / \mathrm{r}}$. As shown in figure 22, $\beta$-catenin protein levels appear to be increased a small amount in both the $\mathrm{Apc}^{\mathrm{r} / \mathrm{r}}$ and $\operatorname{Pten}^{\mathrm{r} / \mathrm{r}}$. Subsequently, these lysates were analyzed for phospho-Akt(Ser473) as a marker for active Akt. As expected, Akt was activated in the $\operatorname{Pten}^{\mathrm{r} / \mathrm{r}}$, but did not appear to be activated in the $\mathrm{Apc}^{\mathrm{r} / \mathrm{r}}$. Next, protein levels of the androgen receptor (Ar) were assayed. Protein expression of the androgen receptor appeared to decrease in the $\mathrm{Apc}^{\mathrm{r} / \mathrm{r}}$. $\beta$-catenin is known to interact with the androgen receptor and affect its transcriptional activity ${ }^{126}$. Therefore, it seems that the most likely explanation for the decrease in androgen receptor expression in the $\mathrm{Apc}^{\mathrm{r} / \mathrm{r}}$ is due to the squamous differentiation. Next, components of the TGF- $\beta$ pathway were assayed to examine if they were increased in the $\mathrm{Apc}^{\mathrm{r} / \mathrm{r}}$, as in the Pten ${ }^{\mathrm{r} / \mathrm{r}}$. In these blots, the components of the TGF- $\beta$ pathway which were increased in the $\operatorname{Pten}^{\mathrm{r} / \mathrm{r}}$, namely Tgfbr2, Smad4 and pSmad2, do not appear to increase in the Apc ${ }^{\mathrm{r} / \mathrm{r}}$. A loading control, gamma-tubulin, is shown for all the blots of figure 22 at the bottom. Therefore, it is possible that $\beta$-catenin may be driving oncogenesis of both these models. Additionally, the TGF$\beta$ pathway is not activated in response to the PIN phenotype when driven by loss of $A p c$. 
Figure 22. Comparison of protein levels for key components of the Apc, Pten and TGF- $\beta$ pathways. Western blots are shown of lysates made from the ventral prostates of 3 wild type, 3 $\mathrm{Apc}^{\mathrm{r} / \mathrm{r}}$ and $3 \mathrm{Pten}^{\mathrm{r} / \mathrm{r}}$ mice as indicated. The blots shown from top to bottom are for $\beta$-catenin, phospho-Akt1(Ser473), Androgen receptor (Ar), Tgfbr2, Smad4, phospho-Smad2(Ser465/467) and gamma-tubulin. Wild type samples are from either 42 or 52 week old mice. Apc ${ }^{\mathrm{r} / \mathrm{r}}$ lysates are from 52 week old mice and Pten ${ }^{\mathrm{r} / \mathrm{r}}$ lysates are from 42 week old mice. 


\section{WT Apc ${ }^{r / r}$ Pten $^{r / r}$}

- - - -Cat

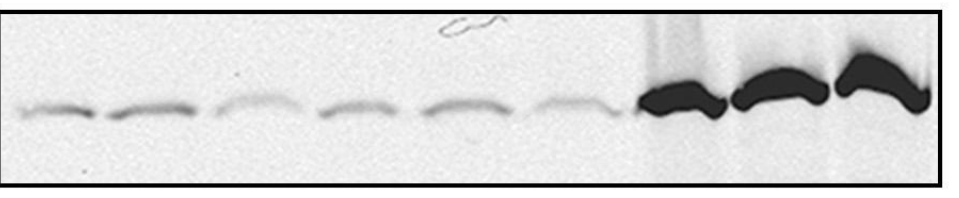

p-Akt

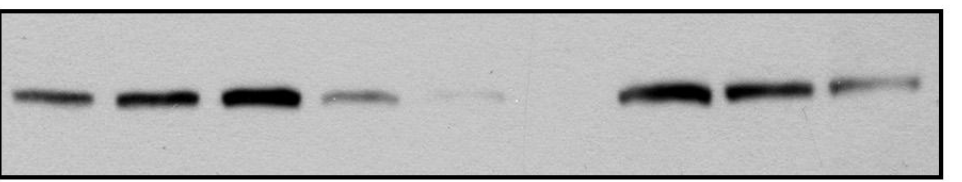

$\mathrm{Ar}$

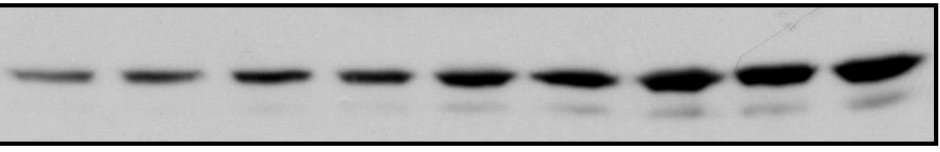

Tgfbr2

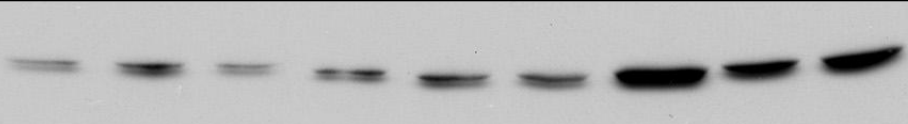

Smad4

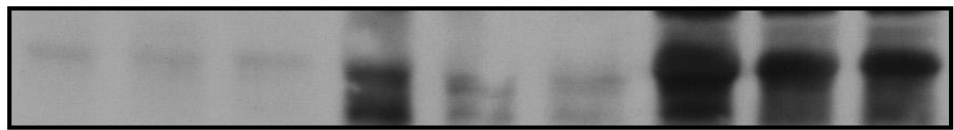

p-Smad2

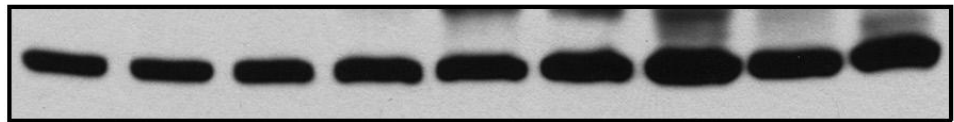

$\gamma$-Tub 


\subsubsection{Analysis of regulators of the cell cycle in Pten null and Apc null based models}

Subsequently, we wanted to examine proliferation in the Apc ${ }^{\mathrm{r} / \mathrm{r}}$ based model compared to the Pten ${ }^{\mathrm{r} / \mathrm{r}}$. Dr. Frierson's technician performed IHC for cyclin D on sections from wild type, $\operatorname{Pten}^{\mathrm{r} / \mathrm{r}}, \operatorname{Pten}^{\mathrm{r} / \mathrm{r}} ; \operatorname{Tgfbr}^{\mathrm{r} / \mathrm{r}}, \mathrm{Apc}^{\mathrm{r} / \mathrm{r}}$ and $\mathrm{Apc}^{\mathrm{r} / \mathrm{r}} ; \mathrm{Tgfbr}^{\mathrm{r} / \mathrm{r}}$, as shown in figure 23. Similar to the results seen with the $\operatorname{Pten}^{\mathrm{r} / \mathrm{r}}$ model, there was an increase in cyclin D staining from wt to $\mathrm{Apc}^{\mathrm{r} / \mathrm{r}}$ and a further increase to $\mathrm{Apc}^{\mathrm{r} / \mathrm{r}} ; \mathrm{Tgfbr}^{\mathrm{r} / \mathrm{r}}$. Levels of the CDK inhibitor $\mathrm{p} 27$ were then assayed by immunofluorescence, as shown in the middle row of figure 23. p27 is shown in red and combined with $\beta$-catenin (shown in green) so any correlation between p27 staining and localization of $\beta$-catenin could be visualized. In the $\operatorname{Pten}^{\mathrm{r} / \mathrm{r}}$ model, $\mathrm{p} 27$ staining was consistent with results shown earlier in chapter 4 , with increased nuclear staining in the $\mathrm{Pten}^{\mathrm{r} / \mathrm{r}}$ and lower staining in the $\operatorname{Pten}^{\mathrm{r} / \mathrm{r}} ; \mathrm{Tgfbr}^{\mathrm{r} / \mathrm{r}}$. However, in the $\mathrm{Apc}^{\mathrm{r} / \mathrm{r}}$ model the results were different. In $\mathrm{Apc}^{\mathrm{r} / \mathrm{r}}$ cells with cytoplasmic $\beta$-catenin staining, the majority of the $\mathrm{p} 27$ staining was cytoplasmic. The opposite effect was seen in the subset of cells that showed membrane staining for $\beta$-catenin, these showed distinct nuclear staining for $\mathrm{p} 27$. In the $\mathrm{Apc}{ }^{\mathrm{r} / \mathrm{r}} ; \mathrm{Tgfbr}^{\mathrm{r} / \mathrm{r}}$ there appeared to be lower levels of $\mathrm{p} 27$ overall and little nuclear staining. This may indicate that $\mathrm{p} 27$ is not restraining the $\mathrm{Apc}^{\mathrm{r} / \mathrm{r}}$, and is an interesting contrast to the Pten ${ }^{\mathrm{r} / \mathrm{r}}$.

\subsubsection{Cellular senescence in the Pten and Apc based models}

We next analyzed whether cellular senescence might be restraining the expansion from HGPIN to invasive carcinoma in the $\mathrm{Apc}^{\mathrm{r} / \mathrm{r}}$ and $\mathrm{Pten}^{\mathrm{r} / \mathrm{r}}$ based models. To assay cellular senescence, whole prostates were stained for senescence associated $\beta$-galactosidase activity. These prostates were then sectioned and counterstained with eosin to provide contrast. As shown in the bottom row of figure 23 , there is little $\beta$-galactosidase staining in the wild type, but in the $\operatorname{Pten}^{\mathrm{r} / \mathrm{r}}$ and the $\mathrm{Apc}^{\mathrm{r} / \mathrm{r}}$ there is staining for senescence associated $\beta$-galactosidase (in blue). The $\beta$ galactosidase staining was not present in every duct with PIN in these samples. 
Figure 23. Analysis of cell cycle and senescence in Pten null and Apc null models. Top row: Cyclin D levels are shown by IHC in wild type (21 weeks), Pten $^{\mathrm{r} / \mathrm{r}}\left(22\right.$ weeks), Pten $^{\mathrm{r} / \mathrm{r}} ;$ Tgfbr $^{\mathrm{r} / \mathrm{r}}$ (11 weeks), $\mathrm{Apc}^{\mathrm{r} / \mathrm{r}}$ (36 weeks), Apc ${ }^{\mathrm{r} / \mathrm{r}} ; \operatorname{Tgfbr}^{\mathrm{r} / \mathrm{r}}(17$ weeks).

Middle row: Immunofluorescence for $\mathrm{p} 27^{\mathrm{Kip} 1}$ (Red) and $\beta$-catenin (Green) is shown. Genotypes are of the following ages: Wild type (21 weeks), $\operatorname{Pten}^{\mathrm{r} / \mathrm{r}}$ (43 weeks), $\operatorname{Pten}^{\mathrm{r} / \mathrm{r}} ; \operatorname{Tgfbr}^{\mathrm{r} / \mathrm{r}}(12$ weeks), $\mathrm{Apc}^{\mathrm{r} / \mathrm{r}}$ (36 weeks), Apc ${ }^{\mathrm{r} / \mathrm{r}} ; \mathrm{Tgfbr}^{\mathrm{r} / \mathrm{r}}$ (18 weeks).

Bottom row: Senescence associated $\beta$-galactosidase is shown for the indicated genotypes at the following ages: wild type (19 weeks), $\operatorname{Pten}^{\mathrm{r} / \mathrm{r}}$ (19 weeks), $\operatorname{Pten}^{\mathrm{r} / \mathrm{r}} ; \operatorname{Tgfbr}^{\mathrm{r} / \mathrm{r}}\left(10\right.$ weeks), Apc $^{\mathrm{r} / \mathrm{r}}$ (51 weeks), $\mathrm{Apc}^{\mathrm{r} / \mathrm{r}} ; \operatorname{Tgfbr}^{\mathrm{r} / \mathrm{r}}(16$ weeks $)$. 


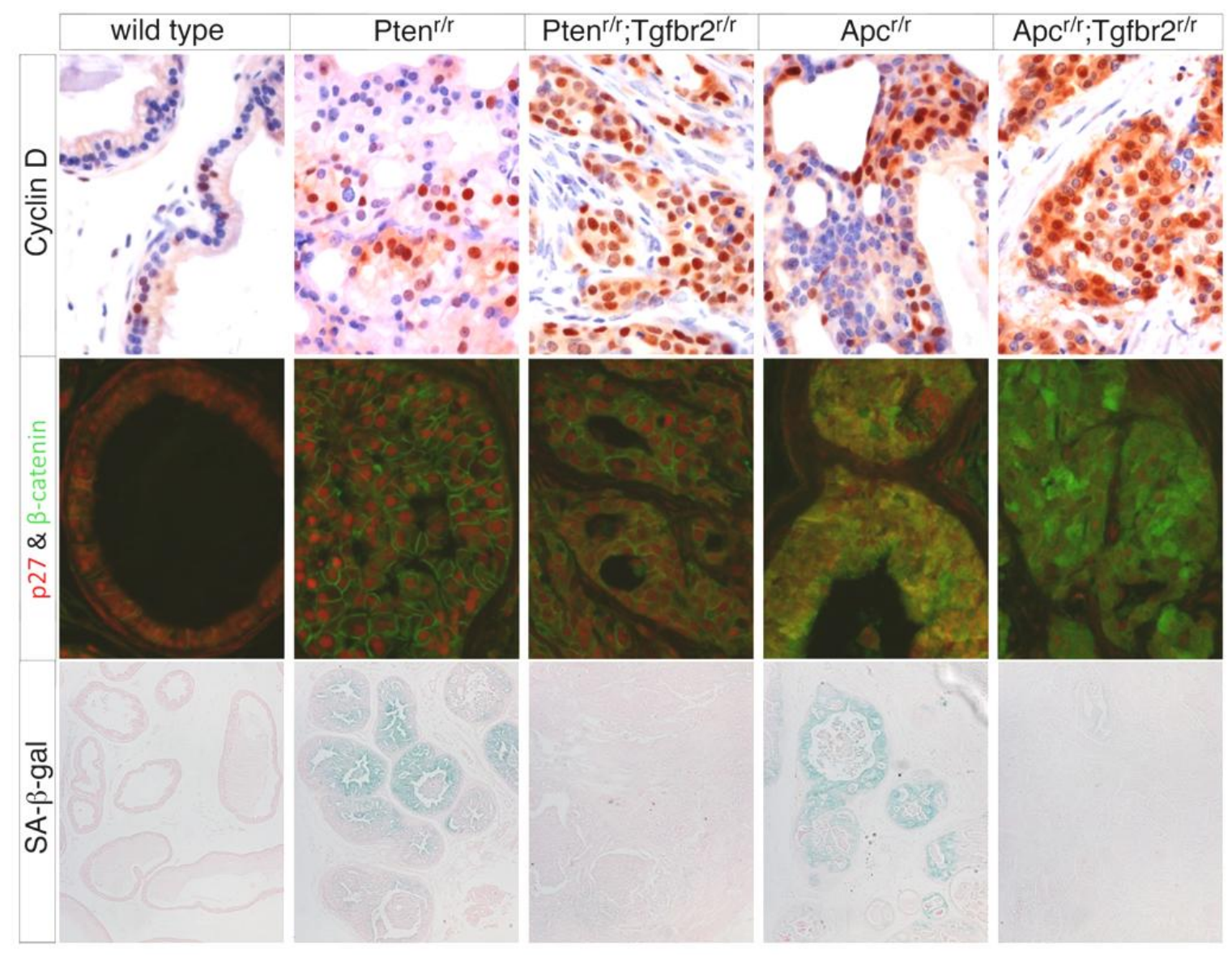


However, there was no staining for $\beta$-galactosidase in the carcinoma areas of $\mathrm{Apc}^{\mathrm{r} / \mathrm{r}} ; \mathrm{Tgfbr}^{\mathrm{r} / \mathrm{r}}$ or $\operatorname{Pten}^{\mathrm{r} / \mathrm{r}} ; \operatorname{Tgfbr}^{\mathrm{r} / \mathrm{r}}$. This leads us to believe that senescence may be at least partially what is keeping the phenotype from progressing further in the $\mathrm{Apc}^{\mathrm{r} / \mathrm{r}}$ and the $\mathrm{Pten}^{\mathrm{r} / \mathrm{r}}$. It also appears that knockout of $T g f b r 2$ bypasses the restrained induced by cellular senescence.

\subsection{Discussion}

In this chapter I have reported another new model of prostate cancer, with the prostate specific knockout of $A p c$ and $T g f b r 2$. This resulted in progression to cancer over twice as fast as loss of $A p c$ alone. The median age at which we had to euthanize our mice at was 151 days, whereas the $A p c$ knockout alone are reported to develop excess tumor burden around 12-15 months ${ }^{97}$. Furthermore, I had $10 \mathrm{Apc}^{\mathrm{r} / \mathrm{r}}$ mice survive to a year old and none of them needed to be euthanized for tumor burden. Additionally, the Williams group reported that they did not observe any metastases in their $\mathrm{Apc}^{\mathrm{r} / \mathrm{r}}$ mice. We have observed $3 \mathrm{Apc}^{\mathrm{r} / \mathrm{r}} ; \mathrm{Tgfbr}^{\mathrm{r} / \mathrm{r}}$ mice with lymph node metastases and one with a lung metastasis. Therefore, loss of $T g f b r 2$ also made these tumors metastatic. The significant problem with this model, as it relates to human cancer, is that it results in squamous differentiation, something that is very rare in human cancers. This squamous differentiation may be why the $\mathrm{Apc}^{\mathrm{r} / \mathrm{r}} ; \mathrm{Tgfbr}^{\mathrm{r} / \mathrm{r}}$ do not metastasize as well as the $\mathrm{Pten}^{\mathrm{r} / \mathrm{r}}$;gfbr $2^{\mathrm{r} / \mathrm{r}}$, as the cells may too easily enter into a differentiated, quiescent state. One of our hypotheses as to why the Pten null, $T g f b r 2$ heterozygous mice metastasize at such a high rate is that the tumors grow more slowly and have more time to metastasize and colonize distant tissues. The low level of metastases in the $\mathrm{Apc}^{\mathrm{r} / \mathrm{r}}$; $\mathrm{Tgfbr} 2^{\mathrm{r} / \mathrm{r}}$ argue against this idea, because the mice have tumors longer and the tumors grow larger than the $\operatorname{Pten}^{\mathrm{r} / \mathrm{r}} ; \mathrm{Tgfbr}^{\mathrm{r} / \mathrm{r}}$, but they develop fewer metastases. Therefore, it seems the higher rate of metastases in the Pten null, Tgfbr2 heterozygous mice is probably due to the genotype. 
As of yet we have not examined what effect the increased stroma may be causing in our model. TGF- $\beta$ signaling is known to be an important modulator of the tumor stroma environment 127. Increase in the TGF- $\beta 1$ ligand has been associated with reactive tumor stroma and upregulation of TGF- $\beta 1$ in the stroma has been associated with a poor clinical outcome ${ }^{128}$. In figure 13, I showed increased ligand (Tgfb1) in the Pten $^{\mathrm{r} / \mathrm{r}}$ by qRT-PCR. This is consistent with the increase in stroma in the $\operatorname{Pten}^{\mathrm{r} / \mathrm{r}}$ and might indicate that the stromal interaction could be promoting tumorigenesis. It has also been shown that human cancers lose expression of Tgfbr2 within the stroma and knockout of $T g f b r 2$ in the mouse prostate stroma led to carcinoma from the epithelial layer by 7 months old. This was reported to be due to an increase in paracrine Wnt signaling ${ }^{129}$. Loss of $T g f b r 2$ in the epithelial layer of our models could be having a similar effect, as we see an increase in Wnt signaling by RNA-seq (Detailed in the next chapter).

In the Pten ${ }^{\mathrm{r} / \mathrm{r}}$; Tgfbr $2^{\mathrm{r} / \mathrm{r}}$ model we saw an increase in the CKI p27, which we think might be restraining tumors. However, in the $\mathrm{Apc}^{\mathrm{r} / \mathrm{r}}$ model we do not see an increase in nuclear $\mathrm{p} 27$. Nuclear localization of p27 is necessary for its CKI activity ${ }^{130}$. Therefore, we do not think p27 is restraining the $\mathrm{Apc}^{\mathrm{r} / \mathrm{r}}$, and loss of Tgfbr2 must be doing something else to allow progression to carcinoma. p27 has been shown to interact with $\beta$-catenin at the cell membrane ${ }^{131}$, but I could not find any of the oncogenic attributes of $\beta$-catenin being attributed to its interference of $\mathrm{p} 27$. Additionally, the apparent decrease from the $\mathrm{Apc}^{\mathrm{r} / \mathrm{r}}$ to the $\mathrm{Apc}^{\mathrm{r} / \mathrm{r}} ; \mathrm{Tgfbr}^{\mathrm{T} / \mathrm{r}}$ is interesting because p27 may have effects outside of its CKI activity. Cytoplasmic p27 has been shown to increase cell migration by activating $\mathrm{RhoA}^{132}$. Therefore, it is interesting why the $\mathrm{Apc}^{\mathrm{r} / \mathrm{r}}$ have lost nuclear p27 and what effect this may be having.

Contrary to the $\operatorname{Pten}^{\mathrm{r} / \mathrm{r}}$ based model, we did not see activation of the TGF- $\beta$ pathway in the $A p c^{\mathrm{r} / \mathrm{r}}$ based model. This leads us to believe that in the $\operatorname{Pten}^{\mathrm{r} / \mathrm{r}}$ model activation of the TGF- $\beta$ pathway is downstream of Akt1 and not due to the PIN phenotype, since PIN in the Apc ${ }^{\mathrm{r} / \mathrm{r}}$ does not activate the TGF- $\beta$ pathway. However, this begs the question of whether activation of the 
TGF- $\beta$ pathway is truly important in the $\operatorname{Pten}^{\mathrm{r} / \mathrm{r}}$, since activation of the pathway is not necessary to restrain growth, as seen in the $\mathrm{Apc}^{\mathrm{r} / \mathrm{r}}$. It would seem that there needs to be something turning on activity of the TGF- $\beta$ pathway to restrain growth in the $\operatorname{Pten}^{\mathrm{r} / \mathrm{r}}$, because there is so little pathway activity otherwise (as shown by phospho-Smad2). Consequently, the lack of p27 and activation of the TGF- $\beta$ pathway in the Apc ${ }^{\mathrm{r} / \mathrm{r}}$ may indicate that loss of Tgfbr2 in the $A p c^{\mathrm{r} / \mathrm{r}}$ is driving cancer by a different mechanism than in the Pten ${ }^{\mathrm{r} / \mathrm{r}}$. Alternatively, it may be that loss of Tgfbr2 is driving tumor formation by an altogether different mechanism in both models.

However, knockout of both Apc and Pten resulted in PIN ducts staining for senescence associated $\beta$-galactosidase activity. This staining was lost in both models with the additional knockout of $T g f b r 2$. Therefore, it is possible that both of these models are being restrained by TGF- $\beta$ induced cellular senescence. A similar result was published for the Pten/Smad4 prostate knockout paper, but they showed bypass of senescence upon knockout of Smad4 ${ }^{95}$. In our models, the induction of senescence does not appear to be due to p27 induction because p27 is not induced in the $\mathrm{Apc}^{\mathrm{r} / \mathrm{r}}$. However, it could be due to other CKIs such as p15 or p21. However, I have assayed both of these by real time RT-PCR. They are both increased in the Pten ${ }^{\mathrm{r} / \mathrm{r}}$, but they do not decrease in the Pten/Tgfbr2 double null. This result was confirmed by RNA-seq also (Data not shown). It is possible they could be regulated at the protein level, but the known regulation of these genes by TGF- $\beta$ is at the transcriptional level ${ }^{46}$. Therefore, we do not know how loss of Tgfbr2 is making these models resistant to senescence.

Overall, the two models that we made appear similar, but also have interesting differences. Carcinoma caused by knockout of either Pten or Apc can be accelerated by additional knockout of $T g f b r 2$, but these tumors progress at different rates. Prostate tumors from $\operatorname{Pten}^{\mathrm{r} / \mathrm{r}} ; \mathrm{Tgfbr}^{\mathrm{r} / \mathrm{r}}$ are poorly differentiated, whereas Apc ${ }^{\mathrm{r} / \mathrm{r}} ; \mathrm{Tgfbr}^{\mathrm{r} / \mathrm{r}}$ tumors show adenosquamous differentiation. The Pten ${ }^{\mathrm{r} / \mathrm{r}}$ knockout may be restrained by $\mathrm{p} 27$, but it appears the $\mathrm{Apc}{ }^{\mathrm{r} / \mathrm{r}} \mathrm{knockout}$ may already be resistant to cell cycle arrest by p27. However, it seems that single knockouts of 
$\operatorname{Pten}^{\mathrm{r} / \mathrm{r}}$ and $\mathrm{Apc}^{\mathrm{r} / \mathrm{r}}$ are both restrained by cellular senescence. This restraint can be bypassed by loss of $T g f b r 2$, resulting in carcinoma. It would appear that a prostate cancer model based on Pten ${ }^{\mathrm{r} / \mathrm{r}}$ would be more relevant for cancer research, since human cancers often show loss of Pten, but not $A p c$. The $\operatorname{Pten}^{\mathrm{r} / \mathrm{r}}$ model also progresses faster and is more metastatic. Additionally, the $A p c$ knockout model results in squamous differentiation, which is not seen in human cancers. 


\section{Chapter 6}

\section{Loss of Tgfbr2 in the Prostate Causes an Expansion of the Basal Cell Lineage}




\subsection{Introduction}

We next wanted to determine the mechanism of rapid tumor growth upon loss of $T g f b r 2$ in conjunction with loss of Pten. In general, the mechanism of tumor suppression by the TGF- $\beta$ pathway is attributed to its activation of CDK inhibitors p15 and p2 ${ }^{46}$. However, we did not detect a decrease in 15 or p21 gene expression upon loss of Tgfbr2 (data not shown). In the DePinho group's paper on knockout of Pten and Smad4, they attributed the mechanism to loss of cellular senescence and activation of cyclin D upon knockout of Smad4. We found the same result of loss of cellular senescence upon knockout of $T g f b r 2$, but we are not as sure of their proposed mechanism for activation of cyclin D. They showed that Smad4 was at the cyclin D promoter by ChIP, but Smad complexes are usually activators of gene transcription, and they offered no explanation of how Smad4 was repressing cyclin D in this context. Therefore, to determine what effect loss of $T g f b r 2$ was having in our model we had RNA sequencing (RNAseq) done on a number of prostate samples. In the RNA-seq data we found an increase in genes specific to the prostate basal lineage and an increase in stem cell genes. Furthermore, as shown by immunofluorescence, there was an increase in basal cells in each model upon loss of $T g f b r 2$. Additionally, in $\operatorname{Pten}^{\mathrm{r} / \mathrm{r}} ; \mathrm{Tgfbr}^{\mathrm{r} / \mathrm{r}}$ tumors the higher proliferation rate was shown to be specific to the basal cells. Finally, there was an increase in cells expressing the stem cell marker CD44 in both the $\operatorname{Pten}^{\mathrm{r} / \mathrm{r}}$ and the Pten ${ }^{\mathrm{r} / \mathrm{r}} ; \operatorname{Tgfbr}^{\mathrm{r} / \mathrm{r}}$ tumors. These data show that loss of $T g f b r 2$ drives tumor formation by allowing proliferation of basal and possibly stem-like cells in the prostate. This information furthers the knowledge of TGF- $\beta$ signaling in prostate cancer and should lead to a clearer understanding of the cell of origin for prostate cancer. 


\subsection{Results}

\subsubsection{RNA-seq Samples and principal component analysis}

To elucidate the mechanism of tumor formation upon loss of $T g f b r 2$ we compared the samples by sequencing their RNA (RNA-seq). RNA was isolated from the ventral prostates of 4 wild type mice (14-20 week old), three 8 week old $\operatorname{Pten}^{\mathrm{r} / \mathrm{r}}$, three 8 week old $\operatorname{Pten}^{\mathrm{r} / \mathrm{r}} ; \operatorname{Tgfbr}^{\mathrm{r} / \mathrm{r}}$, three 22 week old Pten ${ }^{\mathrm{r} / \mathrm{r}}$ and three $\operatorname{Pten}^{\mathrm{r} / \mathrm{r}} ;$ Tgfbr $^{\mathrm{r} / \mathrm{r}}$ whose prostates were taken when they needed to be euthanized for tumor burden (11.5-14 weeks old). We did one set at 8 weeks old to see if we could find early drivers of tumorigenesis. Although, since we were sequencing RNA from whole prostates, we worried that differences in only a subset of the cells would not be detectable.

Therefore, we also sequenced the set of 22 week old $\operatorname{Pten}^{\mathrm{r} / \mathrm{r}}$ and terminal $\operatorname{Pten}^{\mathrm{r} / \mathrm{r}} ; \operatorname{Tgfbr}^{\mathrm{r} / \mathrm{r}}$. These 16 samples were sent away for RNA-seq to the HudsonAlpha Institute for Biotechnology, a nonprofit research institute in Alabama. They performed the library preparation on the samples and sequenced $>25$ million reads per sample. HudsonAlpha gave us the raw data from the reads and we had it analyzed by Stephen Turner, the UVa Bioinformatics Core Director. He performed the necessary quality control, mapped the reads to genes, normalized the read counts and performed principal component analysis for us. This resulted in approximately 16.7 to 23.6 million reads per sample that mapped to genes. To examine how similar each of our groups of samples were, Stephen Turner performed principal component analysis on the data, allowing similarity between samples to be visualized with only two axes. This analysis is shown in figure 24 as a scatter plot with principal component 1 shown on the $\mathrm{X}$ axis and principal component 2 shown on the $\mathrm{Y}$ axis. This graph shows that the groups cluster individually quite well and that we should be able to draw significant conclusions on differences between them. It is interesting to note also that the two sets of 8 week old samples $\left(\operatorname{Pten}^{\mathrm{r} / \mathrm{r}}\right.$ and $\left.\operatorname{Pten}^{\mathrm{r} / \mathrm{r}} ; \mathrm{Tgfbr}^{\mathrm{r} / \mathrm{r}}\right)$ cluster together, rather than by genotype. This seems to indicate that more of the change between the groups is due to age than genotype. 
Figure 24. Clustering of the RNA-seq data by principal component analysis. Each sample is positioned by its similarity along the $\mathrm{X}$ axis for principle component 1 and along the $\mathrm{Y}$ axis for principle component 2. Gray ovals show each of the groups clustering together, with the 8 week $\operatorname{Pten}^{\mathrm{r} / \mathrm{r}}$ and 8 week Pten ${ }^{\mathrm{r} / \mathrm{r}} ;$ Tgfbr $2^{\mathrm{r} / \mathrm{r}}$ clustering similarly. 


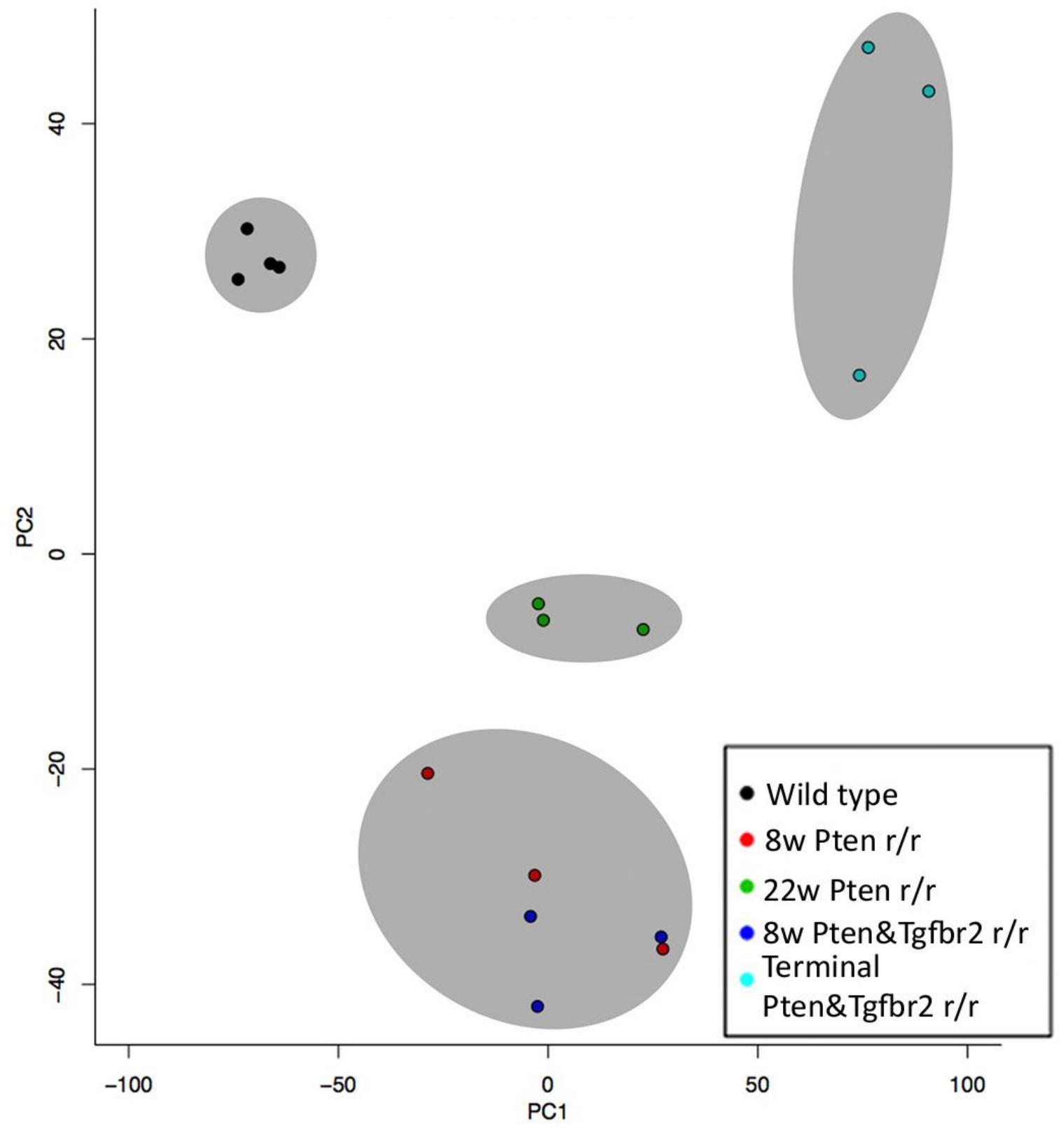




\subsubsection{Gene Ontology on RNA-seq data}

To get an idea of the pathways that were being affected by loss of Tgfbr2, I performed some Gene Ontology (GO) analysis on the data. To do this I used DAVID (Database for Annotation, Visualization, and Integrated Discovery), a web based program made by the Lempicki lab at the $\mathrm{NCI}^{133}$. DAVID uses a number of functional annotations from other sources to find classes of proteins that are enriched in a particular set of genes. Therefore, for direct comparisons of interest (e.g. Terminal Pten ${ }^{\mathrm{r} / \mathrm{r}} ; \operatorname{Tgfbr}^{\mathrm{r} / \mathrm{r}}$ versus 22 week old Pten ${ }^{\mathrm{r} / \mathrm{r}}$ ) the list of genes that changed significantly was processed through DAVID. For most of the comparisons, significantly changing genes were defined as a greater or lesser than $1.5 \log 2$ fold change and an adjusted p-value of $<0.01$. Most of the comparisons had a large number of genes changing and this stringent cutoff could be used. However, for the comparison of 8 week old Pten $^{\mathrm{r} / \mathrm{r}} ; \mathrm{Tgfbr}^{\mathrm{r} / \mathrm{r}}$ versus 8 week old Pten ${ }^{\mathrm{r} / \mathrm{r}}$ a less stringent cutoff had to be used. This cutoff was defined as a Log2 fold change of greater or less than 1 and a p-value of $<0.05$. An example of one GO analysis is shown in figure 25 , for the comparison of terminal Pten ${ }^{\mathrm{r} / \mathrm{r}} ; \operatorname{Tgfbr}^{\mathrm{r} / \mathrm{r}}$ versus 22 week old Pten ${ }^{\mathrm{r} / \mathrm{r}}$. It is shown as the top $10 \mathrm{GO}$ categories as ranked by fold enrichment, with the functional term on the left, the number of genes found, the p-value and the names of the genes. The majority of the down regulated functional categories are related to the immune system, with categories relating to antibody presentation and T cells. This is consistent with the TGF- $\beta$ pathway's known regulation of the immune response ${ }^{43}$. Also one of the most down regulated functional terms was "prostate gland epithelium morphogenesis", which contains prostate development genes including Nkx3.1, which is an important gene in prostate cancer that causes differentiation and is lost in many prostate cancers ${ }^{134}$. Many interesting functional groups were also enriched in the set of genes that were upregulated in the comparison of terminal $\operatorname{Pten}^{\mathrm{r} / \mathrm{r}} ; \operatorname{Tgfbr}^{\mathrm{r} / \mathrm{r}}$ versus 22 week old Pten ${ }^{\mathrm{r} / \mathrm{r}}$. The most highly enriched category was EGF-like \& calcium binding, which contains multiple members of the Notch pathway. 
Figure 25. Table of the top $10 \mathrm{GO}$ terms downregulated or upregulated for the terminal Pten $^{\mathrm{r} / \mathrm{r}}$; Tgfbr2 ${ }^{\mathrm{r} / \mathrm{r}}$ versus 22 week Pten $^{\mathrm{r} / \mathrm{r}}$ comparison. The top 10 Gene Ontology categories as determined by fold enrichment are shown for the comparison of the terminal Pten ${ }^{\mathrm{r} / \mathrm{r}} ; \operatorname{Tgfbr}^{\mathrm{r} / \mathrm{r}}$ versus 22 week Pten ${ }^{\mathrm{r} / \mathrm{r}}$ comparison. Functional categories for downregulated genes are shown in the top table and functional categories for upregulated genes are shown in the bottom table. Also shown is the number of genes changing in that category, the p-value, the gene names and the fold enrichment. 


\begin{tabular}{|c|c|c|c|c|}
\hline $\begin{array}{l}\text { Down in Terminal Pten;Tgfbr2 null } \\
\text { compared to } 22 \text { week Pten null }\end{array}$ & & & & \\
\hline Term & \# & $\begin{array}{c}\text { P- } \\
\text { Value }\end{array}$ & Genes & $\begin{array}{c}\text { Fold } \\
\text { Enrichment }\end{array}$ \\
\hline $\begin{array}{l}\text { Antigen processing and presentation of } \\
\text { exogenous peptide antigen via MHC class } \\
\text { II }\end{array}$ & 9 & $\begin{array}{c}1.38 \mathrm{E}- \\
07\end{array}$ & $\begin{array}{l}\text { H2-EB1, H2-AA, 2610524H06RIK, } \\
\text { H2-DMB1, H2-AB1, H2-DMA, } \\
\text { 1500011B03RIK, CD74, H2-DMB2 }\end{array}$ & 12.6 \\
\hline Thymic T cell selection & 8 & $\begin{array}{c}1.58 \mathrm{E}- \\
06 \\
\end{array}$ & $\begin{array}{l}\text { CARD11, DOCK2, CD3D, CD3E, } \\
\text { ZAP70, H2-DMA, CD74, CD28 }\end{array}$ & 12.0 \\
\hline T Cytotoxic Cell Surface Molecules & 6 & $\begin{array}{l}2.85 \mathrm{E}- \\
04\end{array}$ & $\begin{array}{l}\text { CD3G, CD3D, CD } 8 A, \text { CD } 3 E, \text { CD2, } \\
\text { CD28 }\end{array}$ & 8.7 \\
\hline Thyroglobulin type-1 & 6 & $\begin{array}{c}5.71 \mathrm{E}- \\
04\end{array}$ & $\begin{array}{l}\text { SMOC2, IGFBP6, SPOCK1, IGFBP2, } \\
\text { CD74, IGFBP5 }\end{array}$ & 8.2 \\
\hline Membrane lipid biosynthetic process & 6 & $\begin{array}{c}2.97 \mathrm{E}- \\
03\end{array}$ & $\begin{array}{l}\text { ST6GALNAC4, LASS4, P2RX1, } \\
\text { UGT8A, B4GALT6, A3GALT2 }\end{array}$ & 5.8 \\
\hline Ig-like C1-type & 7 & $\begin{array}{c}1.41 \mathrm{E}- \\
03\end{array}$ & $\begin{array}{l}\text { H2-Q2, AZGP1, H2-EB1, H2-AA, } \\
\text { H2-DMB1, H2-AB1, H2-DMA }\end{array}$ & 5.4 \\
\hline $\begin{array}{l}\text { PLC-like phosphodiesterase, TIM } \\
\text { beta/alpha-barrel domain }\end{array}$ & 6 & $\begin{array}{c}4.94 \mathrm{E}- \\
03\end{array}$ & $\begin{array}{l}\text { PLCL2, PLCE1, PLCB4, GDPD1, } \\
\text { PLCXD2, GDPD2 }\end{array}$ & 5.2 \\
\hline Prostate gland epithelium morphogenesis & 6 & $\begin{array}{c}5.20 \mathrm{E}- \\
03\end{array}$ & $\begin{array}{l}\text { BMP4, NKX3-1, IGF1, HOXB13, } \\
\text { ESR2, SHH }\end{array}$ & 5.2 \\
\hline Primary immunodeficiency & 9 & $\begin{array}{c}2.47 \mathrm{E}- \\
04\end{array}$ & $\begin{array}{l}\text { CIITA, CD8B1, CD19, CD3D, } \\
\text { CD8A, CD3E, ZAP70, AIRE, CD79A }\end{array}$ & 5.2 \\
\hline Glutathione transferase activity & 6 & $\begin{array}{c}6.33 \mathrm{E}- \\
03\end{array}$ & $\begin{array}{l}\text { GSTM2, GSTK1, GSTT1, GSTM6, } \\
\text { GSTM5, GSTM7 }\end{array}$ & 4.9 \\
\hline \multicolumn{5}{|l|}{$\begin{array}{l}\text { Up in Terminal Pten;Tgfbr2 null } \\
\text { compared to } 22 \text { week Pten null }\end{array}$} \\
\hline Term & $\#$ & $\begin{array}{c}\text { P- } \\
\text { Value }\end{array}$ & Genes & $\begin{array}{l}\text { Fold } \\
\text { Enrichment }\end{array}$ \\
\hline EGF-like \& calcium-binding & 7 & $\begin{array}{c}1.71 \mathrm{E}- \\
07\end{array}$ & $\begin{array}{l}\text { NOTCH3, NOTCH1, LTBP1, } \\
\text { LTBP2, JAG2, FBN2, JAG1 }\end{array}$ & 23.1 \\
\hline $\begin{array}{l}\text { S100/CaBP-9k-type, calcium binding, } \\
\text { subdomain }\end{array}$ & 6 & $\begin{array}{l}1.19 \mathrm{E}- \\
04\end{array}$ & $\begin{array}{l}\text { S100A6, S100A16, S100A8, S100A9, } \\
\text { S100A10, S100A14 }\end{array}$ & 11.8 \\
\hline Laminin $\mathrm{G}$ & 8 & $\begin{array}{c}9.37 \mathrm{E}- \\
05\end{array}$ & $\begin{array}{l}\text { COL18A1, LAMA1, LAMA3, FAT2, } \\
\text { CSPG4, CELSR2, CELSR1, COL5A3 }\end{array}$ & 7.3 \\
\hline Kinesin, motor region, conserved site & 7 & $\begin{array}{c}4.81 \mathrm{E}- \\
04\end{array}$ & $\begin{array}{l}\text { KIF23, KIFC1, KIF4, KIF15, } \\
\text { KIF18B, CENPE, KIF26B }\end{array}$ & 6.9 \\
\hline Tissue remodeling & 8 & $\begin{array}{l}1.59 \mathrm{E}- \\
04\end{array}$ & $\begin{array}{l}\text { HOXA3, IL23A, CSPG4, SEMA3C, } \\
\text { FOXC2, FOXC1, MMP14, TGFB2 }\end{array}$ & 6.7 \\
\hline Cell-matrix adhesion & 8 & $\begin{array}{c}2.37 \mathrm{E}- \\
04\end{array}$ & $\begin{array}{l}\text { JUB, LYPD3, ITGA6, COL13A1, } \\
\text { ITGB4, ITGB3, NID2, COL5A3 }\end{array}$ & 6.3 \\
\hline Centromere & 6 & $\begin{array}{c}3.16 \mathrm{E}- \\
03 \\
\end{array}$ & $\begin{array}{l}\text { APITD1, CENPA, HJURP, SGOL2, } \\
\text { CENPE, ERCC6L }\end{array}$ & 5.9 \\
\hline Keratinocyte differentiation & 7 & $\begin{array}{c}1.22 \mathrm{E}- \\
03\end{array}$ & $\begin{array}{l}\text { NOTCH1, KRT6A, SPRR2D, PPL, } \\
\text { TRP63, SFN, SCEL }\end{array}$ & 5.8 \\
\hline Ureteric bud development & 6 & $\begin{array}{l}3.89 \mathrm{E}- \\
03\end{array}$ & $\begin{array}{l}\text { FGFR2, CD44, FOXC2, FOXC1, } \\
\text { RARB, GL13 }\end{array}$ & 5.7 \\
\hline Cytoskeletal keratin & 7 & $\begin{array}{c}1.62 \mathrm{E}- \\
03\end{array}$ & $\begin{array}{l}\text { KRT6A, KRT5, LMNB1, KRT16, } \\
\text { KRT7, KRT14, KRT1 }\end{array}$ & 5.5 \\
\hline
\end{tabular}


There were also a number of tissue remodeling and cell matrix adhesion categories which may help promote cancer. Also of note in these genes were known markers of basal cells in prostate. These include p63 (gene: Trp63), Keratin 5 and Keratin 14. Also of interest, a number of stem cell genes were increased in the $\operatorname{Pten}^{\mathrm{r} / \mathrm{r}} ; \mathrm{Tgfbr}^{\mathrm{r} / \mathrm{r}}$ compared to the $\mathrm{Pten}^{\mathrm{r} / \mathrm{r}}$. CD44 is shown on the GO analysis in the "Ureteric bud development" category and we also found other stem cell genes that were increased including Prom1 (Cd133), c-Kit and Integrin alpha 6.

\subsubsection{Basal and stem cell genes are increased in the $\operatorname{Pten}^{\mathrm{r} / \mathrm{r}} ; \operatorname{Tgfbr}^{\mathrm{r} / \mathrm{r}}$}

To determine if more basal versus luminal genes were changing in our model, we compared our data to a published microarray set from a group who sorted basal and luminal cell populations and then examined differences in gene expression by microarray ${ }^{135}$. They used this data to determine a set of basal specific genes and a set of luminal specific genes. We then overlapped our genes that were found to change significantly with the basal or luminal specific genes, and quantified how many were increasing or decreasing in the Pten ${ }^{\mathrm{r} / \mathrm{r}}$ versus wild type and the $\operatorname{Pten}^{\mathrm{r} / \mathrm{r}} ;$ Tgfbr $^{\mathrm{r} / \mathrm{r}}$ versus Pten $^{\mathrm{r} / \mathrm{r}}$. As shown in figure 26A, basal specific genes seem to be increasing in both comparisons, however there is a larger increase in the $\operatorname{Pten}^{\mathrm{r} / \mathrm{r}} ; \mathrm{Tgfbr}^{\mathrm{r} / \mathrm{r}}$ versus $\operatorname{Pten}^{\mathrm{r} / \mathrm{r}}$. The comparison of $\operatorname{Pten}^{\mathrm{r} / \mathrm{r}}$ versus wild type showed a mixture of luminal genes increasing and decreasing, whereas the Pten ${ }^{\mathrm{r} / \mathrm{r}} ; \operatorname{Tgfbr}^{\mathrm{r} / \mathrm{r}}$ versus $\operatorname{Pten}^{\mathrm{r} / \mathrm{r}}$ comparison showed almost all the luminal genes are decreasing. Therefore, we concluded that in the $\operatorname{Pten}^{\mathrm{r} / \mathrm{r}} ; \mathrm{Tgfbr}^{\mathrm{r} / \mathrm{r}}$ there is an increase in the basal cells relative to the luminal cells. Figure 26B shows the relative amounts of basal genes (Keratin 5, Keratin 14 and p63) in the different RNA-seq samples as compared to

wild type. Also, because we saw an increase in CD44, an important stem cell gene, and because the basal cells are thought to contain the stem cells, we looked at a number of stem cell genes in the RNA-seq data. Figure 26B also shows the relative amounts of four stem cell genes in the different RNA-seq comparisons that were done, all of which were increased significantly. 
Figure 26. Overlap between RNA-seq data and published basal/luminal genes and changes in stem cell genes. (A) Genes that were found to be differentially expressed in the WT vs Pten ${ }^{\mathrm{r} / \mathrm{r}}$ comparison (Black bars) or the Pten ${ }^{\mathrm{r} / \mathrm{r}}$ versus $\mathrm{Pten}^{\mathrm{r} / \mathrm{r}} ; \mathrm{Tgfbr}^{\mathrm{r} / \mathrm{r}}$ comparison (red bars) were compared to a published microarray dataset of basal and luminal specific genes. The number of basal genes changing for each RNA-seq comparison is shown on the left and the number of luminal genes for each RNA-seq comparison is shown on the right. (B) Fold change in gene expression is shown for selected basal and stem cell genes relative to wild type for 8 week Pten $^{\mathrm{r} / \mathrm{r}}$, 8 week $\operatorname{Pten}^{\mathrm{r} / \mathrm{r}} ; \operatorname{Tgfbr}^{\mathrm{r} / \mathrm{r}}, 22$ week Pten $^{\mathrm{r} / \mathrm{r}}$ and terminal Pten ${ }^{\mathrm{r} / \mathrm{r}} ; \operatorname{Tgfbr}^{\mathrm{r} / \mathrm{r}}$. 

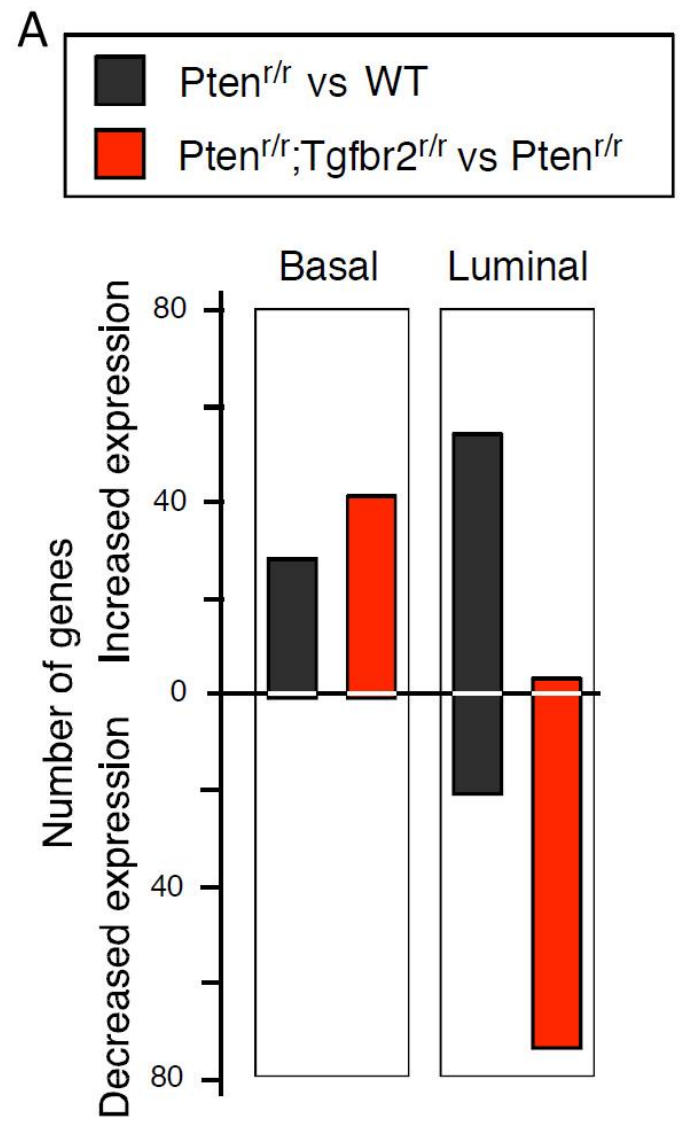

B

\begin{tabular}{|l|c|c|c|c|}
\cline { 2 - 5 } \multicolumn{1}{c|}{} & $\begin{array}{c}\text { 8 week } \\
\text { Pten r/r }\end{array}$ & $\begin{array}{c}\text { 8 week } \\
\text { Pten r/r } \\
\text { Tgfbr2 r/r }\end{array}$ & $\begin{array}{c}\text { Terminal } \\
\text { 22 week } \\
\text { Pten r/r }\end{array}$ & $\begin{array}{c}\text { Pten r/r } \\
\text { Tgfbr2 r/r }\end{array}$ \\
\begin{tabular}{|l|c|c|c|c|}
\hline Basal Genes \\
\hline Krt5 & 0.75 & 2.00 & 1.83 & 44.82 \\
\hline Krt14 & 2.66 & 6.17 & 3.97 & 143.65 \\
\hline Trp63 & 0.88 & 1.60 & 1.05 & 5.81 \\
\hline \multicolumn{5}{|l}{} \\
\hline Stem cell Genes \\
\hline CD44 & 13.05 & 11.63 & 9.04 & 30.37 \\
\hline C-kit & 3.29 & 6.50 & 2.03 & 9.88 \\
\hline Prom1 & 9.54 & 9.56 & 6.27 & 14.52 \\
\hline Itga6 & 2.63 & 2.52 & 1.94 & 6.76 \\
\hline
\end{tabular}
\end{tabular}


Induction of stem cell genes was not specific to the $\mathrm{Pten}^{\mathrm{r} / \mathrm{r}} ; \mathrm{Tgfbr}^{\mathrm{r} / \mathrm{r}}$ though, the genes also increased in the Pten ${ }^{\mathrm{r} / \mathrm{r}}$. Therefore, we believe there is an increase in the basal cells and stem cells upon loss of $T g f b r 2$.

\subsubsection{Basal cells are increased in all models examined upon loss of Tgfbr2}

To determine whether there was an expansion of basal cells upon loss of $T g f b r 2$, immunofluorescence was performed for the basal marker Keratin 5 and the luminal marker Keratin 8. As shown in figure 27, the inner layer of a wild type duct stains for the luminal marker Keratin 8 (in green). Around the outside of the duct, but not in a contiguous layer, there are basal

cells as marked by Keratin 5 (in red). In Tgfbr $2^{\mathrm{r} / \mathrm{r}}$ ducts there may be an increase in the number of Keratin 5 basal cells, but not a dramatic one. In $\operatorname{Pten}^{\mathrm{r} / \mathrm{r}}$ the expansion of cells into the duct, resulting in PIN, appears to consist mostly of luminal cells. However, in the $\operatorname{Pten}^{\mathrm{r} / \mathrm{r}} ; \mathrm{Tgfbr}^{\mathrm{r} / \mathrm{r}}$ there appears to be a large expansion of basal cells as marked by Keratin 5. This expansion is mostly disorganized with basal and luminal mixed together. The expansion of basal cells upon loss of Tgfbr2 is not limited to the Pten ${ }^{\mathrm{r} / \mathrm{r}}$ background. Figure 27 also shows a Tg-Akt1 duct with almost all luminal cells. However, in Tg-Akt1; Tgfbr $2^{\mathrm{r} / \mathrm{r}}$ mice with carcinoma, we also see an expansion of basal cells. Furthermore, $\mathrm{Apc}^{\mathrm{r} / \mathrm{r}}$ ducts are composed mainly of luminal cells. Then, upon loss of $T g f b r 2$, there is again an expansion of basal cells. These data show in three different models of prostate cancer that loss of $T g f b r 2$ leads to an increase of basal cells within the cancer.

\subsubsection{Loss of Tgfbr2 causes an increase in proliferation specific to the basal cells}

Subsequently, we examined markers of proliferation in basal cells versus luminal cells in our model. To do this, I stained slides by immunofluorescence for Ki67 and Keratin 8 (luminal) or Ki67 and Keratin 5 (basal) from 3 different animals for each genotype: wild type, Pten ${ }^{\mathrm{r} / \mathrm{r}}$ and $\operatorname{Pten}^{\mathrm{r} / \mathrm{r}} ;$ Tgfbr $^{\mathrm{r} / \mathrm{r}}$. There were not many proliferating cells in the wild type or $\operatorname{Pten}^{\mathrm{r} / \mathrm{r}}$, in either luminal or basal cells. 
Figure 27. Immunofluorescence for Keratin 5 and Keratin 8. Immunofluorescence was done on 8 different genotypes for Keratin 5 (shown in red) and Keratin 8 (shown in green), nuclei were counter stained blue with DAPI. Ages are as follows: Wild type (25 weeks), Tgfbr $2^{\mathrm{r} / \mathrm{r}}$ (70 weeks), Pten $^{\mathrm{r} / \mathrm{r}}$ (8 weeks), Pten ${ }^{\mathrm{r} / \mathrm{r}} ; \operatorname{Tgfbr}^{\mathrm{r} / \mathrm{r}}$ (10.5 weeks), Tg-Akt1 (20 weeks), Tg-Akt1;Tgfbr2 ${ }^{\mathrm{r} / \mathrm{r}}$ (70 weeks), $\mathrm{Apc}^{\mathrm{r} / \mathrm{r}}$ (36 weeks), $\mathrm{Apc}^{\mathrm{r} / \mathrm{r}} ; \mathrm{Tgfbr}^{\mathrm{r} / \mathrm{r}}(23.5$ weeks). 
Keratin 5 \& Keratin 8




However, in the $\operatorname{Pten}^{\mathrm{r} / \mathrm{r}}$; Tgfbr ${ }^{\mathrm{r} / \mathrm{r}}$ there was an increase in Ki67 positive cells, as expected. Figure 28A shows sample images of the IF for Pten $^{\mathrm{r} / \mathrm{r}} ; \mathrm{Tgfbr}^{\mathrm{r} / \mathrm{r}}$ stained with Ki67 (green) and Keratin 8 (left, red) and Keratin 5 (right, red). I then quantified the number of cells positive for Ki67 as a marker of proliferation in each cell type, within each genotype. The quantification of Ki67 positive cells per cell type and genotype is shown in figure 28B. There is not a significant increase in Ki67 positive luminal cells from wild type to $\operatorname{Pten}^{\mathrm{r} / \mathrm{r}}$ to $\mathrm{Pten}^{\mathrm{r} / \mathrm{r}}$; Tgfbr ${ }^{\mathrm{r} / \mathrm{r}}$. However, in the basal cells there is a slight increase from wild type to $\operatorname{Pten}^{\mathrm{r} / \mathrm{r}}$ and a large, significant increase from $\operatorname{Pten}^{\mathrm{r} / \mathrm{r}}$ to $\operatorname{Pten}^{\mathrm{r} / \mathrm{r}} ; \mathrm{Tgfbr}^{\mathrm{r} / \mathrm{r}}$. Therefore, it appears that loss of $T g f b r 2$ is causing an increase in proliferation specifically in the basal cells.

\subsubsection{Basal cells metastasize to the lungs}

Next, metastases were characterized to determine which cell type was metastasizing. Most of the metastases that we see are hard to detect because they are so small and are usually present in only one histological section. Therefore, it is difficult to fully characterize the metastases with antibodies to multiple proteins. Consequently, we used the large lung metastasis from the $\operatorname{Pten}^{\mathrm{r} / \mathrm{r}} ; \mathrm{Tgfbr}^{+/ \mathrm{r}}$ to see which cell type was metastasizing. I stained sections of this lung by $H \& E$ to find the metastasis, which was confirmed by the pathologist, Dr. Frierson. $H \& E$ staining of the lung metastasis is shown in figure 29A, with a ball of cells in the middle of the section and a thin layer of cells forming a large duct at the top right. An adjacent section was then stained by immunofluorescence for Keratin 8 and Keratin 5 to examine which cell type was metastasizing. This IF is shown in figure 29B, with Keratin 8 in green marking luminal cells and Keratin 5 in red marking basal cells. However, almost all of the cells appear to be basal cells, with very few luminal cells. This area of the lung also stains for Keratin 14, another basal marker (data not shown). Therefore, we believe that it is the basal cells that are metastasizing in the Pten/Tgfbr2 null model. 
Figure 28. Proliferation comparison of luminal and basal cell types. (A)

Immunofluorescence was performed on the prostate of a 10.5 week old $\mathrm{Pten}^{\mathrm{r} / \mathrm{r}}$; $\mathrm{Tgfbr}^{\mathrm{r} / \mathrm{r}}$ for Ki67 (shown in green) along with Keratin 8 (Left; shown in Red) as a marker of luminal cells or Keratin 5 (Right; shown in red) as a marker of basal cells. (B) Quantification of the percent of Ki67 positive cells by genotype and cell type. The ventral prostates from 3 mice per genotype (Wild type, $\operatorname{Pten}^{\mathrm{r} / \mathrm{r}}$ and $\operatorname{Pten}^{\mathrm{r} / \mathrm{r}} ; \operatorname{Tgfbr}^{\mathrm{r} / \mathrm{r}}$ ) were stained by immunofluorescence for Ki67 and either Keratin 8 to mark luminal cells or Keratin 5 to mark basal cells. The percent that were Ki67 positive is shown as the average plus standard deviation. The p-value is shown for $\operatorname{Pten}^{\mathrm{r} / \mathrm{r}} ;$ Tgfbr $^{\mathrm{r} / \mathrm{r}}$ versus Pten $^{\mathrm{r} / \mathrm{r}}$ in the Keratin 5 population as determined by Student's t test. 
A Keratin 8 \& Ki67

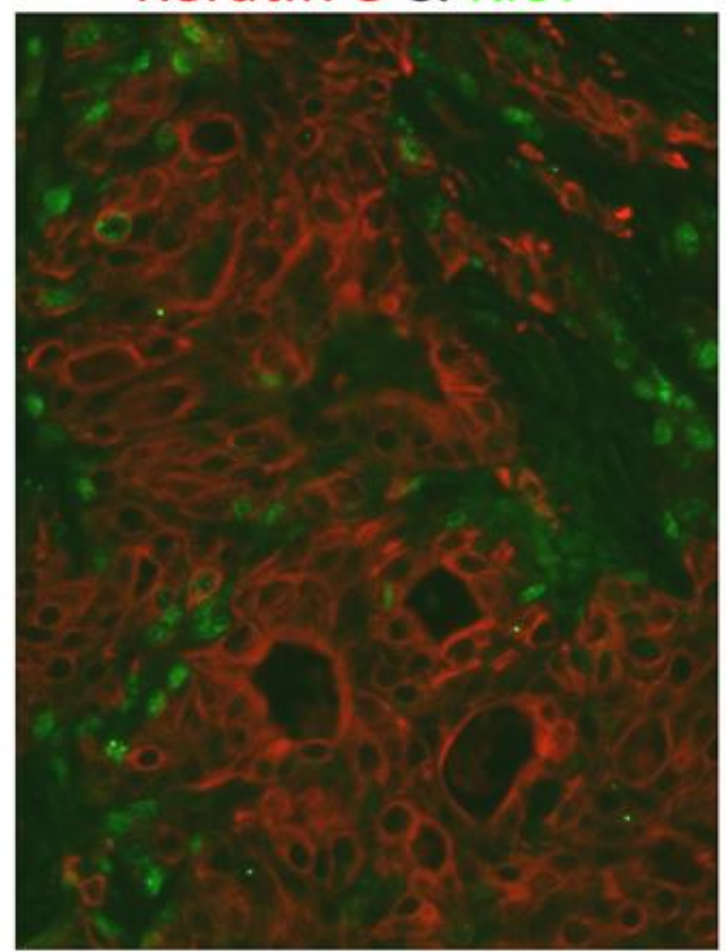

B

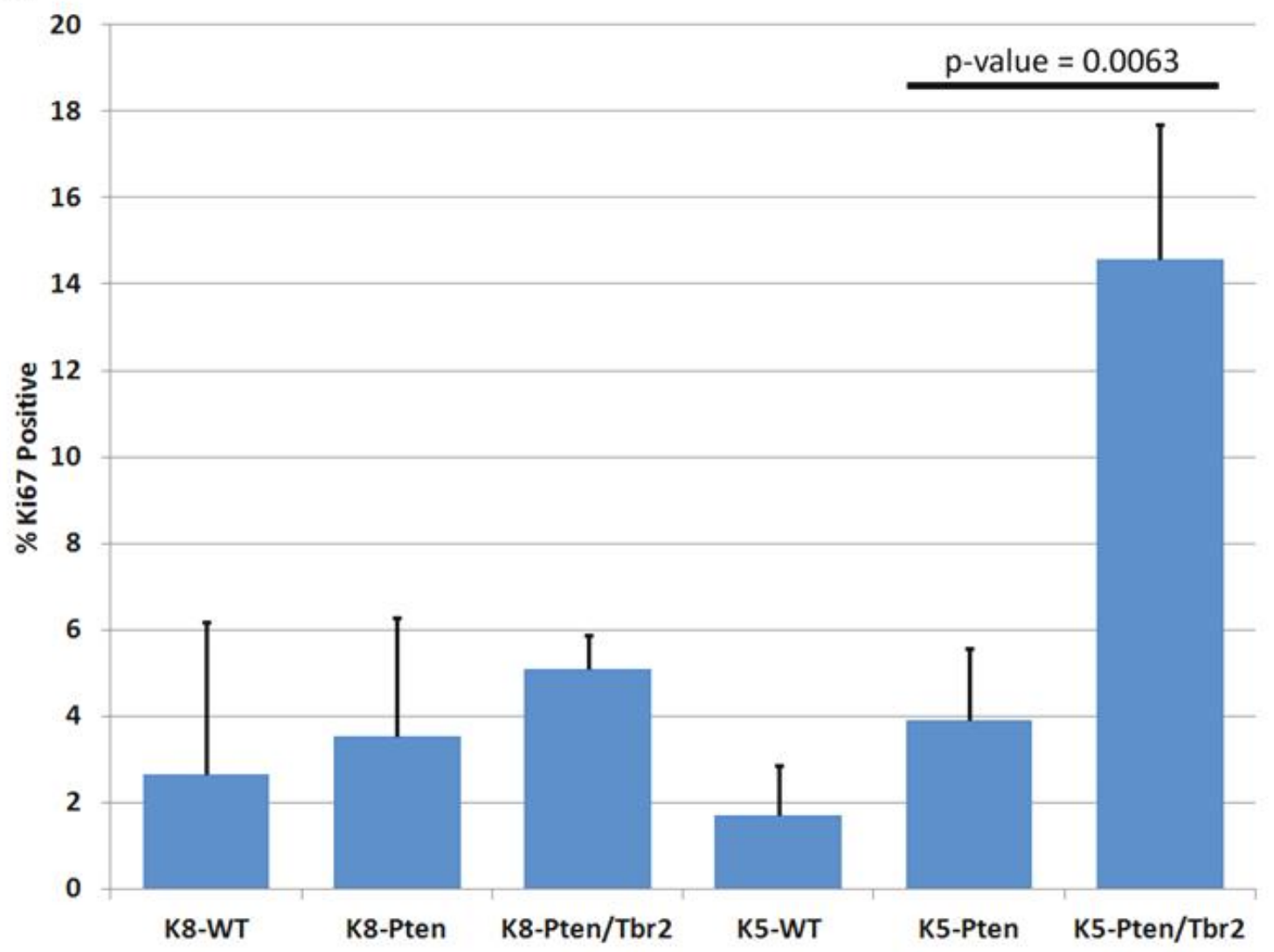

Keratin 5 \& Ki67

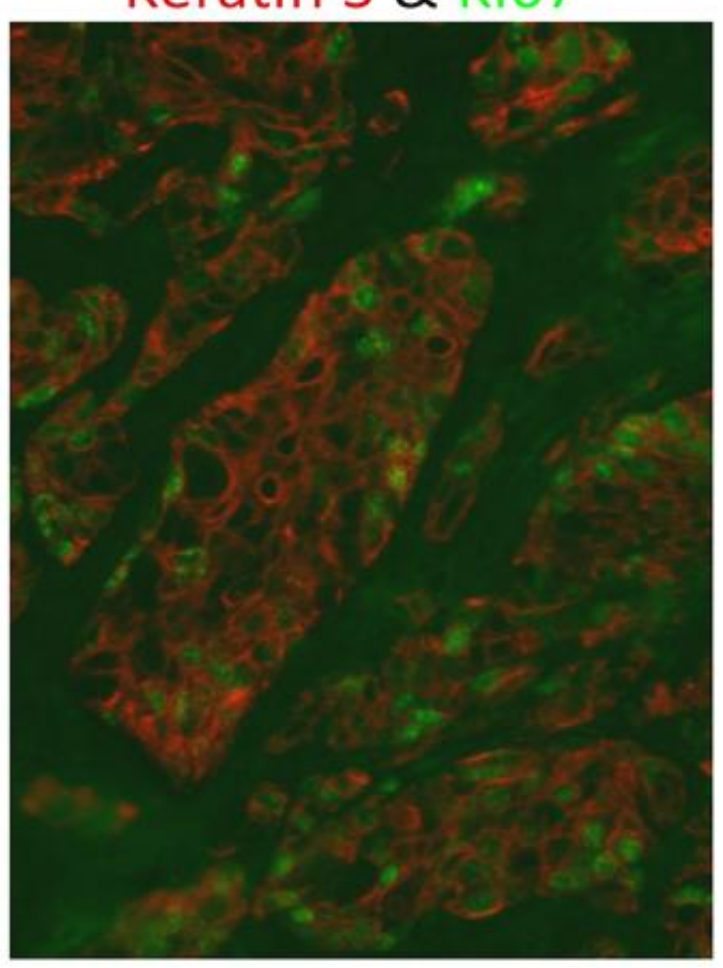


Figure 29. Immunofluorescence of cell types in a lung metastasis. (A) A section of lung from a 54 week old Pten $^{\mathrm{r} / \mathrm{r}} ; \mathrm{Tgfbr}^{+/ \mathrm{r}}$ mouse was stained by H\&E. (B) An adjacent section of lung from the same Pten ${ }^{\mathrm{r} / \mathrm{r}} ; \mathrm{Tgfbr}^{+/ \mathrm{r}}$ mouse was stained by immunofluorescence for Keratin 5 (shown in red) and Keratin 8 (shown in green) with nuclei stained blue with DAPI. 
A

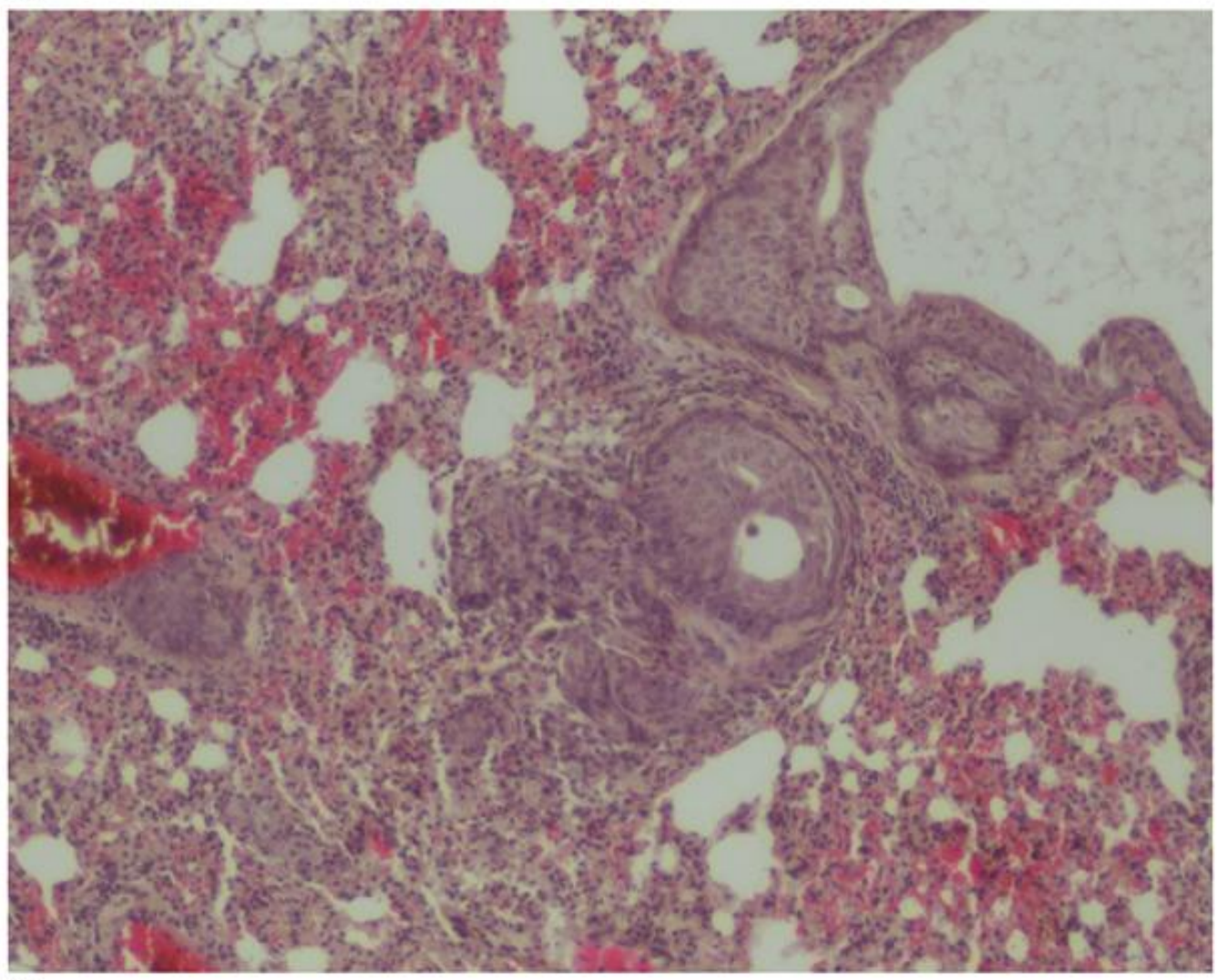

B

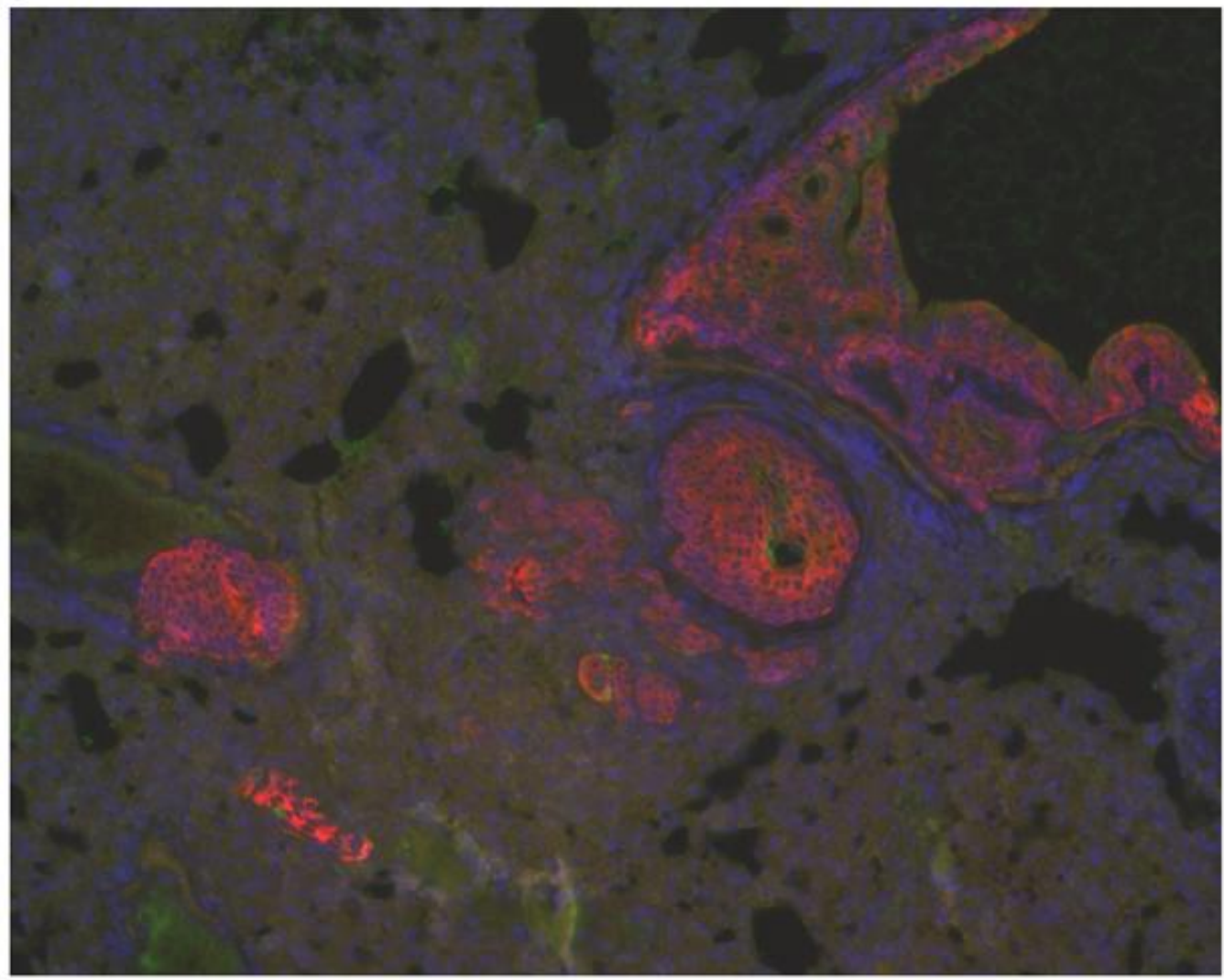




\subsubsection{CD44 and other stem cell genes are increased in the $\operatorname{Pten}^{\mathrm{r} / \mathrm{r}} ; \operatorname{Tgfbr}^{\mathrm{r} / \mathrm{r}}$}

We next verified an increase in stem-like cells in the $\operatorname{Pten}^{\mathrm{r} / \mathrm{r}} ; \mathrm{Tgfbr}^{\mathrm{r} / \mathrm{r}}$ tumors. This was done by examining the protein level and localization for CD44 by immunofluorescence. CD44 is a cell adhesion molecule that is the receptor for hyaluronic acid and also has many functions in cell signaling ${ }^{136}$. Immunofluorescence was performed for CD44 along with Keratin 5 as a marker of basal cells. As shown in figure 30, there were no cells within the epithelium in the wild type or Tgfbr $2^{\mathrm{r} / \mathrm{r}}$ that stained for CD44. There were some cells in the stroma that were CD44 positive. CD44 does appear to be increased in the luminal cells in the Pten ${ }^{\mathrm{r} / \mathrm{r}}$, which is consistent with an increase in CD44 expression in the $\operatorname{Pten}^{\mathrm{r} / \mathrm{r}}$ by RNA-seq. In the $\operatorname{Pten}^{\mathrm{r} / \mathrm{r}} ; \mathrm{Tgfbr}^{\mathrm{r} / \mathrm{r}}$ sample, the majority of the carcinoma cells expressed CD44, some of which colocalized with Keratin 5 positive basal cells. Therefore, both the luminal and basal populations are upregulating CD44. 
Figure 30. Immunofluorescence for Keratin 5 and CD44. Ventral prostates of 4 genotypes of mice were stained by immunofluorescence for Keratin 5 (shown in red) and CD44 (shown in green). Nuclei were stained blue by DAPI. Ages of the mice were: Wild type (13 weeks), Tgfbr2 $^{\mathrm{r} / \mathrm{r}}$ (70 weeks), $\operatorname{Pten}^{\mathrm{r} / \mathrm{r}}$ (22 weeks), Pten $^{\mathrm{r} / \mathrm{r}} ; \operatorname{Tgfbr}^{\mathrm{r} / \mathrm{r}}$ (12 weeks). 
Wild Type
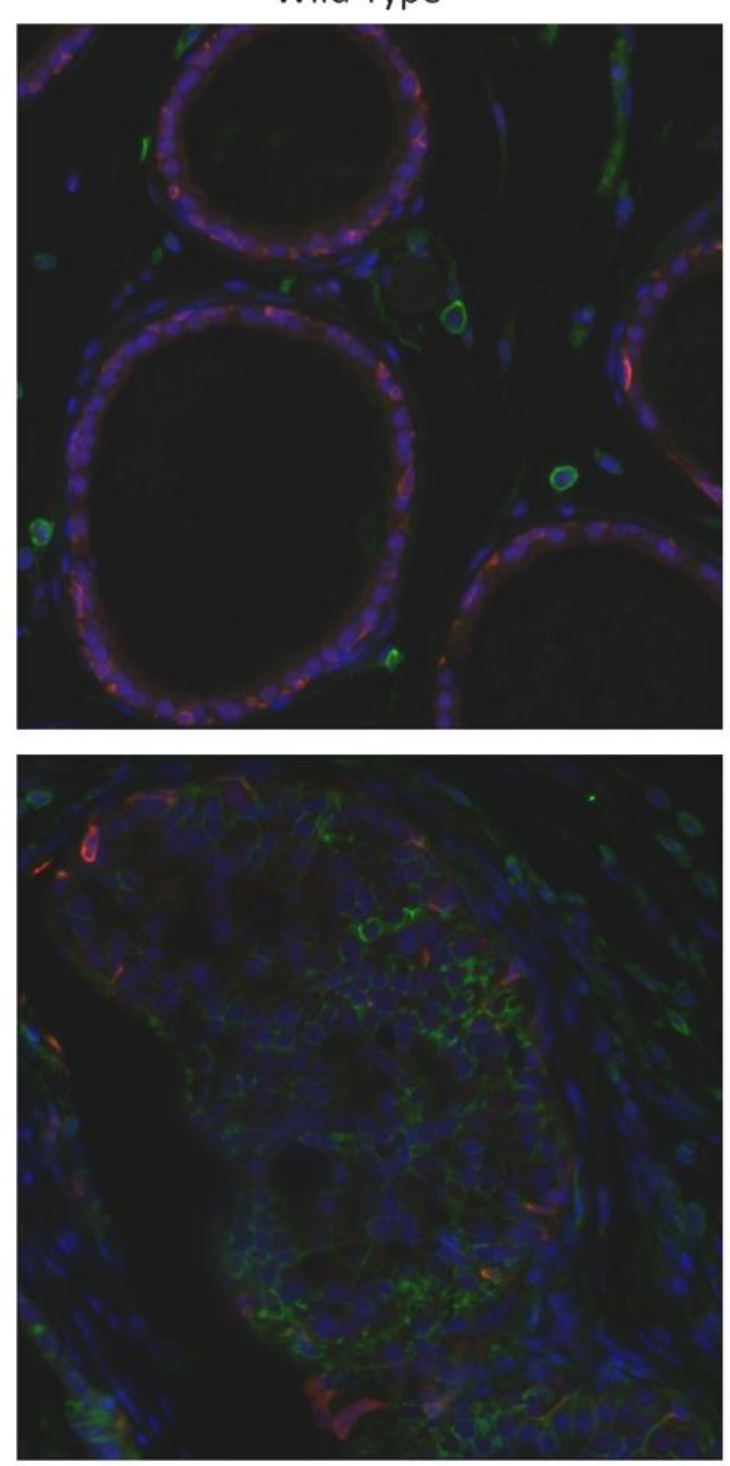

Pten $r / r$
Tgfbr2 r/r
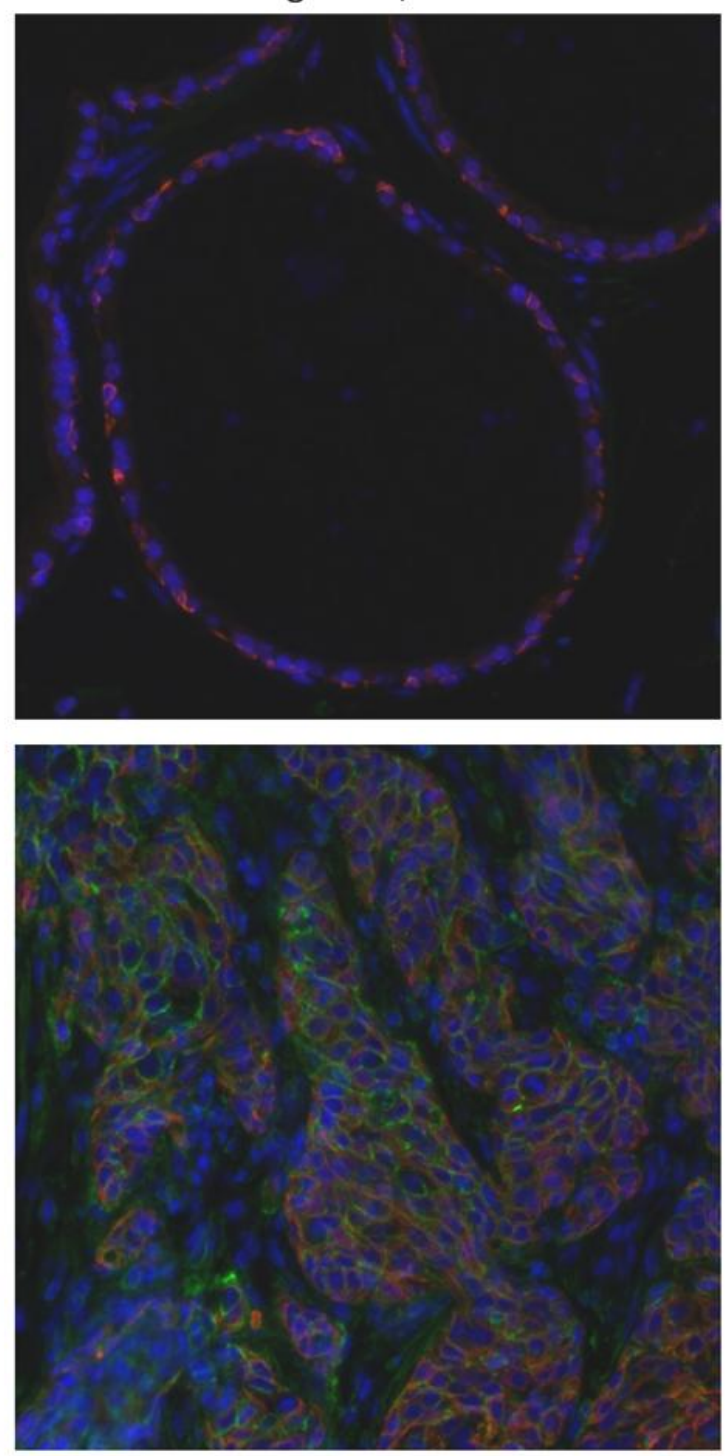

Pten $r / r$ \& Tgfbr2 $r / r$ 


\subsection{Discussion}

In this section I showed RNA-seq data for $\operatorname{Pten}^{\mathrm{r} / \mathrm{r}}$ and $\operatorname{Pten}^{\mathrm{r} / \mathrm{r}} ; \operatorname{Tgfbr}^{\mathrm{r} / \mathrm{r}}$ prostates, which revealed a number of interesting pathways that may be changing in our prostate tumor model. First, in the preliminary GO analysis, there were a couple of categories that were downregulated in our tumor model related to $\mathrm{T}$ cells and antigen presentation to $\mathrm{T}$ cells. I take this to mean that there are fewer T cells infiltrating the $\operatorname{Pten}^{\mathrm{r} / \mathrm{r}} ; \mathrm{Tgfbr}^{\mathrm{r} / \mathrm{r}}$. Therefore, the T cell immune response may be diminished in the Pten ${ }^{\mathrm{r} / \mathrm{r}} ; \operatorname{Tgfbr}^{\mathrm{r} / \mathrm{r}}$ compared to the Pten ${ }^{\mathrm{r} / \mathrm{r}}$. This is consistent with TGF- $\beta$ 's role in modulating the immune system through $\mathrm{T}$ cells. We think this effect may be due to an upregulation of the TGF- $\beta$ ligand in our system. Increased TGF- $\beta$ ligand has been shown to decrease the immune response in tumors, especially via T cells ${ }^{137}$. Subsequently, in a mouse model of prostate cancer it was shown that TGF- $\beta$ functions by an autocrine loop in T cells to suppress the immune response ${ }^{138}$. Therefore, our model may be having the same effect, and this may be the reason for the decrease in immune cell genes in the RNA-seq. Also downregulated were a group of prostate development genes. These included Nkx3.1, which is a known prostate tumor suppressor whose loss correlates with tumor progression ${ }^{134}$, and HoxB13, in which a recurrent mutation was found that correlates with familial prostate cancer ${ }^{139}$. Therefore, it is possible that lowered expression of one or more of these factors is contributing to the rapid prostate tumor progression in our mice.

In the GO terms data shown for genes upregulated in the $\operatorname{Pten}^{\mathrm{r} / \mathrm{r}} ; \mathrm{Tgfbr}^{\mathrm{r} / \mathrm{r}}$ the top term was EGF-like \& calcium binding, which contained numerous members of the Notch signaling pathway. This was interesting because Notch signaling has been implicated in prostate tumorigenesis. However, Karolina Pietrzak in our lab has done western blots for activated Notch on these tumors and has not been able to detect it. Therefore, it may be that Notch signaling is not activated, in spite of the increase at the mRNA level. The second category containing S100 proteins is also interesting. It has been published that S100A8 and S100A9 increase in prostate 
cancer and they have been associated with an inflammatory microenvironment and suppression of the immune response ${ }^{140}$. Also enriched were GO categories for Laminin G, tissue remodeling and cell-matrix adhesion, all of which have to do with remodeling of the extracellular space around the tumors. This could be very important in the progression and metastasis of the $\operatorname{Pten}^{\mathrm{r} / \mathrm{r}} ; \mathrm{Tgfbr}^{\mathrm{r} / \mathrm{r}}$ tumors as remodeling of the extracellular matrix is important for cell movement, signaling and cell survival. However, apart from the IF for CollagenIV that I did before we had the RNA-seq data, we have not yet examined any effect tissue remodeling may be having.

The RNA-seq data also revealed a decrease in luminal genes and an increase in basal genes in the Pten ${ }^{\mathrm{r} / \mathrm{r}} ; \operatorname{Tgfbr}^{\mathrm{r} / \mathrm{r}}$ cancers. I verified this by immunofluorescence in these tumors and discovered that loss of Tgfbr2 also leads to an increase in basal cells in the background of activated Akt1 and Apc knockout. These tumors were highly disorganized and lose almost all of the normal luminal/basal structure. This difference in basal and luminal staining also explained some strange results that we obtained from the Tg-Akt1 mice. First, Dr. Frierson's lab had done IHC on Tg-Akt1;Tgfbr $2^{\mathrm{T} / \mathrm{r}}$ prostates that showed low levels of androgen receptor staining and phospho-Akt1 (Data not shown). This was curious, because we did not understand how cells in the tumor were growing. We hypothesized that the cells were losing most of their AR expression and then since the Akt1 transgene is driven by androgen, that they were losing expression of the transgene. After finding out that the Tg-Akt1;Tgfbr $2^{\mathrm{r} / \mathrm{r}}$ have an increase in basal cells (which have low androgen receptor), we subsequently realized this was why they were losing expression of the Akt1 transgene. As a result, we think this explains at least part of the milder phenotype in the Tg-Akt1; Tgfbr2 ${ }^{\mathrm{r} / \mathrm{r}}$ : Loss of $T g f b r 2$ increases growth only in basal cells in the prostate, but the Tg-Akt1 is not well expressed in basal cells. Therefore, the two effects do not come together in the basal population.

I also showed an increase in proliferation upon loss of $T g f b r 2$ specifically in the basal cells, with the proliferation of luminal cells not changing significantly. The method by which 
$T g f b r 2$ loss leads to expansion of the basal population is still unknown. However, it could be that Tgfbr2 is expressed more in the basal cells. If luminal cells do not express much Tgfbr2, then clearly they would not be affected by its loss. This is thought to be true in breast tissue, where Tgfbr2 is not expressed in the luminal cells, but is expressed in the stem and/or basal cells ${ }^{141}$. We are also not sure why there does not appear to be an increase in the proliferation of the luminal cells in the Pten ${ }^{\mathrm{r} / \mathrm{r}}$. We hypothesize it may be due to when we are looking at the Pten ${ }^{\mathrm{r} / \mathrm{r}}$, which is at around 22 weeks. At this point the luminal cells have mostly filled in the ducts of the prostate and that may have slowed their proliferation. If we looked earlier in the progression of the $P \operatorname{ten}^{\mathrm{r} / \mathrm{r}}$ we think there would be higher proliferation compared to the wild type.

I also showed images of a lung metastasis from a $\operatorname{Pten}^{\mathrm{r} / \mathrm{r}} ; \mathrm{Tgfbr}^{+/ \mathrm{r}}$ mouse that was comprised almost exclusively of basal cells. Therefore, it seems that in our model the basal cells are the proliferative and metastatic cell. Unfortunately, this is not the same as human tumors. Human prostate tumors are comprised almost exclusively of luminal cells ${ }^{81}$. Although, some reports indicate that a portion of human prostate tumors stain for Keratin 5, they also report that human tumors are negative for Keratin $14^{142}$. Tumors from our Pten ${ }^{\mathrm{r} / \mathrm{r}} ; \operatorname{Tgfbr}^{\mathrm{r} / \mathrm{r}}$ mice also stain for Keratin 14 (data not shown), so they are different from human tumors. Human tumors that stain for K5 and lack K14 may be indicative of an intermediate cell type ${ }^{142}$, whereas our model seems to be comprised more of basal cells and possibly stem cells, although the work on characterizing the basal and stem cells is still preliminary. The RNA-seq data revealed a number of upregulated stem cell genes including: CD44, c-Kit, Prom1 and Integrin alpha 6. I also showed that CD44 was increased by immunofluorescence in the Pten ${ }^{\mathrm{r} / \mathrm{r}}$ and the $\operatorname{Pten}^{\mathrm{r} / \mathrm{r}} ;$ Tgfbr $^{\mathrm{r} / \mathrm{r}}$. This confirms that at least some stem cell genes are increased in our model at the protein level. Since CD44 is increased in the Pten ${ }^{\mathrm{r} / \mathrm{r}}$ single at the protein level and most of the stem cell genes increased some in the Pten $^{\mathrm{r} / \mathrm{r}}$ by RNA-seq, I think it possible that both the luminal and the basal populations are capable of becoming stem cells, depending on the oncogenic stimulus. It would 
be interesting to see if what appear to be stem cells in our model have a higher tumor initiating ability than non-stem cells. If this was the case, it may not matter which population gave rise to the tumor initiating cells, but whether they are present and how to inhibit them. Therefore, if our model turns out to have stem cells with similar characteristics to human prostate cancers, it may turn out to be a good model of human cancer, even if our model arose from basal cells.

In conclusion, this section presented gene expression data on our tumors that has led to some preliminary findings on pathways that may be important for the progression in this model, such as immune suppression and prostate development genes Nkx3.1 and HoxB13. I also showed that there is an expansion of basal cells upon loss of $T g f b r 2$. This was not restricted solely to the $\operatorname{Pten}^{\mathrm{r} / \mathrm{r}}$ background, but also occurred in the Akt1 transgenic and $\mathrm{Apc}^{\mathrm{r} / \mathrm{r}}$ models. This growth of basal cells appears to be due to increased proliferation within these cells, at least in the Pten $^{\mathrm{r} / \mathrm{r}}$ background. Finally, preliminary results suggest that there is an increased number of stem-like cells in these tumors, which may be a driving force behind the tumors. 


\section{Chapter 7}

\section{Future Directions}




\subsection{Summary of work on Meis and Pbx proteins}

In Chapter 3, I described a project detailing novel regulation of the transcription of p15 and E-cadherin by Meis2 and Pbx1. I also showed that siRNA knockdown of Meis2 and Pbx1 in HepG2 cells increased the proliferation rate of these cells, presumably through decreased levels of $\mathrm{p} 15$. This was further shown to not be mediated by $\mathrm{Sp} 1$ as first thought, but rather through Klf4. I subsequently discovered more genes regulated by Meis2, Pbx1 and Klf4 in a cooperative manner through a bioinformatics approach and validated two of them as target genes with

luciferase assays. This work was published in Molecular and Cellular Biology in $2011^{113}$. Since p15 and E-cadherin are tumor suppressors, we hypothesized that Meis2 and Pbx1 could be important in cancer, and therefore examined their expression level in cancer using Oncomine. There we found Meis2 and Pbx1 are downregulated in some prostate cancers. However, a number of questions still remain unanswered for this project.

\subsection{How prevalent is the cooperation between Meis/Pbx and Klf4?}

I showed data for four genes that were activated cooperatively by Meis/Pbx and Klf4. From the bioinformatics approach we also have more candidates that may be regulated, but we have not tested them. However, it is unknown how many of these would be validated. The importance of the interaction between Meis/Pbx and Klf4 is dependent on how prevalent this cooperation is. Therefore, it would be helpful to study where these factors are binding DNA in an unbiased manner. This could be done using ChIP-seq for each factor individually and then overlapping sites determined for places where multiple factors bind. This could be combined with siRNA for each factor and gene expression analysis by RNA-seq. This would truly tell us where these factors are cooperating at the endogenous level and how they are affecting gene expression. 


\subsection{Does Pbx1 interact with other Klf family members?}

In this study I examined the interaction between Meis2/Pbx1 and Sp1 or Sp3, which turned out to be DNA dependent. I then examined the interaction between Pbx1 and Klf3 and $\mathrm{Klf} 4$, and found that $\mathrm{Pbx} 1$ interacted with Klf4 specifically. I also performed some luciferase assays with Klf5, which did not activate p15 (Data not shown). Therefore, Pbx1 does not interact with Sp1, Sp3, Klf3 or Klf5, but it could still interact with some of the other 20 remaining members of the Klf family. Klf4 is most closely related to Klf1 and Klf2; these three members have the most similar domain structures compared to the rest of the Klf family ${ }^{24}$. Therefore, it would be worth examining whether Pbx1 can interact with Klf1 and Klf2. If Pbx1 did interact with these related proteins, it would make the interaction between Pbx1 and members of the Klf family more interesting. It would also add to our knowledge of the complex gene regulation between these factors. If Pbx1 is found to not interact with Klf1 and Klf2, it might be worth mapping the site on Klf4 which Pbx1 interacts with. Knowing the domain of Klf4 that interacts with $\mathrm{Pbx} 1$ might allow us to find other transcription factors with a similar domain that can interact with Pbx1. It might also allow us to mutate important residues in Klf4 such that it would no longer be able to interact with Pbx1. This would allow us to study the function of Klf4 and Pbx1 separately.

\subsection{Does the interaction between Meis/Pbx and Klf4 change the spectrum of genes activated by each factor alone?}

As discussed earlier, Klf4 has opposing functions attributed to it in the literature. It is

one of the factors that was found to be necessary for making induced pluripotent stem cells ${ }^{27}$, but it was also found to activate p53 and inhibit the cell cycle ${ }^{29}$. The change in function of Klf4 could be by numerous mechanisms. However, one mechanism that would be consistent with our data is that Klf4 may be recruited preferentially to different sites depending on what other 
transcription factors are expressed. Alternatively, the effect of Klf4 recruitment to DNA (activation or repression of gene expression) could change depending on what other proteins are expressed and present on DNA with Klf4. Therefore, it would be very interesting to examine whether Klf4 and $\mathrm{Pbx} 1$ are recruited to different genes if expressed singly versus together. Testing this could be difficult due to our lack of knowledge about which Klf family and $\mathrm{Pbx}$ family members interact with each other. It might be easier to make interaction mutants of each protein and assay each by ChIP to see if there is a shift in target genes bound. Second, the effect on transcription that Klf4 has upon binding to DNA could be changed by which other proteins are present. Meis2d has a strong transcriptional activation domain when recruited to DNA, but not all Meis2 isoforms do ${ }^{12}$. The specific splice isoform of Meis2 that is expressed and interacting with Klf4 could change the activation or repression by Klf4. Also, there are other members of the Meis family that could be interacting with Klf4. One of which is the Prep family, which are quite similar to the Meis family. However, members of the Prep family are thought not to have

activation domains ${ }^{11}$. Therefore, if Prep can interact with Klf4 and is expressed at a higher level compared to Meis, this could function to blunt the gene activation by Klf4 at sites of cooperative recruitment. Given the renewed interest in Klf4 due to its use in induced pluripotent stem cells, this could be important research.

\subsection{Do Meis and Pbx have an antitumor effect in prostate cancer?}

I demonstrated two potential antitumor effects of Meis2 and Pbx1: activation of CDK inhibitors p15 \& p21, and activation of E-cadherin. These CDK inhibitors function to stop cells from dividing and I showed that HepG2 cells proliferated faster upon Meis2 and Pbx1 knockdown. We did not perform any experiments to test whether changing levels of E-cadherin upon knockdown of Meis2 and Pbx1 were having a functional difference in these cells. It would be interesting to test whether knockdown of Meis2 and Pbx1 would make cells less adherent to an E-cadherin coated substrate. It would also be exciting to test whether Meis2 and Pbx1 have an 
effect on prostate tumorigenesis in vivo. To do this we could express Meis2 and Pbx1 from a bicistronic transgene in the prostate combined with our prostate tumor models of either $\mathrm{Pten}^{\mathrm{r} / \mathrm{r}}$ or $\operatorname{Pten}^{\mathrm{r} / \mathrm{r}} ; \mathrm{Tgfbr}^{\mathrm{r} / \mathrm{r}}$. This would allow us to test if Meis 2 and Pbx1 inhibit tumor growth by inducing CDK inhibitors. Also, if Meis2 and Pbx1 can induce higher expression of E-cadherin in vivo, it could make the tumors less metastatic. The ability to inhibit cell growth and limit metastasis could be a useful two prong effect on cancer progression. In the event that Meis 2 and Pbx1 could inhibit tumor growth in vivo, finding a treatment that causes their induction could be a novel way to treat cancer.

\subsection{Summary of work on prostate models.}

In the next part of my dissertation I described a new mouse model of prostate cancer, driven by the loss of only two endogenous genes: Pten and Tgfbr2. This model results in poorly differentiated prostate cancer with a more rapid progression than any other model that we are aware of. It is especially interesting that loss of $T g f b r 2$ has such a dramatic effect in the background of Pten loss, since knockout of Tgfbr2 alone has no effect. The resulting tumors are characterized by higher proliferation and loss of the CDK inhibitor $\mathrm{p} 27$. The tumors caused by loss of Pten and Tgfbr2 are metastatic and resistant to castration. In the Pten ${ }^{\mathrm{r} / \mathrm{r}}$ and transgenic Akt1 based models we saw an induction of the TGF- $\beta$ pathway, which we hypothesize is a tumor suppressive feedback mechanism upon Akt activation that keeps growth in check. However, in the Apc ${ }^{\mathrm{r} / \mathrm{r}}$ based model we do not see this activation of the TGF- $\beta$ pathway, although the Apc $\mathrm{c}^{\mathrm{r} / \mathrm{r}}$ based model still has a drastically accelerated progression to cancer upon loss of Tgfbr2. Both the $\mathrm{Apc}^{\mathrm{r} / \mathrm{r}}$ and the Pten ${ }^{\mathrm{r} / \mathrm{r}}$ based models appear to be restrained by cellular senescence, as evidenced by $\beta$-galactosidase staining. The senescence associated $\beta$-galactosidase staining is then lost in both models upon knockout of $T g f b r 2$. To try and elucidate the mechanism by which TGF- $\beta$ is restraining tumor progression, I next showed RNA-seq data for $\operatorname{Pten}^{\mathrm{r} / \mathrm{r}}$ and $\operatorname{Pten}^{\mathrm{r} / \mathrm{r}} ; \mathrm{Tgfbr}^{\mathrm{r} / \mathrm{r}}$ tumors that led us to discover a large increase in basal and possibly stem cells 
upon loss of $T g f b r 2$. The increase in basal cells upon knockout of $T g f b r 2$ was seen in the background of Pten ${ }^{\mathrm{r} / \mathrm{r}}$, Tg-Akt1 and Apc ${ }^{\mathrm{r} / \mathrm{r}}$. I also showed for Pten ${ }^{\mathrm{r} / \mathrm{r}} ;$ Tgfbr $^{\mathrm{r} / \mathrm{r}}$ versus Pten ${ }^{\mathrm{r} / \mathrm{r}}$ that the increase in basal cells is due to a higher rate of proliferation in these cells. The discovery that loss of $T g f b r 2$ leads to an increase in basal cells is interesting to us, but this work also leads to a number of important questions.

\subsection{Does the rapid progression in the $\operatorname{Pten}^{\mathrm{r} / \mathrm{r}} ; \operatorname{Tgfbr}^{\mathrm{r} / \mathrm{r}}$ lessen the number of metastases in this model? Is there something we could do to stop bladder obstructions and increase metastases?}

In our model using recombination of Pten and $T g f b r 2$ we see a very rapid progression to cancer, with the mice needing to be euthanized at a median age of 88 days. They become sick because they develop prostate tumors that close off the urethra and then develop bladder obstructions. Comparing images of whole prostates from our model versus other models, it seems that our model may cause bladder obstruction more readily than other models that develop larger tumors ${ }^{95,143}$. Regardless, the tumors they develop would most likely progress further if it was not for the bladder obstruction. Subsequently, we hypothesize metastases in the mice would be more numerous and bigger if they were allowed more time to colonize. One option would be to have a surgeon give the mice a vesicostomy, where the urine from the bladder would be routed out the abdomen of the mice instead of through the urethra ${ }^{144}$. This would bypass the obstruction of the urethra and allow prostate cancer to progress further in the mice. Another option could be to treat the primary tumors with targeted radiation, shrinking the primary tumor and giving metastases more time to develop. However, we would have no guarantee that metastases had formed already and the mice get sick so rapidly that it would be hard to time. We also do not know how well radiation treatment would work on the primary tumors, but characterizing their response to radiation could also be interesting. 


\subsection{Are the metastases colonizing somewhere else and can we capture them to characterize them?}

As stated above, it is possible that the metastatic cells in our $\operatorname{Pten}^{\mathrm{r} / \mathrm{r}} ; \mathrm{Tgfbr}^{\mathrm{r} / \mathrm{r}}$ do not have enough time after escaping from the prostate to form significant metastases. Alternatively, they could be going to a tissue we have not examined, or not be capable of colonizing a distant tissue. To test this we could use the IVIS imaging system here at UVa. This imaging system can visualize either fluorescent proteins such as GFP or luciferase driven by a transgene to image labeled cells within an animal. However, GFP is not visible very deep into a tissue. Therefore, we could breed in a luciferase transgene that would only turn on in the presence of Cre recombinase, thereby marking our tumor cells in the prostate. Using the IVIS system we could then visualize the whole mouse, in an unbiased manner, for metastatic cells that had colonized distant organs. Alternatively, Dan Gioeli and the MAPS core have made a cell line from xenografts derived from the tumor of one of our $\operatorname{Pten}^{\mathrm{r} / \mathrm{r}} ; \operatorname{Tgfbr}^{\mathrm{r} / \mathrm{r}}$ mice. It would be simpler to infect this cell line with a virus expressing luciferase and then inject these cells into a host mouse. Using the IVIS system we could then image where these cells colonize. These experiments would help us determine whether the cells from the $\operatorname{Pten}^{\mathrm{r} / \mathrm{r}} ; \operatorname{Tgfbr}^{\mathrm{r} / \mathrm{r}}$ do not have time to colonize distant organs, or whether they are not capable of forming metastases.

It would also be interesting if we could isolate metastatic cells to characterize. Cells from our Pten ${ }^{\mathrm{r} / \mathrm{r}} ; \mathrm{Tgfbr}^{\mathrm{r} / \mathrm{r}}$ tumors metastasize in such small groups that it could be very hard to isolate them and characterize them. However, one idea would be to utilize a Cre recombinase responsive $\mathrm{mTmG}$ reporter that we just started using in the lab ${ }^{145}$. In the basal state this reporter expresses a membrane targeted Tomato fluorescent protein. However, in the presence of Cre it recombines out the Tomato fluorescent protein and expresses membrane targeted EGFP. Hence, cells that have expressed Cre change color from red to green. If we combined this transgene with our $\operatorname{Pten}^{\mathrm{r} / \mathrm{r}} ; \mathrm{Tgfbr}^{\mathrm{r} / \mathrm{r}}$ mice, it would label any tumor cells green. Subsequently, we could maintain the 
mice as normal and collect lung tissue from the mice when they develop tumor burden. We could then dissociate the lung tissue and isolate any green cells by FACS. RNA-seq could then be performed on these cells to look for any changes in gene expression as compared to the primary tumor. Granted, we would certainly not obtain a lot of cells by this method. However, since RNA-seq methods have been developed that work on single cells ${ }^{146}$, it is theoretically possible. If we did this it would be very interesting to see if metastatic cells developed a way to activate EMT without the TGF- $\beta$ pathway or whether they were metastasizing by some other method.

\subsection{Is the low level of pSmad2 staining significant?}

In figure 13 I showed IF for phospho-Smad2 in different genotypes. The level of phospho-Smad 2 staining increased in the $\operatorname{Pten}^{\mathrm{r} / \mathrm{r}}$ and then decreased in the $\operatorname{Pten}^{\mathrm{r} / \mathrm{r}} ; \mathrm{Tgfbr}^{\mathrm{r} / \mathrm{r}}$. However, it did not go back to the level seen in the wild type or Tgfbr2 null. This could just be that I quantified stromal cells in the Pten ${ }^{\mathrm{r} / \mathrm{r}} ; \operatorname{Tgfbr}^{\mathrm{r} / \mathrm{r}}$ that were not recombined for Tgfbr2 and are therefore still capable of phosphorylating Smad2. However, it could also mean that other type I receptors are active in these tumors and capable of phosphorylating Smad2. Type I receptors of the Activin/Inhibin and Nodal pathways (Alk4 and Alk7) are also capable of phosphorylating Smad $2^{147}$. This then begs the question as to whether this low level of phospho-Smad2 is enough to have an effect. It has been shown that half a dose of Smad3 changed the response to TGF- $\beta$ signaling, making cells more metastatic ${ }^{124}$. Therefore, it seems possible that this low level of Smad 2 phosphorylation could be having an effect. Given TGF- $\beta$ signaling has a pro-metastasis function later in cancer; maybe this low level of phospho-Smad2 is enough to increase metastasis. This could be tested using a small molecule inhibitor of the type I receptors, SB-505124, that

inhibits all the TGF- $\beta$, Activin/Inhibin and Nodal type I receptors ${ }^{148}$. This would allow us to see if complete blockade of Smad2 phosphorylation resulted in lower metastases. It would also be interesting from a clinical perspective. One would surmise that if a human tumor had lost expression of either one of the TGF- $\beta$ receptors, there would be no point in treating the patient 
with a drug that inhibits the type I receptors. However, if there was still enough Smad signaling via other pathways to activate metastasis, it is possible that a type I receptor inhibitor would still be efficacious.

\subsection{Why did knockout of Smad2 in the background of Pten knockout have no effect?}

Two examples from this dissertation indicate that dosage of the TGF- $\beta$ pathway is very important. (1) Knockout of Tgfbr2 in our system does not completely stop phosphorylation of Smad2, but the knockout of Tgfbr2 still has a large effect on tumor progression. (2) Tgfbr2 heterozygotes with Pten knockout have a faster progression to cancer than Pten knockout mice alone. Both of these examples show that dosage of the TGF- $\beta$ pathway is important. Which raises the question of why did knockout of Smad2 not make the Pten knockout progress more quickly? Most of the time people think of Smad2 and Smad3 as indifferent from each other, which is incorrect. For example, the major isoform of Smad2 cannot directly bind DNA, while

Smad3 can ${ }^{149}$. However, if we think of Smad2 and Smad3 as equivalent, then Smad2 loss should have lowered the dose by half and been similar to a Tgfbr2 heterozygote. Additionally, I have tried blotting for phospho-Smad3 and have not been able to detect it in mouse prostate, which could be due to inefficient antibodies, but could also indicate that Smad2 is more active than Smad3 in mouse prostates. One possibility is that the level of receptor Smads is not limiting in our system and reducing the dose by half does not make a difference. It is also possible that Smad2 and Smad3 have different functions in these cells, which could be interesting. We could use a floxed allele of Smad3 to make a prostate specific knockout and compare it to the Smad2 knockout. We could also try recombining out 3 of the 4 alleles between Smad 2 and Smad3, to see if the resulting lowered dosage of receptor Smads would have an effect on tumor progression and metastasis. 


\subsection{How does Pten loss activate the TGF- $\beta$ pathway?}

In chapter 3 I showed that Pten loss activates the TGF- $\beta$ pathway. We like to think of this as a feedback mechanism to the tumor suppressive TGF- $\beta$ pathway that keeps growth in check. I also described how we saw activation of the TGF- $\beta$ pathway upon activation of Akt1 signaling, so we think this activation is probably downstream of Akt1. However, the mechanism by which Akt1 activates the TGF- $\beta$ pathway is unknown. Since multiple components of the pathway are increased it is possible that multiple mechanisms are at work. Because we think the mechanism is downstream of Akt1, we could start testing effectors downstream of Akt, such as mTORC1, 4E-BP1 and p70S6K. We could try knocking these genes down using siRNAs in a cell line that shows upregulation of the TGF- $\beta$ pathway upon Akt1 activation and assaying for loss of phospho-Smad2. This experiment could be problematic; as downstream effectors of Akt signaling are important for cell growth and survival and knocking them down might kill the cells.

However, our data from the Apc knockout and the growth in basal cells calls into question the importance of the activation of the TGF- $\beta$ pathway in the Pten ${ }^{\mathrm{r} / \mathrm{r}}$. We do not see activation of the TGF- $\beta$ pathway in the Apc ${ }^{\mathrm{r} / \mathrm{r}}$, but growth of these neoplasias still only slowly progresses past PIN. Also, when I assayed for activation of the TGF- $\beta$ pathway in the $\operatorname{Pten}^{\mathrm{r} / \mathrm{r}} \mathrm{I}$ was most likely looking at almost exclusively luminal cells, since they constitute the majority of the cells in the $\operatorname{Pten}^{\mathrm{r} / \mathrm{r}}$. Subsequently, upon knockout of $T g f b r 2$, we saw a large increase in the proliferation of the basal cell population. Therefore, we need to look at the activity of the TGF- $\beta$ pathway specifically in the basal cells of the $\operatorname{Pten}^{\mathrm{r} / \mathrm{r}}$ to see whether activated TGF- $\beta$ signaling is keeping these cells from dividing. Only if there is an activation of TGF- $\beta$ signaling in the basal cells in the Pten ${ }^{\mathrm{r} / \mathrm{r}}$, which then proliferate after knockout of $T g f b r 2$, can we say that TGF- $\beta$ functions to keep Akt signaling in check. 


\subsection{How might our model compare to the $\operatorname{Pten}^{\mathrm{r} / \mathrm{r}} ; \operatorname{Smad}^{\mathrm{r} / \mathrm{r}}$ ?}

At first it might seem that our $\operatorname{Pten}^{\mathrm{r} / \mathrm{r}} ; \operatorname{Tgfbr}^{\mathrm{r} / \mathrm{r}}$ model would be very similar to the $\operatorname{Pten}^{\mathrm{r} / \mathrm{r}} ; \operatorname{Smad}^{\mathrm{r} / \mathrm{r}}$ model published by the DePinho group ${ }^{95}$, as both knock out Pten and TGF- $\beta$ signaling. Our model appears to progress more quickly, but not drastically, and mouse strain differences could account for some of the difference. The DePinho group also reported a higher percentage of lymph node metastases, but fewer lung metastases, which could be explained by what lengths each of us went to in looking for metastases. Upon further inspection though, the signaling pathways inhibited are fairly different. First, our model should cause loss of signaling by Tgfbr1 (since Tgfbr1 is activated by Tgfbr2), which signals through more pathways than just the Smad pathway. Tgfbr1 is also reported to signal through the Erk MAPK pathway, the JNK/p38 pathway and Rho-like GTPases ${ }^{44}$. In the Smad4 knockout, Tgfbr1 would still be able to activate these pathways. Accordingly, some cancers that have lost Smad4 have been shown to still respond to TGF- $\beta$ by increasing invasiveness ${ }^{150}$. Second, the DePinho group's Smad4 knockout abrogates all Smad transcriptional activity, including Smad signaling downstream of TGF- $\beta$, Activin/Inhibins, Nodal and BMP signaling. BMP signaling by BMP-6 has been shown to be associated with a more aggressive phenotype in prostate cancer ${ }^{151}$. Conversely, in our model we still have a small amount of Smad2 phosphorylation, and therefore a small amount of Smad transcriptional activity. The balance of effects between pathways activated by Tgfbr1 and Smad pathways could lead to interesting differences between the two models. Additionally, we see an increase in basal cells in our model, both in the primary tumor and in metastases. The DePinho group did not look for basal cells, but they stained for Keratin 8 in the primary tumor, lymph node and lung. All of these stained well for Keratin 8, indicating that they were primarily composed of luminal cells. This is very different from our model that shows a large increase in basal cells in the primary tumors and in the metastases. These findings indicate that our model is clearly different from the $\operatorname{Pten}^{\mathrm{r} / \mathrm{r}} ; \operatorname{Smad} 4^{\mathrm{r} / \mathrm{r}}$ model and I think it would be interesting to compare the 
two models as a way to examine the TGF- $\beta$ pathway. The pathways downstream of Tgfbr 1 could be examined to see if they are activated in the Pten ${ }^{\mathrm{r} / \mathrm{r}} ; \operatorname{Smad} 4{ }^{\mathrm{r} / \mathrm{r}}$ and not in the Pten ${ }^{\mathrm{r} / \mathrm{r}} ; \operatorname{Tgfbr} 2^{\mathrm{r} / \mathrm{r}}$. It would be exciting if MAP kinase pathways or Rho-like GTPases were activated in the Pten/Smad4 knockout, but not in our Pten/Tgfbr2 knockout. Also, our Pten ${ }^{\mathrm{r} / \mathrm{r}} ; \operatorname{Tgfbr}^{\mathrm{r} / \mathrm{r}}$ could still have low activity of pathways activated by Smad transcription factors, such as the regulators of EMT, Snail and Slug, which the Smad4 knockout would not activate. In the Pten/Smad4 knockout study they performed microarray experiments on their tumors. Therefore, we should also try to overlap our RNA-seq data with theirs. This might reveal not only differences in the models, but also important oncogenic drivers in common to the two models.

\subsection{Could we make a better model of the progression to castration resistance?}

Our $\operatorname{Pten}^{\mathrm{r} / \mathrm{r}} ; \mathrm{Tgfbr}^{\mathrm{r} / \mathrm{r}}$ model appears to be already resistant to castration, as shown in figure 12G. Pten $^{\mathrm{r} / \mathrm{r}}$ mice are published to be resistant to castration ${ }^{90}$, but it takes so long for the Pten ${ }^{\mathrm{r} / \mathrm{r}}$ to develop carcinoma that is hard to do castration experiments on them. The Apc $\mathrm{c}^{\mathrm{r} / \mathrm{r}}$ are sensitive to castration ${ }^{97}$, but these mice have squamous differentiation not seen in human cancers. We are currently examining the castration resistance of the $\mathrm{Apc}^{\mathrm{r} / \mathrm{r}} ; \mathrm{Tgfbr}^{\mathrm{r} / \mathrm{r}}$ mice to see if loss of $T g f b r 2$ makes the $\mathrm{Apc}^{\mathrm{r} / \mathrm{r}}$ more resistant to castration, but the squamous differentiation makes it less relevant to human cancer. Most human tumors have lost only one allele of Pten and loss of both alleles is associated with advanced cancer and metastasis ${ }^{91}$. Since Pten nulls are resistant to castration, a Pten heterozygous background or Akt transgene might be a good place to start for a mouse model that is castration sensitive. From our data however, Pten heterozygotes do not develop cancer out to 70 weeks old, only HGPIN. A Pten heterozygote combined with modulation of genes relevant to human cancer, such as deletion of Nkx3.1 or expression of TMPRSS2-ERG, might provide a rapid enough model to study the progression to castration resistance. However, it has been shown that having only one allele of Pten is too easily lost, and that Pten heterozygotes usually completely lose expression of Pten in the progression to cancer 
122. Since Pten ${ }^{\mathrm{r} / \mathrm{r}}$ cancer cells can grow without androgen, this would lead to castration resistance. Therefore, it could be beneficial to make an inducible Akt1 transgenic that is not dependent on androgen signaling for expression, unlike the Tg-Akt $1{ }^{94}$. I think it would be a good idea to make a transgene driven by the Tet-On promoter, followed by a Lox-Stop-Lox sequence, followed by an activated version of Akt1 (either myristoylated, or a phosphomimetic T308 \& S473 to D). This would result in inducible activation in the presence of tetracycline (or doxycycline) due to the Tet-On promoter, but only where Cre recombinase had removed the Lox-Stop-Lox sequence. This would allow us to use $\mathrm{Pb}-\mathrm{Cre} 4$ to make the inducible promoter function only in the prostate. Having this inducible promoter would allow us to tune the level of activated Akt1; possibly allowing us to find a level of Akt1 expression that leads to cancer, but not so much that the cancer is resistant to castration. Additionally, the Sawyers group found using xenografts of human cell lines in castrated mice that the only consistent change in the progression to castration resistance was increased expression of the androgen receptor ${ }^{116}$. Therefore, we could also use this promoter to upregulate androgen receptor expression in the prostate as a model of castration resistance. Furthermore, this inducible promoter could also be used to express ERG, or used in combination with prostate specific knockout of tumor suppressors. Some combination of overexpression or knockout of genes relevant to human cancer is almost certain to be a better model of the progression from androgen dependence to androgen independence than current models. An improved model would be useful because it would be more relevant to human tumors and be a better system for characterizing new therapies for prostate cancer.

\subsection{Which cells in the $\mathrm{Apc}^{\mathrm{r} / \mathrm{r}}$ and $\mathrm{Apc}^{\mathrm{r} / \mathrm{r}} ;$ Tgfbr $^{\mathrm{r} / \mathrm{r}}$ are becoming squamous?}

The $\mathrm{Apc}^{\mathrm{r} / \mathrm{r}}$ mice develop HGPIN, composed mainly of luminal cells, characterized by squamous differentiation. The $\mathrm{Apc}^{\mathrm{r} / \mathrm{r}} ; \mathrm{Tgfbr}^{\mathrm{r} / \mathrm{r}}$ mice develop adenosquamous carcinoma, which is less differentiated than the $\mathrm{Apc}^{\mathrm{r} / \mathrm{r}}$. In the $\operatorname{Pten}^{\mathrm{r} / \mathrm{r}} ; \mathrm{Tgfbr}^{\mathrm{r} / \mathrm{r}}$ we see an increase in what appear to be less differentiated basal or stem cells. Therefore, it may be that $T g f b r 2$ loss is really having the 
same effect in the two models by rescuing the basal cells from terminal differentiation.

Therefore, I think we need to examine which cells in the $\mathrm{Apc}^{\mathrm{r} / \mathrm{r}} ; \mathrm{Tgfbr}^{\mathrm{r} / \mathrm{r}}$ appear to be squamous. I suspect the luminal cells would show squamous differentiation in both the $\mathrm{Apc}^{\mathrm{r} / \mathrm{r}}$ and the $\mathrm{Apc}^{\mathrm{r} / \mathrm{r}} ; \mathrm{Tgfbr}^{\mathrm{r} / \mathrm{r}}$, but the basal cells would be less differentiated and proliferate more than the luminal cells. As of yet we have not looked at any of the stem cell markers, CD44, c-Kit or others in the $\mathrm{Apc}^{\mathrm{r} / \mathrm{r}} ; \mathrm{Tgfbr}^{\mathrm{r} / \mathrm{r}}$. We should also examine these stem cell markers in the $\mathrm{Apc}^{\mathrm{r} / \mathrm{r}} ; \mathrm{Tgfbr}^{\mathrm{r} / \mathrm{r}}$ to see if they are increased. Both models could be producing stem cells with similar characteristics, and the squamous differentiation may not be important. This is interesting because it would imply that the differentiation state of precancerous cells would dictate whether loss of Tgfbr2 would drive tumor formation in those cells.

\subsection{Why do the $\mathrm{Apc}^{\mathrm{r} / \mathrm{r}} ;$ Tgfbr2 $^{\mathrm{r} / \mathrm{r}}$ not metastasize well?}

In figure $17 \mathrm{I}$ showed that the incidence of metastasis formation in the $\mathrm{Apc}^{\mathrm{r} / \mathrm{r}} ; \mathrm{Tgfbr}^{\mathrm{r} / \mathrm{r}}$ is only about a third of what it is in the $\operatorname{Pten}^{\mathrm{r} / \mathrm{r}} ; \operatorname{Tgfbr}^{\mathrm{r} / \mathrm{r}}$. This is curious, considering: (1) the $\mathrm{Apc}^{\mathrm{r} / \mathrm{r}} ; \mathrm{Tgfbr}^{\mathrm{r} / \mathrm{r}}$ mice have cancer for longer, most of them have adenocarcinoma by 14 weeks old (data not shown) and they survive on average $>21$ weeks and (2) their tumors grow larger than the $\operatorname{Pten}^{\mathrm{r} / \mathrm{r}} ; \operatorname{Tgfbr}^{\mathrm{r} / \mathrm{r}}$ (also figure 17). Assuming loss of Tgfbr2 is having the same effect in both models; it seems that Pten loss induces more metastases than Apc loss. To elucidate this mechanism and other differences in the models we are having RNA-seq done on $\mathrm{Apc}^{\mathrm{r} / \mathrm{r}}$ and $\mathrm{Apc}^{\mathrm{r} / \mathrm{r}} ; \mathrm{Tgfbr}^{\mathrm{r} / \mathrm{r}}$ prostates. This could give us an idea of whether or not pro-metastasis genes, such as regulators of EMT, are up in the $\operatorname{Pten}^{\mathrm{r} / \mathrm{r}} ; \operatorname{Tgfbr}^{\mathrm{r} / \mathrm{r}}$ and not in the $\mathrm{Apc}^{\mathrm{r} / \mathrm{r}} ; \mathrm{Tgfbr}^{\mathrm{r} / \mathrm{r}}$. Some of these EMT genes are up a little in the $\operatorname{Pten}^{\mathrm{r} / \mathrm{r}} ; \mathrm{Tgfbr}^{\mathrm{r} / \mathrm{r}}$, but the increase is not drastic (data not shown). I think we should also examine the level of phospho-Smad2 in the $\mathrm{Apc}^{\mathrm{r} / \mathrm{r}} ; \mathrm{Tgfbr} 2^{\mathrm{r} / \mathrm{r}}$, to see if there is a low level of Smad activity (as possibly seen in the $\operatorname{Pten}^{\mathrm{r} / \mathrm{r}} ; \mathrm{Tgfbr}^{\mathrm{r} / \mathrm{r}}$ ) that could be driving metastasis. This could also help further the understanding of metastasis of tumors driven by $\beta$ catenin, about which surprisingly little is known. Increased nuclear $\beta$-catenin has been correlated 
with metastasis in colorectal cancer ${ }^{152}$, however in that particular study $\beta$-catenin expression is associated with loss of E-cadherin, which might indicate that the metastases are due to loss of Ecadherin, rather than a change in $\beta$-catenin. I have performed immunofluorescence for Ecadherin on $\operatorname{Pten}^{\mathrm{r} / \mathrm{r}}$ and $\operatorname{Pten}^{\mathrm{r} / \mathrm{r}} ; \operatorname{Tgfbr}^{\mathrm{r} / \mathrm{r}}$ and the expression and membrane localization does not change from wild type (data not shown). We should examine the level and localization of Ecadherin in the $\mathrm{Apc}^{\mathrm{r} / \mathrm{r}} ; \mathrm{Tgfbr}^{\mathrm{r} / \mathrm{r}}$, which would be interesting regardless of the result. Because tumors in the $\mathrm{Apc}^{\mathrm{r} / \mathrm{r}} ; \mathrm{Tgfbr}^{\mathrm{r} / \mathrm{r}}$ do not metastasize well, I hypothesize that E-cadherin would still be visible at the cell membrane. If E-cadherin is bound to the membrane, we could examine how it was kept there without $\beta$-catenin. If E-cadherin is lost from the membrane, we could investigate why the cells were not metastasizing well upon loss of E-cadherin.

\subsection{What exactly is TGF- $\beta$ signaling doing to restrain growth?}

After getting RNA-seq data on our $\operatorname{Pten}^{\mathrm{r} / \mathrm{r}} ; \operatorname{Tgfbr}^{\mathrm{r} / \mathrm{r}}$ tumors we realized there was an increase in basal cells in these tumors. This seems to be driven specifically by the loss of $T g f b r 2$. However, we still do not know what Tgfbr2 is doing to restrain growth of these basal cells. To elucidate the mechanism one approach would be to segregate basal and luminal cells from Pten ${ }^{\mathrm{r} / \mathrm{r}}$ and $\operatorname{Pten}^{\mathrm{r} / \mathrm{r}} ; \mathrm{Tgfbr}^{\mathrm{r} / \mathrm{r}}$ prostates by FACS (Fluorescence Activated Cell Sorting). This would allow us to directly compare basal populations from each genotype to each other, eliminating any contamination from other cell types that could confound the results. We could compare components of the TGF- $\beta$ pathway to see if they are activated in basal cells in the Pten ${ }^{\mathrm{r} / \mathrm{r}}$ or compare levels of important regulators of the cell cycle, such as p27 and Cyclin D. We could also perform RNA-seq just on the basal populations from wild type, $\operatorname{Pten}^{\mathrm{r} / \mathrm{r}}$ and $\operatorname{Pten}^{\mathrm{r} / \mathrm{r}} ; \mathrm{Tgfbr}^{\mathrm{r} / \mathrm{r}}$. Presumably this would give us a clearer answer as to what genes are changing with only one cell type in the sequencing reaction. Understanding why loss of Tgfbr2 drives basal cells could further our understanding of the TGF- $\beta$ pathway and possibly other cancers that are more 
commonly composed of basal cells, such as basal cell carcinomas of the skin and basal-like breast cancer.

Additionally, the dual role of TGF- $\beta$ in cancer makes it a difficult pathway to target. However, by the time most patients realize they have cancer, the cancer has overcome the cytostatic effect of TGF- $\beta$ and TGF- $\beta$ functions to enhance metastasis. Therefore, cancer therapies targeting the TGF- $\beta$ pathway are designed to be inhibitory ${ }^{153}$. The exact mechanisms of TGF- $\beta$ growth restraint versus TGF- $\beta$ metastasis promotion are not well known. If we could determine what TGF- $\beta$ is doing to restrain growth upon loss of Pten we could potentially separate the two functions of TGF- $\beta$. This might allow us to make a mouse model of prostate cancer without growth arrest by TGF- $\beta$, but still with the metastasis promotion. This could be a very helpful model in the prostate cancer field. Secondly, with a better knowledge of the TGF- $\beta$ pathway, it might be possible to design therapies to shift the TGF- $\beta$ pathway from metastatic promotion back to growth inhibition. A therapy that could do this would be doubly beneficial to prostate cancer patients.

\subsection{What stem cell genes are upregulated in our model? Which cell population are they in, and do they indicate increased tumor initiating ability?}

In figure 26 I presented RNA-seq data that showed upregulation of four stem cell genes (CD44, c-Kit, Prom1 and Integrin alpha 6). To confirm a change in the protein level of CD44, in figure 30 I presented IF for CD44 with increased staining in the $\operatorname{Pten}^{\mathrm{r} / \mathrm{r}}$ and the $\operatorname{Pten}^{\mathrm{r} / \mathrm{s}} ; \mathrm{Tgfbr}^{\mathrm{r} / \mathrm{r}}$. The increase in CD44 staining by IF in the $\operatorname{Pten}^{\mathrm{r} / \mathrm{r}}$ and the $\operatorname{Pten}^{\mathrm{r} / \mathrm{r}} ; \operatorname{Tgfbr}^{\mathrm{r} / \mathrm{r}}$ is consistent with the RNA-seq data and seems to indicate that both the luminal and basal populations may be able to give rise to stem-like cells. This is consistent with data from the Xin group who published that both the luminal and the basal cell populations can initiate tumors upon loss of Pten ${ }^{154}$. It seems that cells with stem-like ability could come from either population depending on the specific 
genetic alterations used to induce tumors. In our system we need to better characterize what stem cell genes are upregulated and which cell population they are in. We need to try some more antibodies by immunofluorescence or sort cells into basal and luminal populations and assay stem cell genes by western blot. We could then sort basal and luminal cells from $\operatorname{Pten}^{\mathrm{r} / \mathrm{r}} ; \mathrm{Tgfbr}^{\mathrm{r} / \mathrm{r}}$ prostates by FACS and see which population harbors the tumor initiating cells. These could then be further subdivided by stem cell markers to obtain a better understanding of what cells initiate tumors. This information could help us know what specific cell in the tumor to target with therapies to help patients in the future.

\subsection{Conclusion}

Prostate cancer is one of the most common cancers in men and a significant health concern worldwide. Despite much research on prostate cancer in recent time, the pathways regulating cancer growth and metastasis are not well understood. The TGF- $\beta$ pathway is known to be very a critical component of both tumor suppression and invasion in cancer. In this work I expanded our knowledge of TGF- $\beta$ 's tumor suppressive and differentiation promoting effects in murine prostate cancer models. A complete comprehension of the various functions of the TGF- $\beta$ pathway is necessary for a true understanding of cancer. Hopefully this work on TGF- $\beta$ signaling provides insight that will lead to improved cancer therapies in the future. 


\section{Chapter 8}

\section{Literature Cited}




\section{References}

1. Mukherjee K, Bürglin TR. Comprehensive analysis of animal TALE homeobox genes: new conserved motifs and cases of accelerated evolution. J Mol Evol. 2007;65(2):137-53.

2. Gehring WJ, Qian YQ, Billeter M, Furukubo-Tokunaga K, Schier AF, Resendez-Perez D, Affolter M, Otting G, Wuthrich K. Homeodomain-DNA Recognition. Cell. 1994;78:211223.

3. Moens CB, Selleri L. Hox cofactors in vertebrate development. Dev Biol. 2006;291(2):193-206.

4. Bürglin TR. Analysis of TALE superclass homeobox genes (MEIS, PBC, KNOX, Iroquois, TGIF) reveals a novel domain conserved between plants and animals. Nucleic Acids Res. 1997;25(21):4173-80.

5. Moskow JJ, Bullrich F, Huebner K, Daar IO, Buchberg AM. Meis1, a PBX1-related homeobox gene involved in myeloid leukemia in BXH-2 mice. Mol Cell Biol. 1995;15(10):5434-5443.

6. Schnabel C, Jacobs Y, Cleary ML. HoxA9-mediated immortalization of myeloid progenitors requires functional interactions with TALE cofactors Pbx and Meis. Oncogene. 2000;19(5):608-16.

7. Wong P, Iwasaki M, Somervaille TCP, Wai CES, Cleary ML. Meis1 is an essential and rate-limiting regulator of MLL leukemia stem cell potential. Genes Dev. 2007;21:27622774.

8. Geerts D, Revet I, Jorritsma G, Schilderink N, Versteeg R. MEIS homeobox genes in neuroblastoma. Cancer Lett. 2005;228(1-2):43-50.

9. Nakamura T, Jenkins N, Copeland N. Identification of a new family of Pbx-related homeobox genes. Oncogene. 1996;13(10):2235-42.

10. Knoepfler PS, Calvo KR, Chen H, Antonarakis SE, Kamps MP. Meis1 and pKnox1 bind DNA cooperatively with Pbx1 utilizing an interaction surface disrupted in oncoprotein E2a-Pbx1. Proc Natl Acad Sci U S A. 1997;94(26):14553-8.

11. Huang H, Rastegar M, Bodner C, Goh S-L, Rambaldi I, Featherstone M. MEIS C termini harbor transcriptional activation domains that respond to cell signaling. J Biol Chem. 2005;280(11):10119-27.

12. Yang Y, Hwang CK, D’Souza UM, Lee SH, Junn E, Mouradian MM. Three-amino acid extension loop homeodomain proteins Meis 2 and TGIF differentially regulate transcription. J Biol Chem. 2000;275(27):20734-41.

13. Aspland SE, Bendall HH, Murre C. The role of E2A-PBX1 in leukemogenesis. Oncogene. 2001;20(40):5708-17. 
14. Laurent A, Bihan R, Omilli F, Deschamps S, Pellerin I. PBX proteins: much more than Hox cofactors. Int J Dev Biol. 2008;52(1):9-20.

15. Lu Q, Kamps MP. Selective repression of transcriptional activators by Pbx1 does not require the homeodomain. Proc Natl Acad Sci U S A. 1996;93(January):470-474.

16. Berkes C, Bergstrom D, Penn BH, Seaver KJ, Knoepfler PS, Tapscott SJ. Pbx marks genes for activation by $\mathrm{MyoD}$ indicating a role for a homeodomain protein in establishing myogenic potential. Mol Cell. 2004;14(4):465-77.

17. Liu Y, MacDonald RJ, Swift GH. DNA binding and transcriptional activation by a PDX1PBX1b-MEIS2b trimer and cooperation with a pancreas-specific basic helix-loop-helix complex. J Biol Chem. 2001;276(21):17985-93.

18. Chang CP, Jacobs Y, Nakamura T, Jenkins N a, Copeland NG, Cleary ML. Meis proteins are major in vivo DNA binding partners for wild-type but not chimeric Pbx proteins. Mol Cell Biol. 1997;17(10):5679-87.

19. Longobardi E, Blasi F. Overexpression of PREP-1 in F9 teratocarcinoma cells leads to a functionally relevant increase of PBX-2 by preventing its degradation. $J$ Biol Chem. 2003;278(40):39235-41.

20. Berthelsen J, Kilstrup-Nielsen C, Blasi F, Mavilio F, Zappavigna V. The subcellular localization of PBX1 and EXD proteins depends on nuclear import and export signals and is modulated by association with PREP1 and HTH. Genes Dev. 1999;13(8):946-53.

21. Shanmugam K, Green NC, Rambaldi I, Saragovi HU, Featherstone MS. PBX and MEIS as non-DNA-binding partners in trimeric complexes with HOX proteins. Mol Cell Biol. 1999;19(11):7577-88.

22. Williams TM, Williams ME, Innis JW. Range of HOX/TALE superclass associations and protein domain requirements for HOXA13:MEIS interaction. Dev Biol. 2005;277(2):45771.

23. Suske G, Bruford E, Philipsen S. Mammalian SP/KLF transcription factors: bring in the family. Genomics. 2005;85(5):551-6.

24. Kaczynski J, Cook T, Urrutia R. Sp1- and Krüppel-like transcription factors. Genome Biol. 2003;4(2):Article 206.

25. Li L, He S, Sun J, Davie JR. Gene regulation by Sp1 and Sp3. Biochem Cell Biol. 2004;82(4):460-471.

26. Li JM, Datto MB, Shen X, Hu PP, Yu Y, Wang XF. Sp1, but not Sp3, functions to mediate promoter activation by TGF-beta through canonical Sp1 binding sites. Nucleic Acids Res. 1998;26(10):2449-56.

27. Takahashi K, Yamanaka S. Induction of pluripotent stem cells from mouse embryonic and adult fibroblast cultures by defined factors. Cell. 2006;126(4):663-76. 
28. Bourillot P-Y, Savatier P. Krüppel-like transcription factors and control of pluripotency. BMC Biol. 2010;8(125).

29. Zhang W, Geiman D, Shields J, Dang D, Mahatan C, Kaestner K, Biggs J, Kraft A, Yang V. The gut-enriched Kruppel-like factor (Kruppel-like factor 4) mediates the transactivating effect of $\mathrm{p} 53$ on the p21WAF1/Cip1 promoter. J Biol Chem. 2000;275(24):18391-8.

30. Nakahara Y, Northcott PA, Li M, et al. Genetic and epigenetic inactivation of Kruppellike factor 4 in medulloblastoma. Neoplasia. 2010;12(1):20-7.

31. Foster KW, Frost AR, McKie-Bell P, Lin C-Y, Engler JA, Grizzle WE, Ruppert JM. Increase of GKLF Messenger RNA and Protein Expression during Progression of Breast Cancer. Cancer Res. 2000;60(22):6488-6495.

32. Wei Z, Yang Y, Zhang P, Andrianakos R, Hasegawa K, Lyu J, Chen X, Bai G, Liu C, Pera M, Lu W. Klf4 interacts directly with Oct4 and Sox2 to promote reprogramming. Stem Cells. 2009;27(12):2969-78.

33. Evans PM, Chen X, Zhang W, Liu C. KLF4 interacts with beta-catenin/TCF4 and blocks p300/CBP recruitment by beta-catenin. Mol Cell Biol. 2010;30(2):372-81.

34. Park M-T, Lee S-J. Cell Cycle and Cancer. J Biochem Mol Biol. 2003;36(1):60-65.

35. Kim WY, Sharpless NE. The regulation of INK4/ARF in cancer and aging. Cell. 2006;127(2):265-75.

36. Tsihlias J, Kapusta L, Slingerland J. The prognostic significance of altered cyclindependent kinase inhibitors in human cancer. Annu Rev Med. 1999;50:401-23.

37. Melin B. Genetic causes of glioma: new leads in the labyrinth. Curr Opin Oncol. 2011;23(6):643-7.

38. Seoane J, Pouponnot C, Staller P, Schader M, Eilers M, Massagué J. TGFB influences Myc, Miz-1 and Smad to control the CDK inhibitor p15INK4b. Nat Cell Biol. 2001;3(April):400-408.

39. Gil J, Peters G. Regulation of the INK4b-ARF-INK4a tumour suppressor locus: all for one or one for all. Nat Rev Mol Cell Biol. 2006;7(9):667-77.

40. Paredes J, Figueiredo J, Albergaria A, et al. Epithelial E- and P-cadherins: role and clinical significance in cancer. Biochim Biophys Acta. 2012;1826(2):297-311.

41. Peinado H, Portillo F, Cano A. Transcriptional regulation of cadherins during development and carcinogenesis. Int J Dev Biol. 2004;48(5-6):365-75.

42. Onder TT, Gupta PB, Mani S, Yang J, Lander E, Weinberg R. Loss of E-cadherin promotes metastasis via multiple downstream transcriptional pathways. Cancer Res. 2008;68(10):3645-54. 
43. Herpin A, Lelong C, Favrel P. Transforming growth factor-beta-related proteins: an ancestral and widespread superfamily of cytokines in metazoans. Dev Comp Immunol. 2004;28(5):461-85.

44. Zhang Y. Non-Smad Pathways in TGF- $\beta$ signaling. Cell Res. 2009;19(1):128-139.

45. Cui W, Fowlis DJ, Bryson S, Duffie E, Ireland H, Balmain a, Akhurst RJ. TGFbeta1 inhibits the formation of benign skin tumors, but enhances progression to invasive spindle carcinomas in transgenic mice. Cell. 1996;86(4):531-42.

46. Massagué J. TGFbeta in Cancer. Cell. 2008;134(2):215-30.

47. Heldin $\mathrm{C}-\mathrm{H}$, Vanlandewijck M, Moustakas A. Regulation of EMT by TGF $\beta$ in cancer. FEBS Lett. 2012;586(14):1959-70.

48. Chalhoub N, Baker SJ. PTEN and PI3-Kinase Pathway in Cancer. Annu Rev Pathol. 2009;4:127-150.

49. Hawkins P, Anderson K, Davidson K, Stephens L. Morton Lecture Signalling through Class I PI3Ks in mammalian cells. Biochem Soc Trans. 2006;34(5):647-662.

50. Altomare D, Testa JR. Perturbations of the AKT signaling pathway in human cancer. Oncogene. 2005;24(50):7455-64.

51. Hers I, Vincent EE, Tavaré JM. Akt signalling in health and disease. Cell Signal. 2011;23(10):1515-27.

52. Tibarewal P, Zilidis G, Spinelli L, Schurch N, Maccario H, Gray A, Perera NM, Davidson L, Barton GJ, Leslie NR. PTEN protein phosphatase activity correlates with control of gene expression and invasion, a tumor-suppressing phenotype, but not with AKT activity. Sci Signal. 2012;5(213):ra18.

53. Kypta RM, Waxman J. Wnt//-catenin signalling in prostate cancer. Nat Rev Urol. 2012;9(8):418-428.

54. Fodde R, Brabletz T. Wnt/B-catenin signaling in cancer stemness and malignant behavior. Curr Opin Cell Biol. 2007;19:150-158.

55. Rao TP, Kühl M. An updated overview on Wnt signaling pathways: a prelude for more. Circ Res. 2010;106(12):1798-806.

56. Huggins C, Hodges C V. Studies on Prostatic Cancer. I. The Effect of Castration, of Estrogen and of Androgen Injection on Serum Phosphatases in Metastatic Carcinoma of the Prostate. Cancer Res. 1941;1(4):293-297.

57. Alva A, Hussain M. The changing natural history of metastatic prostate cancer. Cancer J. 2013;19(1):19-24. 
58. Haddad H, Garcia JA. Novel agents for the management of castration-resistant prostate cancer. Curr Opin Urol. 2012;22(3):175-182.

59. Clarke J, Armstrong A. Novel therapies for the treatment of advanced prostate cancer. Curr Treat Options Oncol. 2013;14(1):109-26.

60. Barlow LJ, Shen MM. SnapShot: Prostate Cancer. Cancer Cell. 2013;24(3):400-400.e1.

61. Clark JP, Cooper CS. ETS gene fusions in prostate cancer. Nat Rev Urol. 2009;6(8):42939.

62. Phin S, Moore MW, Cotter PD. Genomic Rearrangements of PTEN in Prostate Cancer. Front Oncol. 2013;3(September):240.

63. Taylor BS, Schultz N, Hieronymus H, et al. Integrative genomic profiling of human prostate cancer. Cancer Cell. 2010;18(1):11-22.

64. Bitting RL, Armstrong AJ. Targeting the PI3K/Akt/mTOR pathway in castration-resistant prostate cancer. Endocr Relat Cancer. 2013;20(3):R83-99.

65. Roychowdhury S, Chinnaiyan AM. Advancing precision medicine for prostate cancer through genomics. J Clin Oncol. 2013;31(15):1866-73.

66. Levy L, Hill CS. Alterations in components of the TGF-beta superfamily signaling pathways in human cancer. Cytokine Growth Factor Rev. 2006;17(1-2):41-58.

67. Aitchison A a, Veerakumarasivam A, Vias M, Kumar R, Hamdy FC, Neal DE, Mills IG. Promoter methylation correlates with reduced Smad4 expression in advanced prostate cancer. Prostate. 2008;68(6):661-74.

68. Ding Z, Wu C-J, Jaskelioff M, et al. Telomerase reactivation following telomere dysfunction yields murine prostate tumors with bone metastases. Cell. 2012;148(5):896907.

69. Brase JC, Johannes M, Mannsperger H, et al. TMPRSS2-ERG -specific transcriptional modulation is associated with prostate cancer biomarkers and TGF- $\beta$ signaling. BMC Cancer. 2011;11(1):507.

70. Chipuk JE, Cornelius SC, Pultz NJ, Jorgensen JS, Bonham MJ, Kim S-J, Danielpour D. The androgen receptor represses transforming growth factor-beta signaling through interaction with Smad3. J Biol Chem. 2002;277(2):1240-8.

71. Hayes SA, Zarnegar M, Sharma M, Yang F, Peehl DM, Dijke P, Sun Z. SMAD3 Represses Androgen Receptor-mediated Transcription. Cancer Res. 2001;61(5):21122118.

72. Assinder SJ, Dong Q, Kovacevic Z, Richardson DR. The TGF-beta, PI3K/Akt and PTEN pathways: established and proposed biochemical integration in prostate cancer. Biochem $J$. 2009;417(2):411-21. 
73. Vo BT, Morton D, Komaragiri S, Millena AC, Leath C, Khan SA. TGF- $\beta$ effects on prostate cancer cell migration and invasion are mediated by PGE2 through activation of PI3K/AKT/mTOR pathway. Endocrinology. 2013;154(5):1768-79.

74. Jerónimo C, Bastian PJ, Bjartell A, Carbone GM, Catto JWF, Clark SJ, Henrique R, Nelson WG, Shariat SF. Epigenetics in prostate cancer: biologic and clinical relevance. Eur Urol. 2011;60(4):753-66.

75. Gupta S, Iljin K, Sara H, Mpindi JP, Mirtti T, Vainio P, Rantala J, Alanen K, Nees M, Kallioniemi O. FZD4 as a mediator of ERG oncogene-induced WNT signaling and epithelial-to-mesenchymal transition in human prostate cancer cells. Cancer Res. 2010;70(17):6735-45.

76. Wu L, Zhao JC, Kim J, Jin H-J, Wang C-Y, Yu J. ERG Is a Critical Regulator of Wnt/LEF1 Signaling in Prostate Cancer. Cancer Res. 2013:6068-6079.

77. Pienta KJ, Abate-Shen C, Agus DB, et al. The current state of preclinical prostate cancer animal models. Prostate. 2008;68(6):629-39.

78. Abate-Shen C, Shen M. Molecular genetics of prostate cancer. Genes Dev. 2000;14(19):2410-2434.

79. Ittmann M, Huang J, Radaelli E, Martin P, Signoretti S, Sullivan R, Simons BW, Ward JM, Robinson BD, Chu GC, Loda M, Thomas G, Borowsky A, Cardiff RD. Animal Models of Human Prostate Cancer: The Consensus Report of the New York Meeting of the Mouse Models of Human Cancers Consortium Prostate Pathology Committee. Cancer Res. 2013.

80. Kasper S. Exploring the origins of the normal prostate and prostate cancer stem cell. Stem Cell Rev. 2008;4(3):193-201.

81. Goldstein AS, Huang J, Guo C, Garraway IP, Witte ON. Identification of a cell-of-origin for human prostate cancer. Science (80- ). 2011;329(5991):568-571.

82. Wang X, Kruithof-de Julio M, Economides KD, Walker D, Yu H, Halili MV, Hu Y-P, Price SM, Abate-Shen C, Shen MM. A luminal epithelial stem cell that is a cell of origin for prostate cancer. Nature. 2009;461(7263):495-500.

83. Ali S, DeCaprio J. Cellular transformation by SV40 large T antigen: interaction with host proteins. Semin Cancer Biol. 2001;11(1):15-23.

84. Hirano D, Okada Y, Minei S, Takimoto Y, Nemoto N. Neuroendocrine differentiation in hormone refractory prostate cancer following androgen deprivation therapy. Eur Urol. 2004;45(5):586-92; discussion 592.

85. Zhang J, Thomas TZ, Kasper S, Matusik RJ. A small composite probasin promoter confers high levels of prostate-specific gene expression through regulation by androgens and glucocorticoids in vitro and in vivo. Endocrinology. 2000;141(12):4698-710. 
86. Wu X, Wu J, Huang J, Powell WC, Zhang J, Matusik RJ, Sangiorgi FO, Maxson RE, Sucov HM, Roy-Burman P. Generation of a prostate epithelial cell-specific Cre transgenic mouse model for tissue-specific gene ablation. Mech Dev. 2001;101(1-2):61-9.

87. Ellwood-Yen K, Graeber TG, Wongvipat J, Iruela-Arispe ML, Zhang J, Matusik R, Thomas G V, Sawyers CL. Myc-driven murine prostate cancer shares molecular features with human prostate tumors. Cancer Cell. 2003;4(3):223-38.

88. Branda CS, Dymecki SM. Talking about a Revolution : The Impact of Site-Specific Recombinases on Genetic Analyses in Mice. Dev Cell. 2004;6:7-28.

89. Wang S, Garcia AJ, Wu M, Lawson D a, Witte ON, Wu H. Pten deletion leads to the expansion of a prostatic stem/progenitor cell subpopulation and tumor initiation. Proc Natl Acad Sci U S A. 2006;103(5):1480-5.

90. Wang S, Gao J, Lei Q, Rozengurt N, Pritchard C, Jiao J, Thomas G V, Li G, Roy-Burman $\mathrm{P}$, Nelson PS, Liu X, Wu H. Prostate-specific deletion of the murine Pten tumor suppressor gene leads to metastatic prostate cancer. Cancer Cell. 2003;4(3):209-21.

91. Trotman LC, Niki M, Dotan Z a, Koutcher J a, Di Cristofano A, Xiao A, Khoo AS, RoyBurman P, Greenberg NM, Van Dyke T, Cordon-Cardo C, Pandolfi PP. Pten dose dictates cancer progression in the prostate. PLoS Biol. 2003;1(3):E59.

92. Bayascas JR, Leslie NR, Parsons R, Fleming S, Alessi DR. Hypomorphic mutation of PDK1 suppresses tumorigenesis in PTEN(+/-) mice. Curr Biol. 2005;15(20):1839-46.

93. Chen M-L, Xu P-Z, Peng X, Chen WS, Guzman G, Yang X, Di Cristofano A, Pandolfi $\mathrm{PP}$, Hay N. The deficiency of Akt1 is sufficient to suppress tumor development in Pten+/mice. Genes Dev. 2006;20(12):1569-74.

94. Majumder PK, Yeh JJ, George DJ, Febbo PG, Kum J, Xue Q, Bikoff R, Ma H, Kantoff PW, Golub TR, Loda M, Sellers WR. Prostate intraepithelial neoplasia induced by prostate restricted Akt activation: the MPAKT model. Proc Natl Acad Sci U S A. 2003;100(13):7841-6.

95. Ding Z, Wu C-J, Chu GC, et al. SMAD4-dependent barrier constrains prostate cancer growth and metastatic progression. Nature. 2011;470(7333):269-73.

96. Zhou Z, Flesken-Nikitin A, Corney DC, Wang W, Goodrich DW, Roy-Burman P, Nikitin AY. Synergy of p53 and Rb deficiency in a conditional mouse model for metastatic prostate cancer. Cancer Res. 2006;66(16):7889-98.

97. Bruxvoort KJ, Charbonneau HM, Giambernardi T a, et al. Inactivation of Apc in the mouse prostate causes prostate carcinoma. Cancer Res. 2007;67(6):2490-6.

98. Fine SW. Variants and unusual patterns of prostate cancer: clinicopathologic and differential diagnostic considerations. Adv Anat Pathol. 2012;19(4):204-16. 
99. Hyman-Walsh C, Bjerke GA, Wotton D. An autoinhibitory effect of the homothorax domain of Meis2. FEBS J. 2010;277(12):2584-2597.

100. Chang C-P, Stankunas K, Shang C, Kao S-C, Twu KY, Cleary ML. Pbx1 functions in distinct regulatory networks to pattern the great arteries and cardiac outflow tract.

Development. 2008;135(21):3577-86.

101. Cai C, Hsieh C-L, Omwancha J, Zheng Z, Chen S-Y, Baert J-L, Shemshedini L. ETV1 is a novel androgen receptor-regulated gene that mediates prostate cancer cell invasion. $\mathrm{Mol}$ Endocrinol. 2007;21(8):1835-46.

102. Silvestri C, Narimatsu M, von Both I, Liu Y, Tan NBJ, Izzi L, McCaffery P, Wrana JL, Attisano L. Genome-wide identification of Smad/Foxh1 targets reveals a role for Foxh1 in retinoic acid regulation and forebrain development. Dev Cell. 2008;14(3):411-23.

103. Shields JM, Yang VW. Identification of the DNA sequence that interacts with the gutenriched Krüppel-like factor. Nucleic Acids Res. 1998;26(3):796-802.

104. Chytil A, Magnuson MA, Wright CVE, Moses HL. Conditional Inactivation of the TGFbeta Type II Receptor Using Cre : Lox. Genesis. 2002;32(2):73-75.

105. Stambolic V, Suzuki a, de la Pompa JL, Brothers GM, Mirtsos C, Sasaki T, Ruland J, Penninger JM, Siderovski DP, Mak TW. Negative regulation of PKB/Akt-dependent cell survival by the tumor suppressor PTEN. Cell. 1998;95(1):29-39.

106. Kuraguchi M, Wang X-P, Bronson RT, Rothenberg R, Ohene-Baah NY, Lund JJ, Kucherlapati M, Maas RL, Kucherlapati R. Adenomatous polyposis coli (APC) is required for normal development of skin and thymus. PLoS Genet. 2006;2(9):1362-1374.

107. Truett GE, Heeger P, Mynatt RL, Truett AA, Walker JA, Warman ML. Preparation of PCR-quality mouse genomic DNA with hot sodium hydroxide and tris (HotSHOT). Biotechniques. 2000;29(1):52-54.

108. Sundararajan S, Wakamiya M, Behringer RR, Rivera-Pérez J a. A fast and sensitive alternative for $\beta$-galactosidase detection in mouse embryos. Development.

2012;139(23):4484-90.

109. Blume SW, Snyder RC, Ray R, Thomas S, Koller CA, Miller DM. Mithramycin inhibits SP1 binding and selectively inhibits transcriptional activity of the dihydrofolate reductase gene in vitro and in vivo. J Clin Invest. 1991;88(5):1613-21.

110. Lai JS, Herr W. Ethidium bromide provides a simple tool for identifying genuine DNAindependent protein associations. Proc Natl Acad Sci U S A. 1992;89(15):6958-62.

111. Elrod-Erickson M, Pabo CO. Binding Studies with Mutants of Zif268. J Biol Chem. 1999;274(27):19281-19285. 
112. Yori JL, Johnson E, Zhou G, Jain MK, Keri R a. Kruppel-like factor 4 inhibits epithelialto-mesenchymal transition through regulation of E-cadherin gene expression. J Biol Chem. 2010;285(22):16854-63.

113. Bjerke GA, Hyman-Walsh C, Wotton D. Cooperative transcriptional activation by Klf4, Meis2, and Pbx1. Mol Cell Biol. 2011;31(18):3723-33.

114. Rhodes DR, Yu J, Shanker K, Deshpande N, Varambally R, Ghosh D, Barrette T, Pandey A, Chinnaiyan AM. ONCOMINE: A Cancer Microarray Database and Integrated DataMining Platform. Neoplasia. 2004;6(1):1-6.

115. Tomlins S, Mehra R, Rhodes D, Cao X, Wang L, Dhanasekaran SM, Kalyana-Sundaram S, Wei JT, Rubin M a, Pienta KJ, Shah RB, Chinnaiyan AM. Integrative molecular concept modeling of prostate cancer progression. Nat Genet. 2007;39(1):41-51.

116. Chen CD, Welsbie DS, Tran C, Baek SH, Chen R, Vessella R, Rosenfeld MG, Sawyers CL. Molecular determinants of resistance to antiandrogen therapy. Nat Med. 2004;10(1):33-9.

117. Jiang F, Wang Z. Identification and characterization of PLZF as a prostatic androgenresponsive gene. Prostate. 2004;59(4):426-35.

118. Shiraishi K, Yamasaki K, Nanba D, Inoue H, Hanakawa Y, Shirakata Y, Hashimoto K, Higashiyama S. Pre-B-cell leukemia transcription factor 1 is a major target of promyelocytic leukemia zinc-finger-mediated melanoma cell growth suppression. Oncogene. 2007;26(3):339-48.

119. Mahmoud AI, Kocabas F, Muralidhar S a, Kimura W, Koura AS, Thet S, Porrello ER, Sadek H a. Meis1 regulates postnatal cardiomyocyte cell cycle arrest. Nature. 2013;497(7448):249-53.

120. Axlund SD, Lambert JR, Nordeen SK. HOXC8 inhibits androgen receptor signaling in human prostate cancer cells by inhibiting SRC-3 recruitment to direct androgen target genes. Mol Cancer Res. 2010;8(12):1643-55.

121. Juárez P, Guise T. TGF- $\beta$ in cancer and bone: implications for treatment of bone metastases. Bone. 2011;48(1):23-9.

122. Blando J, Portis M, Benavides F, Alexander A, Mills G, Dave B, Conti CJ, Kim J, Walker CL. PTEN deficiency is fully penetrant for prostate adenocarcinoma in C57BL/6 mice via mTOR-dependent growth. Am J Pathol. 2009;174(5):1869-79.

123. Wang W, Ungermannova D, Jin J, Harper JW, Liu X. Negative regulation of SCFSkp2 ubiquitin ligase by TGF-beta signaling. Oncogene. 2004;23(5):1064-75.

124. Kohn E, Yang Y-A, Du Z, Nagano Y, Van Schyndle CM, Herrmann M, Heldman M, Chen J-Q, Stuelten CH, Flanders KC, Wakefield LM. Biological Responses to TGF- $\beta$ in the Mammary Epithelium Show a Complex Dependency on Smad3 Gene Dosage with Important Implications for Tumor Progression. Mol Cancer Res. 2012;10(10):1389-99. 
125. Chen Z, Trotman LC, Shaffer D, Lin H-K, Dotan Z a, Niki M, Koutcher J a, Scher HI, Ludwig T, Gerald W, Cordon-Cardo C, Pandolfi PP. Crucial role of p53-dependent cellular senescence in suppression of Pten-deficient tumorigenesis. Nature. 2005;436(7051):725-30.

126. Truica CI, Byers S, Gelmann EP. $\beta$-Catenin Affects Androgen Receptor Transcriptional Activity and Ligand Specificity. Cancer Res. 2000;60:4709-4713.

127. Tuxhorn JA, Ayala GE, Smith MJ, Smith VC, Dang TD, Rowley DR. Reactive Stroma in Human Prostate Cancer: Induction of Myofibroblast Phenotype and Extracellular Matrix Remodeling. Clin Cancer Res. 2002;8:2912-2923.

128. Wikstrom P, Stattin P, Franck-lissbrant I, Damber J, Bergh A. Transforming Growth Factor B1 Is Associated With Angiogenesis, Metastasis, and Poor Clinical Outcome in Prostate Caner. Prostate. 1998;37:19-29.

129. Li X, Placencio V, Iturregui JM, Uwamariya C, Koyama T, Hayward SW, Bhowmick NA. Prostate tumor progression is mediated by a paracrine TGF-B/Wnt3a signaling axis. Oncogene. 2008;27(56):7118-7130.

130. Denicourt C, Dowdy SF. Cip/Kip proteins: more than just CDKs inhibitors. Genes Dev. 2004;18(8):851-5.

131. Theard D, Raspe MA, Kalicharan D, Hoekstra D, Ijzendoorn SCD Van. Formation of ECadherin/B-Catenin- based Adherens Junctions in Hepatocytes Requires Serine-10 in p27(Kip1). Mol Biol Cell. 2008;19:1605-1613.

132. Besson A, Gurian-West M, Schmidt A, Hall A, Roberts JM. p27Kip1 modulates cell migration through the regulation of RhoA activation. Genes Dev. 2004;18(8):862-76.

133. Dennis G, Sherman BT, Hosack D a, Yang J, Gao W, Lane HC, Lempicki R a. DAVID: Database for Annotation, Visualization, and Integrated Discovery. Genome Biol. 2003;4(5):R60.1-R60.11.

134. Bowen C, Bubendorf L, Voeller HJ, Progression T, Slack R, Willi N, Sauter G, Gasser TC, Koivisto P, Lack EE, Kononen J, Kallioniemi O, Gelmann EP. Loss of NKX3.1 Expression in Human Prostate Cancers Correlates with Tumor Progression. Cancer Res. 2000;60:6111-6115.

135. Peng W, Bao Y, Sawicki J. Epithelial cell-targeted transgene expression enables isolation of cyan fluorescent protein (CFP)-expressing prostate stem/progenitor cells. Transgenic Res. 2011;20(5):1073-86.

136. Patrawala L, Calhoun T, Schneider-Broussard R, Li H, Bhatia B, Tang S, Reilly JG, Chandra D, Zhou J, Claypool K, Coghlan L, Tang DG. Highly purified CD44+ prostate cancer cells from xenograft human tumors are enriched in tumorigenic and metastatic progenitor cells. Oncogene. 2006;25(12):1696-708. 
137. Torre-amione G, Beauchamp RD, Koeppen H, Park BH, Schreiber H, Moses HL, Rowley DA. A highly immunogenic tumor transfected with a murine transforming growth factor type B1 cDNA escapes immune surveillance. Proc Natl Acad Sci U S A. 1990;87:14861490.

138. Donkor MK, Sarkar A, Savage P a, Franklin R a, Johnson LK, Jungbluth A a, Allison JP, Li MO. T cell surveillance of oncogene-induced prostate cancer is impeded by T cellderived TGF- $\beta 1$ cytokine. Immunity. 2011;35(1):123-34.

139. Ewing CM, Ray AM, Lange EM, et al. Germline Mutations in HOXB13 and ProstateCancer Risk. N Engl J Med. 2012;366(2):141-149.

140. Grebhardt S, Veltkamp C, Strobel P, Mayer D. Hypoxia and HIF-1 increase S100A8 and S100A9 expression in prostate cancer. Int J Cancer. 2012;131:2785-2794.

141. Tan AR, Alexe G, Reiss M. Transforming growth factor-B signaling: emerging stem cell target in metastatic breast cancer? Breast Cancer Res Treat. 2009;115(3):453-495.

142. Van Leenders GJ, Aalders TW, Hulsbergen-van de Kaa C a, Ruiter DJ, Schalken J a. Expression of basal cell keratins in human prostate cancer metastases and cell lines. $J$ Pathol. 2001;195(5):563-70.

143. Aytes A, Mitrofanova A, Kinkade CW, Lefebvre C, Lei M, Phelan V, LeKaye HC, Koutcher JA, Cardiff RD, Califano A, Shen MM, Abate-Shen C. ETV4 promotes metastasis in response to activation of PI3-kinase and Ras signaling in a mouse model of advanced prostate cancer. Proc Natl Acad Sci U S A. 2013;110(37):E3506-15.

144. Carpenter AR, Becknell B, Hirselj DA, McHugh KM. Urinary diversion via cutaneous vesicostomy in the megabladder mouse. Methods Mol Biol. 2012;886:393-402.

145. Muzumdar MD, Tasic B, Miyamichi K, Li L, Luo L. A Global Double-Fluorescent Cre Reporter Mouse. Genesis. 2007;45(9):593-605.

146. Tang F, Barbacioru C, Wang Y, Nordman E, Lee C, Xu N, Wang X, Bodeau J, Tuch BB, Siddiqui A, Lao K, Surani MA. mRNA-Seq whole-transcriptome analysis of a single cell. Nat Methods. 2009;6(5):377-82.

147. Shi Y, Massagué J. Mechanisms of TGF-beta signaling from cell membrane to the nucleus. Cell. 2003;113(6):685-700.

148. Byfield SD, Major C, Laping NJ, Roberts AB. SB-505124 Is a Selective Inhibitor of Transforming Growth Factor-B Type I Receptors ALK4, ALK5, and ALK7. Mol Pharmacol. 2004;65(3):744-752.

149. Dunn NR, Koonce CH, Anderson DC, Islam A, Bikoff EK, Robertson EJ. Mice exclusively expressing the short isoform of Smad2 develop normally and are viable and fertile. Genes Dev. 2005;19(1):152-63. 
150. Subramanian G, Schwarz RE, Higgins L, Dugar S, Reiss M. Targeting Endogenous Transforming Growth Factor $\beta$ Receptor Signaling in SMAD4-Deficient Human Pancreatic Carcinoma Cells Inhibits Their Invasive Phenotype. Cancer Res. 2004;64:5200-5211.

151. Darby S, Cross S, Brown N, Hamdy F, Robson C. BMP-6 over-expression in prostate cancer is associated with increased Id-1 protein and a more invasive phenotype. $J$ Pathol. 2007;214:394-404.

152. Lugli a, Zlobec I, Minoo P, Baker K, Tornillo L, Terracciano L, Jass JR. Prognostic significance of the wnt signalling pathway molecules APC, beta-catenin and E-cadherin in colorectal cancer: a tissue microarray-based analysis. Histopathology. 2007;50(4):453-64.

153. Connolly EC, Freimuth J, Akhurst RJ. Complexities of TGF- $\beta$ targeted cancer therapy. Int J Biol Sci. 2012;8(7):964-78.

154. Choi N, Zhang B, Zhang L, Ittmann M, Xin L. Adult murine prostate basal and luminal cells are self-sustained lineages that can both serve as targets for prostate cancer initiation. Cancer Cell. 2012;21(2):253-65. 